\title{
MANUAL ON \\ PROTECTION AND CONTROL OF
COASTAL EROSION In INDIA
}

P. Bruun and B. U. nayak

6

कर

$+$

$=1+\frac{1}{2}+x^{2}=10$

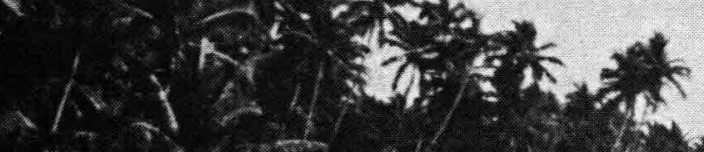

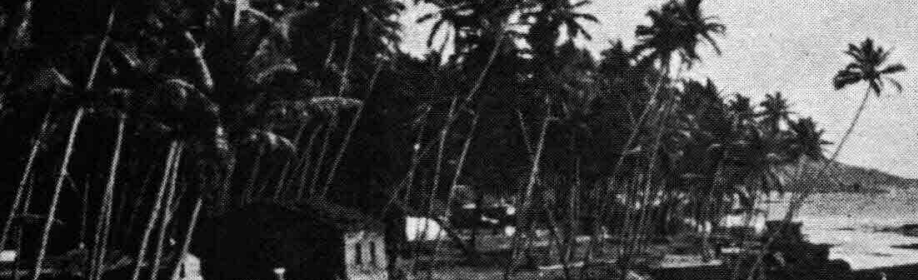

$=$

3. $\mu^{2}-y^{2}-2$

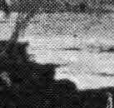

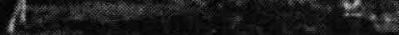

$33^{3}$

national !nstitute of Oceanography

Dona-Paula, Goa, India. 


\section{COVER PHOTO:}

Anjuna Beach, Goa, India - protruding rocky cliffs offering natural protection to pocket beaches 


\section{Manual on \\ Protection and Control of Coastal Erosion in India}

P. Bruun* and B. U. Nayak**

Special Publication

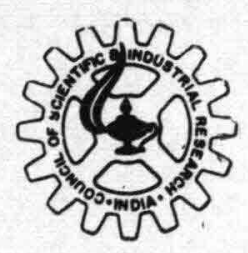

National Institute of Oceanography, Dona Paula Goa-403 004, India

1980

* The Norwegian Institute of Technology, N-7034, Trondheim-NTH, Norway

**National Institute of Oceanography, Dona Paula, Goa-403004, India 
1980 N. I. O.

\section{Published by}

National Institute of Oceanography, Dona Paula Goa- 403 004, India

Printed at

Samyukta Karnataka Press (Job), Koppikar Road, Hubli-580020, India 


\section{Contents}

Preface

List of Figures

$\cdots$

List of Tables

.. $\quad$ iii

.. vii

I. Introduction

I.I General review on causes of beach erosion

I.2 Rise of sea level

.. 1

.. 1

1.3 Heavy storms, storm surges, wave action and its seasonal effects

.. 2

.. 2

1.4 Littoral drift barriers, natural and man-made conditions in India

$\begin{array}{ll}. . & 10\end{array}$

2. Beach Surveys

.. 19

2.1 Bathymetric surveys

.. 19

2.2 Sand sampling and analysis

$2 \cdot 2.1$ Sand sampling

2.2.2 Sample analysis

.. 21

.. 21

2.2.3 Beach fill models

.. 21

.. 21

2.3 Wave surveys

.. 24

2.3.1 General

2.3.2 Wave measurements

.. 24

2.3.3 Relationship between the visual

.. 25 and the instrumental data

.. 25

2.4 Current and tide surveys

.. 25

2.4.1 General

2.4.2 Current measurements

2.4.3 Long term analysis of current data

.. 25

.. $\quad 26$

2.4.4 Tide surveys

.. 26

.. 26

2.5 Littoral drift surveys

3. Coastal Protection

$\begin{array}{ll}. & 31\end{array}$

3.I Basic aspects

3.1.1 Material balance

3.1.2 Beach and bottom profiles

.. 31

.. 31

.. 35

3.1.3 Wave machanics aspects

3.2 Review of coastal protective measures

3.2.1 Natural and man-made coastal protection

.. $\quad 36$

.. 36

3.2.2 Pre-requisites for coastal protection

.. 36

..$\quad 40$ 
3.2.3 Types of coastal protection

$3 \cdot 2 \cdot 4$ Choice of protective measures

3.3 Design details

3.3.1 Seawalls and revetments

3.3.2 Dunes and dykes-overflow protection

‥ 3.3 .3 Groins

3.3.4 Offshore breakwaters

3.3.5 Nourishment of beaches

3.3.6 Bypassing of material at tidal inlets

.. 40

. 41

.. 42

.. 42

.. 47

.. 55

.. 56

.. $\quad 57$

.. $\quad 59$

4. Coastal Protection Management

Appendix A Wave Data Analysis

Appendix B Design of Sloping Rock Structures, Uprush Elevation and Rock Size

Appendix C Sampling Procedures and Sediment Analysis

Appendix D Stability of Earth Slopes and Retaining Structures

Appendix E Rocks for Coastal Protection 


\section{Preface}

Erosion prevailing along the vast coastline of India has a long history. Coastal erosion, very often, poses a serious problem. The nature and degree of protection required for a given cosst vary widely depending upon the environmental conditions prevailing in the area.

A comprehensive environmental study of the problem is required for developing a suitable solution to any specific coastal problem. In general, there will be more than one method applicable to protecting an eroding area. Hence, it is very desirable to consider both short-term and long-term effects very carefully before determining the most suitable remedial measure to combat erosion problem.

In this manual, an attempt has been made to present some of the remedial measures including the guidelines for suitable designs to control coastal erosion with special reference to Indian conditions. While some of the basic information has been presented in the text under various sections, more detailed information has been included separately under six appendices in the manual. Although the techniques presented in the manual are generally applicable to most of the coastal erosion problems, competent engineering judgement, based on experience, is necessary for determining their application to any specific problem.

This manual is first of its kind in India. It is intended to be precise and effective and makes no claim to be exhaustive. Nevertheless, the value of a manual of this nature, dealing with diverse aspects of coastal erosion and its protection, cannot be denied.

The original idea for preparing this manual came from Professor Per Bruun, who has considerable experience of working in Indian conditions for the past fifteen years or so. His major contribution and guidance during the preparation of this manual is indeed greatly appreciated.

I would like to express my gratefulness to my colleagues at the National Institute of Oceanography for giving valuable support to Prof. Bruun in the preparation of this manual. Colleagues who made significant contributions to this manual are: Dr. B. U. Nayak, Mr. N. M. Anand, Dr. A. K. Jain, Dr. A. G. Untawale, Mr. B. G. Wagle and Mr. K. H. Vora. Very useful suggestions and reviews were offered by Mr. N. P. Bhakta, Director, Pre-investment Survey of Fishing Harbours, Bangalore and Dr. V. V. R. Varadachari, Mr. H. N. Siddiquie and Dr. J.S. Sastry. The valuable assistance rendered by Mr. K. G. Chitari of the Drawing Section and Mr. S. P. Sharma of the Planning and Data Division in connection with the printing of the manual is gratefully acknowledged.

I would like to express my gratitude to the U. S. Army Corps of Engineers, Coastal Engineering Research Centre, Virginia and M/s. Litton Educational Publishing Inc., New York for their kind permission to reproduce some of the material and figures from their publications.

Comments and suggestions from readers on this publication would be most welcome for improving and up-dating the manual in the future.

National Institute of Oceanography

Dona Paula, Goa-403 004, India

S. Z. QASIM

15 February, 1980.

Director 


\section{List of Figures}

Fig. 1.1 Some examples of coastal erosion on the west coast of India

Fig. 1.2

Fig. 1.3

Fig. 1.4

Fig. 1.5

Fig. 1.6

Fig. 1.7

Fig. 1.8

Fig. 1.9

Fig. $1 \cdot 10$

Fig. 1.11

Fig. 1.12

Fig. 1.13

Fig. $1 \cdot 14$

Fig. 2.1

Fig. 2.2

Fig. $2 \cdot 3$

Fig. 2.4

Fig. $2 \cdot 5$

Fig. 2.6

Fig. 2.7

Fig. $3 \cdot 1$

(ref. 43)

Fig. $3 \cdot 2$

Longshore transport rate as a function of deep water wave height and deep water
wave angle (ref. 43 )

Fig. 3.3 Swell profile and storm wave profile

Fig. 3.4 Various types of wave breakers

Fig. 3.5 Breaker height index versus deep water wave steepness (ref. 43)

Fig. 3.6 Relative depth at wave breaking versus breaker steepness (ref. 43)

Fig. $3 \cdot 7$

Fig. 3.8

Fig. $3 \cdot 9$

Schematic of a rock mound wall in front of a dune on an open beach

Schematic of a rock revetment for dune protection on an open beach

Schematic of a rock revetment for protect
with a provision of an access to the beach

Fig. $3 \cdot 10$

Fig. $3 \cdot 11$

Fig. 3:12

Fig. $3 \cdot 13$

Fig. $3 \cdot 14$
Schematic of a vertical rock gravity wall (for wave heights less than $0.5 \mathrm{~m}$ )

Schematic of a double piled fascine or bag crib (for wave heights less than $1 \mathrm{~m}$ )

Schematic of a single piled rock crib (for wave heights less than $1.5 \mathrm{~m}$ )

Schematic of a simple mattress or gabion wall (for wave height less than $1 \mathrm{~m}$ )

Schematic of a simple revetment of sand bags (for wave heights less than $1 \mathrm{~m}$ )

\begin{tabular}{lr}
.. & 3 \\
.. & 5 \\
.. & 6 \\
.. & 7 \\
\hline & \\
.. & 9 \\
.. & 9 \\
.. & 10 \\
.. & 11 \\
.. & 12 \\
.. & 13 \\
.. & 14 \\
.. & 15 \\
.. & 16 \\
& \\
.. & 17 \\
\hline & \\
.. & 20 \\
.. & 20 \\
.. & 22 \\
.. & 22 \\
.. & 23 \\
.. & 27 \\
.. & 28 \\
\hline & \\
\hline & \\
.. & 32 \\
\hline & \\
.. & 33 \\
.. & 35 \\
.. & 37 \\
.. & 38 \\
.. & 39 \\
.. & 45 \\
\hline & 46 \\
\hline & 47 \\
\hline & 49 \\
\hline
\end{tabular}


Fig. 3.15 Effect of a group of T-groins on a beach

Fig. 3.16 Design of terminal groins on a sand spit

.. 53

Fig. 3.17 A withdrawn dune or dyke ( ref. 8)

.. 54

Fig. $3 \cdot 18$

Laboratory tests on dune-building with a single and a double fence system (ref. 26)

.. 54

Fig. 3.19

Laboratory tests with a fence on a plain ground or a bull-dozed dune (ref. 26)

Fig. $3 \cdot 20$

Mechanics of building-up of dunes by multiple fencing system (ref. 26)

Fig. 3.21 By-passing plants and arrangements (ref. 4)

Fig. $3 \cdot 22$ Inlet maintenance to improve navigation by dredging

Fig. 3.23 Maintenance of inlet to improve navigation and to decrease loss of material to deeper water by ebb flows during the monsoon

.. 55

.. 56

.. 58

60

.. 60

Fig. A.1 A definition sketch of a wave record

Fig. A.2 Relationship of $\frac{\sqrt{m_{0}}}{\mathrm{H}_{1}}$ and $\frac{\sqrt{m_{0}}}{\mathrm{H}_{2}}$ as a function of $\mathrm{N}_{\mathrm{Z}}$ (ref. 12)

.. $\quad 70$

Fig. A.3 A typical Weibull plot for wave data at New Mangalore Harbour

Fig A.4 Wave energy density spectrum (ref. 6)

.. 70

.. $\quad 72$

.. 75

Fig. B.1 Wave runup on smooth impermeable slopes for $d_{\mathrm{s}} / \mathrm{H}_{0}{ }^{\prime}=0$ with structure fronted by a $1: 10$ slope (ref. 15 )

Fig. B. 2 Wave runup on smooth impermeable slopes for $d_{\mathrm{S}} / \mathrm{H}_{0}{ }^{\prime}=0.45$ with structure fronted by a $1: 10$ slope (ref. 15)

Fig. B. 3 Relative runup for smooth slopes on 1 on 10 bottom, $l / L \geqslant 0.5$ $d_{\mathrm{S}} / \mathrm{H}_{0}^{\prime}=0.6$ (ref. 17)

.. 80

Fig. B.4 Wave runup on smooth impermeable slopes for $d_{\mathrm{S}} / \mathrm{H}_{0}{ }^{\prime}=0.80$ with structure fronted by a 1: 10 slope (ref. 15) 2. $\quad 8 \quad 82$

Fig. B.5 Relative runup for smooth slopes on 1 on 10 bottom, $l / \mathrm{L} \geqslant 0 \cdot 5, d_{\mathrm{S}} / \mathrm{H}_{0}{ }^{\prime}=1.1$ (ref. 17) .. $\quad 83$

Fig. B. 6 Relative runup for smooth slopes on 1 on 10 bottom, $l / \mathrm{L} \geqslant 0.5$, $d_{\mathrm{S}} / \mathrm{H}_{0}{ }^{\prime}=1 \cdot 5$ (ref. 17)

Fig. B.7 Wave runup on smooth impermeable slopes for $d_{\mathrm{S}} / \mathrm{H}_{0}{ }^{\prime}=2 \cdot 0$ with structure fronted by a $1: 10$ slope (ref. 15)

.. 84

Fig. B. 8 Relative runp for smooth slopes on 1 on 10 bottom, $l / \mathrm{L} \geqslant 0.5 d_{\mathrm{S}} / \mathrm{H}_{0}{ }^{\prime}=3.0$ (ref. 17) $\quad . . \quad 86$

Fig. B.9 Runup correction for scale effects (ref 15)

Fig. B·10 Runup correction for scale effects (ref. 17)

Flg. B.11 Wave runup on impermeable stepped $1: 1.5$ slope versus $H_{0}^{\prime} / g \mathrm{~T}^{2}$ for various $d_{\mathrm{S}} / \mathrm{H}_{0}^{\prime}$ (ref. 15)

.. 87

.. 88

.. 89

Fig. B.12 Wave runup on impermeable rip-rap slope of $1: 1 \cdot 5$ versus $\mathrm{H}_{0}{ }^{\prime} / g \mathrm{~T}^{2}$ for various $d_{\mathrm{S}} / \mathrm{H}_{0}^{\prime}$ (ref. 15)

Fig. B.13 Wave runup/rundown on a smooth quarry stone slope (ref. 3)

Fig. B.14 Wave runup/rundown on rough quarry stone slope (ref. 3 )

Fig. B.15 Relative runup $R_{P} / R_{S}$ or a relative wave height $H_{p} / H_{S}$ as a function of the probability of exceedance $P$

Fig. B.16 Slope dependence of zero-damage stability number (ref 3 )

.. 90

.. 91

.. 92

.. 93

Fig. C.1 Sampling scheme along a beach profile

.. 94

Fig. C.2 Sampling scheme along a shoreline

.. $\quad 98$

Fig. C.3 Cumulative size plot (ref. 1)

.. $\quad 98$

.. 100

Fig. D.1 Failure mechanism for an embankment slope

.. 104

Fig. D.2 Failure mechanism for a stepped seawall slope

.. 104

Fig. D.3 Failure mechanism for a revetment slope

.. 105 


$$
\begin{array}{cc} 
& \text { Page } \\
. . & 105 \\
. . & 106 \\
. . & 106 \\
. . & 106 \\
. . & 108 \\
& \\
. . & 109 \\
& \\
. . & 114 \\
. . & 116 \\
. . & 117 \\
& \\
. . & 120 \\
. . & 123 \\
. . & 127 \\
& \\
. . & 128 \\
. . & 128 \\
. . & 129 \\
. . & 129 \\
. . & 130 \\
. . & 130 \\
. . & 131 \\
. . & 131 \\
. . & 132 \\
. . & 132 \\
. . & 133 \\
. . & 133 \\
\hline &
\end{array}
$$

Fig. D.4 Forces acting on a gravity seawall

Fig. D.5 Circular slip surface for a seawall (ref. 8)

Fig. D.6 Non-circular slip surface for a seawall (ref. 8)

Fig. D.7 Some failure mechanisms for piled retaining walls (ref. 8)

Fig. D.8 Effect of slope angle and friction angle on stability factor (ref. 8)

Fig. D.9 Stability factors for failure plane passing through and below the toe of a structure (ref. 8 )

Fig. E-1 Geological map of north-west coast of India

Fig. E·2 Geological map of south-west and south-east coasts of India

Fig. E·3 Geological map of north-east coast of India

Fig. F.1 Climatological factors at Jamnagar, Marmugao, Visakhapatnam and Pamban

Fig. F.2 Succession of dune plants at Miramar beach, Goa

Fig. F,3 Protection of transplanted seedlings by 'Checker board' method

Plate F.1 (a) Dune formation by Spinifix littoreus at Miramar, Goa

(b) Growth of $S$. littoreus

Plate F.2 (a) Development of shoot and rootlets at nodal region in S. littoreus

(b) Female flowers of $S$. littoreus

Plate F.3 (a) Growth of 1 . pescaprae on the sandy dune

(b) Typical bilobed and fleshy leaves of $I$. pescaprae $\quad \ldots c c$

Plate F.4 (a) Carpet flora of Cyperus arenarius on sand dune at Miramar, Goa

(b) Mixed vegetation of $C$. arenarius and $I$. pescaprae

Plate F.5 (a) Growth of Periploca sp. on sand dunes of Saurashtra

(b) Periploca sphylla growing in sand in an arid region

Plate F.6 (a) Coastal erosion of sandy beach at Miramar, Goa

(b) Coconut plantation on sandy beaches 


\section{List of Tables}

Table 1.1 Causes of erosion attributable to nature and man (ref. 3)

Page

Table 2.1 Steps for sampling and analysis

.. 2

Table 2.2 Summary of littoral drift calculation for Ramayapatnam covering the period from $31 \cdot 5 \cdot 1972$ to $15 \cdot 6 \cdot 1973$ (ref. 29)

.. 24

Table 3.1 Breaker type in relation to the parameter $\xi$ or $\xi_{\mathrm{b}}$

.. $\quad 29$

Table 3.2 Natural and man-made coastal protection (ref. 3)

.. 36

.. 40

Table 3.3 Needs for coastal protection (ref. 3)

.. 40

Table 3.4 Coastal protective measures classified in accordance with their ability to provide protection to large and small shore areas and their influence on the adjoining shores (ref. 3)

Table 3.5 Coastal protection in relation to source of materials and conditions of beach profiles for beneficial versus adverse effects

.. 42

Table 3.6 Details of the performance of seawalls (ref. 3)

.. 43

Table 3.7 Details of the performance of groins (ref. 3)

.. 43

Table 3.8 Details of the performance of offshore breakwaters (ref. 3)

.. 44

Table 3.9 Details of the performance of artificial nourishment (ref. 3)

.. 44

Table 3.10 Future coastal protective measures (ref. 3)

.. 57

Table A.1 Parameters of long-term distributions of individual wave heights (ref. 10)

.. $\quad 73$

Table B.1 Values of $\mathrm{r}$ for various slope characteristics (ref. 16)

.. 79

Table B.2 Approximate rock sizes in kilograms for various wave heights, slopes and wave periods $T=6$ to 10 seconds (specific gravity 2.65)

Table C.1 Grain size scales and soil classification systems

.. 99

Table E.1 Important engineering properties of common rock types (ref. 15)

.. 112

Table F.1 Distribution of sandy beaches along the Indian coastline

.. 121

Table F.2 Distribution of dune species along the Indian coast

.. 122 


\section{Introduction}

This manual is written as a guide for those who are concerned with planning and designing of practical and economical methods of protecting the eroding shores on the Indian coast. The sandy shores of India, specially the barrier beaches of different coastal states with a high population density, are being eroded mainly by waves particularly when these get combined with storm tides. Coastal erosion in India has resulted in the loss of valuable beaches and adjacent coastal land used for habitation, agriculture and recreation, loss of marshes and wetland essential for marine life and fishery activities. Erosion also leads to damage and destruction of coastal highways, industries, bridges and other coastal installations. It increases the risk of life as seas encroach into highly populated or urban coastal areas. Considerable expenditure has been and is being incurred almost every year in constructing temporary remedial measures largely to handle emargency situations of severely eroding shore segments.

Fortunately, India has an abundance of natural rocks along most of its coastline in the form of granite, basalt, laterite, limsstone and sandstones. These rocky materials have, through the centuries, proven their worth as a building material for coastal structures to withstand hostile forces of the sea. Properly designed structures have largely been successful but nothing could remain successful in the long run against the continued eroding astion of the sea without proper maintenance. In certain parts of the Indian coast, the situation is so severe that hardly any extra land remains to be lost further as a result of shore erosion. There is a greater need today than ever before for proper planning and developing optimum solutions to the problems of coastal erosion in India so that the most suitable and economical measures could be adopted to combat erosion of a given shore segment.

Keeping the above aspects in view and taking into consideration the special conditions prevailing in India, this manual has been prepared to act a as guide. It is, therefore, hoped that the guidelines given in the manual will be of particular interest to public agencies and consulting engineers who may want to avoid the pitfalls of approving or designing inadequate and ineffective measures.

This manual covers the basic design aspects which should be considered in any analysis that leads to the selection and recommendation of a specific type of coastal protection. Furthermo e, it gives specific advices on the selection and design of coastal protection measures for conditions prevailing in India.

The manual describes several ways to reduce shorefront damage such as:

( $i$ ) structural - prevention of coastal erosion by the use of seawalls, revetments, dunes or dykes and groins;

(ii) conservation - preserving and enhancing the natural protective features like the dunes by sand fencing and vegetation to intercept the natural sand supply;

(iii) restoration of beaches and dunes by direct placement of sand from inland or from the ocean bottom or by erecting sand bypassing plants to restore normal littoral drift along the shores. In some cases feeding of the existing groin fields suffering from starvation may be advisable.

\subsection{General review on causes of beach erosion}

Beach and shore erosion is an evil which is found all over the world. Perhaps there are only a few countries which do not suffer from coastal erosion because their shores are predominantly rocky. By far, 
most countries of the world are surrounded by shores of alluvial materials derived from inland and offshore sources.

Erosion is caused by the forces of nature, sometimes enhanced by man-made structures or by man's activity of removing the material from the shore for building or other commercial purposes. Table 1.1 summarises some of the causes leading to natural and man-made erosion.

Table 1.1 Causes of erosion attributable to nature and man (ref. 3 ).

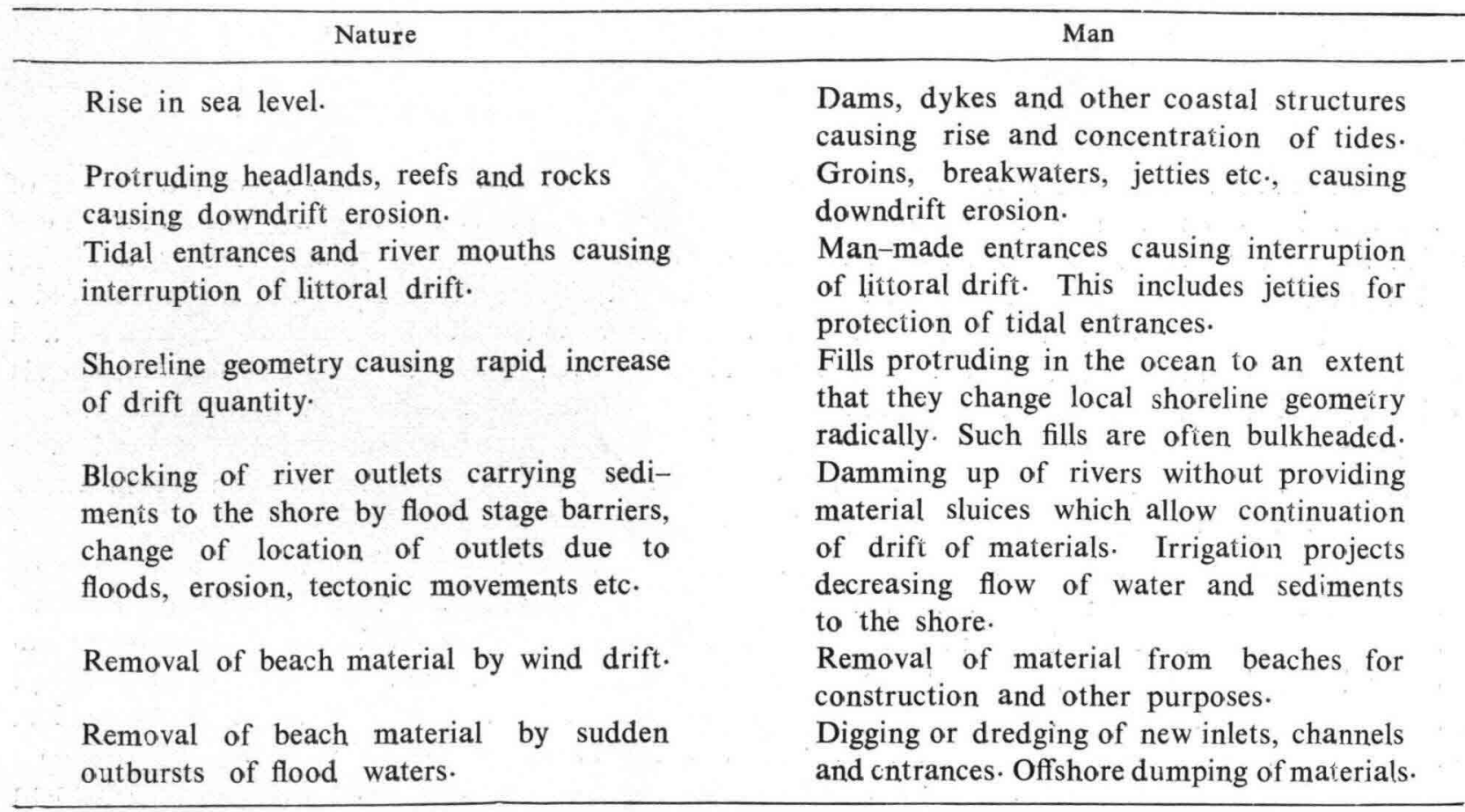

The following paragraphs give the overall explanations for erosion. Section 3.1 describes basic physics and engineering aspects of the erosion problem.

\subsection{Rise of sea level}

Alm sst all the shores in India erode (refs. 25, 28, 34, 35, 40 and 41). Figs. 1.1 (a) to (h) show some of the examples of beach erosion occurring on the west coast of India.

One general reason for erosion is the rise of the sea level. The sea level rise (refs. 2 and 13) may sound insignificant but it is necessary to realise how narrow a beach is, as compared to the offshore area, which has to be nourished by the material eroded from the beach in order to compensate for the rise of the sea level. With an equal amount of the deposited matcrial at the bottom, it is easy to work out how an average sea level rise of just $1 \mathrm{~mm}$ per year could cause a shorelinc recession in the order of about 0.5 meire per year. The actual rise of the sea level along the Indian coast is not well established. However, it is generally ascepied that while the sca level is rising, a consolidation by settling takes place at the same time in the river deltas like the Hooghly. The average rise of the sea level appears to be of the order of 1 to $2 \mathrm{~mm}$ per year, which is the average rate accepted universally.

\subsection{Heavy storms, storm surges, wave action and its seasonal effects}

It is well known that heavy storms including severe monsoons, hurricanes and cyclones cause the maximum erosion rates. The explanation for this is that high and steep waves break on the shores producing highly turbulent waters and uprushes which often atta:k the dunes or coastal platforms directly, thereby, causing erosion and creating vertical scarps, which in turn cause reflection of the waves, increase the 


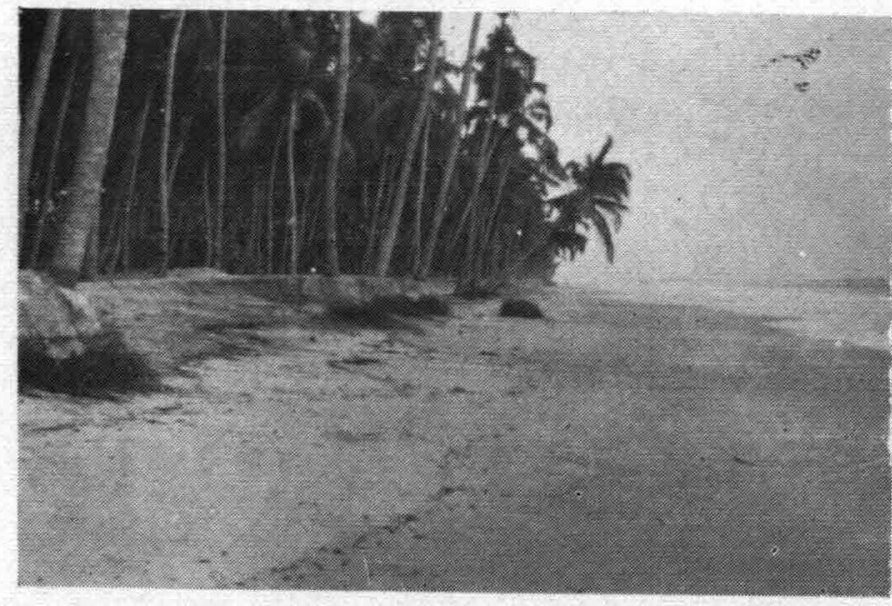

(a) Photograph showing beach erosion at Punnapra, Kerala during the Monsoon of 1967.

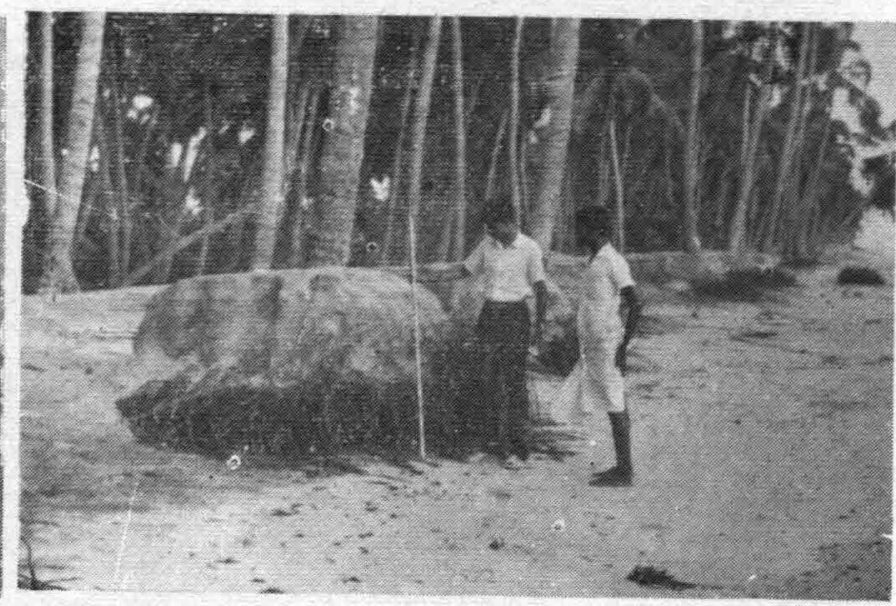

(b) Photograph showing how the coconut trees were being uprooted at Punnapra, Kerala due to beach erosion (1967).

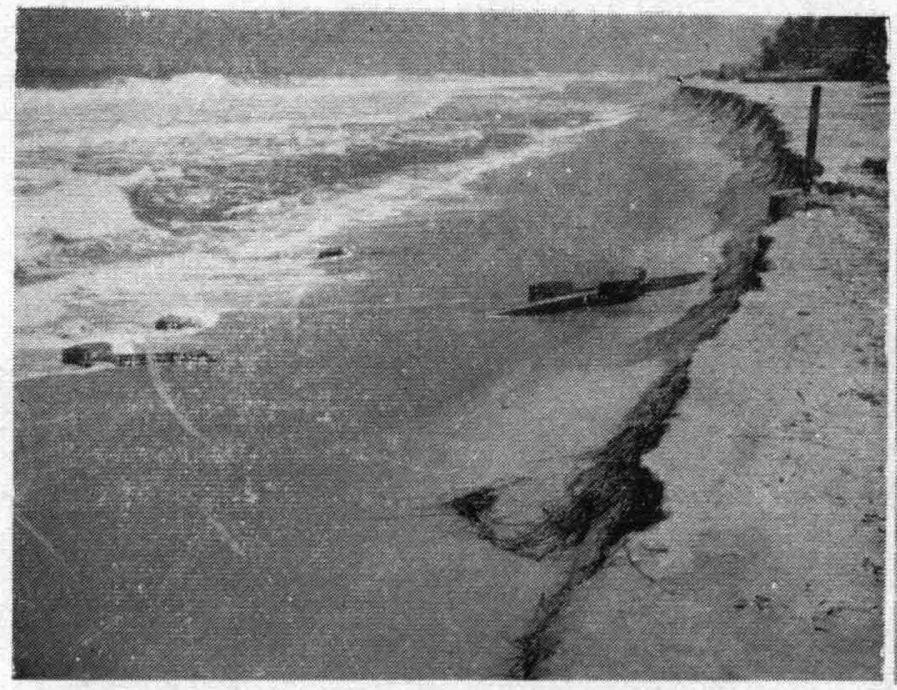

(c) Photograph shcwing erosion problem at a beach at Trivandrum, Kerala during the Monsoon of 1976.

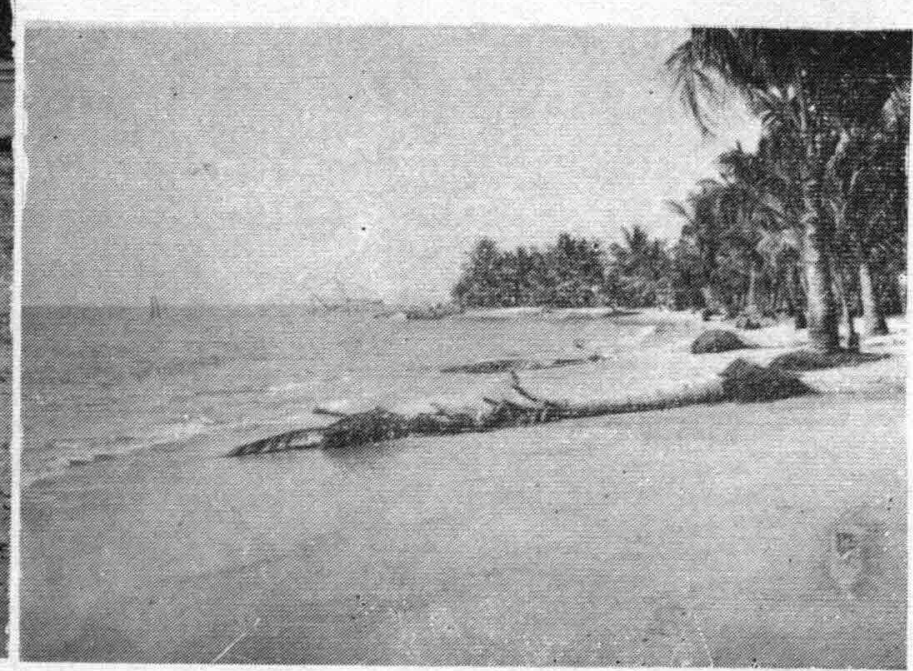

(d) Photograph showing the uprooted ccconut trees at Vypeen, Kerala due to the terminal effect of a seawall.

Fig. 1.1 Some examples of coastal erosion on the west coast of India. 


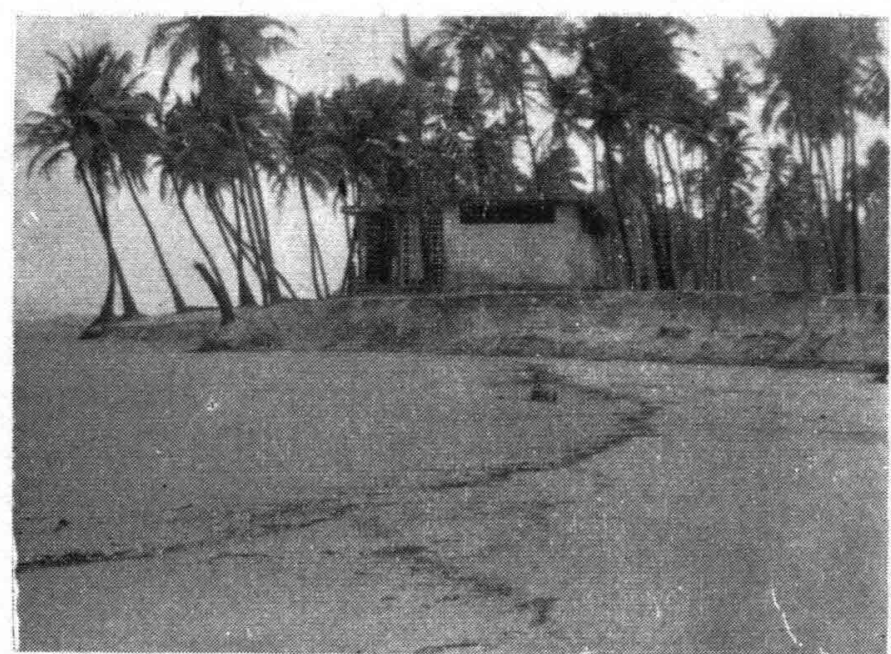

(e) Photograph showing erosion problem at Colva Beach, Goa during the monsoon of 1975 .

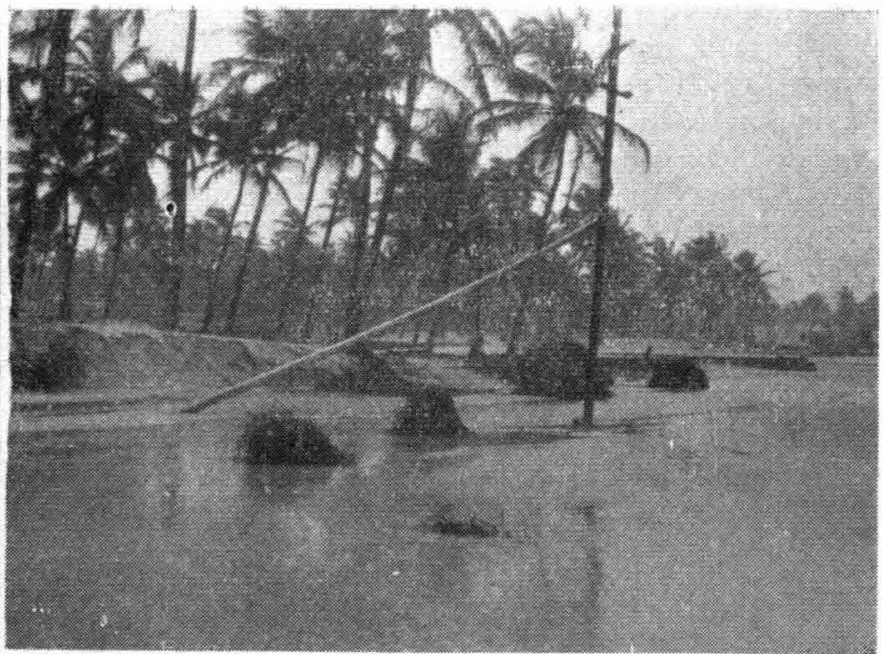

(f) Photograph showing the uprooted coconut trees at Colva Beach, Goa during the monsoon of 1975 .

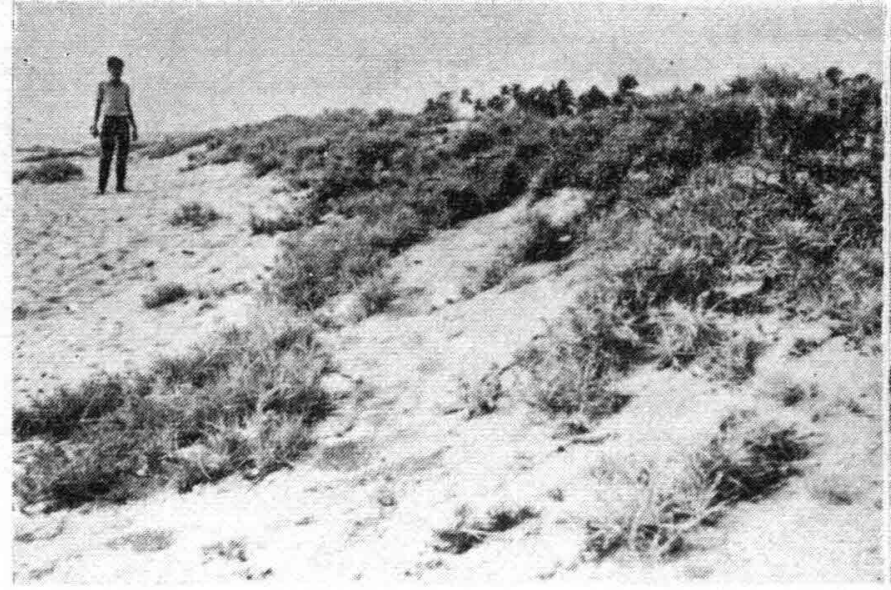

(g) Photograph showing dune erosion by wind at Calicut, Kerala and stabilization by growing dune grass.

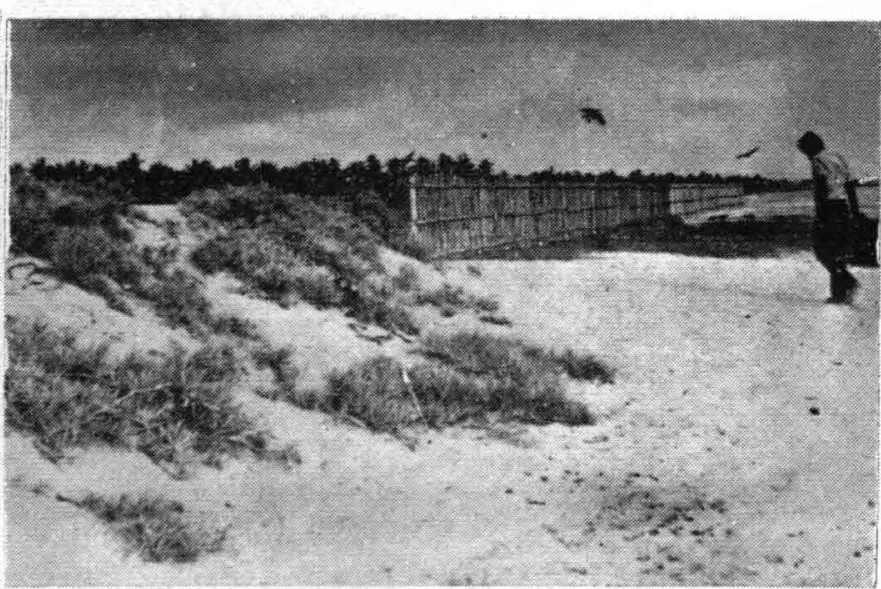

(h) Photograph showing dune erosion by wind at Calicut, Kerala and dune building by sand fencing.

Fig. 1.1. Continued. 


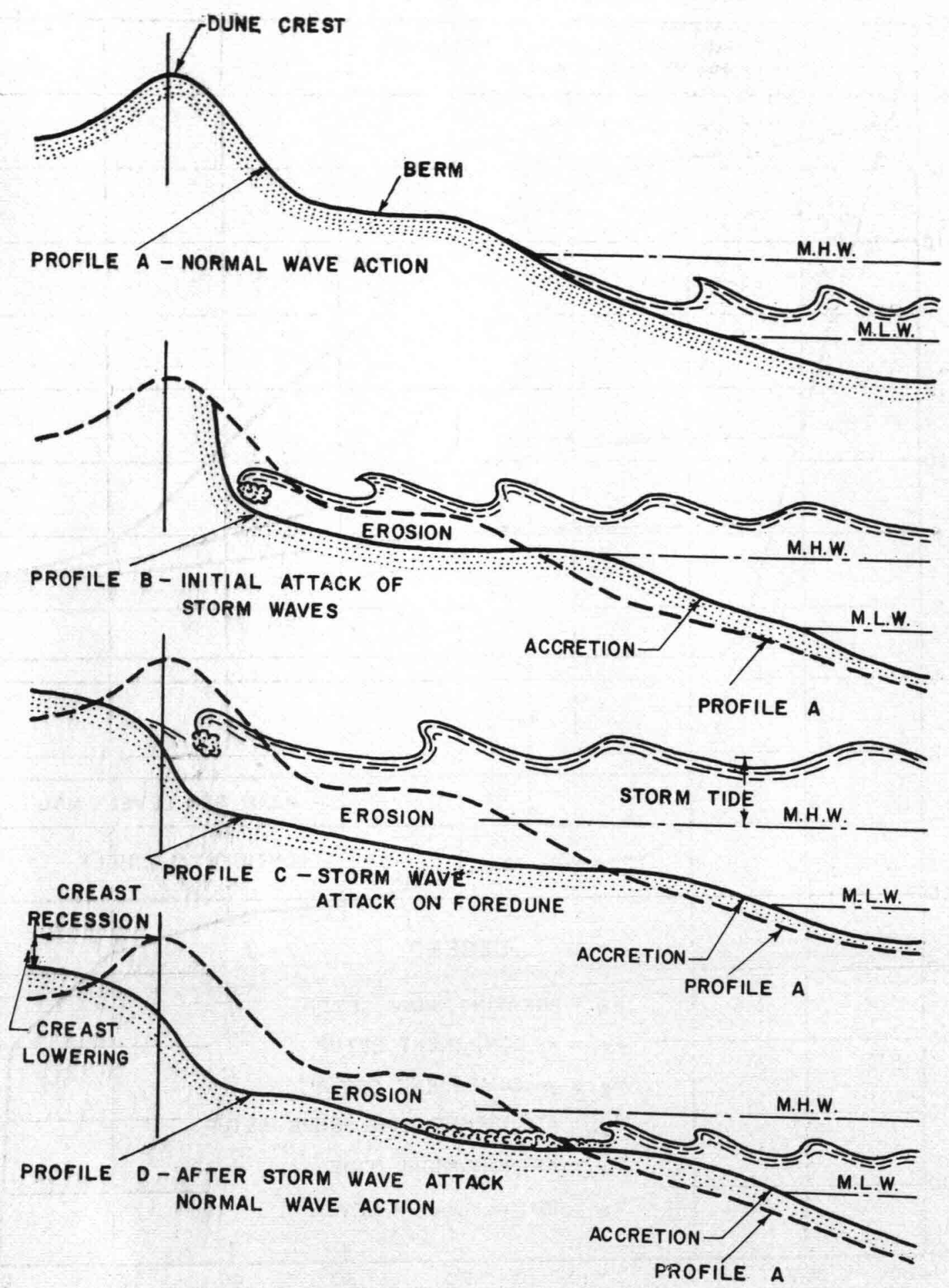

Fig. 1.2 Schematic diagram showing attack of storm waves on beaches and dunes (ref. 43 ). 


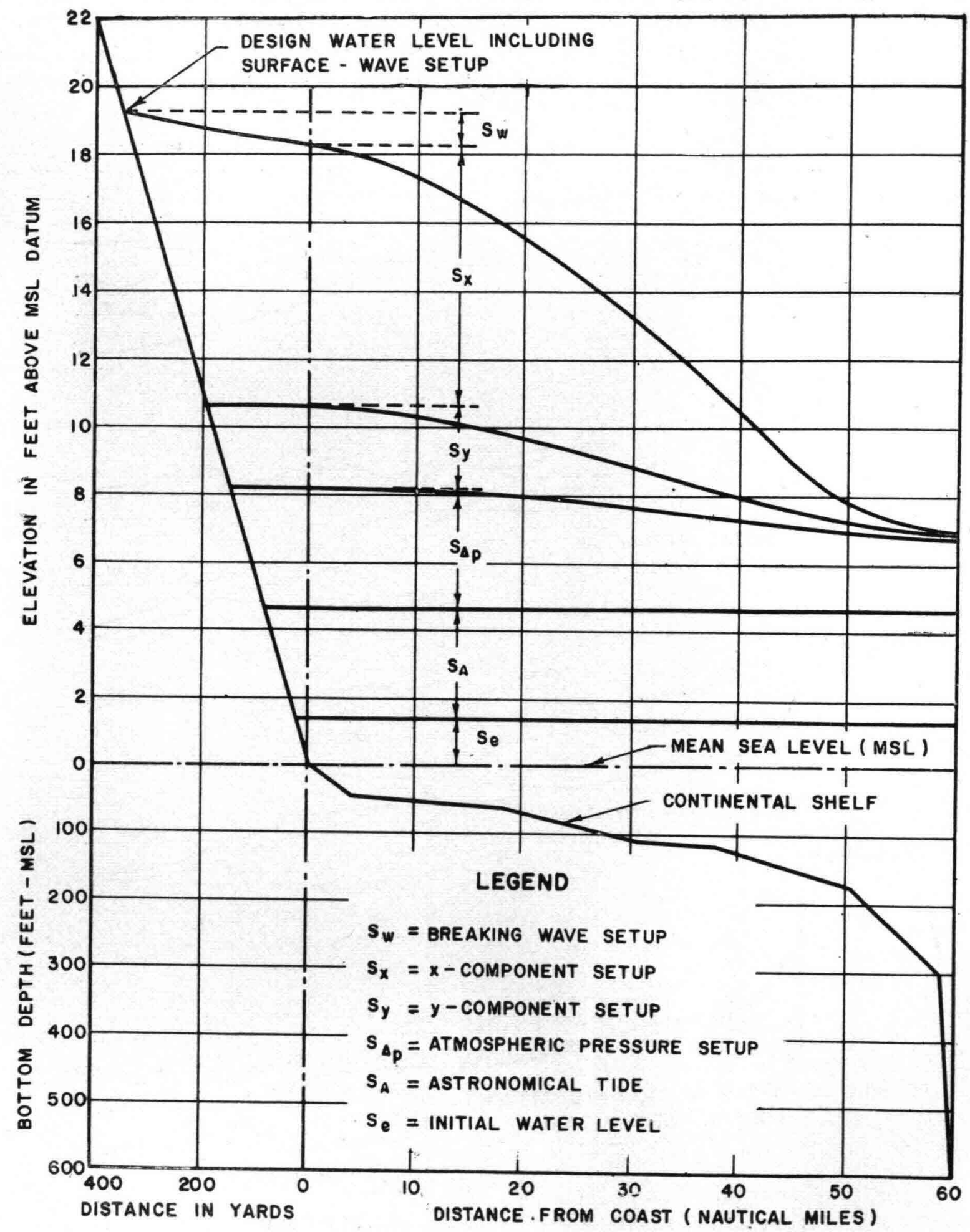

Fig. 1.3 Various setup compozents over the continental shelf (ref. 43). 
turbulence and thereby accelerate erosion further. The erosion by wave action is well illustrated by the schematic Fig. 1.2. It is easy to understand that an increase in the tidal elevation also increases the erosion, as higher tides bring in higher waves causing runup to greater elevations. The worst erosion, therefore, takes place when a combination of high tides and high and steep waves occurs which leads to crosion profiles as explained in Section 3.1.2 with reference to Fig. 3.3.

The total rise in the water level along the coast is the sum of all the components which lead to changes in the water level resulting from a meteorological storm plus those which are not related to the storm but occur simultaneously. Fig. 1.3 (ref. 43) gives the various setup components contributing to the rise in the sea water level over the continental shelf over and above the initial water level. These are:

$$
\begin{array}{ll}
\mathrm{S}_{\mathrm{W}}=\text { Wave setup caused by breaking waves } & \mathrm{S}_{\mathrm{P}}=\text { Atmospheric pressure setup } \\
\mathrm{S}_{\mathrm{X}}=\mathrm{X} \text {-component of wind setup } & \mathrm{S}_{\mathrm{A}}=\text { Astronomical tide. } \\
\mathrm{S}_{\mathrm{Y}}=\text { Y-component of wind setup } &
\end{array}
$$

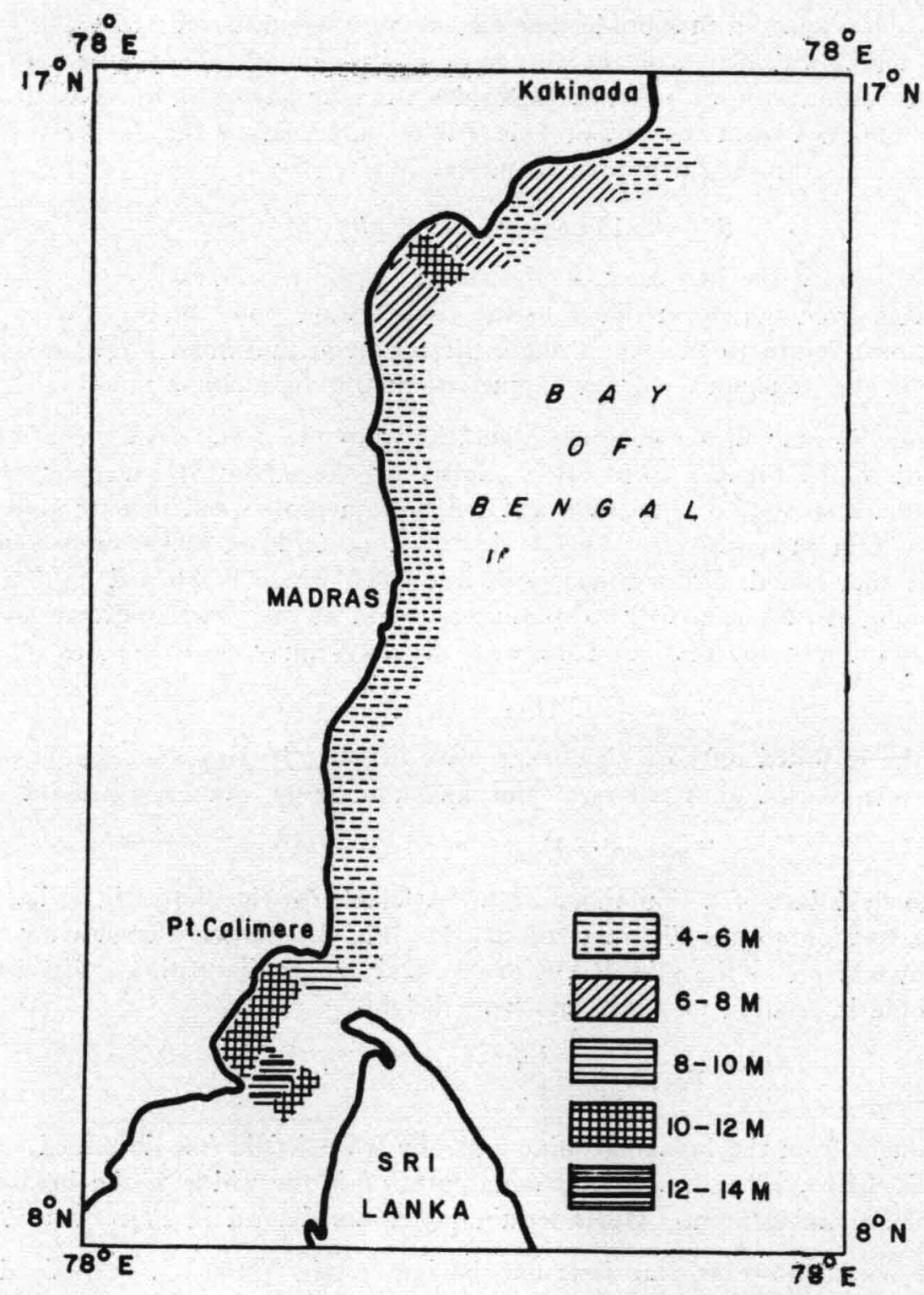

Fig. 1.4 Probable elevation of maximum storm surge on the south-east coast of India, 
The wind setup components include the effects of surface wind-shear stresses and bottom friction as well as the influence of earth's rotation.

The largest component contributing to the rise of the sea level during storms, cyclones or hurricanes is the wind shear stresses acting over the surface of water. Computational procedures for the determination of wind setup arc given in a number of publications including ref. 43. However, it is important to note that the wind pileup is proportional to the second power of the wind velocity and inversely proportional to the water depth. The wind setups or storm surges during the cyclones and hurricanes are, therefore, largest in the shallow water areas of the continental shelf as in the upper part of the Bay of Bengal and in the Gulf Coast of Florida.

Fig. 1.4 gives the probable elevations of maximum storm surges on the south-east coast of India. These values are computed based on the assumptions that a sustained wind of $40 \mathrm{~m} / \mathrm{sec}$ is blowing in an onshore direction and the central pressure depression is $35 \mathrm{mb}$ when the storm is approaching the coast. It is also assumed that the storm surge coincides with the high spring tide (ref. 33). The astronomical tide, in general, is quite small in magnitude, but can be very significant at certain geographical locations like the Gulfs of Cambay and Kutch on the west coast and the mouth of Hooghly river on the east coast. Storm surges in combination with astronomical high tides can play havocs in the coastal zone. Information on the tides can be obtained from the Indian Tide Tables published by the Survey of India, Dehra Dun. The atmospheric pressure setup, $S_{\triangle p}$ expressed in metres is given by

$$
\mathrm{S}_{\triangle \mathrm{p}}=0 \cdot 13\left(p_{\mathrm{n}}-p_{\mathrm{o}}\right)\left(1-e^{-\mathrm{R} / \mathrm{r}}\right)
$$

where $p_{\mathrm{n}}$ is the pressure at the periphery of the storm, $p_{\mathrm{o}}$ is the central pressure in cm of mercury, $r$ is the radial distance from the storm centre to the computation point on the traverse line and $\mathrm{R}$ is the distance from the storm centre to the point where the region of maximum winds intersects the shoreline. $\mathrm{R}$ and $r$ should be in the same units say in kilometres, metres or nautical miles.

The wave setup $S_{w}$ may also contribute significantly to the total elevation of the water level in the region shoreward of the breaker zone. It is caused by the inflow of water by wave-breaking and depends upon the charasteristics of the wave and the bottom profile and their mutual interaction, tides, energy dissipation, bottom materials etc. This is described in detail in ref. 12 which gives the results of field tests on the German Island, Sylt on the North Sea coast where beach and bottom profiles and wave characteristics have considerable similarity to conditions found in the nearshore areas of the east and west coasts of India. Accordingly, the maximum wave set up, $\eta_{\max }$ may be written as

$$
\eta_{\max }=0 \cdot 3 \mathrm{H}_{\mathrm{OS}}
$$

in which $\mathrm{H}_{\mathrm{OS}}$ is the recorded offshore significant wave height. If $\mathrm{H}_{\mathrm{BS}}$ the significant breaking wave height in the surf zone is used as a reference, the maximum setup can be expressed as

$$
\eta_{\max }=0 \cdot 5 \mathrm{H}_{\mathrm{BS}}
$$

As long as no field data of a similar nature are available for the shores in India, one may use the above expression in relation to the diagrams of ref. 12. Fig. 1.5 shows schematically the wave setup in the breaking zone in relation to the tide, beazh profile and energy dissipation. Fig. 1.6 shows the wave setup along the profile in relation to significant wave height.

$$
\text { Factor } \beta=\frac{L_{h}}{L_{b}}
$$

where $L_{h}$ is the distance from the breaking point until the wave height has decreased to $0.5 \mathrm{H}_{B}\left(\mathrm{H}_{B}\right.$ is the breaker height). $\mathrm{L}_{b}$ is the wave length at the breaking point, $B$ is the width of the breaker zone and $\mu \mathrm{B}$ is the wave setup at the breaking point. Other terminologies are defined in Figs. 1.5 and 1.6.

Waves in the ocean, however, are irregular having certain spectra as explained in Appendix A. In wave science and engineering, one distinguishes between a generation phase when the waves are 
generated by the winds shearing the sea surface. Next follows a peak phase when the wind velocities are the highest and the wave heights and periods reach their maximum values- When winds start slacking, the wave heights gradually decrease whereas the average periods continue to increase because the short period waves lose their energy most rapidly and attenuate. This is called the attenuation phase. When the waves reach the shore they may or may not break but, in any case, they runup on the beach. Wave breaking and uprush are dealt-with in Sections 3.1.3, 3.3.1 and in Appendix B.

The uprush or runup elevation depends upon the wave characteristics, bottom and beach geometry, friction and permeability characteristics. Natural sandy beaches may be considered hydraulically smooth and impermeable.

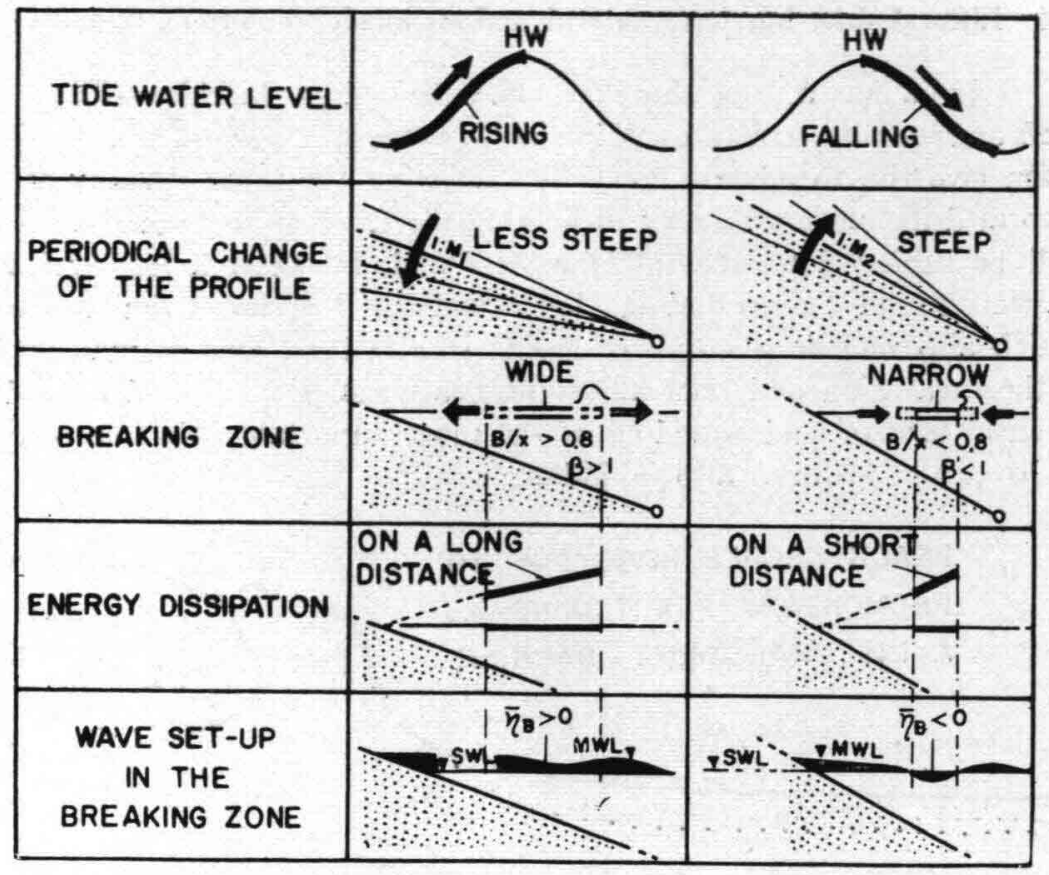

Fig. 1.5 Wave setup in a breaking zone in relation to tides, beach profile and energy dissipation (ref, 12).

Although they are not exactly straight,

their geometry is usually simple and may in cross-section, be approximated by a straight line or by two straight lines-one for lower part and the other for upper part of the beach. Sometimes the beach may have a gentle slope in the middle.

The uprush on beaches and coastal structures is discussed in detail in Appendix B. For smooth slopes (beaches) Figs. B.1 to B.8 give diagrammatic representations from which it can be secn that maximum runup or uprush occurs for the slopes of 1 in 1 to 1 in 2 . For rough slopes, e.g., rock mounds or revetments, the uprush decreases depending upon the character of the roughness as explained in Table B.1. Appendix B also indicates how it is possible to evaluate the uprush by irregular waves from the known data for regular waves (Fig. B.13).

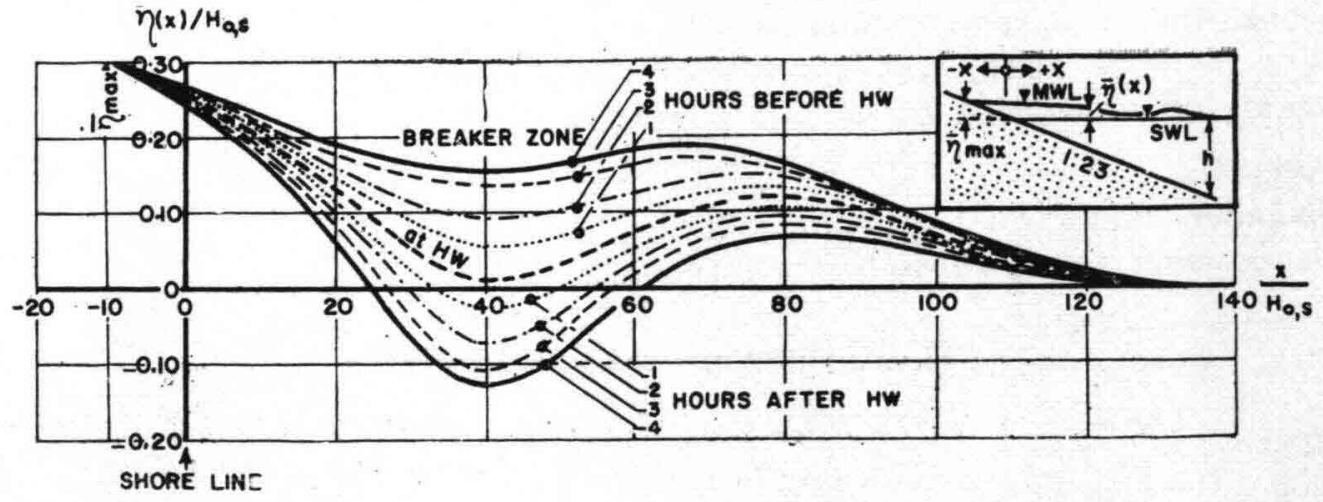

Fig. 1.6 Wave setup along a beach profile in terms of significant wave height (ref. 12). 


\subsection{Littoral drift barriers, natural and manmade conditions in India}

India has a long shoreline characterized by varieties of coastal features like rocky headlands, coral reefs and reef-like structures, tidal inlets, estuaries, lagoons, barrier islands, bays etc. Such coastal features often give rise to adverse conditions affecting the shore stability as they would act as complete or partial litioral drift barriers thereby preventing the drift of the material to downdrift shores which, as a result, will be subjected to erosion. Figs. 1.7 and 1.8 show a few typical examples of such natural structural barriers found on the Indian shores and Fig. 1.9 shows similar barriers caused by man-made structures which also include a group of groins (Fig. 1.10). One of man's worst destructive activities on the beaches is the excavation and removal of the beach material for land or road fill or for other construction purposes. Such a lack of understanding of the most important principle of conservation is of common occurrence all over the world as also in India.

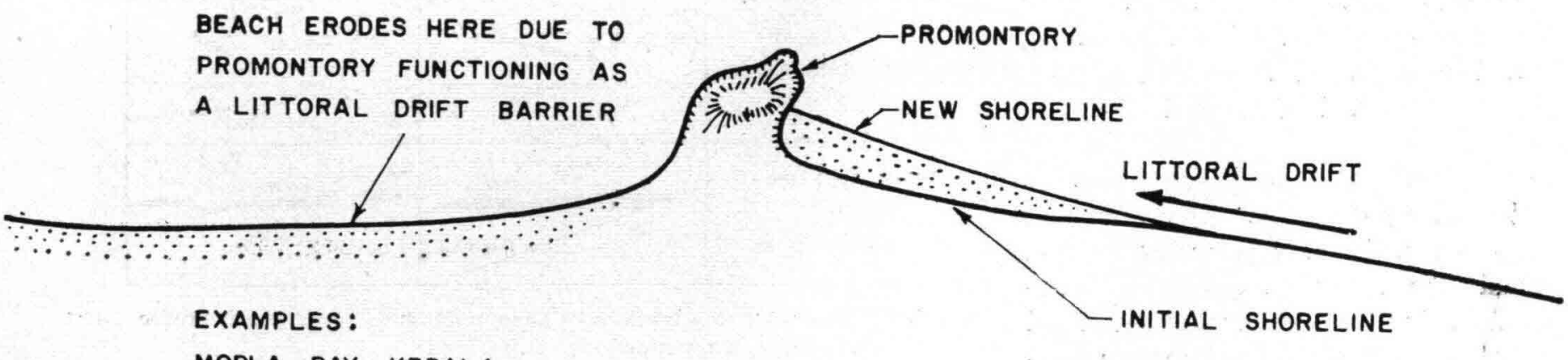

MOPLA BAY, KERALA

WALTAIR POINT, ANDHRA PRADESH

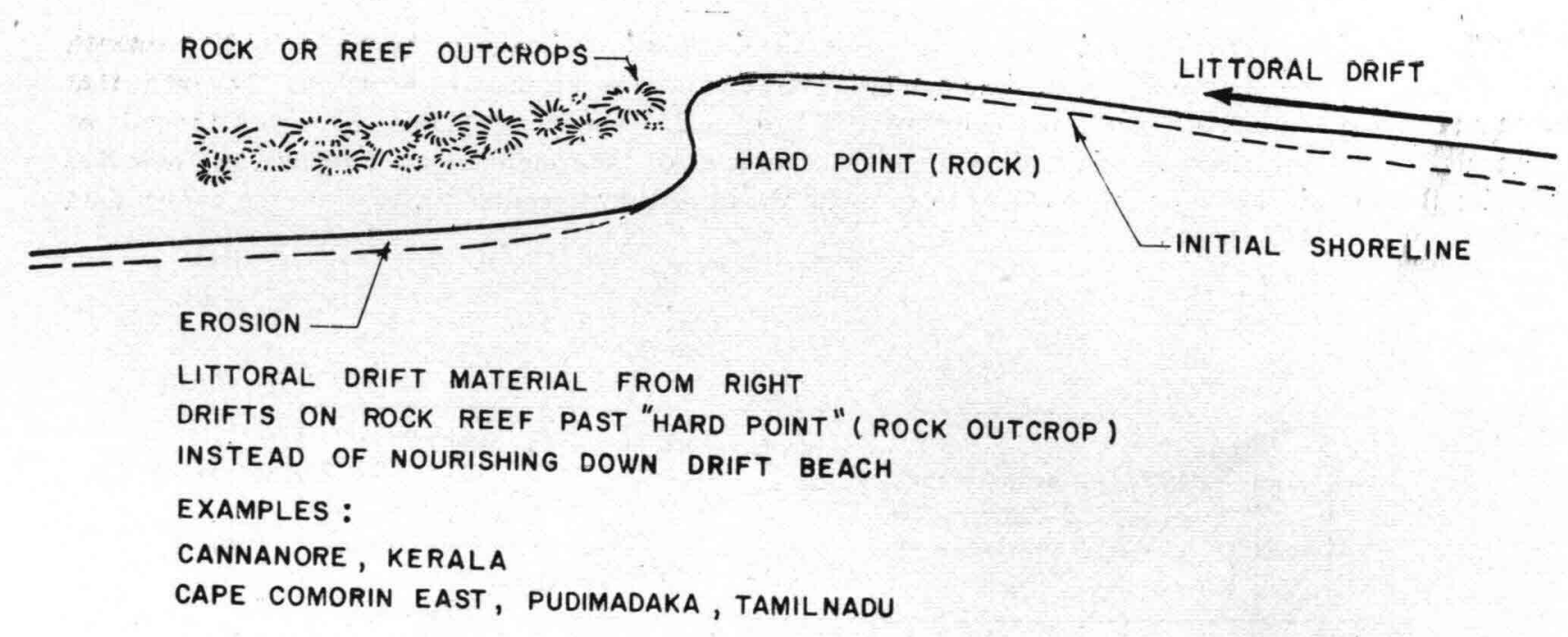

Fig. 1.7 Natural littoral drift barriers and headlands.

Fig. 1.11 shows how a natural inlet or an estuary may interrupt the longshore drift thereby causing downdrift crosion. This typc of situation is very frequently seen both on the east and west coasts of India. As it is known, somo matcrial will always bypass the inlet and this process may be assisted either by the inlet currents or by the presence of bars or by a combination of both. The various degrees of effectiveness 


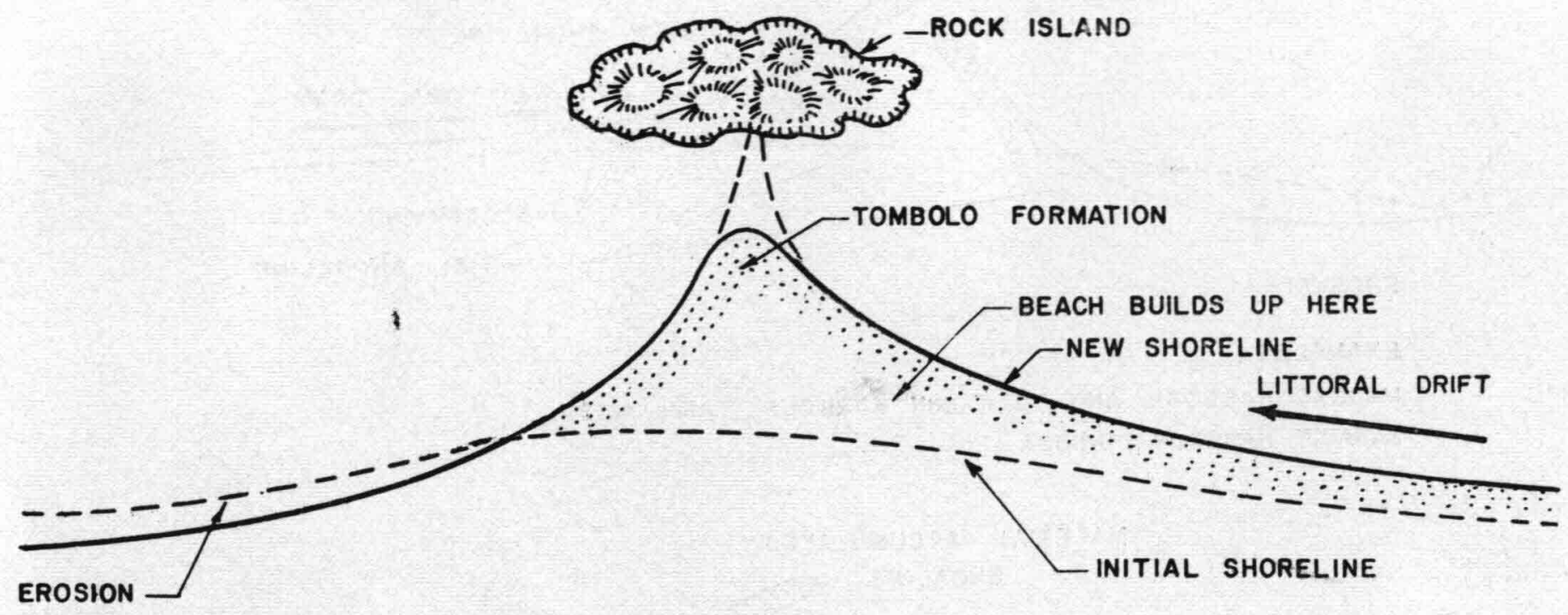

EXAMPLES :

MALPE (IN FORMATION), KARNATAKA.

TUTICORIN, TAMIL.NADU.

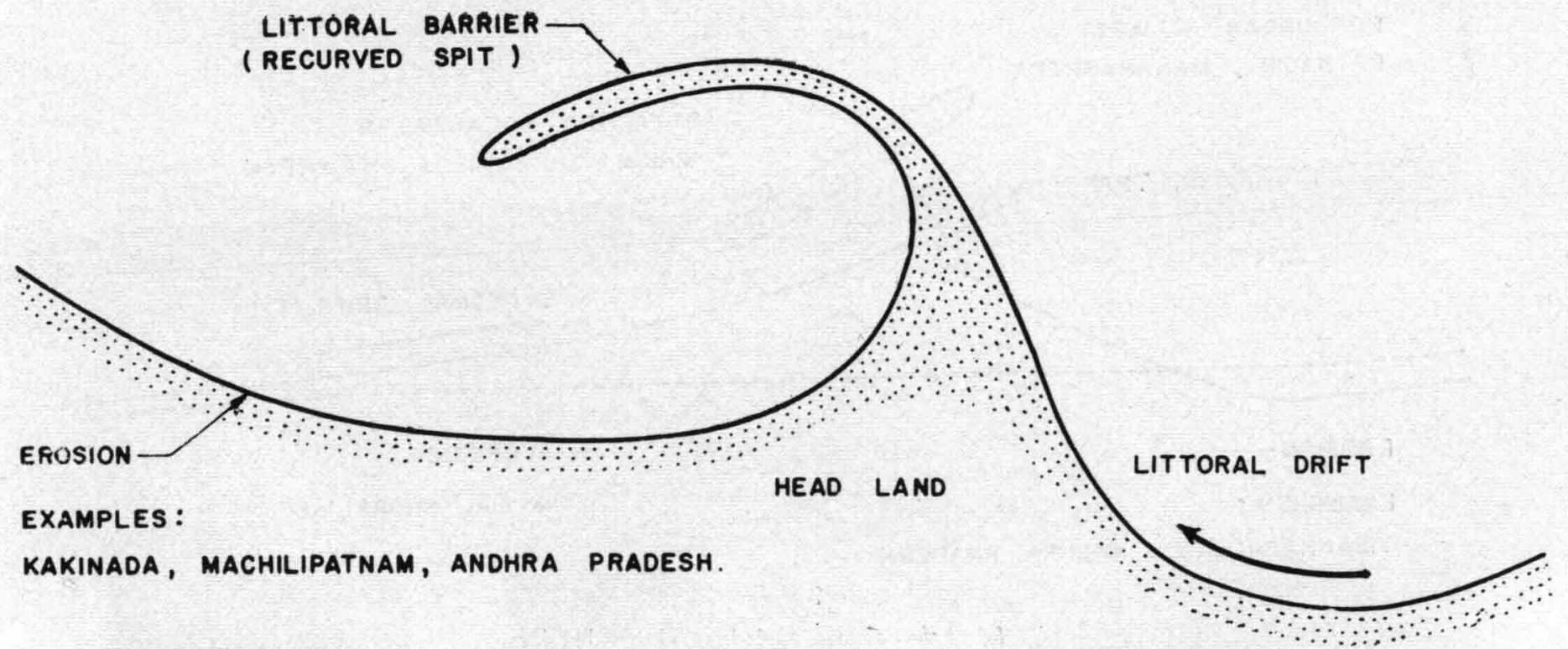

Fig. 1.8 Natural littoral drift barriers- tombolo and recurved spit. 


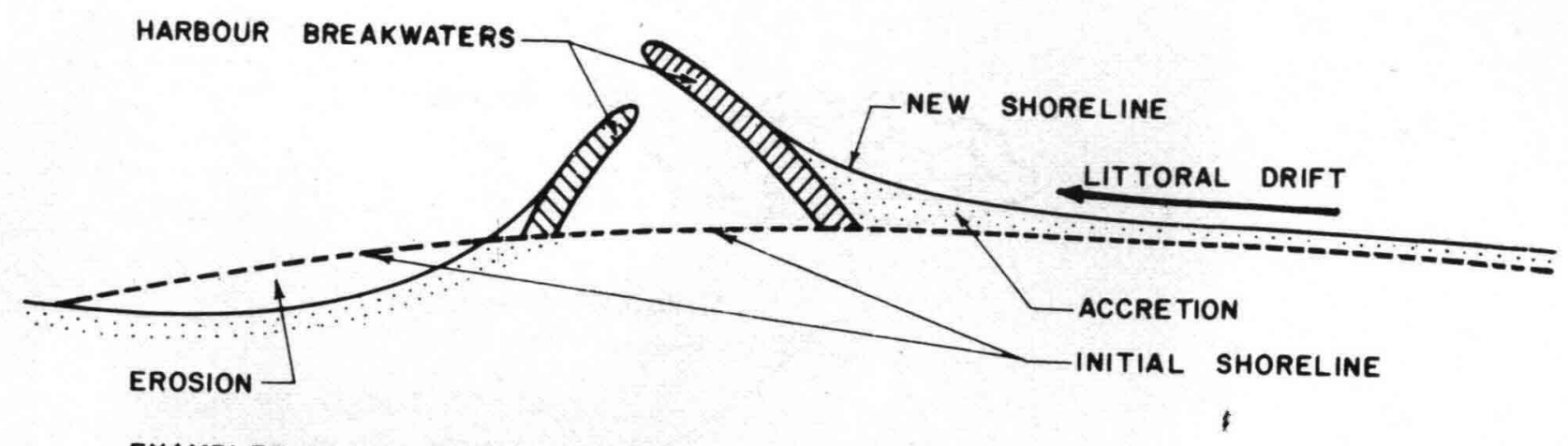

EXAMPLES :

MADRAS HARBOUR AND TUTICORIN HARBOUR, TAMIL NADU

PARADIP HARBOUR, ORISSA

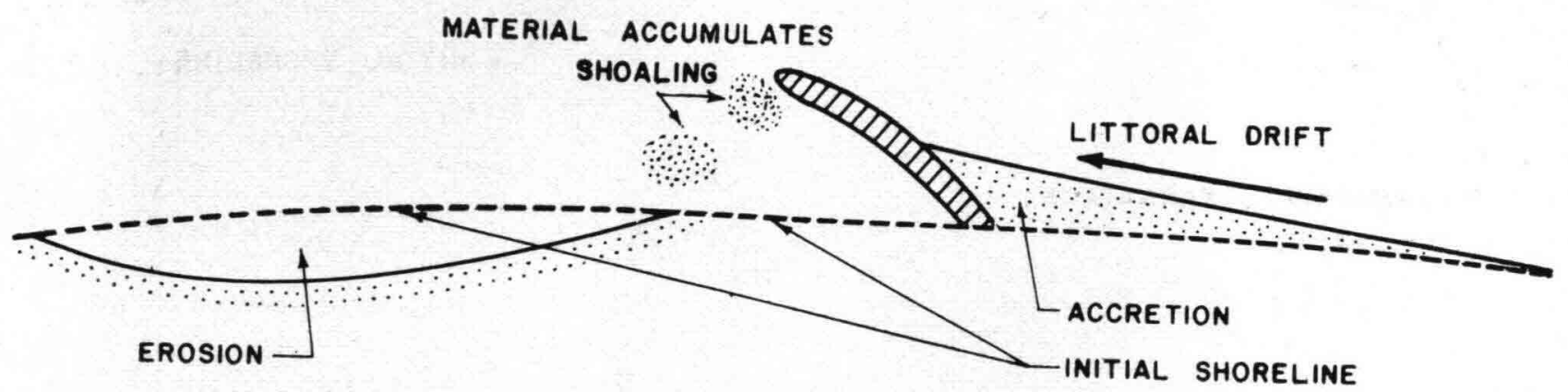

EXAMPLES :

PORBUNDAR, GUJARAT

RATNAGIRI, MAHARASHTRA

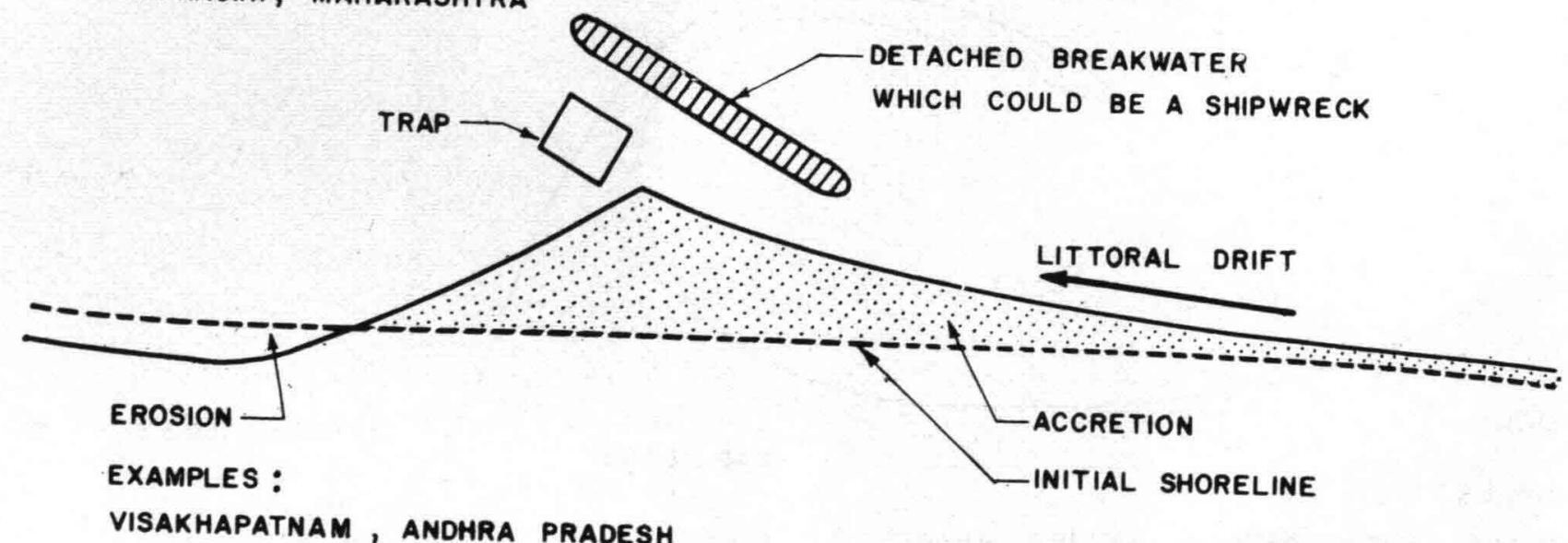

VISAKHAPATNAM, ANDHRA PRADESH

Fig. 1.9 Effect of man-made littoral drift barriers. 


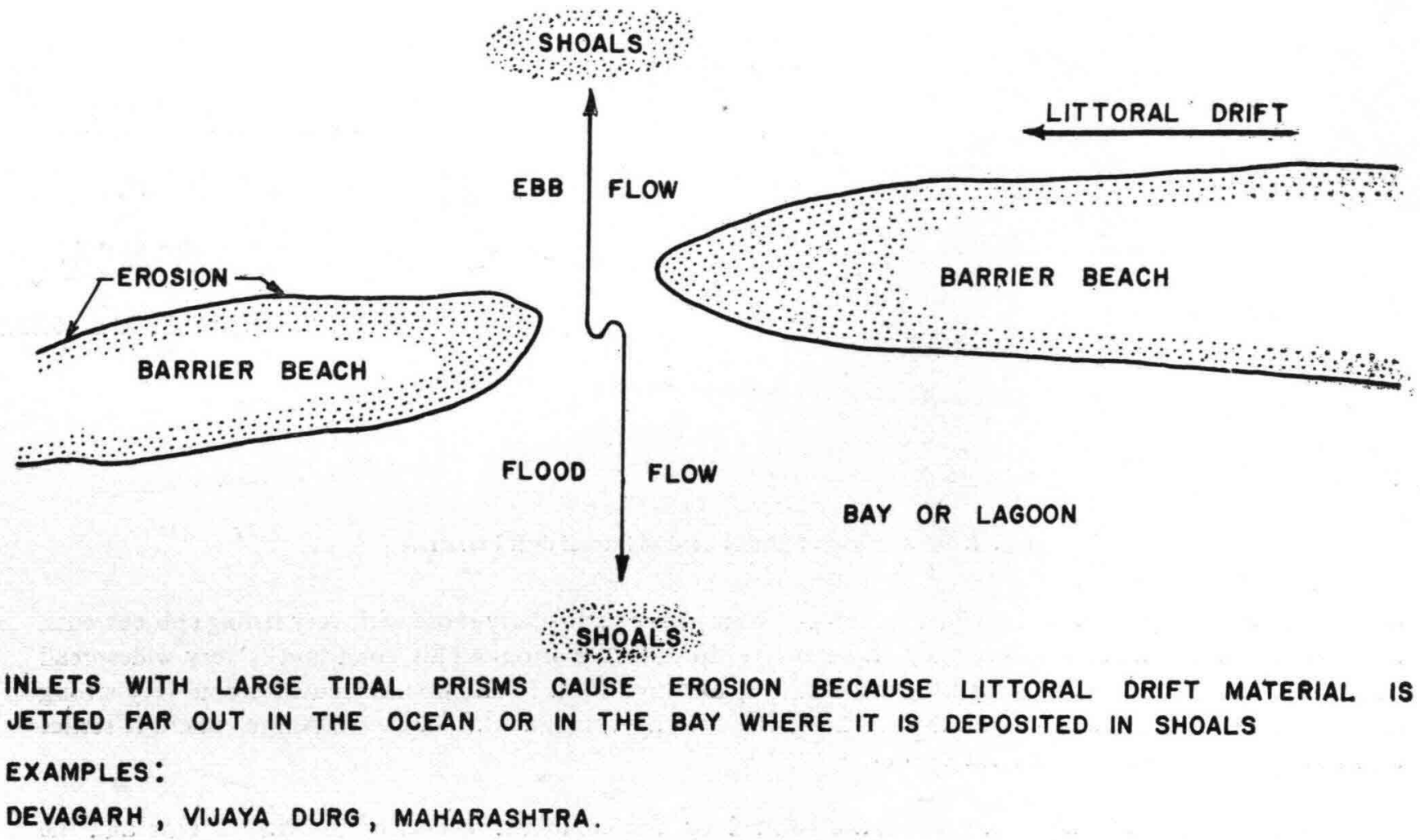

\section{EBB FLOW}

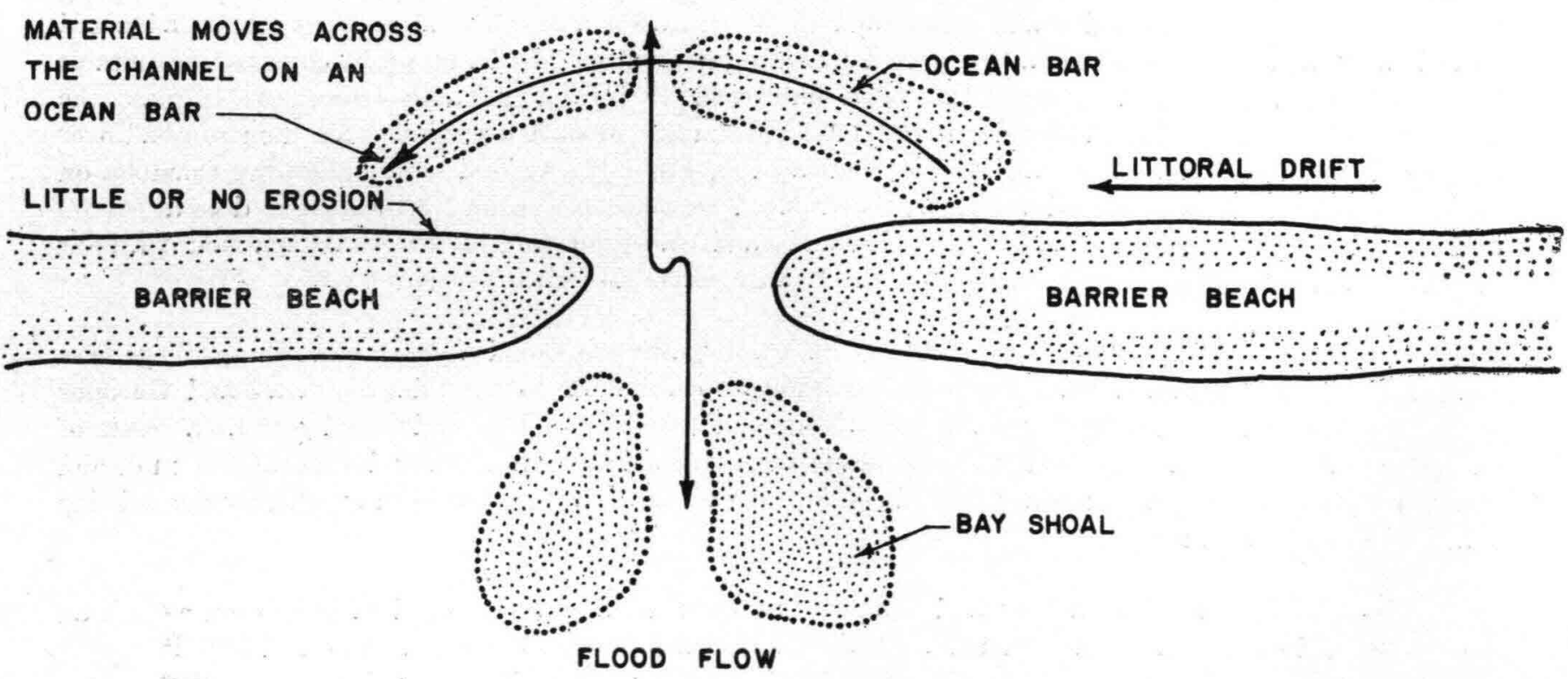

INLETS WITH SMALLER TIDAL PRISMS CAUSE LESS OR NO EROSION DOWN DRIFT AS MATERIAL DRIFTS ACROSS THE CHANNEL ON AN OCEAN BAR

EXAMPLES :

BAYPORE, KERALA

HONNAVAR, COONDAPUR, KARNATAKA

KRISHNAPATAM, MACHILIPATAM, ANDHRA PRADESH

CHILKA LAKE INLETS, ORISSA

Fig. 1.11 Some problems of littoral drift at tidal inlets. 


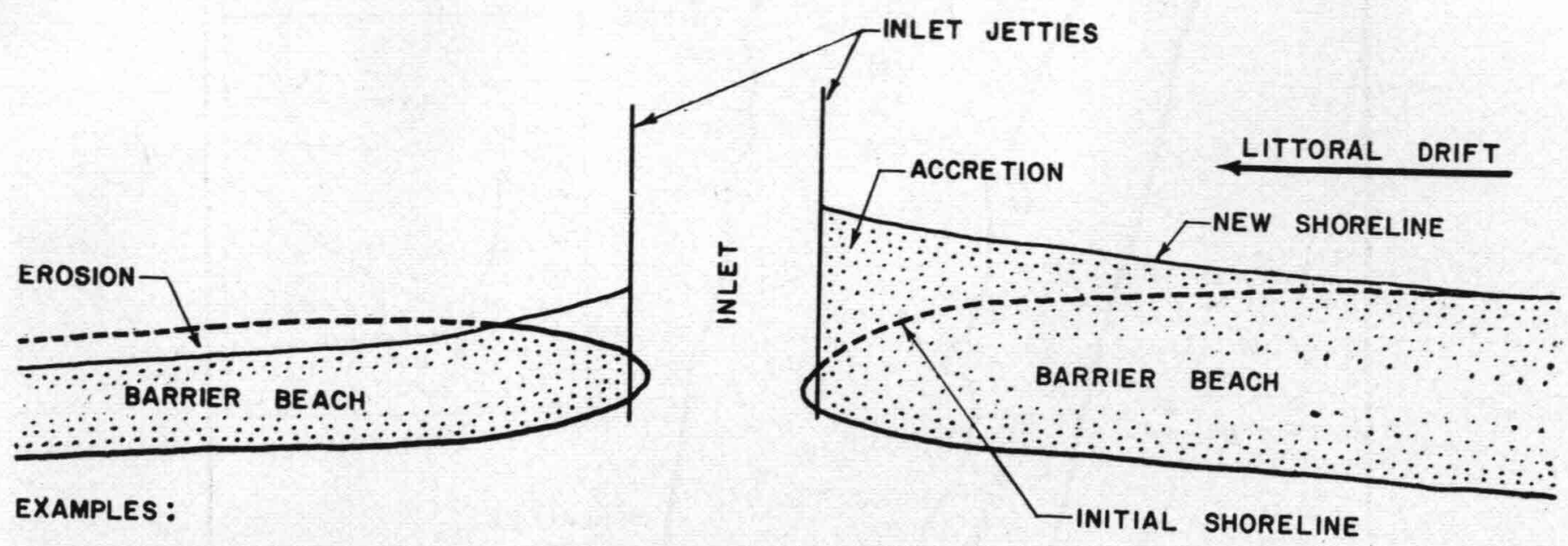

MALPE, KARNATAKA, NEENDAKARA, KERALA, PARADIP, ORISSA
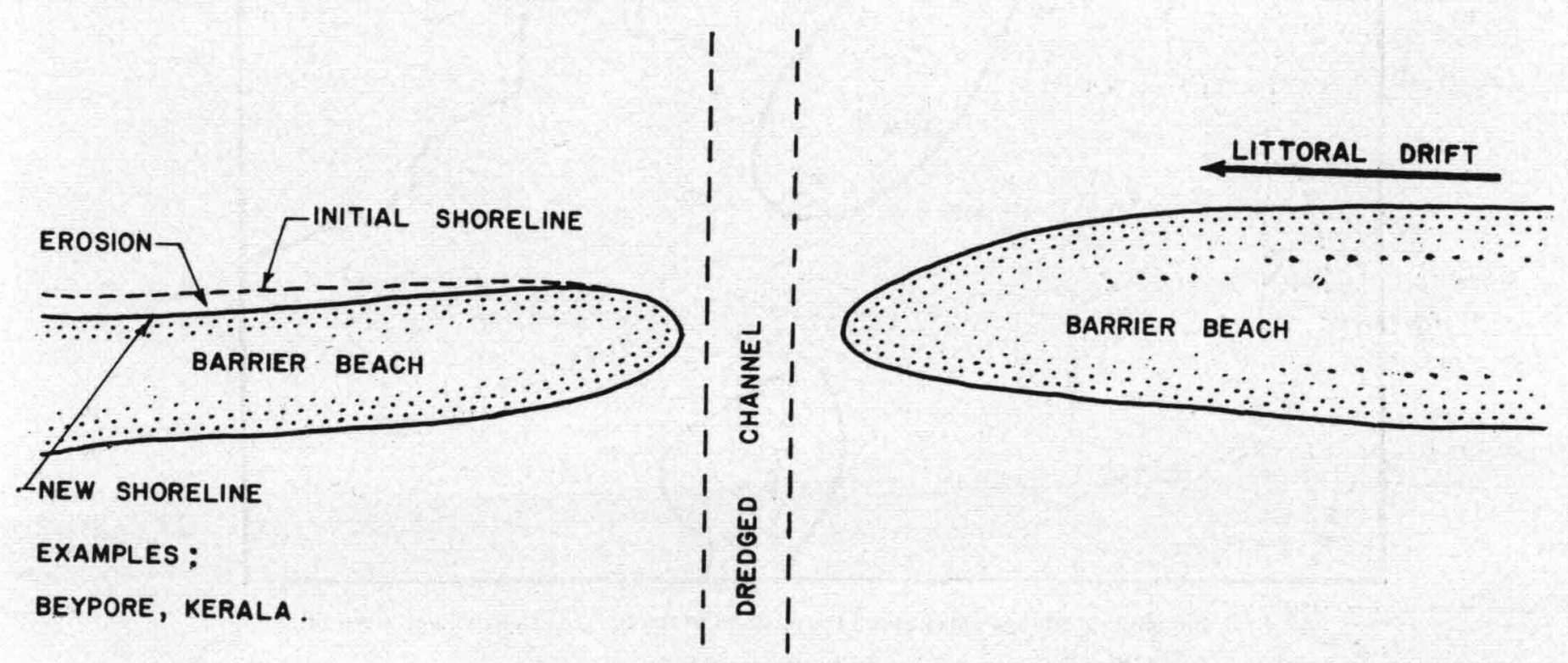

Fig. 1.12 Improved tidal inlets as littoral drift barriers.

material thus available gets exhausted, erosion continues to occur due to the interruption of the drift causing starvation of the downdrift side. The indication of such an occurrence on the beach and offshore bottom profiles is when the erosion of the beach starts of at a rapid rate. As a consequence of this, the nearshore bottom in front of the beach tends to develop a more gentle plafform-like slope and, in some cases a shoreline recession of this type would lead to simultaneous seaward movement of depth contours caused by temporary deposition of eroded beach matcrial in the offshore arcas. The latter phenomenon may get further aggravated due to the formation of rip-currents along the jetty as shown in Fig. 1.14.

It is very important to consider all possible adverse effects noted above when any improvement is planned or executed along the shoreline. In all problems related to coastal protection, it seems, somewhat 


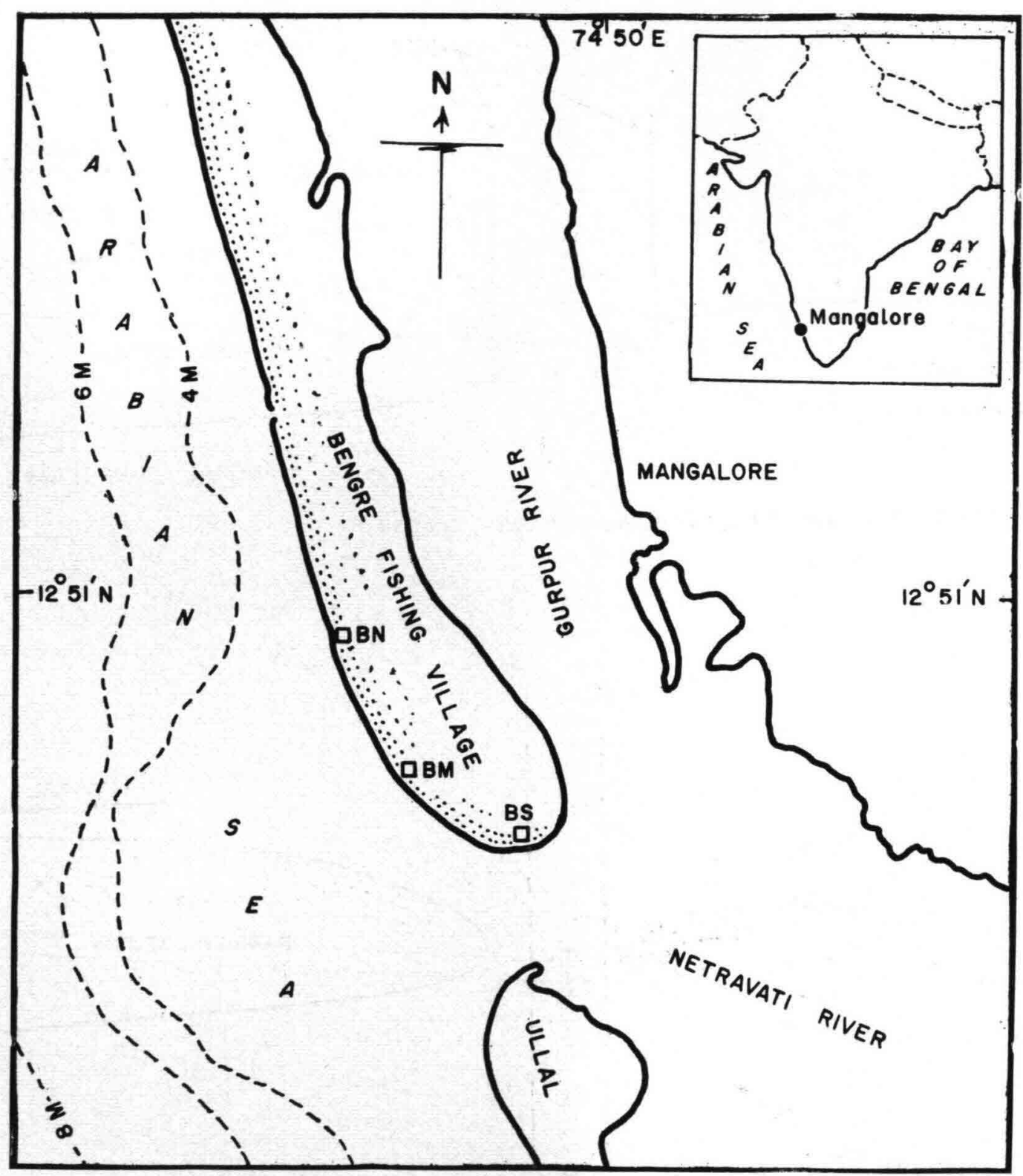

Fig. 1.13 Shoreline at Mangalore showing the location of the Bengre fishing village (ref. 34).

illogical or undesirable to construct a structure for protecting or stabilizing a shoreline. Because, such an action, after taking into consideration all the factors on a broader perspective, may tend to produce more harm than good (See sections 3.2.3, 3.2.4 and 3.3.3). It would also be wrong to allow harbour entrance structures or jetties to cause serious erosion on their downdrift side, often leading to serious loss of valuable land and property.

This type of calamity can now always be foresecn and rectified before any damage could occur. This requires a thorough study of the problem and proper planning before such projects are carried out. A coastal engincer, confronted with a shore protection or improvement problem, should be in a position to evolve an economical and technically viable design making the best use of the environmental data, uptodate knowledge, experience and judgement. 
PERSISTENT SWELL
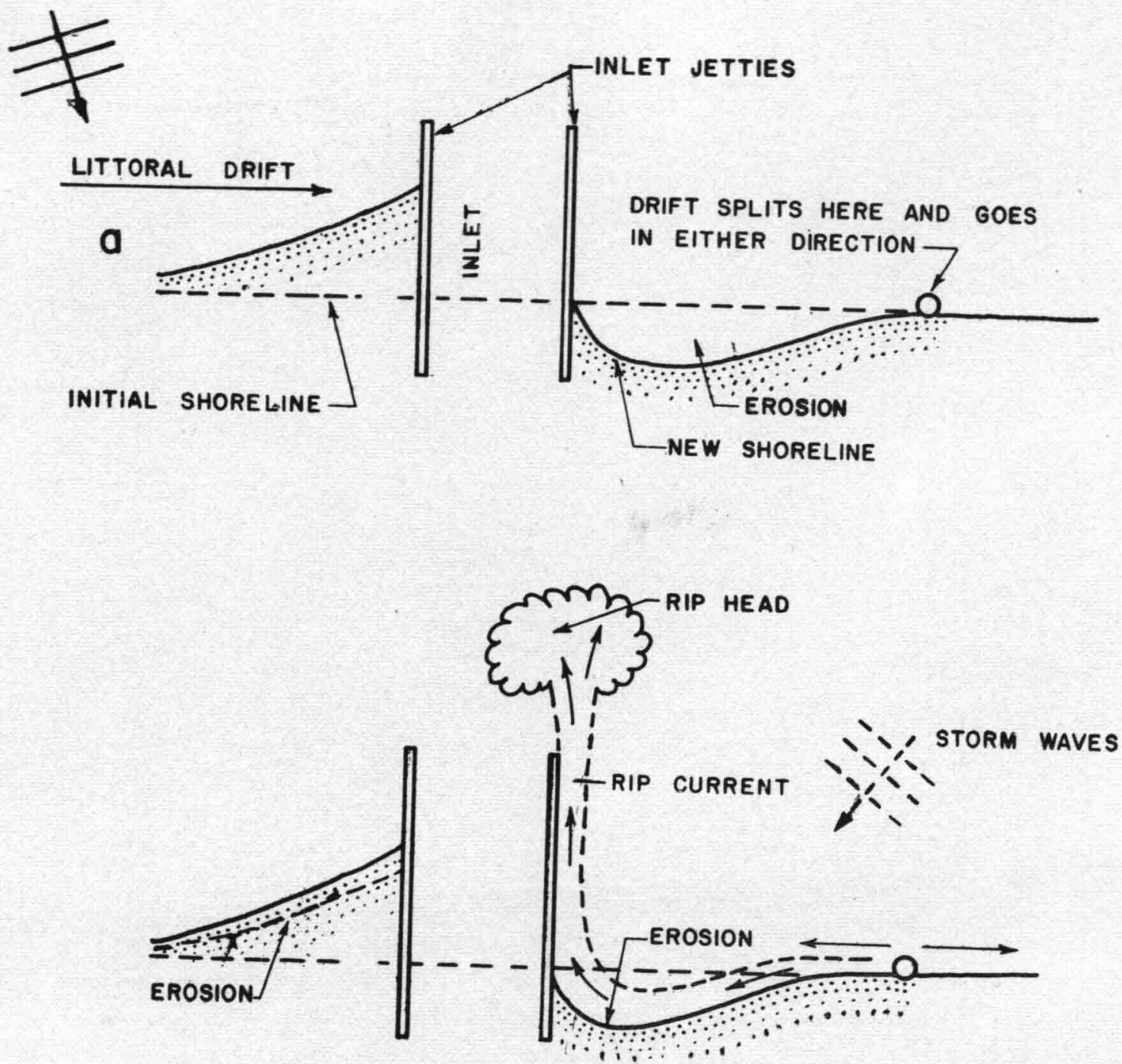

Fig. 1.14 Developing erosion at a jetty improved tidal inlet (a) showing persistent swell conditions, (b) during storm wave condition. 


\section{Beach Surveys}

\subsection{Bathymetric surveys}

A simple but approximate method of measuring beach profiles, as described below, can easily be adopted after establishing a reference level on a backshore sand dune by driving a peg or burying a large rock. This reference level should be connected to a more permanent nearby bench mark which in turn should be connected to the nearby Survey of India bench mark, if available. In order to measure the beach profile at the same location each time, another object such as a light post, corner of a building etc. should be used in line with the reference point and perpendicular to the shore. Fix stations at $3 \mathrm{~m}$ intervals (Fig. 2.1).

The technique of levelling requires two persons, one person to hold the graduated staff and the other to observe from the reference point. The observer sights on the vertical staff from the top of the reference level and notes down the reading of the horizon. Since the line of vision to the horizon is nearly horizontal, the reading on the pole which is graduated from the bottom will give the difference in height of the station below the reference level. This procedure is repeated for all the stations and the heights noted. Generally, additional reference points are required along the profile since the staff used is not of sufficient height to cover the entire drop in sand level across the beach profile. These can be easily established along the line of the stations as required. Sand level of each station can be computed with reference to the original reference level (Fig - 2.1).

For more accurate profile surveys, and when the horizon is not clearly visible, the usual surveying methods using either plane table or spirit level can be adopted. In shallow water and the surf zone, modification in the method is necessary. A wader then operates the level staff or stadia board. In deeper areas an electronic depth recorder (echosounder) can be used to take continuous soundings of the bottom. Alternatively, a leadline can be used to take spot soundings. Fixing the position of the levelling stations can be made from the shore using transits or pre-determined rangelines and measuring tapes or from the survey boat itself using sextant angles to three fixed objects on the shore.

As an example, a specific procedure for rapid and accurate beach and nearshore bathymetric survey can be as follows: A baseline is established along the stable landward area of the beach which is to be used as a basic control for survey ranges (profile lines) normal to the baseline. These ranges, along which the profiles are taken, run from the baseline across the beach seaward. For a long-term beach study, the baseline can be monumented by erecting masonry or concrete posts. Any existing siructure like curbs, lamp posts, fishing piers, buildings can also serve to establish and relocate a baseline or the survey ranges. The position fixing along the range line can be secured by a transit intersecting a level staff or a sounding boat operated along these ranges as illustrated in Fig. 2.2.

Prior to each sounding run, the survey boat powered by an outboard motor with a minimum crew of two, a sounder operator and a boat operator, proceeds to a point on the range at the required depth. The sounder operator then logs in pertinent information on the sounding record (paper chart) prior to each run, namely the station number of the range line, the starting time and the date. The boat then proceeds towards the shore along the predetermined range line either by the monuments fixed 


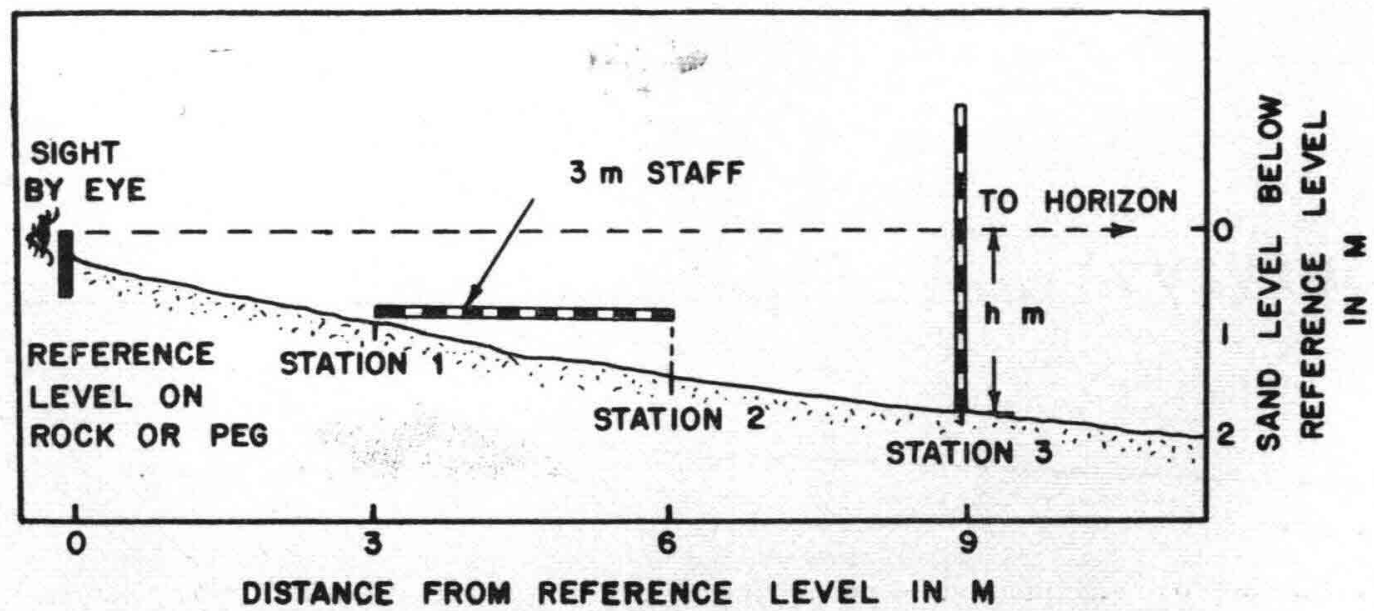

Fig. 2.1 A simple procedure for measuring beach and offshore bathymetric surveys.

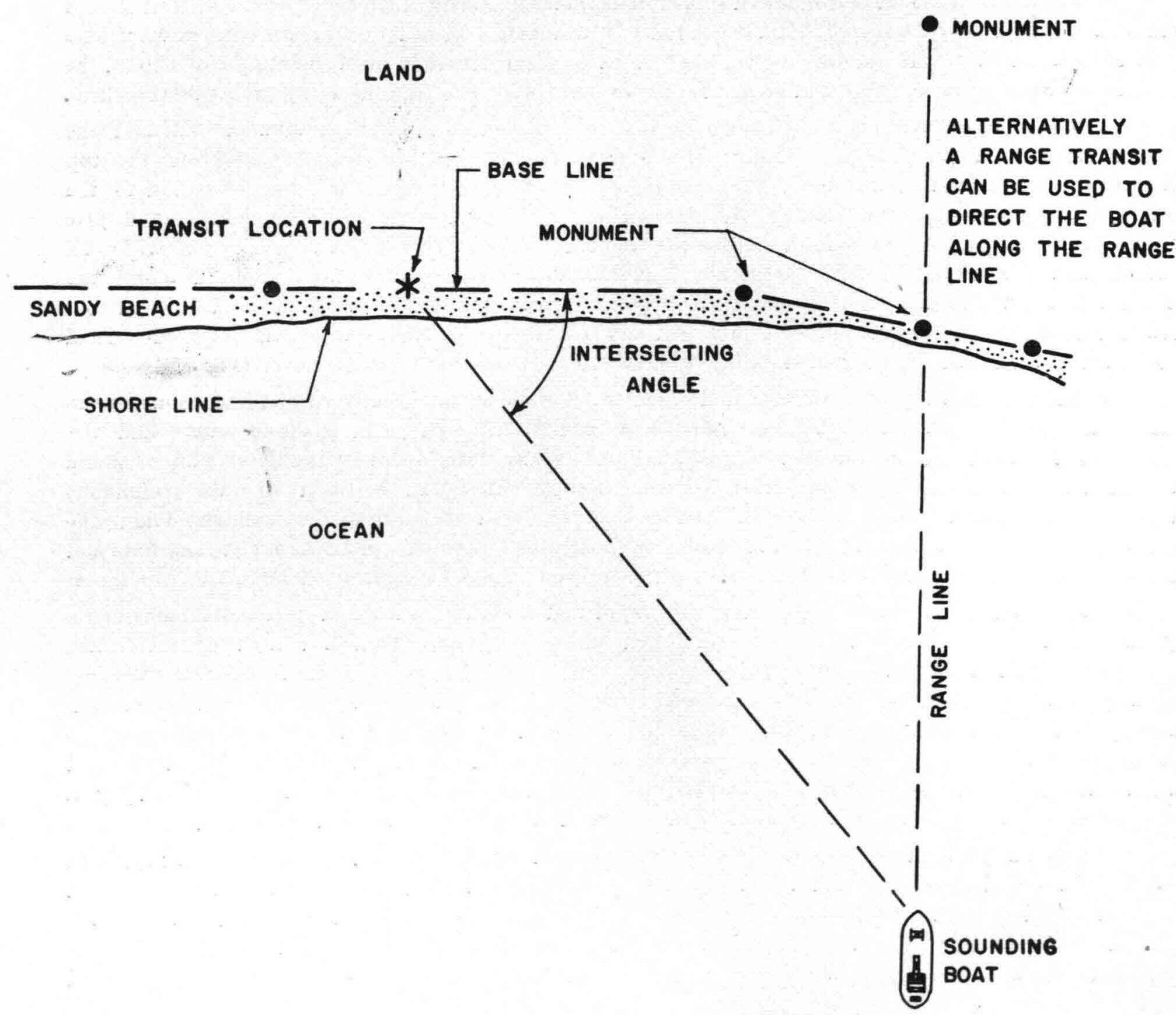

Fig. 2.2 Procedure for rapid and accurate beach and offshore bathymetric surveys. 
on the coast in line with the range or by the range transit operator signalling with right and left flags to the boat operator. Radio communication system or walkie-talkies can be advantageously used for this purpose. The depth recorder makes a continuous record of the depths (some 480 soundings per minute). The boat location on the range line is determined every 10 to 15 seconds by continuous tracking and recording at the cut-in transit location. For approximate position fixing at regular intervals, a sextant can also be used in the absence of a cut-in transit.

Besî results are obtained with the boat working at high tide and the beach levelling done at low tide. Corrections for waves and tides should be applied to the echosounding record so that the depth readings with respect to a standard datum such as mean lower low water (MLLW) or mean sea level (MSL) or chart datum are obtained for plotting purposes.

A beach sled similar to that fabricated at the Kerala Engineering Research Station, Peechi can be used for measuring the beach profiles. This sled is dropped beyond the surf zone by a boat and then pulled across the surf zone by one or two persons on the beach using a rope and taking water level readings on its graduated vertical staff.

Alternatively, a wave sled similar to that fabricated at the National Institute of Oceanography, Goa can also be used conveniently. This is designed to move offshore across the surf zone by the waves, and after the desired distance is reached, it can be recovered from the beach by an attached rope. The level readings are taken from the vertical graduated staff and the distance is measured using the rope which is marked for measuring distances. It is important to apply tidal corrections to the readings before plotting the beach profiles.

\subsection{Sand sampling and analysis}

2.2.1 Sand sampling: Design schemes for sediment sampling should be made in such a way that sedimenis of the whole beach which vary: $(a)$ across the beach profile through the varied energy zones, $(b)$ along the beach within any one energy zone, $(c)$ between the seasons within the three dimsnsional geometry of the beach, and $(d)$ with depth at each of the sampling spots on the active profile are represented in the scheme (ref. Table 2.1). Appendix C gives the procedures for sampling and sediment analysis.

2.2.2 Sample analysis : Although Indian Standard Classification System and Wentworth Scale System of grain size analysis are generally used in coasial engineering practice, it has been found that logarithmic transformation $\phi$ (phi) of the Wentworth Scale is most useful. In mathematical terminology $\phi$ can be written as (ref. 17 and 18)

$$
\phi=-\log _{2} \mathrm{D} \quad \ldots
$$

where $\mathrm{D}$ is size of the particle in $\mathrm{mm}$ and negative sign is used to give $\phi$ a positive value for finer sediments.

To compare different beach sediments, a most common approach is to plot the cumulative weight percentage of each sample coarser than a given series of size classes (Figs. 2.3a and b). But it has been observed in these curves that in finer sizes, the curve becomes straight and steep and tails out towards the coarser sizes. If a number of plots of several beach samples are plotted together they look similar even though these are texturally distinct from cach other. Thus a plot of weight percentage for each size in $\phi$ values is found to be more offective as each size class tends to be fairly symmetrical for the most frequently oscurring sizes (Fig. 2.3c). In this distribution, maximum frequency occurs at $\phi=\mu$ and inflexion points at $\mu \pm \sigma$ where $\mu$ is phi mean and $\sigma$ is phi sorting. Using the combination of these $\mu$ and $\sigma$ each curve is defined independent of the other.

2.2.3 Beach fill models : Using composite mean and sorting values of the bcach and borrow material, the filling of the beach can be estimated using various beach fill models. Basically there are two types of mathematical models for beach fill problems. The first method enables the calculation of overfill fastor which is an estimatc of the volume of a specific fill material needed to create a unit volume of the native beach materia!. Generally overfill factor excceds onc, indicating that from the borrow material, unsuitable parts from the fill will be removed by winnowing action of the water. 


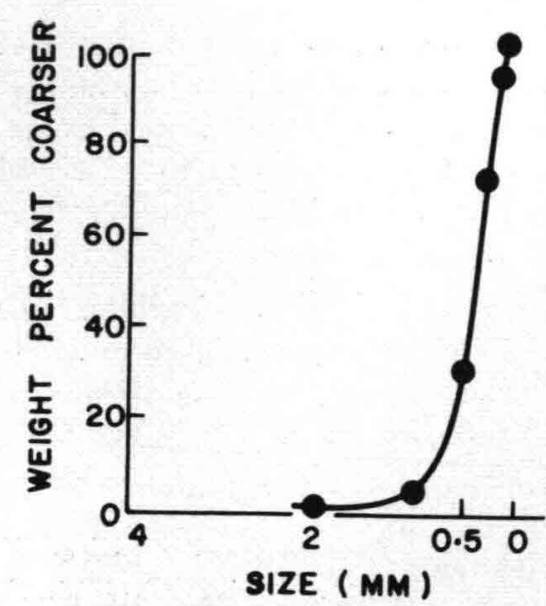

(a)

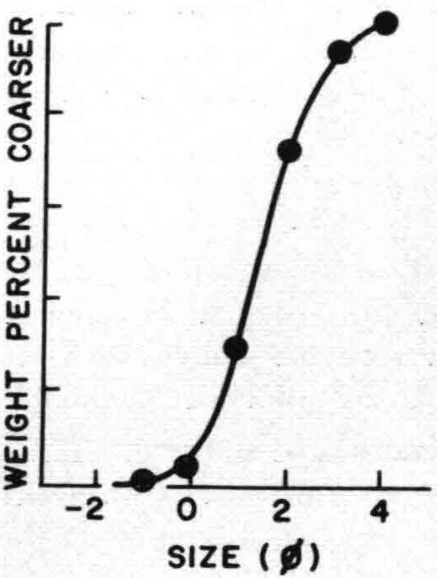

(b)

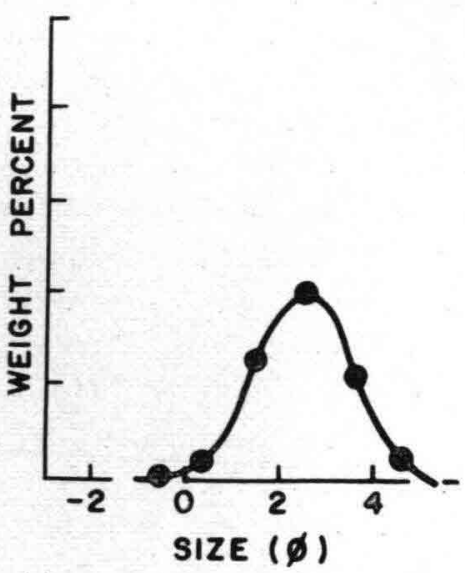

(s)

Fig. 2.3 Size frequency plots.

Overfill factor method: There are three different approaches for determining the overfill factor (refs. 10, 17 and 20). The mathematical model underlying these three methods are similar but fill ratios are not the same. The fill factor method proposed by James (ref. 17) provides modifications to the other two methods and is thus more useful. The basic assumptions in the method are:

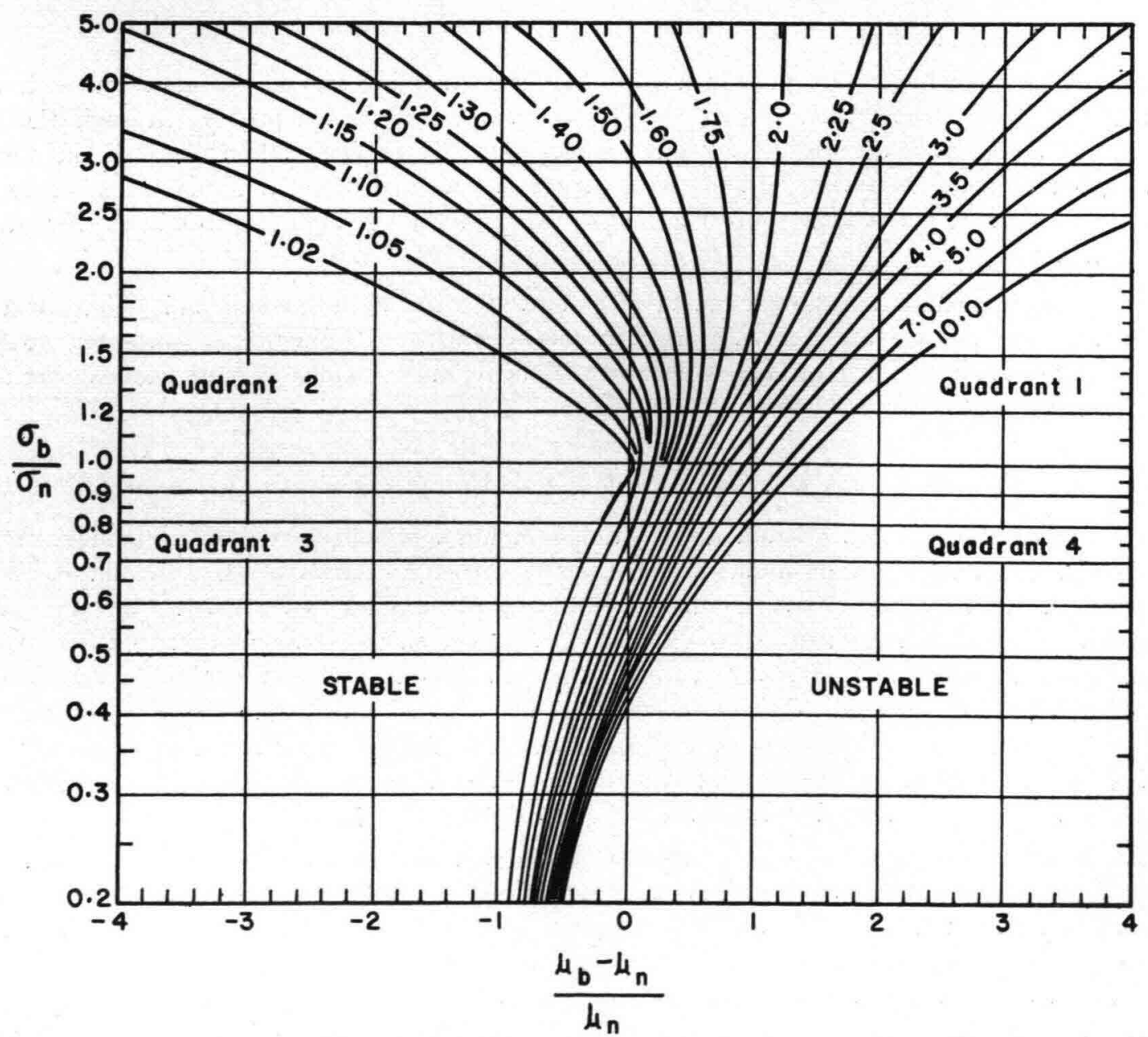

Fig. 2.4 Overfill factor $\left(R_{A}\right)$ versus phi mean difference and phi sorting ratio (ref. 17). 
( $i$ ) beach sediment is considered to be most stable for the environment,

(ii) the entire volume of the fill material placed on the beach is sorted by local processes to achieve a grain size distribution similar to the beach material, and

(iii) sorting processes change the fill materials into the beach-like sediments by winnowing out a minimum amount of the original fill.

The above method proposed by James (ref. 17) is based on the selection of the critical or stable grain size distribution of the borrow site sediments and it quantifies the amount by which that distribution is to be modified to resemble the beach sediments. Actual calculations of $\mathrm{R}$ (ratio of the weight percentage of the beach to that of the borrow site composite) involve complicated mathematics but accurate graphical estimates can be obtained using the curves shown in Fig. 2.4. The basic information required is the phi mean and phi sorting values for beach and borrow site sediments.

Renourishment factor method: It is a dynamic approach to describe how beach processes can be expected to modify specific fill sediments (ref. 16). This technique is used to estimate how often placement of a particular fill will be required to maintain specific beach dimensions. It attempts to evaluate long term performance of different fill materials with regard to suitability, maintenance and cost. In this method, the active beach system is treated as a compariment which receives sediments through longshore transport and from gradual erosion of the inactive reservoir of the sediments which form the backshore. The method estimates mass balance of the compartment using the relative retreat-rate equation

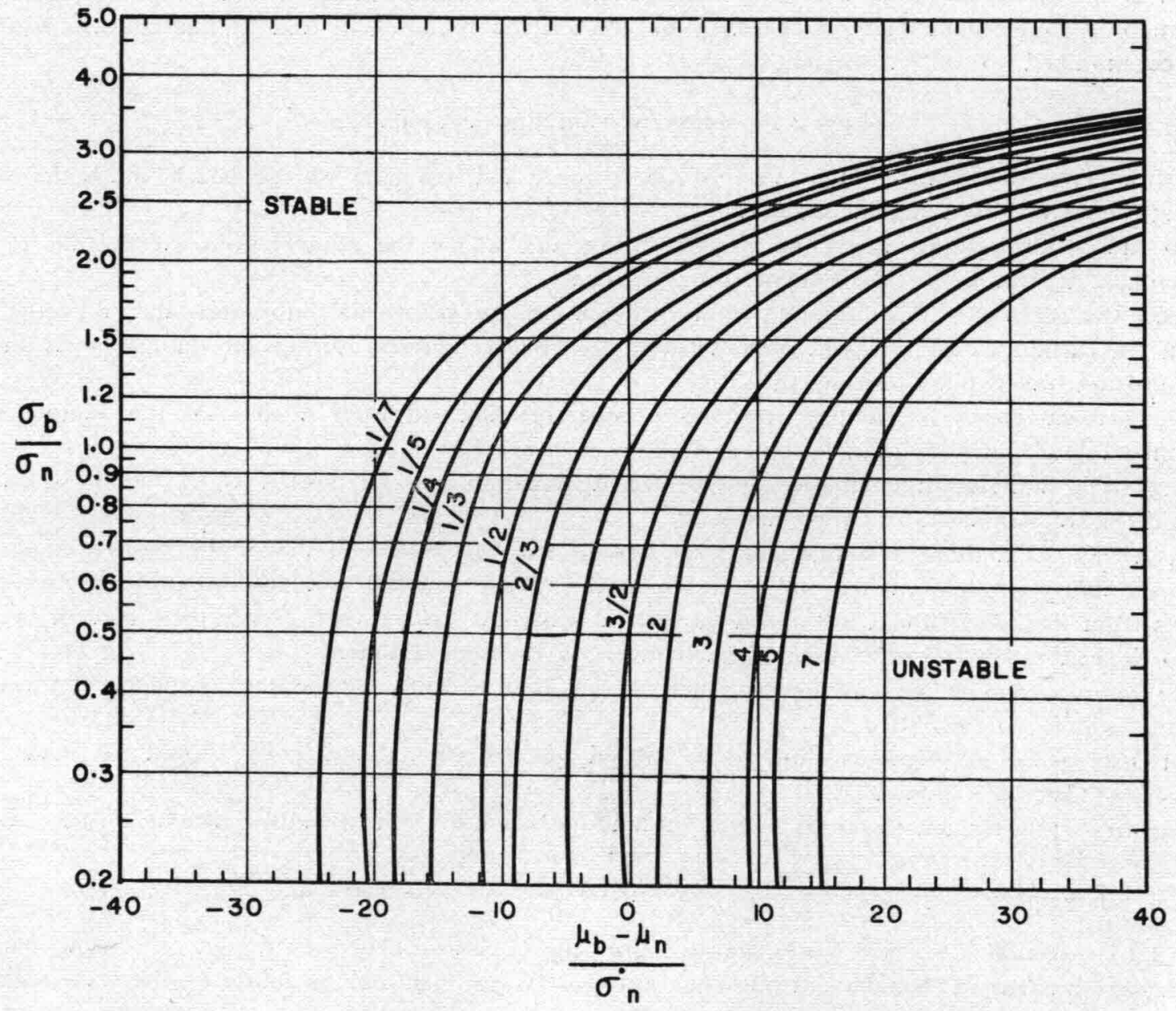

Fig. 2.5 Renourishment factor versus phi mean difference and phi sorting ratio (ref. 16). 


$$
\log R_{j}=\Delta\left(\frac{\mu_{1}-\mu_{n}}{\sigma_{n}}\right)-\frac{\Delta^{2}}{2} \frac{\sigma_{n}^{2}-1}{\sigma_{b}} \quad \ldots \quad \ldots
$$

where $\mathbf{R}_{\mathbf{j}}=$ relative retreat rate (ratio of the borrow to beach retreat rates)

$\mu, \sigma=$ mean and phi sorting respectively (see Appendix C for more details)

$b, n=$ subscripts for borrow and beach material respectively

$\Delta=$ dimensionless parameîer $(0.5$ to 1.5$)$.

Using $\Delta$ as unity, Fig 2.5 shows $R_{j}$ contours plotted against the standard reference axes that compares textural parameiers for the native and borrow composite. A renourishment factor of $\frac{1}{3}$ means that borrow material is three times as stable as the native sediment. On the other hand, $R_{j}$ of 3 indicates that the borrow material is one third as stable, and if used as beach fill, would require renourishment threc times as often as the native sediments.

Being simple in nature, these beach fill models should be used considering the practical environment of real and unique engineering problems like:

(i) will a fill factor apply to all the beach fill placed ?

(ii) which sedimentary data should be selected to compute a specific composite?

(iii) would the placement of fill on different parts of a beach require different fill factors ?

(iv) how should a borrow site composite distribution be modified to reflect the effects of different kinds of equipment and techniques?

Table 2.1 gives the general steps for the sampling, analysis of beach and borrow site sediments. These are only rough guidelines. Depending on the specific requirement and unique characteristics, they are to be modified to suit a specific purpose.

Table 2.1 Steps for sampling and analysis.

1. Depending on the relative importance of the project and gcometry of the beach, mark the stations along the beach at a regular interval.

2. Also mark the stations across the profiles below and above the plunger zonc at certain elevation difference depending on the steepness of the beach.

3. Collect the surface sediment sample from each station just before the monsoon and after the monsoon. In certain cases, it would be advisable to collect samples during the monsoon as most of the erosion takes place during this time.

4. Making 3 categories of samples (nearshore, offshore and onshore) a split of the sample should be mixed thoroughly by adding equal weights of the splits.

5. Using sieve analysis, a composite grain size distribution may be plocted as in Fig. C.3. Calculate $\mathrm{S}$ and $\mathrm{M}$, as explained in Appendix C.

6. Considering the amount available from each borrow sie, relative economics of the borrow material and the suitability of the scdiment for probable composite fill material and the borrow site be selected.

7. Splits from the cores should be mixed in such a way that each layer gets represented in weighted ratio depending on the thickness of each layer of different sediments.

8. Core samples should be collected in such a way that it will describe the sediment characieristics of the whole borrow site.

9. Composite grain size analysis should be carried out by sieving and plots should be made as in Fig. C.3. Calculate S and M.

10. Using the renourishment factor technique, the amount of renourishment can be calculated using $\triangle$ as unity.

\subsection{Wave Surveys}

2.3.1 General : Surface waves play a major role in coastal processes, design of coastal structures, maintenance of navigation channel and port operations. A thorough understanding of the wave regime of the area in question is, therefore, necessary. 
There are various ways of collecting and computing the wave data and several methods are in use for their analysis. The most common ones are : (a) visual observations, $(b)$ hind-casting and (c) by using wave recording instruments. Most of the data on waves presently available are based on visual observations made from the ships. By hind-casting the wave heights are computed for an area using the past meteorological data of the region. The advantage of this method is that the results will be based on comparatively large wave data which would help in extrapolations. Instrumental data pertaining to waves at prescnt are very few. These are morc reliable and necessary for spectrum analysis. The instruments used for wave measurements are either surface (e.g. wave rider buoys) or sub-surface (e.g. OSPOS) type.

2.3.2 Wave measurements : Waves car be measured in the coastal zone by adopting easy as well as less expensive methods. Locally available materials and workshop facilities could be made use of for the design and fabrication of a suitable system for the collcction of wave data. For examplc, spar buoys, wave poles etc-, could casily be fabricated and installed. The measurement procedure involved and the analysis are quite simple. Proper training to local persons is all what is nceded for the collection of wave data. Wave observations may be made for a group of say, 30 waves and the average height of these waves $\left(\mathrm{H}_{\mathrm{m}}\right)$ and the highest 10 per cent waves $\left(\mathrm{H}_{10}\right)$ are recorded. Other observations should include breaking wave height, angle made by breaking wave with the shoreline, breaker types etc.

For visual wave observations, the following table may be used for recording the wave data:

\begin{tabular}{lllllll}
\hline Date & Time & Period & Height & Direction & Breaker type & Remarks \\
\hline
\end{tabular}

2.3.3 Relationship between the visual and the instrumental data : As mentioned carlier, the data presently available are largely visual. Hence, it is essential to find a relationship between the visual wave height $H_{v}$ and the visual wave period $T_{v}$ and the significant wave height $H_{s}$ and $T_{z}$ (zero crossing period).

Nordenstrom (ref. 27) has worked out a relationship between $H_{v}$ and $H_{s}$ based on North Sea wave data as follows:

$$
\mathrm{H}_{\mathrm{s}}=1.68 \mathrm{H}_{\mathrm{v}}{ }^{0.75} \text {. } \quad \ldots \quad \ldots \quad 2.3
$$

The above equation gives the relationship between $\mathrm{H}_{\mathrm{v}}$ and $\mathrm{H}_{\mathrm{s}}$ at the same level of probability. Similarly, the relationship between $T_{z}$ (zcro-crossing period) and $T_{v}$ (visual wave period) can be expressed as

$$
\mathrm{T}_{\mathrm{z}}=0.74 \mathrm{~T}_{\mathrm{v}} \text {. } \quad \ldots \quad \ldots
$$

The above relationships can be assumed to be valid for Indian waters until adequate field data are collected for developing suitable relationships for Indian conditions.

The collection of wave parameters as explained above over a few years will provide a good data base for further analysis and for the determination of long term statistics and return periods as described in Appendix A. This appendix includes information on the wave spectrum also.

\subsection{Current and tide surveys}

2.4.1 General : Currents are one of the most complex phenomena in the ocean as they are generated by various driving mechanisms. The principal parts of a current system in the coastal zone are tidal currents, wind driven currents, wave induced longshore currents and rip currents.

To understand the phenomena of sediment transport, current system can be divided into two parts, viz., within the surf zone and beyond the surf zone. The current systems in the surf zone are very important for the sediment transport. They derive energy from breaking waves. The current systems beyond the surf zone are mainly governed by the wind and tides. 
2.4.2 Current measurements : Current measurements could be made using either of the two well known approazhes, viz., Eulerian or Lagrangian. In the former method, measurement is made as water passes a fixed point and in the latter, by following the path of water particles. Both principles have their limitations but measurements at fixed points with current meters are far more common than the path following method using neutrally buoyant floats (Swallow's floats) or parachute drogues.

But again it is important to study thc requirement for which the measurement is necessary. In the case of forces on offshore structures, both in the short and long term statistics, the only type of data that could be used is from the Eulerian iype of current measurement. The path following method or the indirect way of deducing currents by surface floats or other devices will most certainly be of great importance in the study of nearshore currents and currents in the surf zone, which influence the coastal processes.

Current measurements in the surf zone arc made by using dyes and floats. The dyes are packed in bags which are either porous enough to allow water into them or dissolve in water thereby exposing the dye. The rate at which the dye patch moves, gives the speed of the current.

Measurements of currents using floats consist of a system in which a ball of say $15 \mathrm{~cm}$ in diameter is connected to another ball of $7.5 \mathrm{~cm}$ in diamcter with a fishing linc of say $3 \mathrm{~m}$ length. The larger ball is filled with sca water using an injector and the whole system is thrown by hand into the surf zone from the shore. The position of the bigger ball is measured each time with respect to the floaing small ball which is connected to it.

Most common and simple equipment used beyond the surf zone for measurements are neutrally buoyant floats or parachute drogues. These arc released at known depths and tracked with the help of theodolites from shore or they can even be followed by boats and their positions can be fixed by sextants.

The following table can be used for recording the current observations in the field:

\begin{tabular}{lllllll}
\hline Date & Time & Depth $(\mathrm{m})$ & Speed $(\mathrm{m} / \mathrm{sec})$ & & Direction & Remarks \\
\hline
\end{tabular}

2.4.3 Long term analysis of current data: Current specd data as it is, are not analyscd for the prediction of extreme values. This is because the currents consist of periodic components (tidal components) added to the residual components. First, the periodic components are to be subtracted and later spectrum analysis can be made for the residual components. A detailed analysis of this nature is of much importance for the design and operation of offshore works and hence is not treated here in detail.

2.4.4 Tide surveys : Information on the tides is equally important as tides directy influence the limit of wave attack, port navigation, flushing in estuaries and inlets etc. Variation of water levels due to tides can be recorded either by erecting tide poles or by water level recorders which are readily available. In the case of tide poles, daily readings for the low and high waters should be taken.

Measurements using a water level recorder should be a continuous process indicating the variation of the tide elevation over a required period of study.

For areas nearer to harbours and anchorage points, the Indian Tide Tables published by the Survey of India, Dehra Dun for the year under consideration may be referred to.

The tidal currents vary from place to place depending upon the character of the tide, the water depth and the configuration of the coast. The tidal components of the current in the sea or bay are periodic in behaviour and repeat themselves as regularly as the tides to which they are related. In general, it is necessary to study the change in water levcls and associated currents at least for a period 
covering both neap tide and the ensuing spring tide at a locality. Several such studies may, sometimes, become necessary depending upon the complexity of the problem being investigated at a given coastal area.

\subsection{Littoral drift surveys}

To evaluate the possibility and the expected rate of erosion caused by the establishment of littoral drift barrier, it is necessary to know the predominant direction of the drift, and if possible, the magnitude of drift in either direction of the shore, say, $\mathrm{N} \mathrm{m}^{3} /$ year moving north and $\mathrm{S} \mathrm{m}^{3} /$ year moving south. These data are important for the development of port structure or a tidal inlet or when an estuary is to be improved by jetties or dredging. Littoral drift surveys are needed for the collection of data and calculations should be made as explained in Section 3.1.1.

Usually it is not too difficult to determine the predominant direction of the drift, particularly if the shore has some headlands or reefs or man-made structures which, by the sand accumulation pattern, will show the predominant direction of drift (Fig. 1.7). If no natural or man-made obstruction is available, as in the case of many shore segments along the east coast of India, a study of the migration of natural inlets along the coast would give the desired information as the inlets migrate in the direction of the predominant littoral drift. It will, however, be difficult to determine the relative magnitude of the drift in either direction. Evaluation of the ratio between drift quantities in two directions may be done by the use of tracers. Fig. 2.6 illustrates how tracers can be used for the determination of relative magnitude of drift in either direction.

If tracers are injected in the beach and the samples are taken from the beach and offshore areas to cover one cycle, the ratio of southward drift to northward drift along a beach of length $S$ can
be written as

$$
\int_{0}^{\infty} C_{s} d S / \int_{0}^{\infty} C_{n} d S=A / B \quad \ldots \quad \ldots \quad \ldots
$$

where $C_{s}$ and $C_{n}$ are the concentrations of the tracer material at distance $S$, from the injected areas. Subscripts $s$ and $n$ are used to indicate south and north directions respectively. A and B are southward and northward drift in cubic metres per year respectively.

Calling this ratio $\alpha$, the stability criteria is $T=A-B$, where $T$ is the balance of drift, usually called the predominant drift, one has

$$
\mathrm{A} / \mathrm{B}=\alpha \text { or } \mathrm{B}=\frac{\mathrm{A}}{\alpha} \text { and } \mathrm{T}=\mathrm{A}\left(\frac{\alpha-1}{\alpha}\right) \quad \ldots \quad \ldots
$$

Hence, if $\mathrm{A}$ and $\alpha$ are known it will then be possible to compute $\mathrm{B}$ and $\mathrm{T}$.
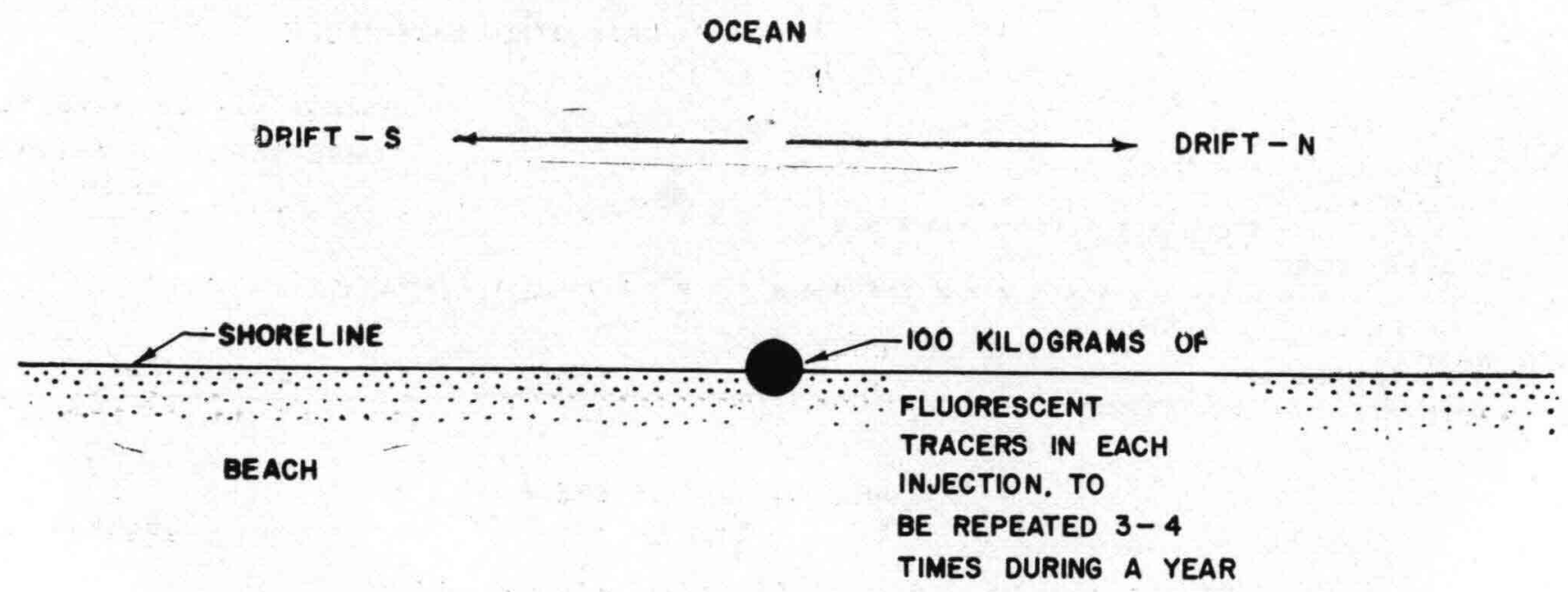

Fig. 2.6 Tracer experiments to determine the predominant direction of littoral drift, 
The determination of the quantity A may, however, involve considerable difficultics unless a proper littoral drift barrier is available. It could be a natural headland, a harbour or inlet jetties or a dredged channel. Such barriers, howcver, are generally not available close to the site in question. Therefore, computations of the drift could be made as mentioned below.

Using the littoral data from the various sources, formulae and diagrams as mentioned in Section 3.1.1 have been prepared. Sce ref. 29 and 43 in which littoral difrt formulae have been compiled. Sce also Chapter 6 of ref. 2. A simple field method was adopted by the Pre-Investment Survey of Fishing Harbours, Government of India, Bangalore, for evalua ing the littoral drift conditions at Ramayapatnam in Andhra Pradesh (ref. 29).

Wave data were obtained using a graduated pole driven down in the bottom on the outer slope of the offshore bar. Observations were made visually by means of binoculars from a $4 \mathrm{~m}$ high tower as illustrated in Fig. 2.7.

Records on tides, waves etc. were then used for computing the quantity of littoral drift based on the formula

$$
\mathrm{Q}=0.04\left(\mathrm{H}_{\mathrm{ar}}^{2.5}+\mathrm{H}_{\mathrm{l} / 3}^{2.5}\right) \sin 2 \alpha_{\mathrm{b}} \mathrm{m}^{3} / \mathrm{sec} \quad \ldots
$$

where

$\mathrm{Q}=$ the quantity of littoral drift in $\mathrm{m}^{3} / \mathrm{sec}$

$\mathrm{H}_{\mathrm{av}}=$ average height of the breaking wave in metres

$\mathrm{H}_{1 / 3}=$ height of the significant wave at the time of or just before breaking in metres

$\alpha_{b}=$ the angle of the breaker crest to the shoreline in degrees.

OCEAN

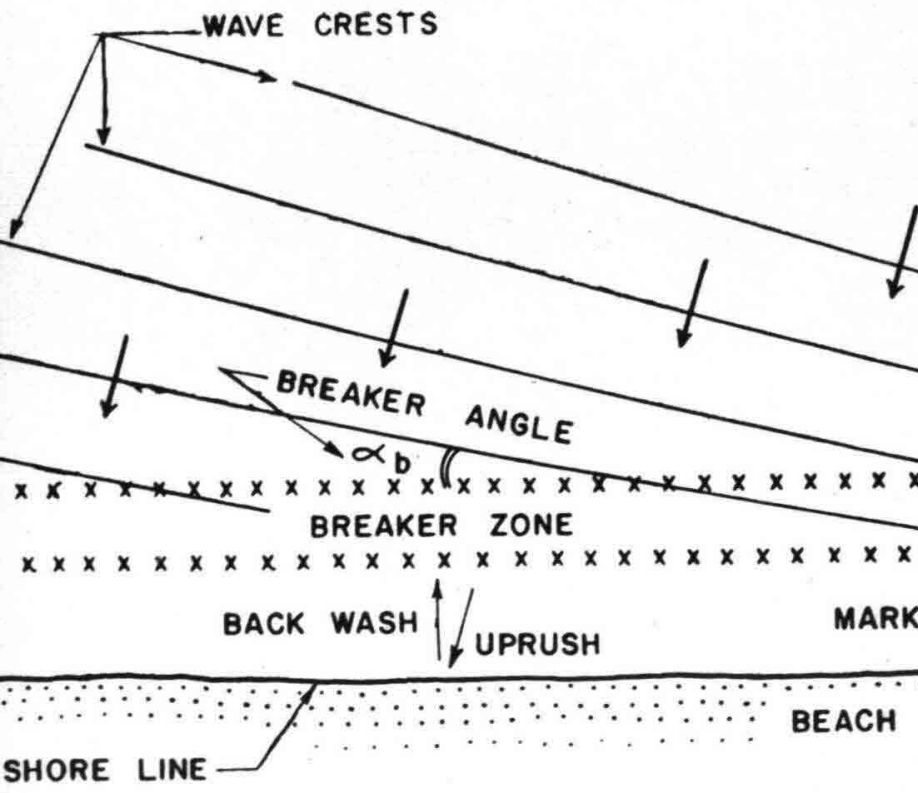

SHORE LINE

BEACH

WAVE DIRECTION

L Graduateo wave pole

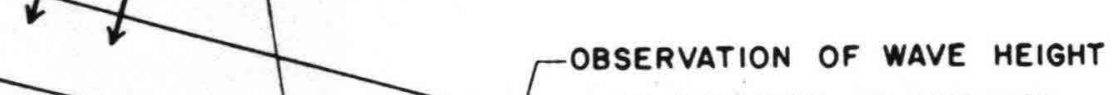
HEIGHT

OBSERVATION OF BREAKER

ANGLE

Fig. 2.7 A simple wave observation procedure to evaluate littoral drift 
For the above formula, the relation between $\mathrm{H}_{\mathrm{br}}$, height of the wave at the time of its breaking and $\mathrm{H}_{\mathrm{p}}$ the height of the same wave while passing the wave polc are needed (see Fig. 2.7). Further field observations on the following lines were made to arrive at a relationship between $\mathrm{H}_{\mathrm{br}}$ and $\mathrm{H}_{\mathrm{p}}$ with special reference to monsoon waves.

Step 1: From the knowledge of the bottom topography, refraction diagrams for different wave directions were drawn to trace the path of the waves.

Step 2: Using the data from the Shore Protection Manual of the U. S. Army Coastal Engineering Research Centrc (ref. 43) for the obscrved direction, the height of the wave at the pole and the approximate depth at wave breaking were determined. A marker buoy was placed at that point (see Fig. 2.7).

Step 3: From the knowledge of the distance through which the wave had to travel, the actual time required for a wave to travel from the wave pole to the point of its breaking at the marker buoy was noted as $t$ seconds.

Step 4: Two theodolites were set up as close as possible at a strategic location to get a clear view of the crest and trough of the breaking waves and the distances between the marker buoy and the theodolites were computed.

Step 5: A person was posted to observe the wave height of a passing wave at the pole. At the same time he signals the other two persons at the two theodolites. A stopwatch was used by the posted person to count the time $t$ for the wave to travel from the pole to the buoy. At the end of $t$ seconds, and on receiving the signal, the vertical angles to the crest and a few seconds later to the trough, were read at the buoy by the two theodolites. The procedure was repeated for a number of waves passing the wave pole.

Step 6: From the above data and after knowing the vertical angle between the crest and the trough and the horizontal distance between the theodolites and the buoy, the height of the wave at the time of its breaking was computed.

From a sufficient number of readings, the following relationship between $\mathrm{H}_{\mathrm{br}}$ and $\mathrm{H}_{\mathrm{p}}$ was arrived at:

$$
\mathrm{H}_{\mathrm{br}}=1.45 \mathrm{H}_{\mathrm{p}} \text { (valid for waves of almost equal steepness) }
$$

Using this relationship and adopting the above integrated formula, the amount of littoral drift each day for a period of one year was calculated. Table 2.2 is a summary of the littoral drift calculations (ref. 29).

Table 2.2 Summary of littoral drift calculation for Ramayapatnam covering the period from 31.5 .1972 to 1.5 .1973 (ref. 29).

\begin{tabular}{ll}
\hline Total drift & $=16,80,446 \mathrm{cu} \cdot \mathrm{m}$ \\
Drift south to north & $=15,56,564 \mathrm{cu} \cdot \mathrm{m}$ \\
Drift north to south & $=1,23,882 \mathrm{cu} \cdot \mathrm{m}$ \\
Net drift (south to north) & $=14,32,682 \mathrm{cu} \cdot \mathrm{m}$
\end{tabular}

The quantity of net drift given in Table 2.2, most probably, is on the higher side. However, it has the right order of magnitude as compared to the drift at the Madras harbour which has a similar wave climate as at Ramayapatnam. The above example shows how a difficult task could be accomplished using simple methods. 



\section{Coastal Protection}

\subsection{Basic aspects}

3.1.1 Material balance : Consider two points on a beach A and B. The natural, mostly wave-induced, drift of the material along the shore is assumed to be from A to B. If the drift at A equals the drift at $B$, the beach would be in an equilibrium state. If, however, the drift is larger at B than at A $(B>A)$, then the shore between $\mathrm{A}$ and $\mathrm{B}$ will definitely erode. If, on the other hand, $\mathrm{A}>\mathrm{B}$ then the accumulation would take place between $A$ and $B$.

The increase in erosion (or accumulation) between A and B may be caused by the shoreline turning in a direction in which the drift quantity increases (or decreases). This can be evaluated from a number of available littoral drift formulae. They all assume a linear dependency between longshore transport rate and longshore component of the wave energy flux.

Figs. 3.1 and 3.2 both in English units are examples of such calculations (ref. 4.3). Fig. 3.1 shows the longshore transport rate as a function of longshore energy flux. Fig 3.2 shows the annual longshore transport in cubic yards ( $1 \mathrm{cu} \cdot \mathrm{yd}=0.75 \mathrm{cu}$. metres), as a function of significant deep water wave height $\mathrm{H}_{\mathrm{o}}$ and deep water wave angle $\alpha_{0}$. For more detailed information the reader may refer to Sections $1.4,2.5$ and ref. 43 .

As mentioned in Section 2.5, littoral drift quantities can also be computed from the observation of wave heights at breaking and the corresponding breaker angle. The study made by the Pre-Investment Survey of Fishing Harbours at Ramayapainam (Andhra Pradesh) illustrates how it would be possible, using a simple indigenous method to estimate the order of magnitude of longshore drift based on continuous observation of waves and their breaker angles taken from a tower erected on the beach as explained in
detail in Section 2.5.

To determine which type of beach protection is preferable, the situation regarding the beach meterial balance or erosion condition has to be properly evaluated. This can be done using a simple classification such as 'undernourished', 'sufficiently nourished' and 'overnourished' profiles and terminologies such as 'source' and 'drain' or 'sink' of the materials (ref. 3).

Based on the studies of beach profiles and from the grain sizes ranging from 0.15 to $0.3 \mathrm{~mm}$ occurring in most of the beaches in India, it is possible to distinguish between the 'overnourished', the 'sufficiently nourished' and the 'undernourished profiles' (ref. 3). These terminologies are especially useful for an evaluation in regard to what kind of coastal protection is preferable and to assess how satisfactory such protection will be. The Over-nourished beach profiles are fed by nature with more material than the waves are able to shape them into regular beach profiles. These profiles, therefore, are irregular and may, sometimes, appear as irregular shoals.

There are two different types of sufficiently-nourished profiles. In one type, the profiles are not fed with more material than what is required by the waves to shape them into profiles having an 'equili- 
brium form'. In the other, the loss of material equals the supply of material and the profiles are able to maintain an equilibrium form.

The Undernourished beach profiles erode, that is, the shoreline and the depth contours shift shoreward. The undernourished beach profiles will always maintain an equilibrium form but its form may change from one locality to another, depending upon the local conditions. It seems, therefore, that beach and shore accumulation may take place with or without equilibrium profiles while the erosion of a shore takes place only for equilibrium profiles ataining maximum steepness corresponding to the quantity and characteristics of the littoral drift. An equilibrium profile, therefore, can be defined as a stable profile with maximum steepness. The erosion of the bottom decrcases seaward until an 'eroded base' is reached where it becomes

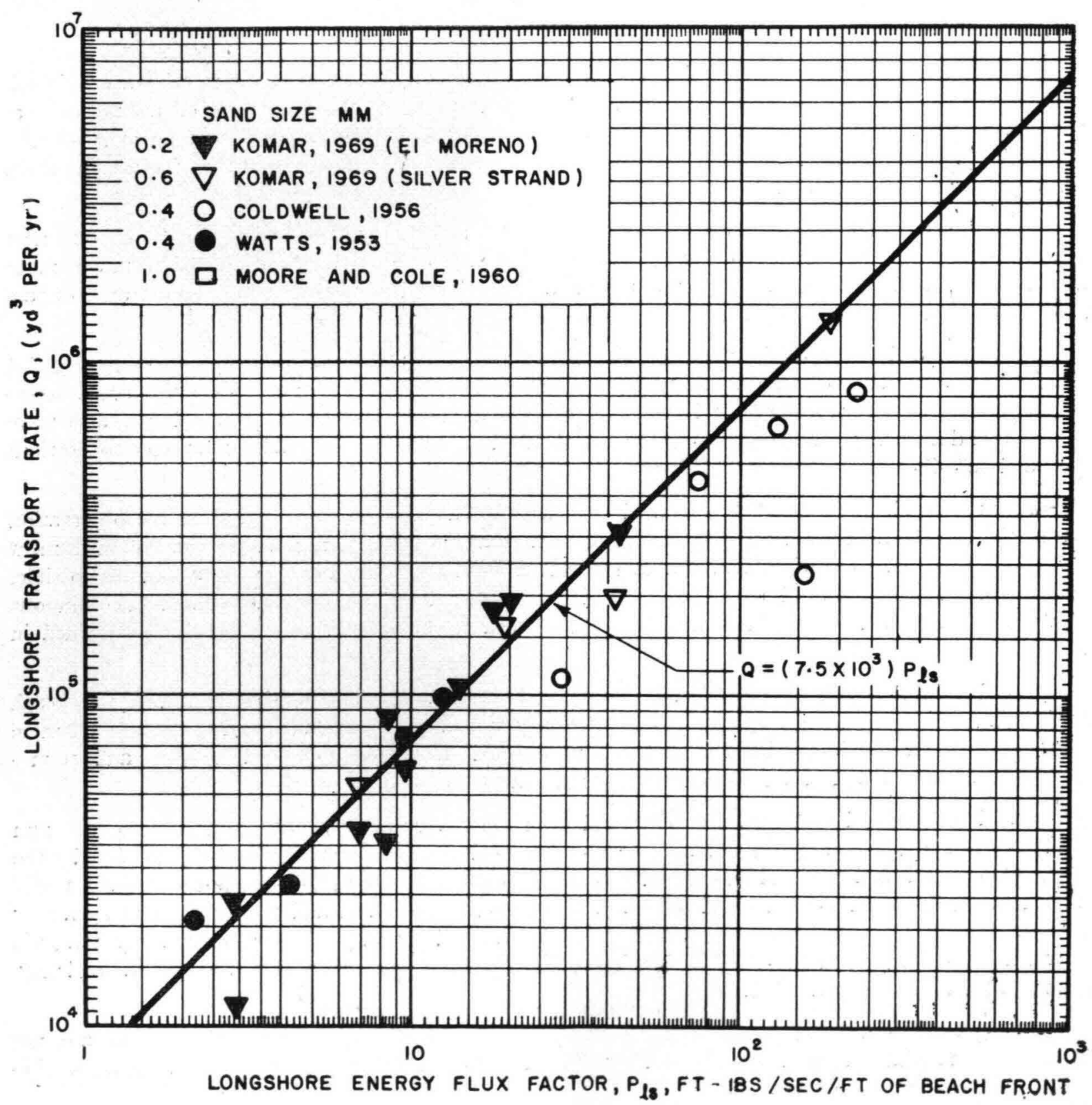

Fiz. 3.1 Longshore transport rate versus longshore energy flux factor for field conditions (ref. 43). 


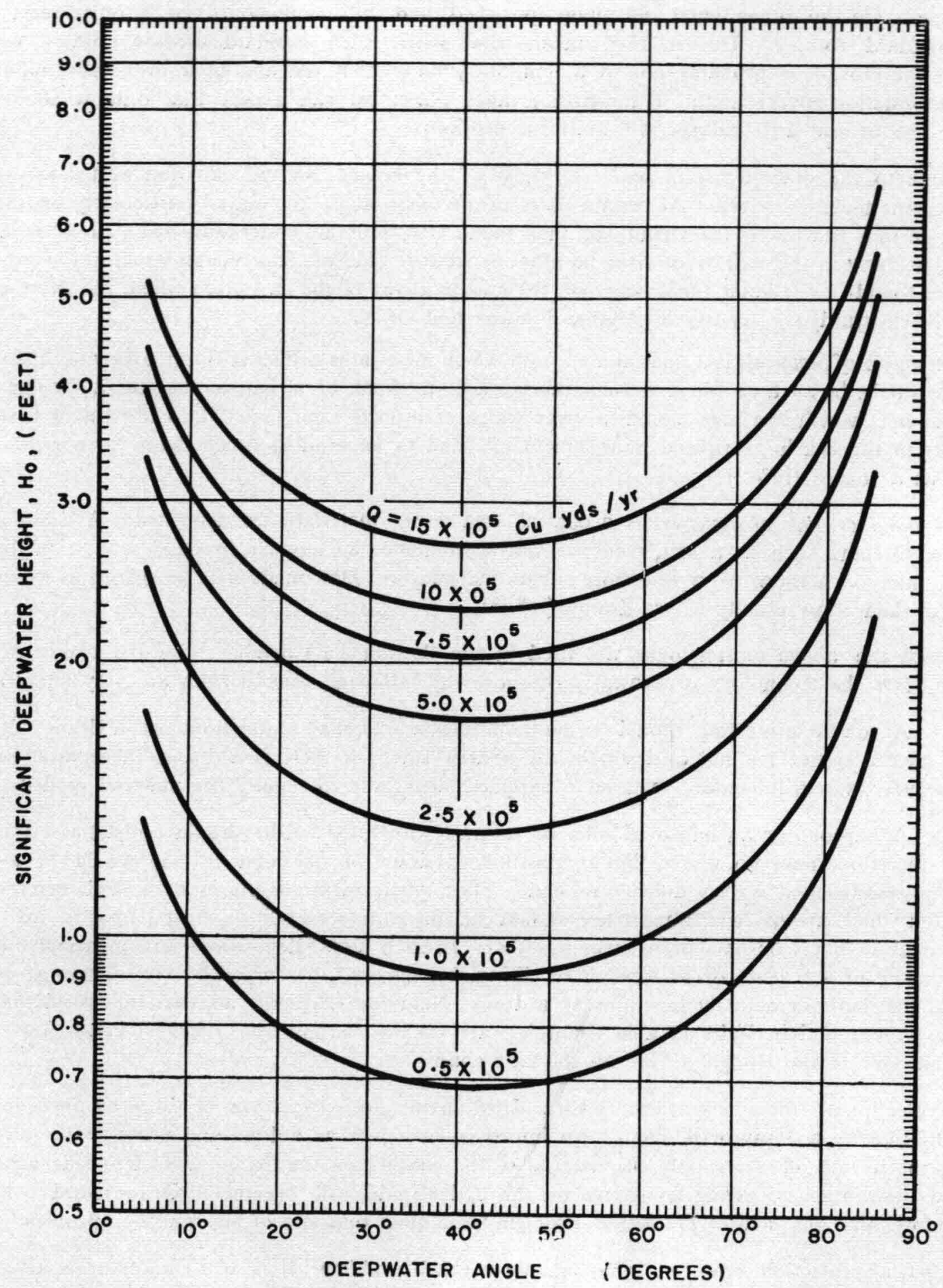

Fig. 3.2 Longshore transport rate as a function of deep water wave height and deep water wave angle (ref. 43), 
zero. This base may bo located between 4 and $6 \mathrm{~m}$ depth for less exposed shores and 15 to $20 \mathrm{~m}$ depth on exposed shores. It cannot be expected, however, that all undernourished profiles will always attain the same shape. On the other hand, all undernourished and sufficiently-nourished profiles seem to have certain 'standard forms'. This in turn, means that where such 'standard erosion profiles' occur, we know that the erosion is probably not of a temporary nature but old and of a progressive nature. This type of information is very useful. If no erosion takes place, we can expect that only a slight adverse change in the littoral drift balance will start the erosion.

Due to the gradual rise in sea level, most of the beaches on the east and west coasts of India tend to become undernourished. At certain parts of the west coast of India, particularly on the Kerala coast and certain beaches in the vicinity of man-made structures are undernourished. However, at certain shores, particularly in the vicinity of river mouths or updrift side of man-made structures overnourished profiles are found. The latter types occur on the northern part of the east coast where the shore gradually turns north-eastward, e.g., coasts of Andhra Pradesh and Orissa.

A source of materials is a coastal area from which material is delivered continuously to other bcaches. The source might be an area where erosion takes place, a shoal or a bar in the sea, a shallow area in front of an inlet which has been closed, a river which transports sand material to the sea or a sand drift from dunes to the beach. Artificial nourishment of sand to an eroding beach from a borrow pit also functions as a source (ref. 3).

A drain or sink of materials is a coastal arca where materials are deposited. A drain could be any marine foreland such as a spit, recurved spit, a tombolo, an angular foreland, etc. It might also be a bay, an inlet or a shoal or a nearshore submarine canyon. Man-made structures such as jetties, groins or dredged sand traps usually act as drains (ref. 3 ).

Both the above terminologies are used in the Section 3.2.4 dealing with the choicc of coastal protection. For the technology of coastal protection, the following general rules are very imporiant:

1. A coastal protection should be built in such a way that it functions as a drain. It should therefore, have a source but not a drain on the updrift side. If there is a drain, the coastal protection will not be very successful unless material is supplied artificially to replase the material eroded.

2. A harbour or an improved inlet on a coast with littoral drift should not act as a drain (sink). It should, therefore, have no source, but if possible, a drain on the updrift side would be a suitable proposition. However, it is very difficult to find a plase where ideal conditions exist, and therefore, many other fastors which are of lozal importance should be taken into account. Most harbours are built in sheltered areas in inlets or bays or in river mouths. In such areas, depositions will invariably take place either from the littoral drift or as a result of silting, by material discharged by rivers, sewers, etc. This means that the harbour actually functions as a drain. Numerous harbours all over the world function on the above pattern and in India no able examples are Cochin harbour on the west coast (ref. 32) and Calcutta harbour in the Hooghly river on the east coast.

Protection of the inlets against littora! drift on the open coast can be done by the construction of jetties for making an 'improved inlet'. An improved inlet acts as a drain and protects the inlet, but at the same time it cuts off the supply of material to the beaches on the lee or downdrift side which again means that these beashes, having no source on the updrift side, will become undernourished. It will be seen, therefore, that the coastal protection problems are quite opposite of the harbour problems.

Coastal protection, however, is not merely a bcach problem. It is also equally necessary to determine whether loss of material takes place from the offshore bottom due to large steepness of the bottom profiles or, by the existence of a submerged canyon which may drain material from the shore during storms (see Section 3.1.2). Both undoubtedly happen at several Indian rocky shores and are detrimental to the success of any coastal protection. 
3.1.2 Beach and bottom profiles: It is well known that beaches and dunes mainly erode during the periods of storms when the wavcs are high and steep. On the other hand, beaches build up during calm weather periods when long waves called 'swells' occur (Fig. 3.3). The reason for this difference has bcen very well cxplained by both laboratory and field tests. It is related to the ratio of the time duration between the start and the completion of an uprush/downrush cycle with downrush in its lowest position ( $t_{\mathrm{ud}}$ ) to the wave period (T) (refs. 21 and 22). If $t \mathrm{ud} / \mathrm{T}$ is less than 1 , a 'swell' or 'ridge' profile devclops which means that the beach builds up. If $t$ ud/T is greater than 1, 'storm' or 'bar' profile will develop which means that the beach erodes. Ridge profiles develop during the swell periods occurring along the shores of India during the non-monsoon season (ref. 25). Bar or storm profiles develop during the monsoon season when there are steeper and more choppy waves.

As an example, take a nearshore profile. If an offshore bar appears at some disiance from the shore, it may not disappear during the swell-season but it tends to migrate towards the shore. The normal way of cxpiessing this development is by saying that the shorcs build up during the summer season and erode during the winter season. But this has nothing to do with summer and winter seasons of India where seasons in regard to bcaches are classified in ascordance with the wave action during the monsoon and non-monsoon seasons. The net result of such a seasonal profile movement would be zero. While considering the siability of a coastal structure it is important to know the magnitude of seasonal movements in onshore and offshore directions. A survey of a swell profile may lead to a very false impression of the geometry and stability of the profile. To plan coastal structures properly in such situations, the maximum beach fluctuations with special reference to the minimum elevation occurring during the monsoon period, should be known (see Section 3.3.1).

The beach profile may, however, be subjected to a continuous loss of material to deeper offshore waters from whore the material may not return to the shore. Such losses, in particular, take place at steep shores and generally oscur at some of the rosky shores of India which have lost thcir beaches, sometimes leaving interlocked pocket beaches. Other losses may take place in submarine canyons extending from

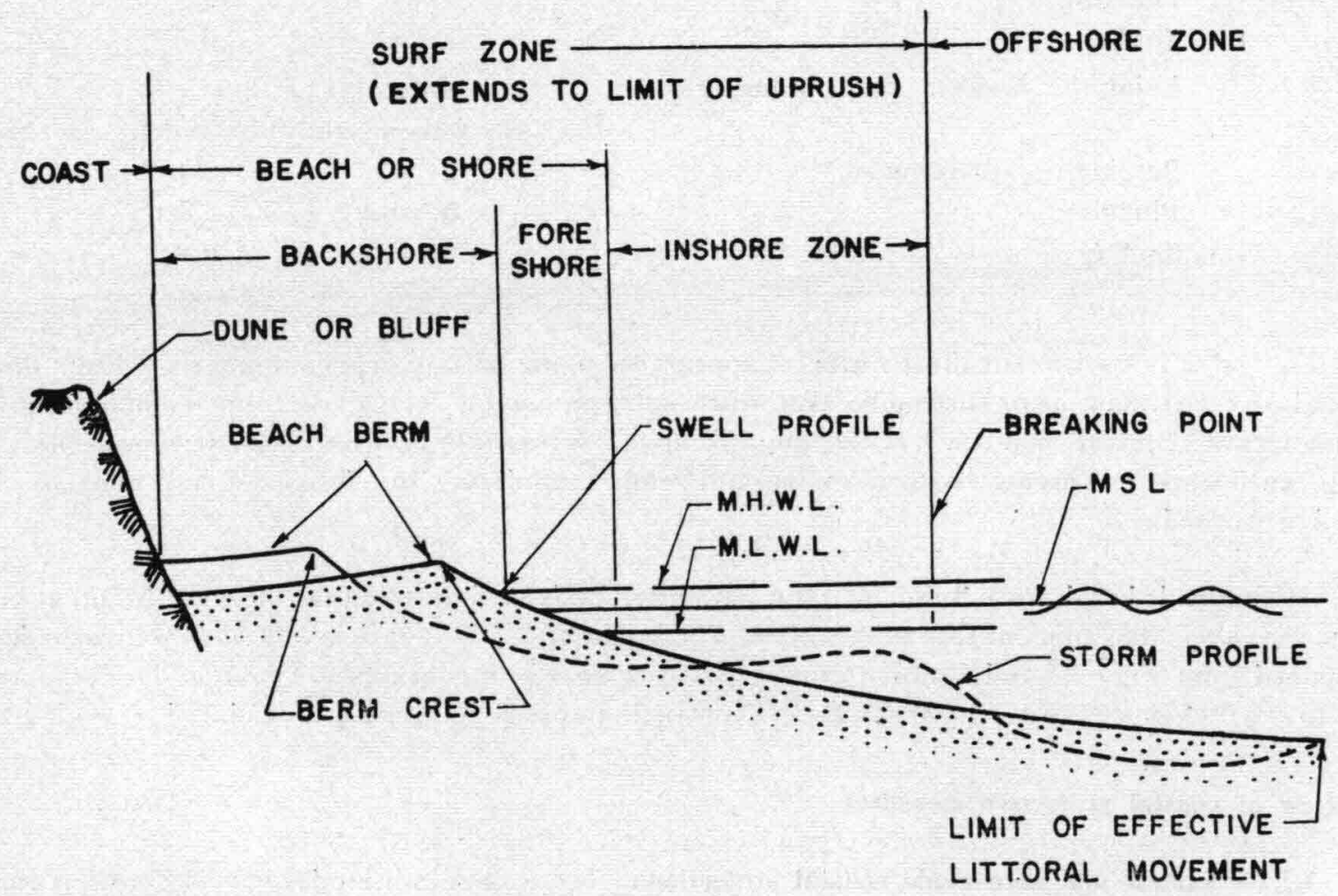

Fig. 3.3 Swell profile and storm wave profile. 
offshore to nearshore. Such canyons are not common in India but they do occur at places south of Pondicherry, e.g. at Cuddalore. Material may drift towards offshore in the form of the so called bottom creep which occurs on the steep shores or with the transversal currents called rip currents which carry sediments-laden water across the surf zone in large sediment plumes recognizable because of their distinct colour difference from the surrounding waters.

3.1.3 Wave mechanics aspects : From the Scction 3.1.2 it is evident that the wave climate is of utmost importance for the geometry and stability of a beach. The nearshore interaction between the waves and the profiles is related to the character of wave breaking.

A fastor, $\xi$ is introduced which is defined as

$$
\begin{aligned}
\xi & =\tan \alpha / \sqrt{\mathbf{H} / \mathbf{L}_{o}}, \\
\text { where } & =\text { slope angle } \\
H & =\text { wave height at the toe of the slope and } \\
L_{0} & =\text { deep water wave length }
\end{aligned}
$$

As explained in the Section 3.3.1 and Appendix B, wave uprush is maximum when $\xi \geqslant$ about 3. Waves

\begin{tabular}{|c|c|c|}
\hline Breaker Type & & Limiting Criteria \\
\hline Surging or collapsing & if & $\xi>3.3$ \\
\hline Plunging & if & $0.5<\xi<3.3$ \\
\hline Spilling & if & $\xi<0.5$ \\
\hline Using the breaker surf parameter & \multicolumn{2}{|c|}{$\begin{array}{c}\xi_{\mathrm{b}}=\tan \alpha / \sqrt{\mathbf{H}_{\mathrm{b}} / \mathrm{L}_{\mathrm{o}}} \\
\mathrm{H}_{\mathrm{b}} \text { is the wave height at breaking }\end{array}$} \\
\hline Surging or collapsing & if & $\xi_{\mathrm{b}}>2.0$ \\
\hline Plunging & if & $0.4<\xi_{b}<2.0$ \\
\hline Spilling & if & $\xi_{\mathrm{b}}<0.4$ \\
\hline
\end{tabular}
are then in the so-called collapsing-surging breaker stage. Table 3.1 describes the breaker type in relation to the so called surf parameter $\xi$ (Appendix B).

Table 3.1 Breaker type in relation to the parameter $\xi$ or $\xi_{\mathrm{b}}$.

Fig. 3.4 shows schematically the general appearance of the various types of breakers. From this it can be deduced why the collapsing or surging breaker which suffers minimum energy loss from its plunging gives the maximum uprush. Uprush on a beach is maximum from the waves with relatively low steepness ratio and for the steep beach slopes. This factor is very important while considering the design of any dune or dyke as explained in Appendix B.

As can be deduccd from Table 3.1, the parameter $\xi_{b}$ defined in terms of the wave height at breaking $\mathrm{H}_{\mathrm{b}}$, somewhat alters the ranges of the breaker types. The height of the wave at breaking and the breaker depthcan be determined from Figs. 3.5 and 3.6 for various types of beaches or for the offshore bottom slopes ranging from $m=0.01$ to $m=0.15$ (1:100 to $1: 7)$. When $\xi_{\mathrm{b}} \geqslant 2$ maximum uprush on a beach is produced.

\subsection{Review of coastal protective measures}

3.2.1 Natural and man-made coastal protection: Nature not only erodes but also protects and it can safely be inferred that there is no protection offered by man which has not been demonstrated earlier by nature. 

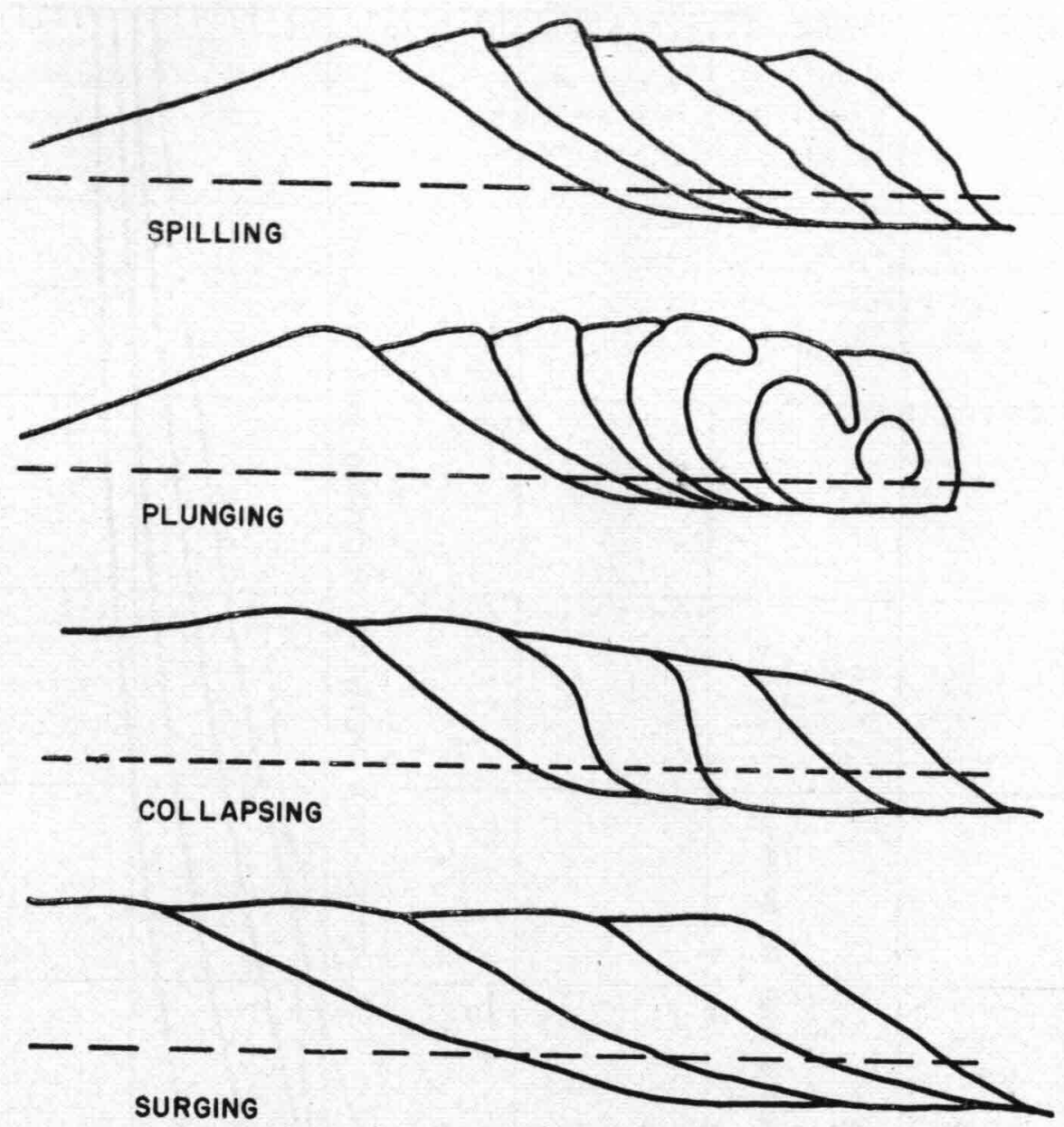

Fig. 3.4 Various types of wave breakers.

Nature developed all types of shore protection much before man studied and deduced from them. Consequently we should learn more from nature. This would mean that the right type of field data must be obtained. We must also admit that nature has been more imaginative and has often achieved more success than man. Perhaps what we observe in nature and collect as our discovery is mainly the success nature has achieved (ref. 3 ). Where nature has failed, nothing was left. Coastal geographers and geologists often describe nature's coastal protection in non-technical terms (ref. 39). Technologists can learn from them too.

Table 3.2 gives some of the examples of nature's protective measures and also the imitations of nature demonstrated by man. Nature has all types of resources at its disposal and is able to give a full demonstration whereas man is limited by his meagre resources, instruments and other facilities. He, very often, lacks the proper tools and adequate facilities.

Nature's coastal protection is demonstrated everywhere in India at the headlands, reefs, rocky shores, dunes and at the points where rivers supply material to the shore. There are few places in the world which have such an abundance of natural protection as in India. Nature's seawall is most often made of lateritic rock which has proved to be quite safe against abrasion and weathering (Appendix E). From the point of view of coastal protection, the supplies of material by rivers to the shore of India mainly during the monsoon is a blessing despite the fact that deposits at entrances create problems for navigation. The mud banks of the Kerala coast have also been an advantage but due to the fact that they migrate along the shore, their beneficial effect is only intermittent (ref. 11). They cause severe terminal erosion problem due to changes in wave characteristics brought about by them. 


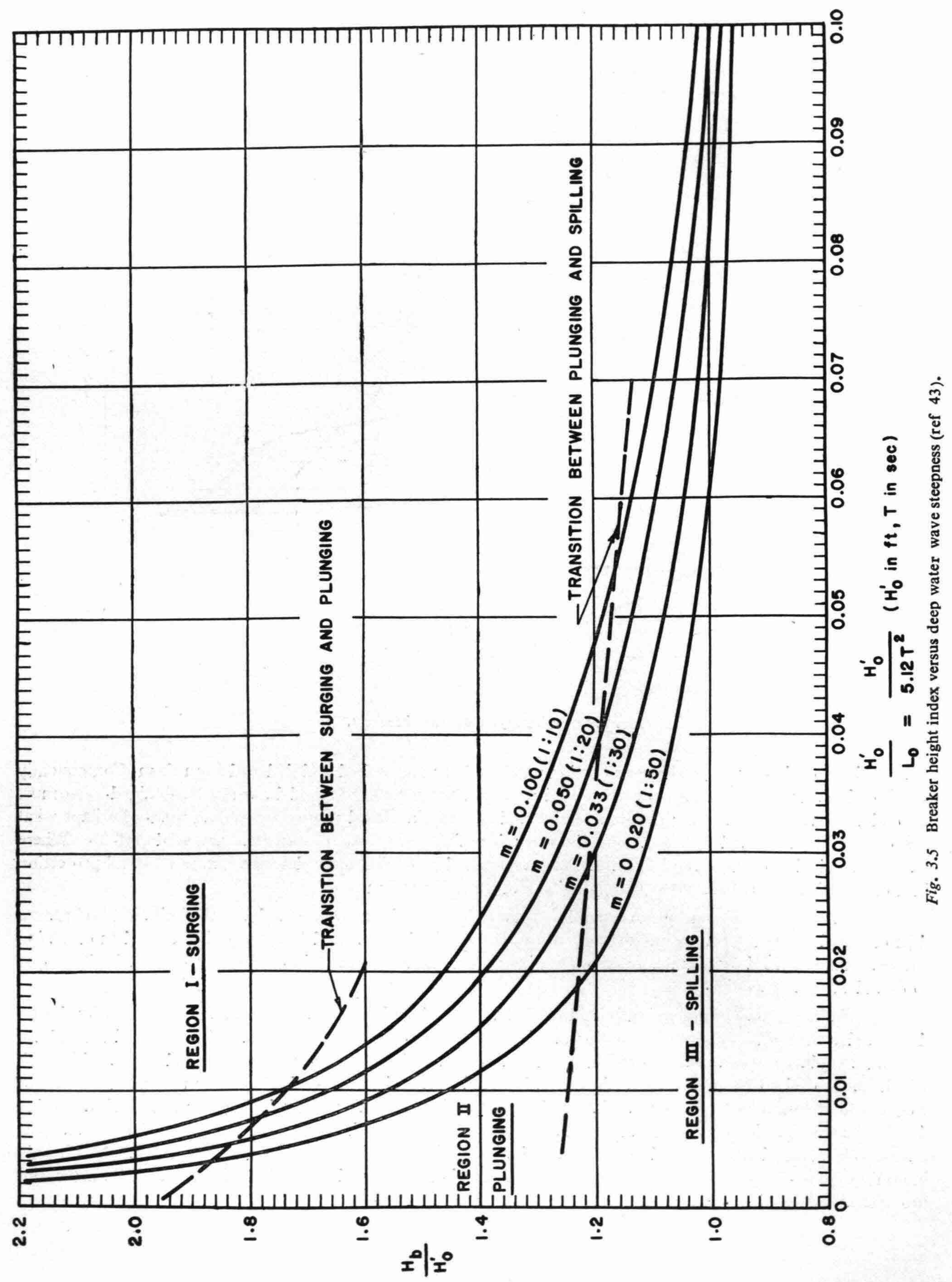




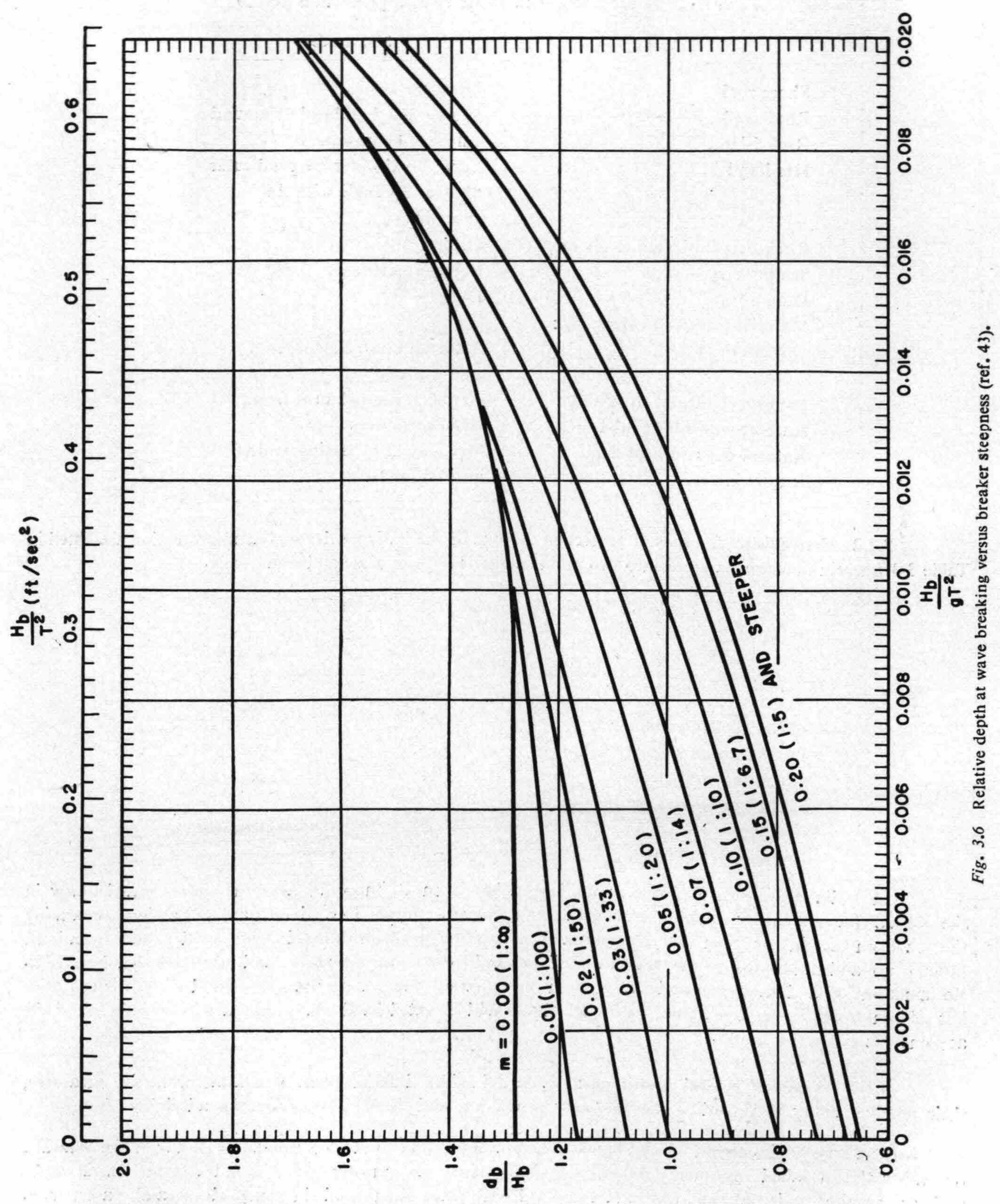


Table 3.2 Natural and man-made coastal protection (ref. 3).

\begin{tabular}{|c|c|}
\hline Natural & Man-made \\
\hline Shore rock & Seawall \\
\hline Rock reef & Submerged bulkhead or mound \\
\hline Rock island & Offshore breakwaters \\
\hline Headland & $\begin{array}{l}\text { Large breakwater perpendicular } \\
\text { to or at an angle with the } \\
\text { shoreline }\end{array}$ \\
\hline Rock perpendicular to shore & Groins \\
\hline Sea floor vegetation & Bottom mattresses \\
\hline Dune & Dyke \\
\hline \multicolumn{2}{|l|}{ Material transfer to shore by: } \\
\hline Wind drift & Artificial nourishment from \\
\hline Rivers & land sources \\
\hline $\begin{array}{l}\text { Longshore littoral drift and } \\
\text { sea bottom onshore drift }\end{array}$ & $\begin{array}{l}\text { Artificial nourishment from } \\
\text { offshore sources }\end{array}$ \\
\hline $\begin{array}{l}\text { Natural bypassing of drift } \\
\text { at tidal inlets }\end{array}$ & $\begin{array}{l}\text { Mechanical bypassing of drift } \\
\text { at tidal inlets }\end{array}$ \\
\hline
\end{tabular}

3.2.2 Prerequisites for coastal protection : Some of the basic needs for coastal protection are listed in Table 3.3 wherein they are classified into two main categories-large scale and small scale.

Table 3.3 Needs for coastal protection (ref. 3).

\begin{tabular}{lcc}
\hline & Large scale & Small scale \\
\hline $\begin{array}{l}\text { Reclamation of land and protection } \\
\text { of the reclaimed land }\end{array}$ & $\times$ & \\
$\begin{array}{l}\text { Protection of property and } \\
\text { structures on the coast } \\
\begin{array}{l}\text { Construction and protection of } \\
\text { beaches }\end{array}\end{array}$ & $\times$ & Pocket beaches \\
\hline
\end{tabular}

In India protection of property on the beaches is most important as some shores, particularly in the Kerala State, are very populous. The fact that they are often located on narrow barriers separating the sea from lagoons or from low lying wetlands makes the problem rather difficult. Under such situations, little or no land can be lost to the sea. Rather, the need for recovering more land from the sea is urgent. Reclamations of land have been undertaken from the estuaries, backwaters, mangroves and rivers for centuries but seldom from the open seashore, although dunes and elevated sand platforms have been built or rebuilt at some places on the shores.

3.2.3. Types of coastal protection : Table 3.4 gives different types of coastal protective measures, their relative ability in providing the necessary protection and their influence on the adjoining shores.

The type of protection which is most practical under the conditions prevailing today is the seawalls or rather the so-called revetments or sloping walls. These are mostly built in India from coastal rocks such as granite and laterite (Appendix E). Groins have been used in some 'desperate' cases, e.g. 
Table 3.4 Coastal protective measures classified in accordance with their ability to provide protection to large and small shore areas and their influence on the adjoining shores (ref. 3).

\begin{tabular}{|c|c|c|c|c|}
\hline & Large scale & Small scale & Effect & nfluence on neighbouring shores \\
\hline Groins & $x$ & $x$ & $\begin{array}{l}\text { May stop or decrease shoreline } \\
\text { recession but not if offshore } \\
\text { erosion continnes. }\end{array}$ & $\begin{array}{l}\text { Adverse, often } \\
\text { very severe. }\end{array}$ \\
\hline Seawalls & $x$ & $x$ & $\begin{array}{l}\text { Stop erosion where they are built } \\
\text { but do not stop offshore erosion. }\end{array}$ & $\begin{array}{l}\text { May to some } \\
\text { extent become adverse. }\end{array}$ \\
\hline $\begin{array}{l}\text { Shore parallel } \\
\text { breakwaters }\end{array}$ & $x$ & $x$ & $\begin{array}{l}\text { Will probably stop erosion and } \\
\text { build up beach where they are erected. }\end{array}$ & $\begin{array}{l}\text { Adverse, often } \\
\text { very severe. }\end{array}$ \\
\hline Artificial nourishment & $x$ & & $\begin{array}{l}\text { Widens beaches, provides full } \\
\text { protection if well maintained. }\end{array}$ & Beneficial. \\
\hline
\end{tabular}

on the downdrift side of the improved inlets (Cochin harbour, Kerala) and at the beaches downdrift of headlands (Moplah bay, Kerala), but unfortunately they have not been very successful although they have benefitted some localized points. The overall effect of groins on erosion often is to do more harm than good due to the unavoidable leeside erosion (ref. 3). Groins should, therefore, be avoided unless their main purpose is to keep a beach at one particular position at the cost of adjoining areas. In such cases the so-called T-groins which trap the beach material are preferable (see Fig. 3.15). But the adverse effect of T-groins is similar to that of other groins (see also Section 3.3.3).

Shore parallel breakwaters (see Fig. 1.9) have hardly ever been used for coastal protection in India but some harbour breakwaters extending from headlands such as at Cannanore and Vizhinjam in Kerala have faced adverse effects on the downdrift beaches and also on the maintenance of depths in the respective harbours. Artificial nourishment of beaches has not yet started in India but it will undoubtedly become the most widely used method for protection in India in the near future. There is hardly any place in the world where it is better justified than India because of the heavy population pressure on some highly developed shores of India. Nourishment will then mostly, if not always, have to come from the sea comprising everything from man-powered draglines and winches to hydraulic dredging to be discharged on the beach. Wherever harbour structures have caused erosion due to their effect as littoral drift karriers, the transfer of material by pumping should be initiated, e.g. at Madras and Paradip harbours. Special types of intermittent hydraulic transfers have been tested, e.g. at Nagapattinam while others are in the planning stage (see also Section 3.3.6).

3.2.4 Choice of protective measures : It is easy to make a right choice of coastal protection for the conditions existing in India, but perhaps the choice will invariably rest on some type of seawall. This report provides further details on the choice and design of seawalls and revetments.

The most important basic factors to evaluate the need for a seawall and its expected functions are the erosion situation of the offshore bottom and the availability of material for natural nourishment of the beaches. Table 3.5 gives a summary of Table 6 in reference 3 and explains how the seawalls and revetments are expected to function.

Similarly, Table 3.6 gives further details of seawalls. Table 3.7 and 3.8 refer to groins and offshore breakwaters. They are included for the purpose of general information about their performance although they may not deserve the same interest and practical use as seawalls and revetments. Table 3.9 gives the details of the performance of artificial nourishment. Furthermore special attention should be paid to bypassing of material at harbours and tidal inlets which is dealt with in Section 3.3.6. 


\title{
3.3 Design details
}

3.3.1 Seawalls and revetments : The basic parameters which are important for planning and designing of coastal protection and the surveys requircd havc bcen given in Sections 2.3.1 and 2.3.2. For the seawalls much emphasis should be given on profile surveys as mentioned in Section 3.1.2 to determine the movement and the stability of the beach and the bottom profiles in rclation to tides and wave action during the storms. Furthermore, information on soils is also necessary (Appendix D). The various components involved in storm tides are mentioned in Section 1.3.

The general design criteria for the conditions prevailing in India are that the seawalls should be as cheap as possible and therefore must be built from the local materials using local labour. Similarly, mechanization should be as modest as possible and manual work should be preferred within the limits set for proper construction and reasonable time schedule.

Table 3.5 Coastal protection in relation to source of materials and conditions of beach profiles for beneficial versus adverse effects.

\author{
Coastal situation : actual conditions of \\ source of material and beach profiles \\ Seawalls and revetments
}

A. Plenty of source material: Overnourished profiles.

B. Source material available:

Sufficiently nourished profiles.

Balance between material eroded and deposited.

C. Only limited source.

C(a). Erosion only up to limited depth in the sea.

$\mathbf{C}(\mathrm{b})$. Erosion up to deep water in the sea.
Might be necessary to avoid attack under extreme high water and storm conditions. Should be built in such a way that they contribute to as little erosion of beach as possible. Vertical walls built too close to the shoreline increase erosion. Energy absorbing walls, revetments or rubble mounds are usually preferable.

Same as above.

C(al). Source of material :

Can stop erosion provided they are stable at the depth at which erosion takes place. Even if groins are built, a seawall might also be necessary to avoid attack at toe of dune or cliff under extreme high water and storm conditions. It is very important that they be built in such a way that they contribute to erosion as little as possible. Sloping walls, revetments and rubble mounds work better than the other types in avoiding beach erosion due to low reflection of wave energy.

$\mathrm{C}(\mathrm{a} 2)$. No source of material. Same as above.

$\mathrm{C}(\mathrm{bl})$. Source of material :

Unless material is supplied artificially to balance erosion, the groins built will work only for a limited period before collapsing. It is very important that they contribute to erosion as little as possible. Sloping walls, revetments and rubble mounds contribute by themselves to little beach erosion as compared to other types because of low reflection.

$\mathrm{C}$ (b2). No source of material :

Unless material for total balance of erosion is supplied, groins built, will work only for a limited time before collapsing. It is very important that they are built in such a way that they contribute to erosion as little as possible. This would mean low reflection. Sloping walls, revetments and rubble mounds by themselves contribute to little beach erosion as compared to the other types. 
Table 3.6 Details of the performance of seawalls (ref. 3 ).

\begin{tabular}{|c|c|c|c|}
\hline & & & Comments : \\
\hline 1. & What is wanted : & $\begin{array}{l}\text { Storm tide and/or extreme protection } \\
\text { of shore and beach. Protection of } \\
\text { specific valuable areas 'industry, buil- } \\
\text { dings, highways etc ). }\end{array}$ & $\begin{array}{l}\text { Energy-adsorbing wall or revetment } \\
\text { on dyke or dune. Any type of substan: } \\
\text { tial wall with as little adverse effects } \\
\text { as possible. }\end{array}$ \\
\hline 2. & Layout and geometry: & $\begin{array}{l}\text { As streamlined as possible. It is best } \\
\text { to leave and maintain a beach in front } \\
\text { of the wall. }\end{array}$ & $\begin{array}{l}\text { Erosion may be stopped at the wall } \\
\text { but artificial nourishment may be } \\
\text { needed to maintain beach in front } \\
\text { of the wall. }\end{array}$ \\
\hline & & Influence on adjoining shores. & $\begin{array}{l}\text { Leeside erosion may result if erosion } \\
\text { continues leaving wall as protruding } \\
\text { headland or if wall is built too far } \\
\text { seaward and is not streamlined in hori- } \\
\text { zontal geometry. Transfer of sand } \\
\text { or other nourishment of downdrift } \\
\text { shore may be needed. }\end{array}$ \\
\hline 3. & $\begin{array}{l}\text { Combination with } \\
\text { other coastal protective }\end{array}$ & Groins. & $\begin{array}{l}\text { To break longshore current and possi- } \\
\text { bly build up beach in front of wall. }\end{array}$ \\
\hline & measur & Artificial nourishment & $\begin{array}{l}\text { To maintain beach in front of wall } \\
\text { and/or to check downdrift erosion. }\end{array}$ \\
\hline & Design: & $\begin{array}{l}\text { Energy - absorbing (sloping and / or } \\
\text { mound type). } \\
\text { Non-energy-absorbing (vertical sheet } \\
\text { pile or slab). }\end{array}$ & $\begin{array}{l}\text { Considerate to beach stability due to } \\
\text { friction and low reflection. } \\
\text { May create local erosion due to less } \\
\text { friction against currents and more } \\
\text { reflection. }\end{array}$ \\
\hline
\end{tabular}

Table 3.7 Details of the performance of groins (ref. 3 ).

\section{Degree of efficiency wanted:}

2. Layout and geometry:

3. Combinations with other coastal protective measures :

4. Design :

Length in agreement with point 1 .

Height to match beach profile wanted to the practical extent possible.

Length / spacing ratio from $1: 1$ to $1: 4$ depending upon quantity of drift and beach material. Most common ratio is $1: 2$.
Just beach stabilization.

Also widening of beach.

Streamlined in horizontal geometry. No sharp turns or corners.

Seawalls:

Artificial nourishment.

Impermeable: Energy absorbing. Non energy absorbing. Adjustable elevation.

Fixed elevation.

Permeable : May be adjustable or fixed.

\section{Comments :}

Short groins mainly covering the beach. Longer groins, possibly extending beyond bar or breaker zone.

Reaction of shore protected Stable or widening and then stable.

Influence on adjoining shores: Usually beneficial or neutral updrift but adverse downdrift.

To cope with extreme conditions including storm surges.

To fill groins and widen beach initially and maintain width.

To eliminate adverse effects on downdrift beaches.

Less reflection, less loss of sand.

More reflection, more loss of sand.

May be operated to match fluctuations of beach

Can not be operated to match fluctuations of beach.

"To blow and have flour in your mouth at the same time." May provide beneficial results where currents are the main agents in transport of materials, that means in rivers and estuaries. 
Table 3.8 Details of the performance of offshore breakwaters (ref. 3).

\section{Comments :}

1. What is wanted: Protection or protection and beach.

2. Layout and geometry:

Parallel to shore or largely following depth contours.

3. Combination with other coastal protective measures :

4. Design :
Seawalls.

Artificial nourishment.

Groins.

A

Energy absorbing structures preferable.

See Table $3 \cdot 6$. Combination with natural reefs often advantageous.
If breakwater is built on littoral drift shore both are usually obtained.

Tombolo formation will result on shore to be protected. Severe downdrift erosion may result due to littoral barrier effect.

This combination is unlikely unless groins are used to check downdrift erosion, thereby transferring problem further downdrift.

May be built to protect against extreme storms and tides to check downdrift erosion.

May be used to create beach more rapidly if natural supply of material is limited or to check downdrift erosion.

Table 3.9 Details of the performance of artificial nourishment (ref. 3 ).

1. What is wanted: Protection and beach.

2. Layout and geometry : Follow natural shoreline closely on straight or streamlined shores.

3. Combinations with other coastal protective measures: Fill in pockets on headland shores and artificial pockets.

Groins: to create or maintain beach and to eliminate leeside erosion.

Seawalls: to protect wall and/or create or maintain beach in front of wall and to eliminate leeside erosion.

Offshore breakwaters: to create and maintain protective beach.

4. Design :

Nourishment from land or offshore sources. Offshore equipment under development. Various methods tested in actual operation. Sand shall be suitable for nourishment. Main requirement is that sand should be as coarse or coarser than the natural beach material and of no less specific gravity. Bypassing arrangements by fixed or movable plants including weirs and floating plants. Movable arrangements preferable.

Seawalls can be classified into three groups, namely, sloping walls of revetment type, vertical gravity walls and piled structures or simple mound structures to control emergency situations. Figs. 3.7 to 3.14 show the cross sections of the various types of seawalls or revetments designed under a varieíy of conditions.

Rock mounds and revetments: Figs 3.7, 3.8 and 3.9 present the general design parameters as explained below. Hydraulic and wave mechanics design criceria are given in Appendix A and B whereas the soil stability characteristics are presented in Appendix D. With these details it is possible to determine the armour weights and the top elevation of the wall based on the information on waves and tides and predict the foundation stability. Additional information on revetment design is given in refs. $3,6,7,14$ and 43.

Gravity walls: Graviity walls, as shown in Fig 3.10, are useful at plares where wave action is limiicd, e.g. in estuarics and protected kays. At the same time they may function as berthing plases for small vessels. Their main drawback is that they, due to their vertical fases, have a high reflection coefficient. This stirs up the beach and bottom sediments in front of the siructure (refs. 6,14 and 43). A protective apron, therefore, in 
front of such walls becomes absolutely necessary. Many gravity walls are known to have collapsed due to the lack of such a protective apron. It may also be necessary to apply a proper oversplash protection to avoid erosion of the area just behind the wall. Informations on the wave height at the breaking point and the breaking depth may be obtained from Figs. 3.5 and 3.6 for various depths and bottom slopes. The wave pressures on such walls can be calculated using the principles and methods outlined in ref. 30 recommended by the International Waves Committee and in refs. 43 and 44. Details on soil aspects can be obtained from Appendix D.

Piled walls: Figs. 3.11 and 3.12 show two inexpensive piled walls which may be used in areas of limited wave action. Both piled walls and particularly the fascine wall must be constantly maintained. Measures may have to be taken against scour at the toe of the structure. The materials available for such walls are timber piles or palm trees and fascines of available local shrubbery or brush wood. Mangroves are not very useful for this purpose. The fascines may be developed on a so-called fascine bent which is shown schematically in Fig. 3.11.

The crib type wall shown in Fig 3.12 is generally more useful than the fascine wall because it can resist wave action better. It is important, however, to point out that erosion should not be allowed to take place in front of the wall because it could ultimately lead to a collapse by overturning or sinking of the wall by undercutting. If signs of such a development appear, appropriate remedial measure should be taken up immediately, e.g. using toe protection.

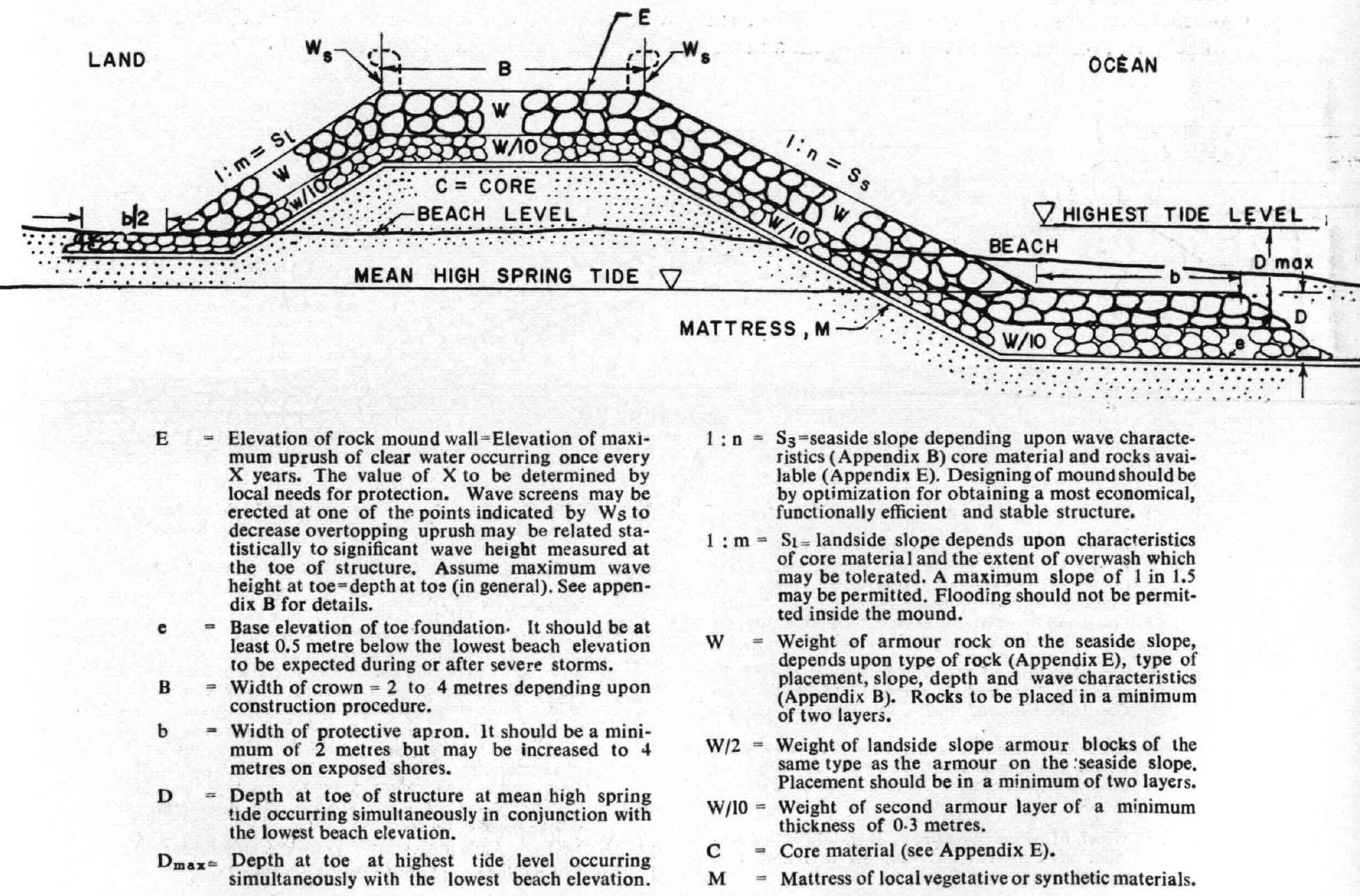

Fig. 3.7 Schematic of a rock mound wall in front of a dune on an open beach. 
Simple mound walls: Fig 3.13 gives an inexpensive mound wall whereas Fig. 3.14 gives an inexpensive revetment of sand filled bags. These structures may be built from large bags made of jute or synthetic materials if available at a reasonable cost. Bags could be filled with small rocks or pebbles of local origin or with sand. These structures are generally used for an emergency purpose only as a temporary measure. It should, however, be noted that such structures require regular maintenance. Unless the maintenance part is properly execuied, the structure cannot last long. Other emergency steps are also mentioned in ref. 7 but they require the use of heavy materials and lifting equipment.

Mattresses: Any structure resting on an erodible sea bottom should be protected against scour which could result in undermining. This may be achieved using various types of mattresses.

Basic materials, which can be used for building mattresses, include coconut (coir) or other pa'm fibres and local shrubbery or brushwood. In Kerala, bamboo fascines are successfully used. These are fairly cheap and appear to be suitable for protective measures. The durability of such mattresses could become a problem. In recent years, synthetic mattresses have been introduced and these are available in India also. They are usually made of polyethylene or polypropelene fibres and are commercially available in fabrics of various mesh sizes. Fabrics should be more or less impermeable to sand which means that little sind should pass through them. But they should be permeable to water. If the soil contains organic or shell material, the bags made of such fabrics may clog rapidly and become impermeable to water also. In the latier case, graded filters of rock, e.g., lowest sublayer of $\frac{1}{2}-2^{\prime \prime}(1$ to $5 \mathrm{~cm})$ gravel, next sublayer $10-50 \mathrm{~kg}$ rock 'one man stone' are to be placed on this filter material before the armour layer of bigger rock is placed (refs. 3 and 43 ).

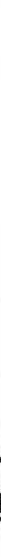

$\mathrm{E}=$ Elevation of rock mound wall = Elevation of maximum uprush of clear water occurring once in every $\mathrm{X}$ years. The value of $\mathrm{X}$ to be determined by local needs for protection. Wave screens may be erected at one of the points indicated by $\mathrm{W}_{\mathrm{s}}$ to decrease overtopping. Assume maximum wave height at toe $=$ Depth at toe $($ in general). See Appendix B for details.

e = Base elevation of toe foundation. It should be at least 0.5 metre below the lowest beach elevation to be expected during or after severe storms.

$\mathbf{P} \quad=$ Width of oversplash platform placed on a slope $1: 10$. $P$ depends upon elevation $E$, slope and wave characteristics. A minimum of 2 metres should be provided. See Appendix B.

b = Width of protective apron. It should be a minimum of 2 metres but may be increased to 4 metres on exposed shores.
D = Depth at toe of structure at mean high spring tide occurring in conjunction with the lowest beach elevation.

$D_{\max }=$ Depth at toe of structure at highest tide level occurring in conjunction with the lowest beach elevation.

$1: \mathrm{n}=\mathrm{S}_{\mathrm{g}}=$ Seaside slope depending upon wave characteristics (Appendix B), core material and rocks available (Appendix E). Design of mound should be by optimization for obtaining a most economical, functionally efficient and stable structure.

$\mathrm{W}=$ Weight of armour tock. Depends upon type of rock. type of placement, slope. depth and wave characteristics. See Appendix B and E. Rock to be placed in a minimum of two layers.

$\mathrm{W} / 10=$ Weight of second armour layer of a minimum thickness of 0.3 metre.

$\mathbf{M}=$ Matt ress of local vegetative or synthetic materials.

F = Fill on dune or platform. See Appendix D.

Fig. 3.8 Schematic of a rock revetment for dune protection on an open beach. 
3.3.2 Dunes and dykes-overflow protection: Sometimes erosion is caused by the waves and high tides during storms. If the shore is high, erosion takes place only on the front side of the cliffs or dunes. On the other hand if the shore is low, the wave uprush may overflow across the dune or ridge moving the eroded material from the front side to crown inland. This often occurs on low barriers separating the main sea from the bay or lagoon on littoral drift shores. Similar situation may also arise on barrier ridges covering low marsh lands and mangroves. As a consequence, the low dunes or ridges gradually move inland and a situation may finally arise resulting in general recession of the major part of the shoreline.

Overflow of coastal dunes and barriers takes place at many plases on the Indian shores but it is predominantly on the barrier beaches of the east and west coasts. One of the best ways of solving this problem wou'd be by constructing a 'withdrawn dyke' as shown in Fig. 3.17. A withdrawn dyke is a dyke built at such a distance from the shoreline that it is attacked by the sea very infrequently, that means, it can only happen under extreme tide and wave conditions (ref. 8). It serves as a final defence line and is supposed to stay intact even under the most severe storm and flood conditions. Dykes of this nature are usually located well up on the ba:kshore and at a certain distance from the first defence line which may be a sea dyke close to the shore or natural dune functioning as a sea dyke. Withdrawn dykes are

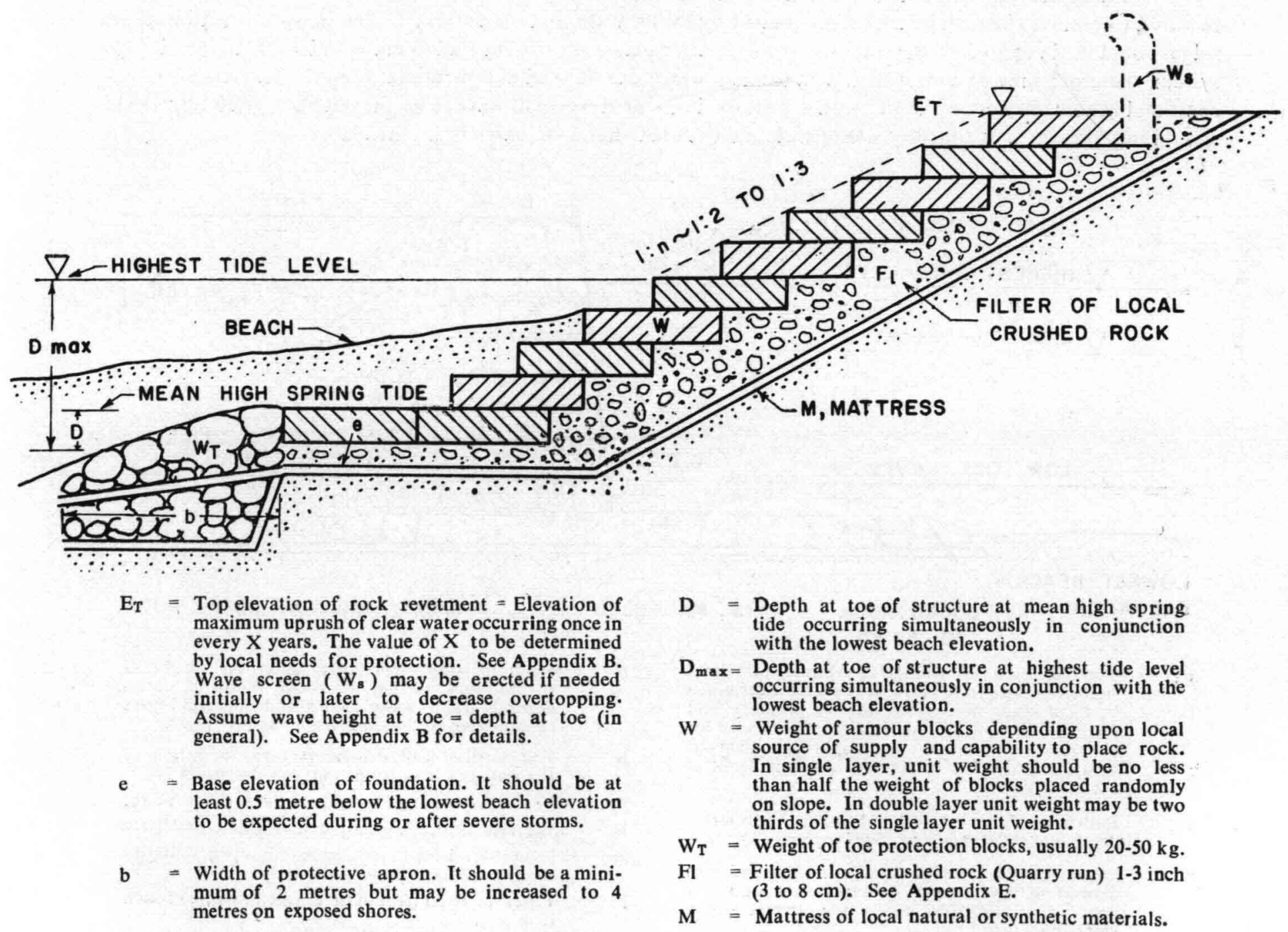

Fig. 3.9 Schematic of a rock revetment for protecting the valuable shore property with a provision of an access to the beach. 
commonly found along the shores of the low lying countries of the North Sea where a breakthrough into the low lying land could cause severe flooding. A dyke like Fig. 3.17 is also suitable for the low lying areas of the east and west coasts of India. The top elevation of the dune or dyke should be determined as described in Sections 1.2, 1.3 and Appendix B. A seaward slope of 1 in 7 is used based on the experience obtained from the rough North Sea coast.

Dune protection using withdrawn dykes seems, at first, to offer a number of technical advantages. Experience has shown that it has, essentially, just one disadvantage, and that is, the possibility it offers for the formation of a pool in between the two dykes by the overwash caused by extensive wave uprushes overtopping the crown of the sea dyke (ref. 23). Seepage may then oscur through the withdrawn dyke, leading ultimately to a slide or even a breakthrough causing flooding of the adjoining area. If such a slide takes place, presumably during a storm or cyclone, a catastrophe may result. If the slide occurs after the storm, flooding and damage of the land at the back of the dyke may be limited but damage to coastal roads or railway lines may be quite extensive. It is, therefore, very important that the formation of such a pool be avoided. The stability of sand slopes is discussed in Appendix D.

Earth-moving equipment such as bulldozers and scraper pans, or considerable man-power may be required to remove the high beach ridges created by swells at the end of a storm. The pools formed inside the ridges could be dangerous to the stability of the beash because they could lead to mass-slides. A double defence system, therefore, may be an excellent arrangement which can be used at several places on the barriers of the east coast and at some plases on the west coast. Shore dunes or dykes will have to be moved back gradually. This should not present any difficulty where wide uninhabited shores or barriers are available.

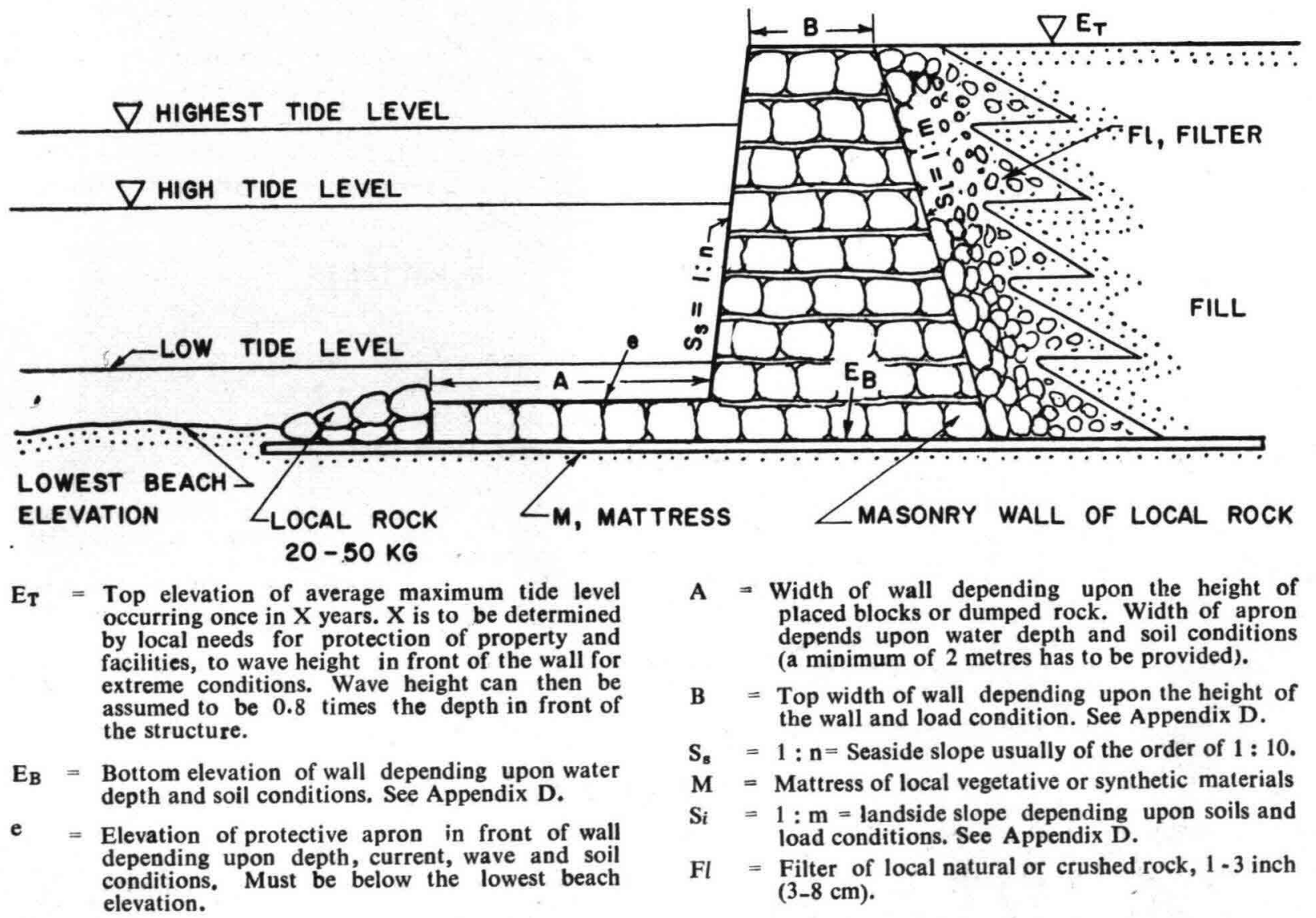

Fig. 3.10 Schematic of a vertical rock gravity wall (for wave heights less than $0.5 \mathrm{~m}$ ). 
TOP ELEVATION = STORM TIDE ELEVATION +1.5 WAVE HIGHT AT TOE OF STRUCTURE $\nabla$ MEAN HIGH TIDE

\section{LOWEST BEACH ELEVATION-}

$\because \because \because \because \because \nabla \nabla$ MEAN LOW TIDE

TOE PROTECTION IF NECESSARY

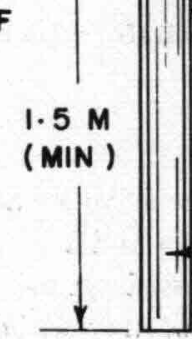

Fig. 3.11 Schematic of a double piled fascine or bag crib (for wave heights less than $1 \mathrm{~m}$ ).
TOP CARVED OUT AND FILLED WITH TAR. ROCK OR SAND FILLED BAGS ON TOP
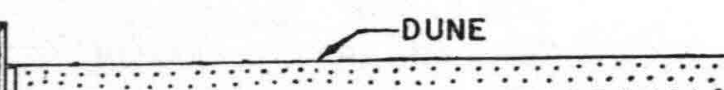

DOUBLE COIL ROPE OR TWISTED

TAUT WIRE AND LOCKED

FASCINE BUNDLES

MIN $20 \mathrm{CM}$ LOGS

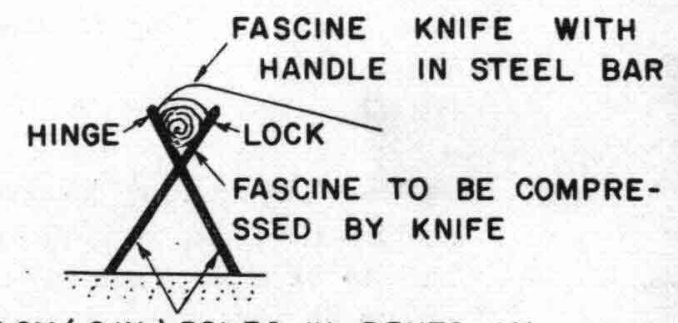

$15 \mathrm{CM}$ ( 6 IN ) POLES IN BENTS $1 \mathrm{M}$

(ALL PROVIDED WITH KNIVES)

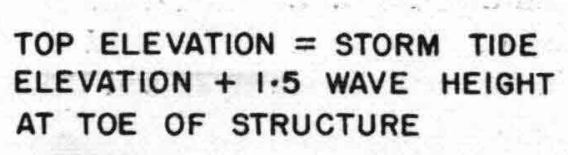

AT TOE OF STRUCTURE

$\nabla$ MEAN HIGH TIDE LEVEL

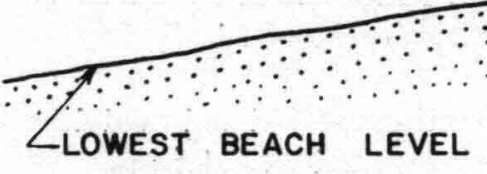

$\nabla$ MEAN LOW TIDE LEVEL

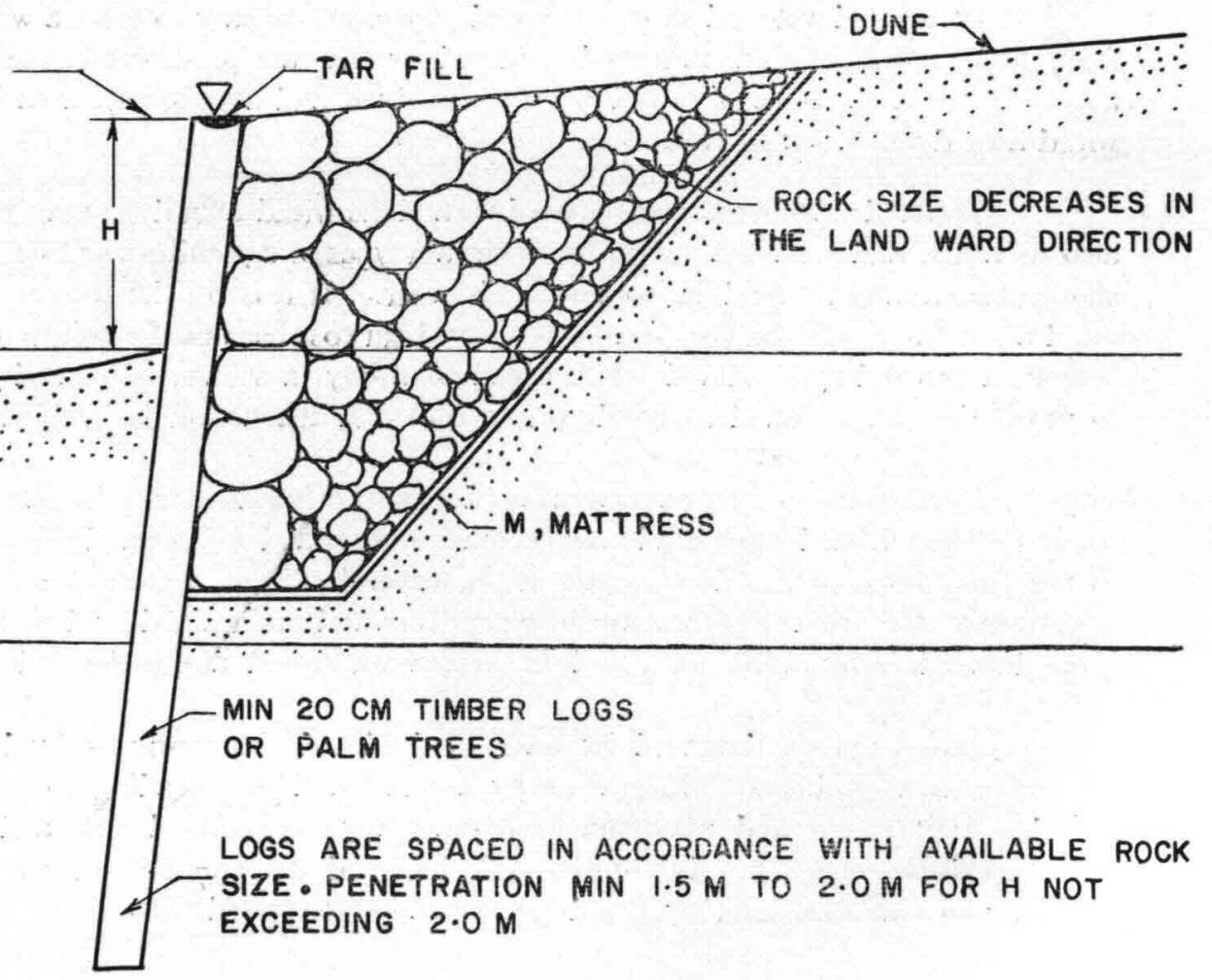

Fig. 3.12 Schematic of a single piled rock crib (for wave height less than $1.5 \mathrm{~m}$ ). 


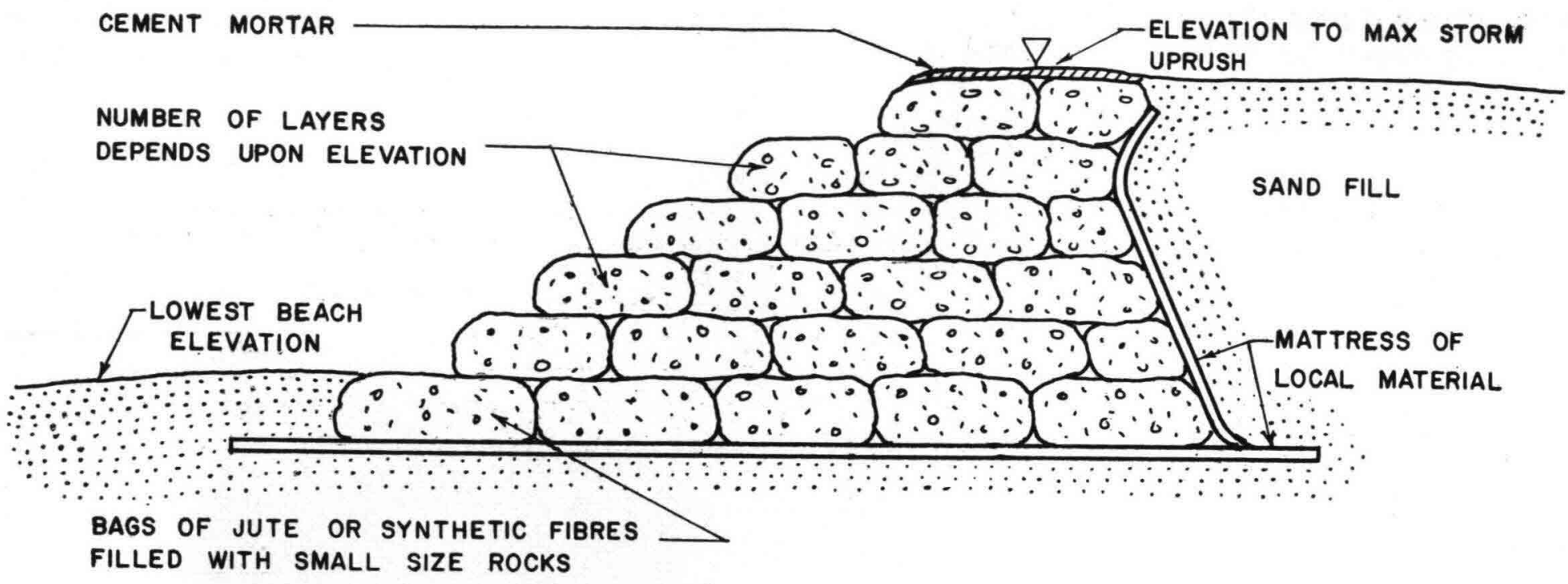

Fig. 3.13 Schematic of a simple mattress or gabion wall (for wave height less than $1 \mathrm{~m}$ ).

The situation, however, becomes different if the barrier is very narrow or the land area behind the shore is developed or is profusely inhabited as is often found in India. In such a situation, the dyke may have to be built in the bay or lagoon as a dam, which at exposed places, may have to be reinforced by a revetment protection. It is also to be noted that the erection of any withdrawn dyke as a second defence or flood protection line, at a certain distance from the shoreline, will cause problems connected with the land development (see Section 4).

On an undeveloped shore, it would, however, be easy to erect a withdrawn dyke at a certain distance from the shoreline. This distance is determined by the rate of shoreline recession. The to al cost involved in acquiring the area to be oxcupied by the new dyke and also of the area in between the sea dyke and the withdrawn dyke will also have to be considered.

The land mass in between the sea dyke and the withdrawn dyke may be used for recreation purposes and also as a fish and wild-life reserve or for certain types of agriculture or forest development. On the developed shore, the situation would be somewhat different. If it is on the fringes of a ciíy, it will be necessary to build a special protection for the area at a very high cost because if erosion continues, the city area will gradually become a protruding headland. If, instead of a city, a village is located on the fringes, it might be better to move the village inland, if conditions permit and the action is justified by the cost involved.

Dune formation: By natural means dunes start building up when an obstruction to wind and sand drift occurs. The seaward slope gradually becomes steeper and steeper and the wind blown sand particles move up to the front slope of the dune, settle in the leeward side in a steep slope making the dune migrate in the direction of the wind. Dunes are often built up and maintained by different beach vegetation. Appendix $F$ gives detailed information on the dune vegetation found along the Indian coasts.

Dunes may be damaged by waves and tides during storms or by drought and diseases destroying the vegetative area or due to overgrazing by animals and thus leading to wind blow outs. Dune management includes stabilization and maintenance of naturally occurring dunes, and the creation and maintenance of protective dunes where they do not exist. Although dunes can be constructed using mechanical means, it is necessary to stabilize them by the dune vegetation (Appendix F). 

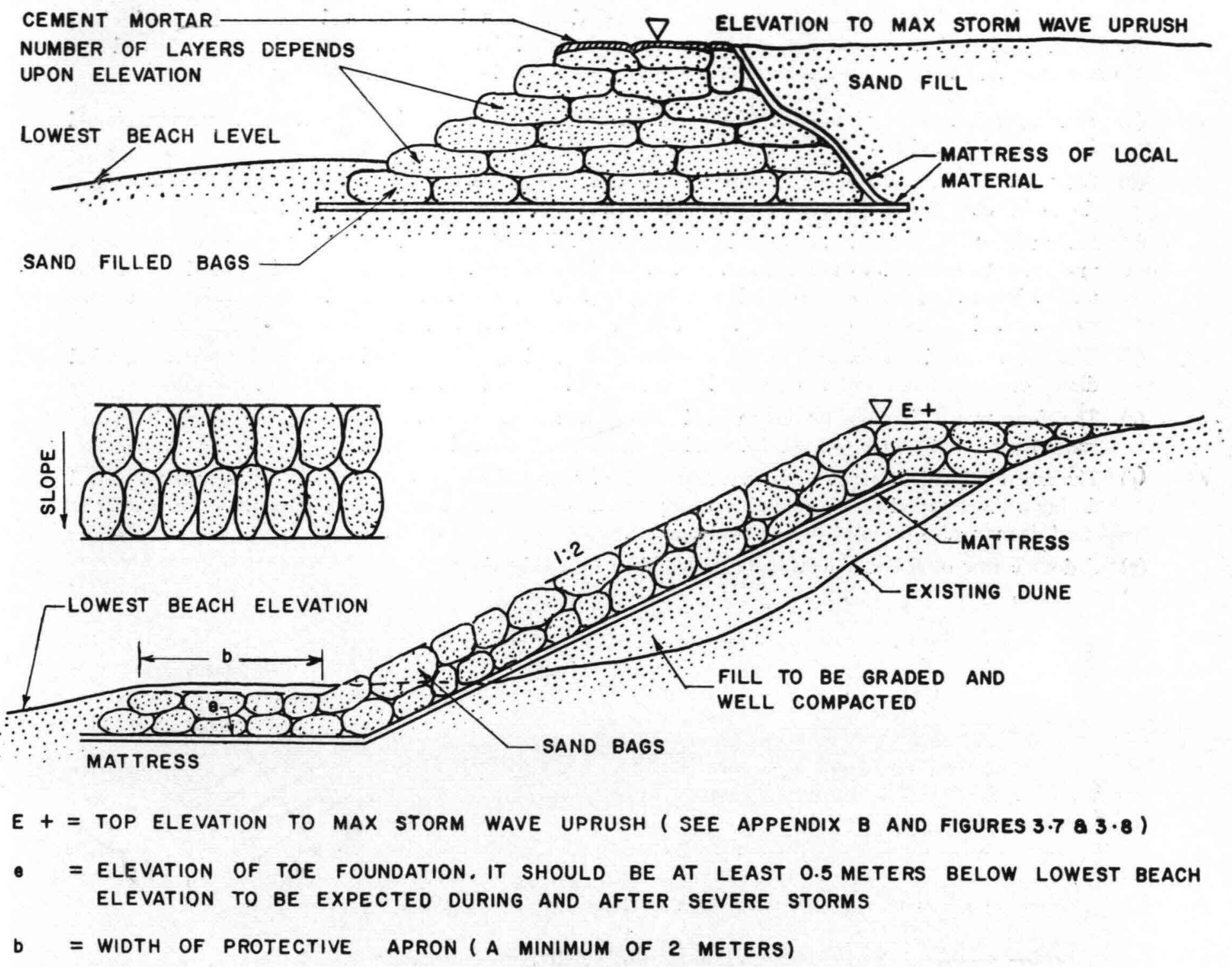

Fig. 3.14 Schematic of a simple revetment of sand bags (for wave height less than $1 \mathrm{~m}$ ). 
Dune construction: Various machanical mcíhods, such as fencing made of brush wood or bamboo have been used to construct dunes (ref. 26). Relatively inexpensive 'snow fencing' is used almost exclusively for the artificial dune construction in the United States. In many European countries, brush wood fences are common, e.g., various kinds of spruces (Denmark) or willows (Holland). Fig. 1.1(h) shows a bamboo sand fence used in Calicut (Kerala) for dune construction.

Studies on the techniques for the construction of dunes of a desired size and profile using sand fences have been conducted at many places in Europe and the United States (refs. 1, 9, 15, 24, 26, 31,38 and 43). However, certain basic principles as given below should be followed for their construction:

(a) Fencing with a porosity (ratio of area of open space to the total projected area) of about 50 per cent should be used (ref. 26 and 43 ).

(b) Only straight fence alignment is recommended. Fence configurations with side spurs or zigzag alignment do not increase the effectiveness of trapping of sand and these become uneconomical.

(c) Placement of the fence at a proper distance shoreward from the berm crest may be critical. The fence must not be exposed to frequent wave attacks. The selected fence line should coincide with the natural vegetation line or the foredune line prevalent in the area. This distance varies from coast to coast and is known to be the widest on the most exposed. Indian shores (ref. 25).

(d) The fence should be parallel to the shoreline. It need not be perpendicular to the prevailing wind direction. The fence will also get filled if constructed using a small angle to the wind direction.

(e) The dune which develops by this method will be almost as high as the fence. The dune slopes will range from about 1 on 4 to 1 on 7 depending on the grain size and the wind velocity.

(f) The rate of fill will not remain constant but will vary with the local conditions. A fence may get filled during a short period of high wind velocity. If another fence is erected shortly after the earlier is filled, it may also get filled during the same season.

(g) A double row of fences will facilitate the building of a wider dune.

PREDOMINANT

DIRECTION OF

OCEAN
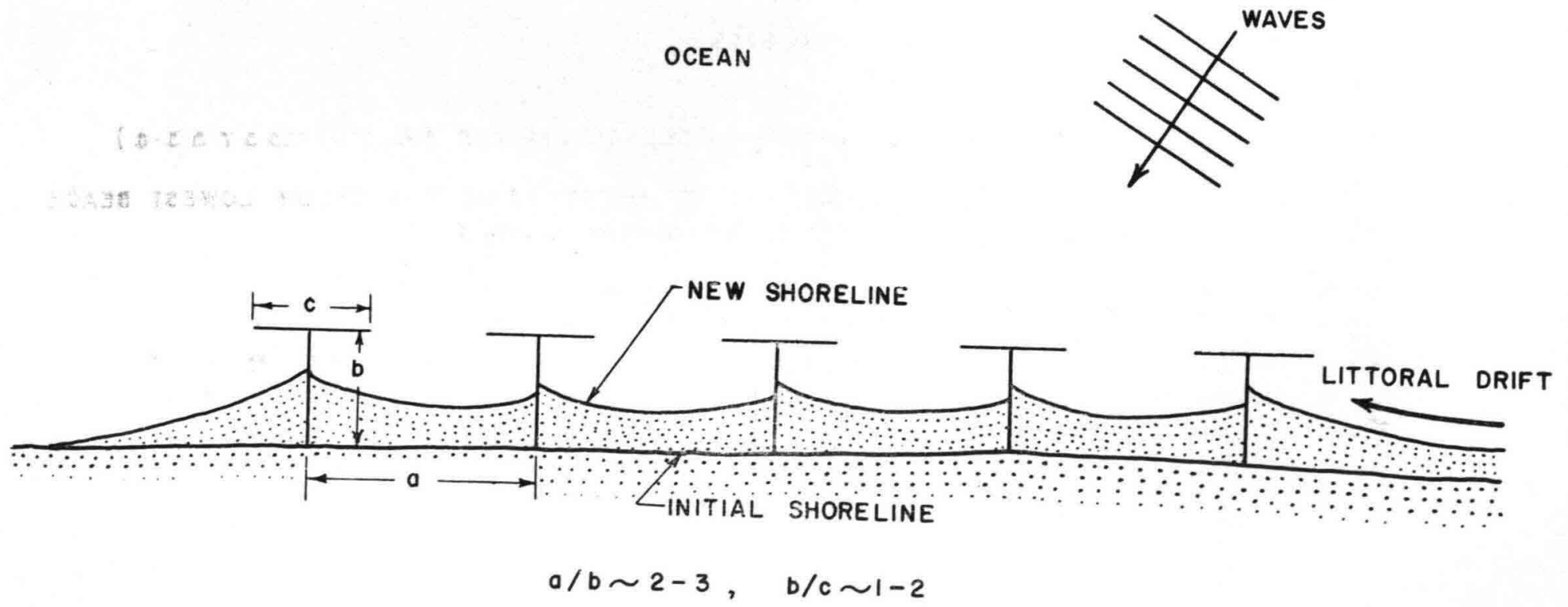

Fig. 3.15 Effect of a group of T-groins on a beach. 

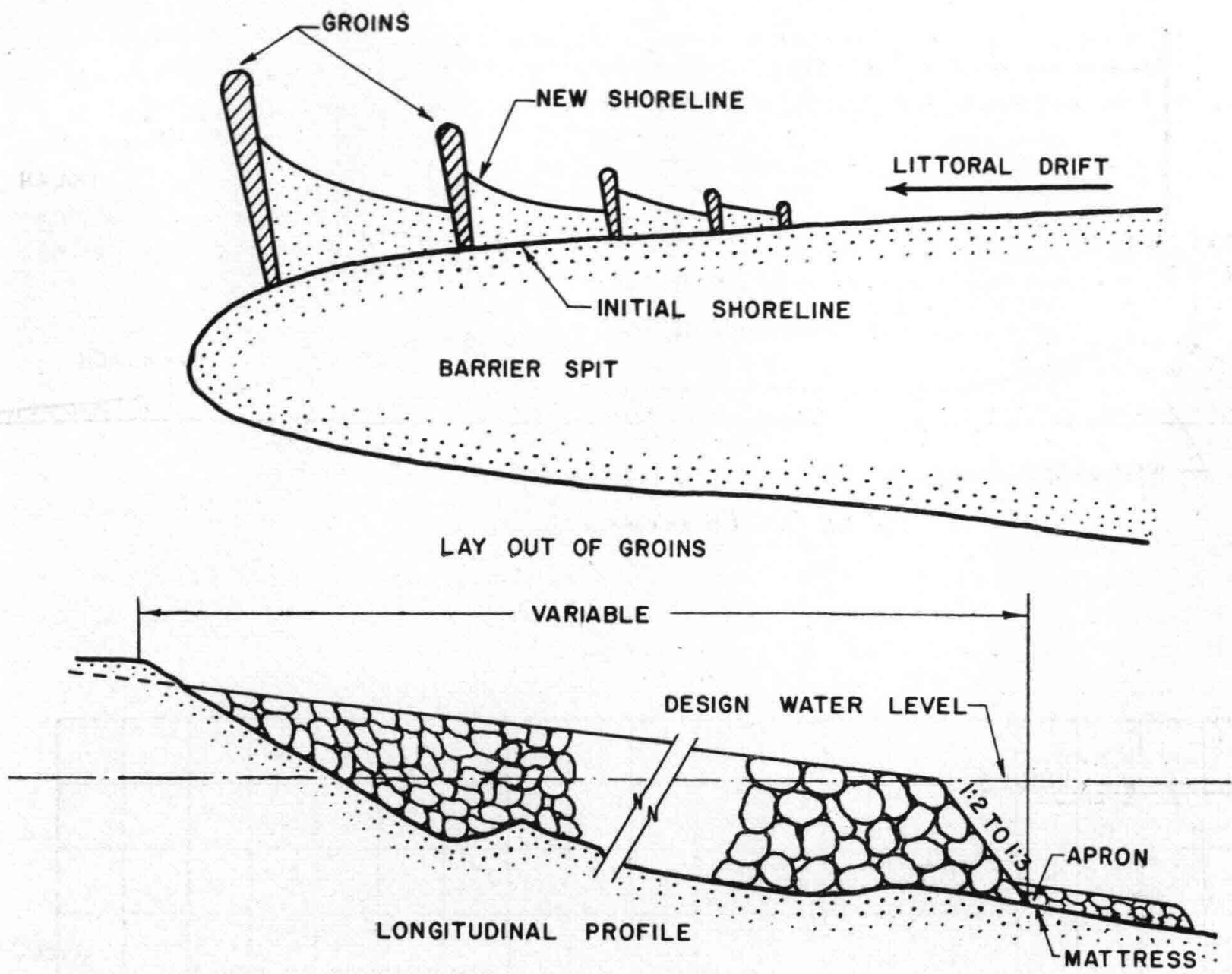

NOTE: DIMENSIONS AND DETAILS TO

BE DETERMINED BASED ON LOCAL CONDITIONS

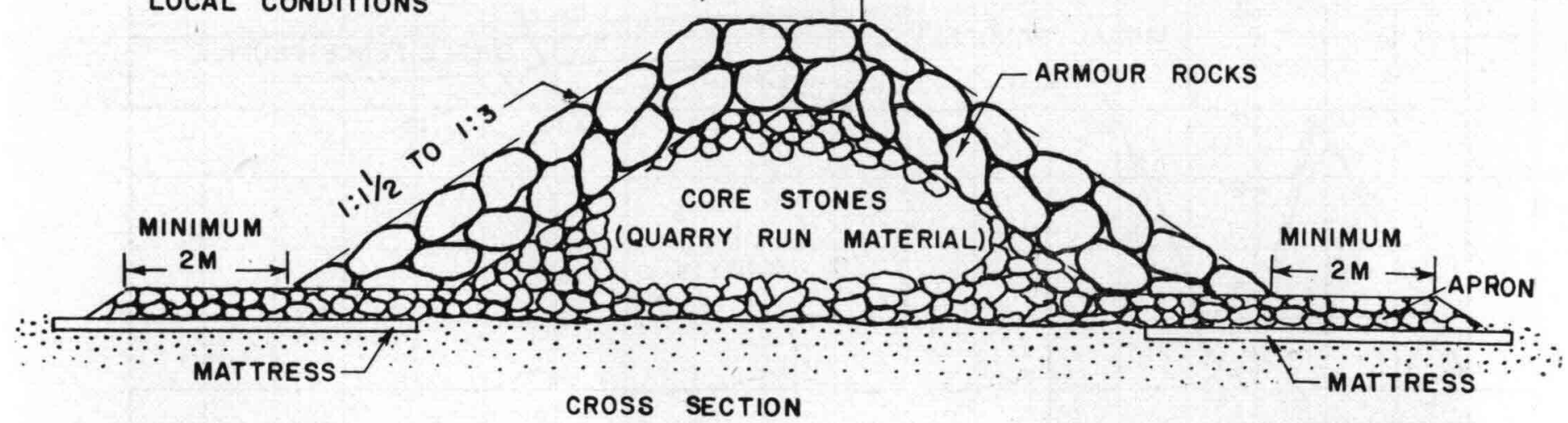

APRON AT SEAWARD END OF THE GROIN SHOULD BE TWICE AS WIDE AS ON SIDES. GENERALLY TOP OF GROIN FOLLOWS BEACH SLOPE. GROIN SHALL BE WELL ANCHORED IN DUNE BY EXTENDING ITS LAND WARD END AT LEAST 6 METERS INTO THE DUNE OR BACK SHORE. FOR SIZE OF ARMOUR ROCK AT HEAD OF GROIN SEE APPENDIX B. SIZE OF ARMOUR ROCK ON SIDES OF GROIN DECREASES TOWARDS SHORE AND HALFSIZE AT THE MIDDLE OF THE GROIN AND QUARTER SIZE AT LAND WARD END. USE OF MATTRESS ESSENTIAL FOR STABILITY.

Fig. 3.16 Design of terminal groins on a sand spit. 


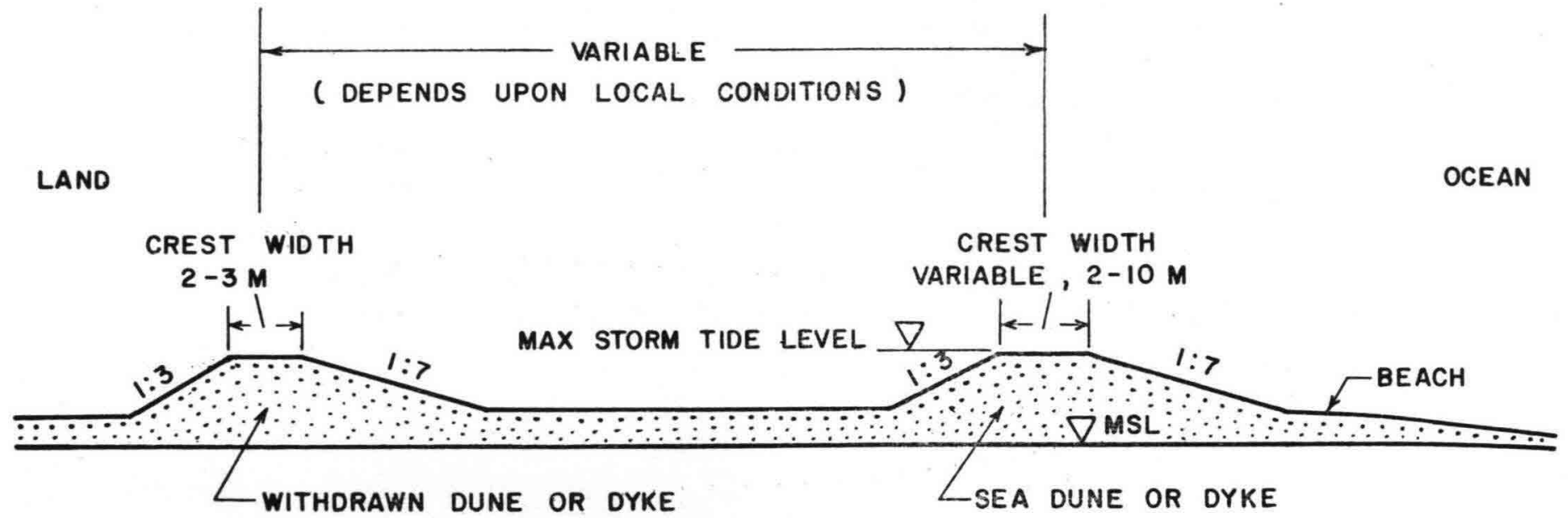

Fig. 3.17 A withdrawn dune or dyke (ref. 8).

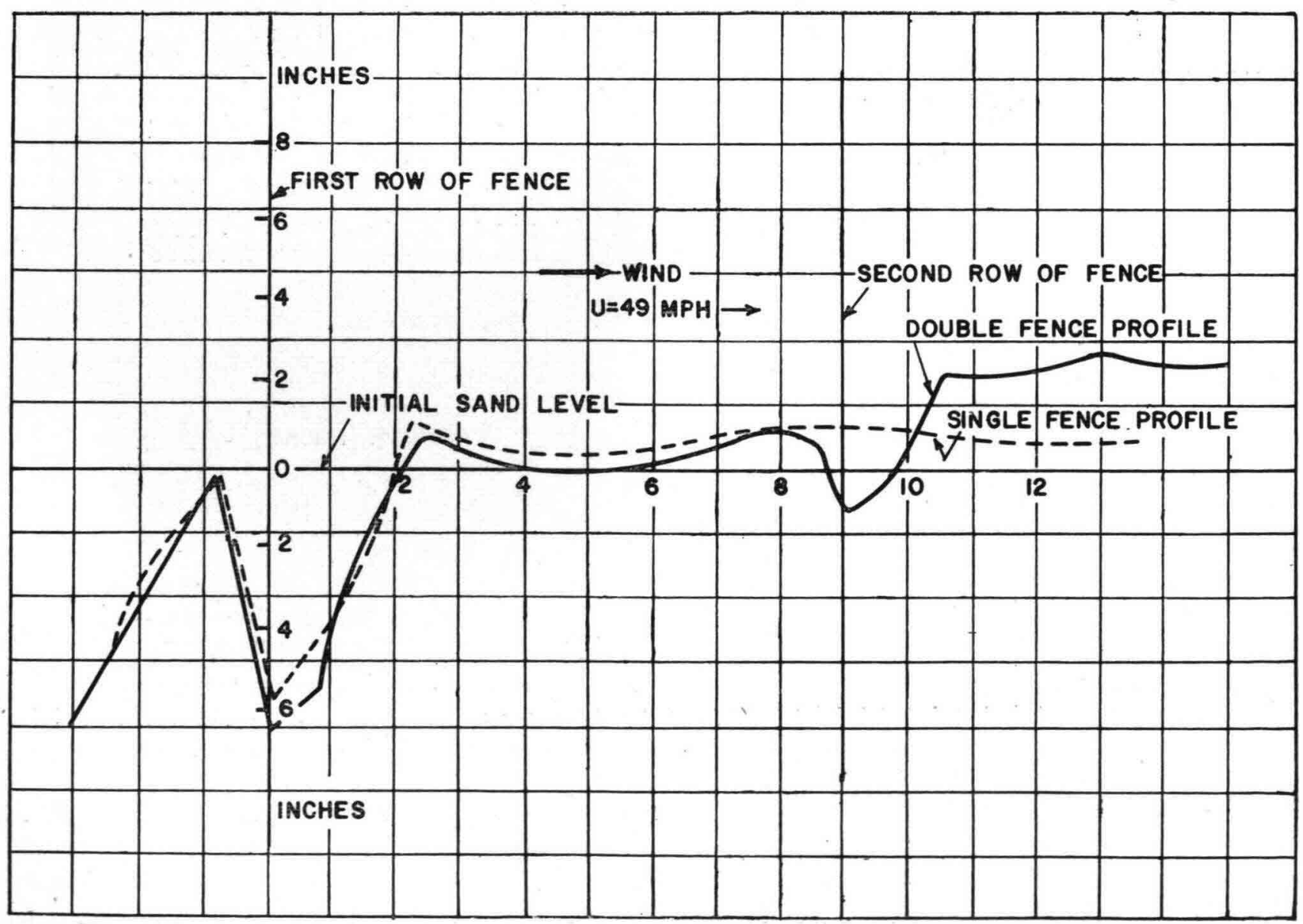

Fig. 3.18 Laboratory tests on dune-building with a single and a double fence system (ref. 26). 
Fig. 3.18 presents the results of laboratory tests with a single and double fence. It is seen that the double fence is more effective than a single fence (ref. 26). The spa:ing between the fence lines should be about four times the fence height.

Fig. 3.19 shows the results of laboratory tests on a single and double row fences on a plain ground and with a fence placed on bulldozed dunes. It appears that although the bulldozing gives a 'flying start', on a long term basis, it is hardly worth the effort.

Fig, 3.20 shows the mechanics of building up a larger dune by erecting properly designed fences on the top of an existing dune. Double row fencing provides a wider and larger dune (ref. 26).

(h) Unless maintained properly, the dunes created by fencing may become short-lived duc to the destruction of fencing as a result of corrosion of wire and deterioration of the wood or due to destruction caused by man himself.

(i) In India, a wide variety of natural materials including bamboo is available for sand fencing. The best way to maintain a fence-constructed dune is to plant some vegetation over it. A few plant species would survive even in the harsh beash environment (see Appendix $\mathrm{F}$ for details).

3.3.3 Groins : Figs. 3.15 and 3.16 show layouts and cross-sections of groins. As explained in the Section 3.2.4, the selection of groins as a coastal protection measure should be evaluatcd vcry carcfully because the overall effect of a group of groins could easily become more harmful than bencficia!. Groins, as described in Table 3.8 may, however, be beneficial to specific areas where a protcction is definitely

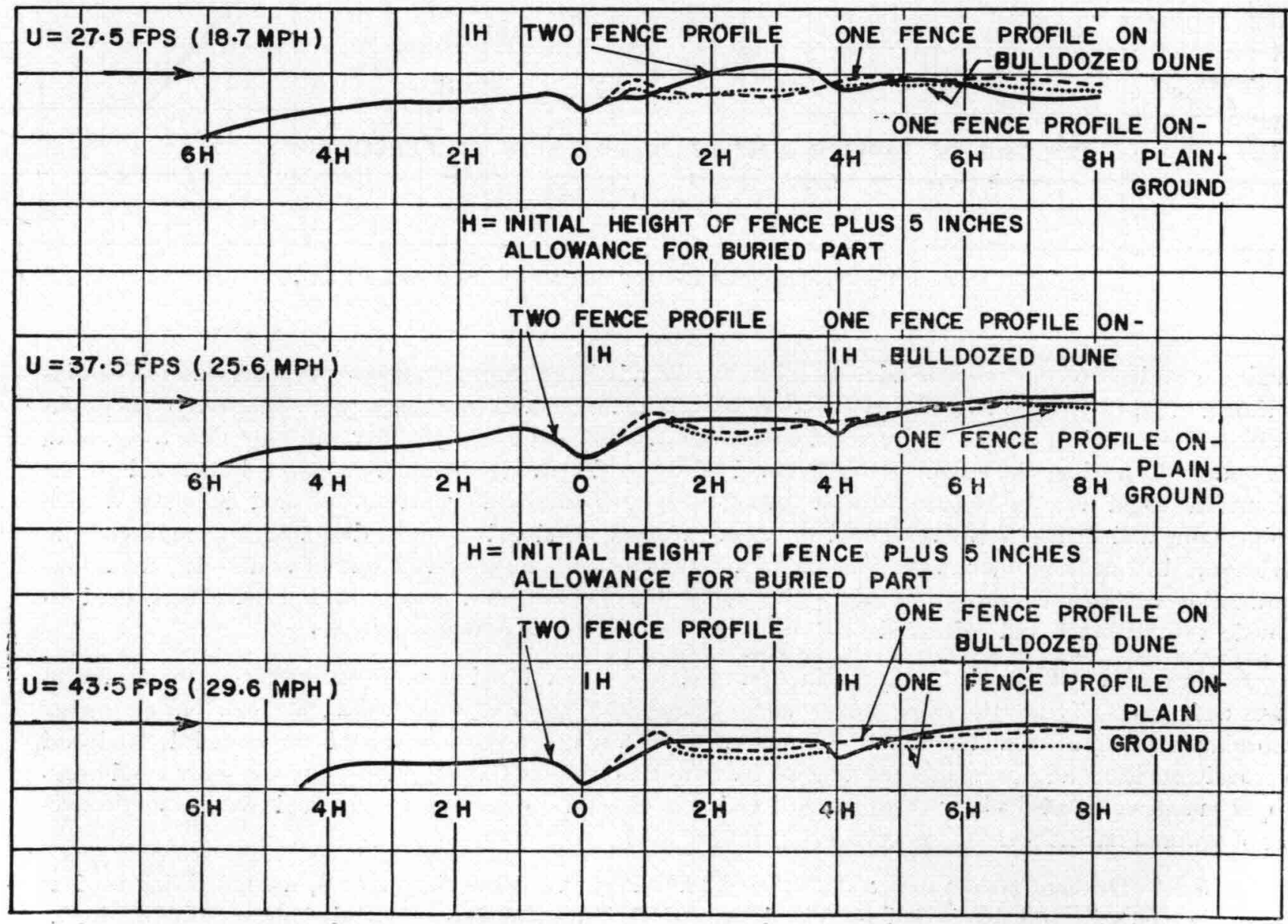

Fig. 3.19 Laboratory tests with a fence on a plain ground or a bulldozed dune (ref. 26). 


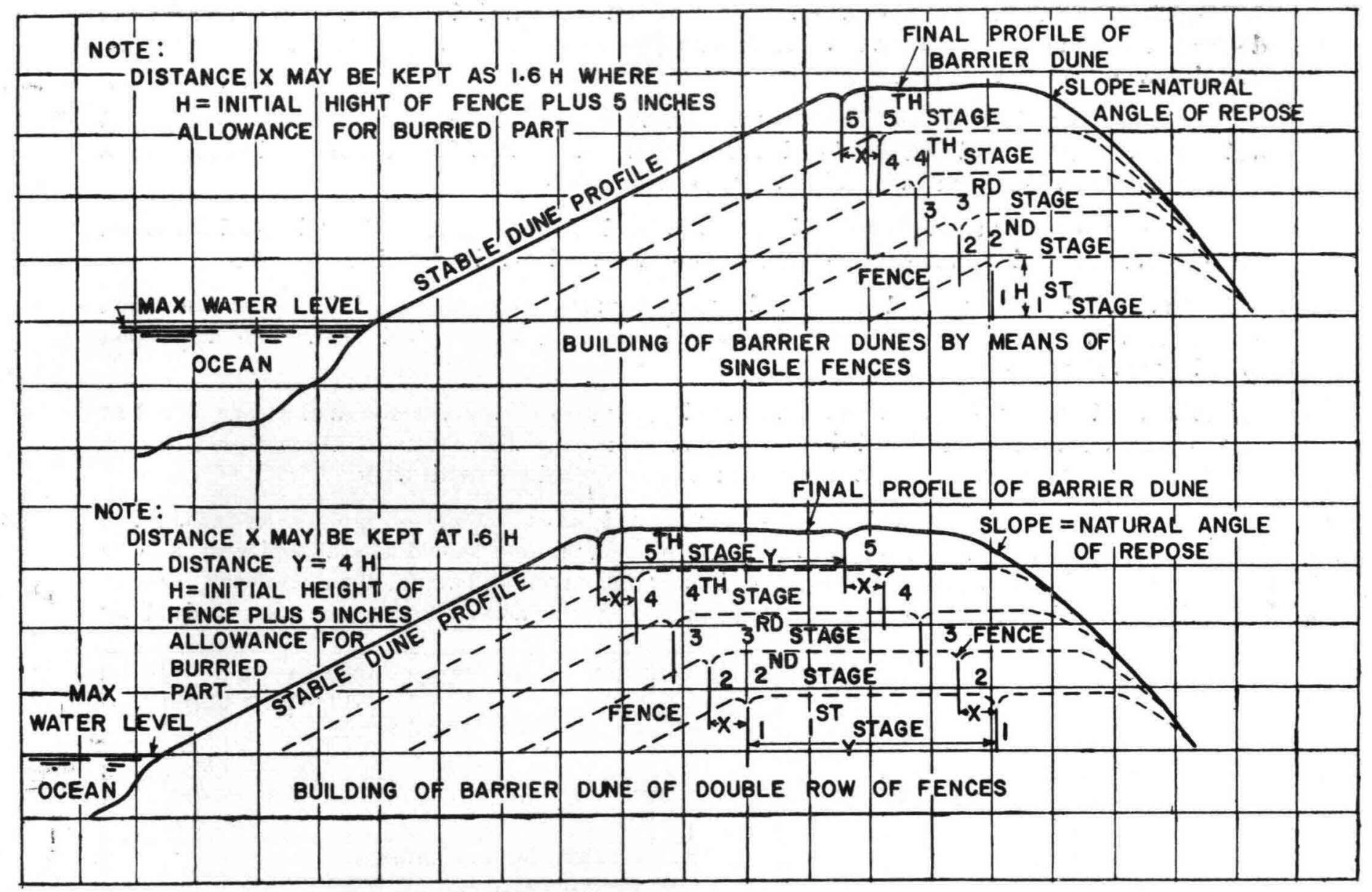

Fig. 3.20 Mechanics of building-up of dunes by multiple fencing system (ref. 26).

wanting regardless of the possible adverse effects on the adjoining shores (ref. 28). In such cases, T-groins as shown in Fig. 3.15 are most effective because they compartmentalise the beach more effectively. If groins are built at the end of the beach, e.g., on a barrier spit as shown in Fig. 3.16, they will only have a beneficial effect partly by ho'ding the beach at the spit and partly by decreasing the shoaling effect at the end of the spit which could also be beneficial to navigation. Fig. 3.16 shows a typical layout and design of a rock groin. Long and high groins can be used to act as artificial headlands if it is desirable to completely trap the littoral drift. Such groins may be constructed as terminal groins at the updrift side of a tidal inlet, a harbour entrance or a submarine canyon. Long groins in conjunction with beach nourishment have been used to provide a stable beach and reduce adverse effects on the downdrift beachcs (ref. 28) .

In general, the head of the groin located at the seaward end is more vulnerable to the attack of waves and scour. It is, therefore, important to design this porition with a gradual slope having energy absorbing charasteristics and a suitable apron placed on a mattress. Groins should be extended landward to provide sufficient anchoring into the dune or backshore to prevent flanking during severe wave conditions. Proper maintenance particularly their seaward ends, is essential to prolong the life and functional effectiveness of groins (ref. 28).

3.3.4 Offshore breakwaters : Offshore breakwaters, as shown in Fig. 1.9, are not being uscd at present for coastal protoction in India. The design of their armour layer should, however, follow similar principles as outlincd in Appendix B for seawalls. For such large and expensive structures, it is imporiant 
that the wave conditions are known in greater detail with particular reference to storms. The design procedure should then follow the guidelines given in the permanent International Association of Navigation Congresses in their report prepared by the Waves Committee, 1976 ( ref. 30) and presented briefly in Appendix B. The maintenance of breakwaters is essential to avoid rapid breakdown of the breakwater if left unattended and unrepaired.

3.3.5 Nourishment of beaches: Table $3 \cdot 10$ shows how the coastal protection is likely to develop in the future. It may be noted that artificial nourishment is becoming the most essential part of future protection. But it requires large and effective pumping equipment. As the sources of sand for nourishment in the future will mainly come from the offshore bottom, pumping equipment must be able to operate in low to moderate sea conditions, that means wave conditions up to 2-3 metres. As the wave climate on Indian shore is not very severe, it may be stated that India is very fortunate with respect to operational aspects of beach nourishment from the offshore sources as the only time of the year when offshore dredging, using modern equipment, cannot be done would be during the monsoon periods. From the economic point of view, the artificial nourishment usually is the most advantageous. But nourishment could possibly be undertaken in India using simpler means including the use of animal or even manpowered draglines (ref. 3).

Table 3.10 Future coastal protective measures (ref. 3).

\begin{tabular}{ll}
\hline \multicolumn{1}{c}{ Large scale } & \multicolumn{1}{c}{ Small scale } \\
\hline AN & SW \\
$\begin{array}{l}\text { Possibly combined with artificial } \\
\text { dunes or dykes providing storm }\end{array}$ & To protect a particular area sloping \\
tide protection. &
\end{tabular}

$\mathrm{AN}+\mathrm{SW}$

$\mathrm{SW}$ to reinforce dyke or dune against extreme conditions of waves and tides.

$\mathrm{AN}+\mathrm{GR}$

When GR are justified economically if it decreases maintenance costs.

GR

May be justified in local areas if well planned and kept filled by nature and/or by man.

$\mathrm{SW}+\mathrm{GR}$

To protect a particular area where groins are needed as current breakers.

$\mathrm{AN}+\mathrm{SW}+\mathrm{GR}$

In unusually difficult situations.

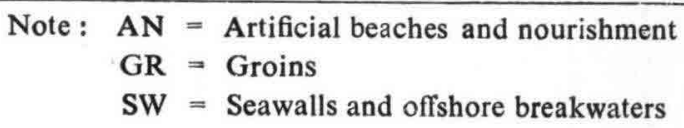

Certain basic requirements should be fulfilled to ensure high initial stability and as little maintenance as possible. In general, these requirements are:

(a) Grain size of the fills should be sufficiently coarse or atleast coarser than the natural beach sand.

(b) Materials should be relatively well sorted with particle size distribution to cover a!l grain sizes present in the original environment. It should include as little fine material $(<0.15 \mathrm{~mm})$ as possible and also little coarse meterial, e.g., particles $>2 \mathrm{~mm}$ to avoid separation and formation of a steep and unstable beach.

(c) The fill material should be resistant to abrasion against wave attack (quartz, feldspar and similar minerals).

(d) Needless to say that it should be clean without much clay, silt and organic matier. 


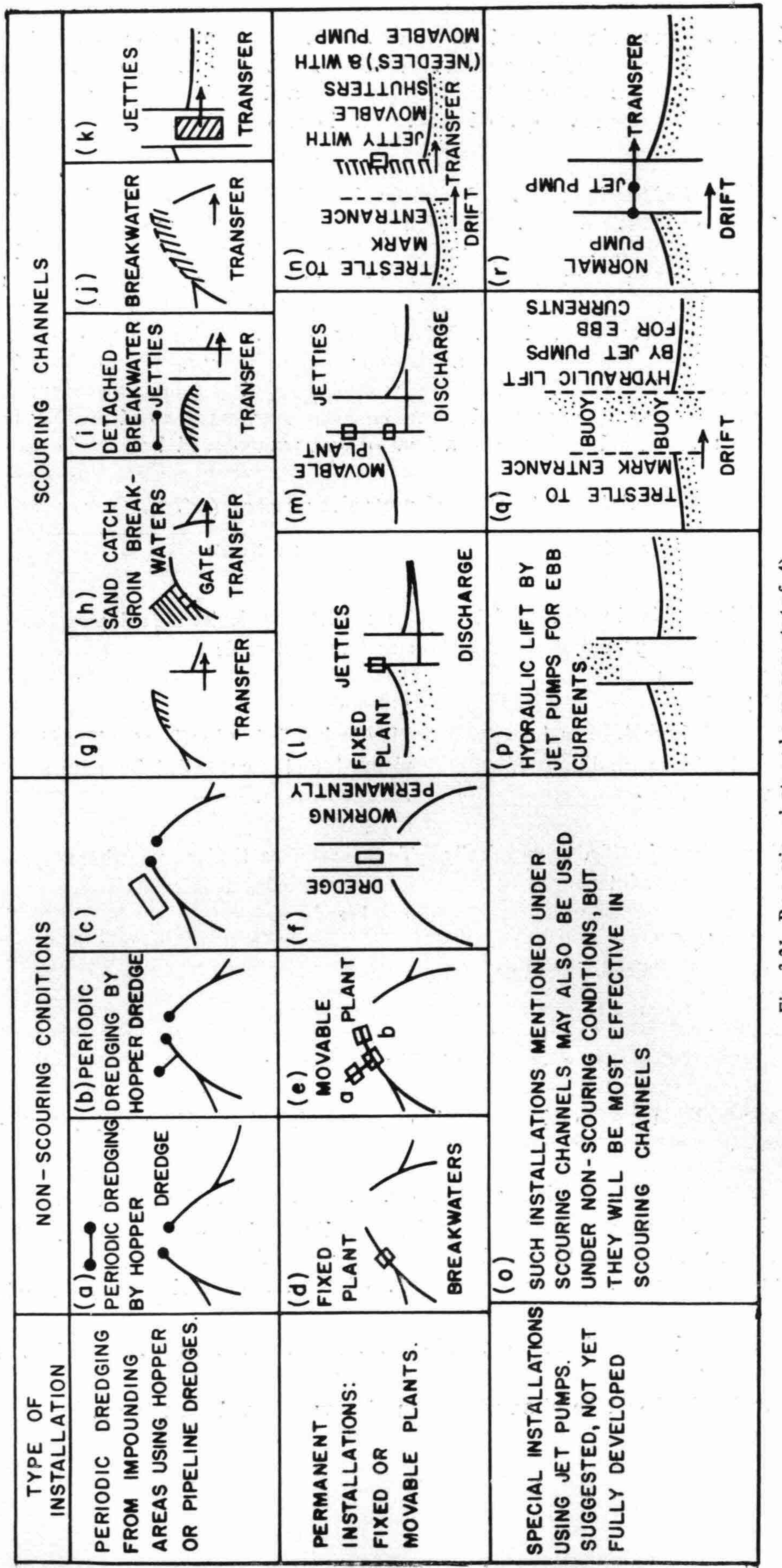


(e) It is very important to note that all material required to fill in a beach need not be of a first class grade. All exposed material is considered as suitable. Even the low grade matcrial may prove to be quite suitable to provide volume and support for the upper layer of the actual beach material. However, this upper layer must be maintained by replenishment as and when required.

Section 2.2 and Appendix $\mathrm{C}$ give information on how sampling and analysis should be carried out to secure information on the overfill ratios and the relative retreat rate. The former is calculated on the assumption that some portion of the borrowed material is absolutely stable and hence a finite proportion of the original material will remain on the beach indefinitely. The relative retreat rate is calculated on the reverse assumption that no material is absolutely stable, and that the finer material is less siable than the coarser material. Hence a coarser beach fill will require nourishment less frequently than a finer one. Overfill ratios can never be less than unity because a beach will not retain more material than what is added to it. Relative retreat rates can be less than unity because a new fill might erode more slowly than the native beach material.

The two methods can be compared simply because both of them ultimately attcmpt to predict the economic factors associated with the utilization of potential materials to be borrowed. In monetary sense, the engineer can interpret the overfill ratio as a fastor to be applied to the actual unit cost of obtaining a given material to be borrowed in quantities sufficient to ultimately establish optimum planned project dimensions. The relative retreat rate can be interpreted as a factor to be applied to the maintenance costs assosiatcd with its periodic renourishment. The determination of these nourishment requirements is based on natural erosion rates of the native maierial.

Both models are quite simple from a conceptual standpoint. Therefore, it scems unlikely that either of them would fully describe any real shore situation. However, a subtle distinction can be made in the types of uses to which these methods are put to. On one hand, the engineer wanis to estimate the total cost associated with the selection of a given borrowed material. The application of the two methods will give some indication of the possible range of such values but a strict use of the either method seems unjustified, when the inherent simplicity of the models is weighed against the staggering complexities of the physical prosesses operating in the nearshore and beach environment. On the other hand, the engineer is usually limited to a few economically feasible sources of borrowed materials and he must choose one, regardless of the absolute azcurasy of his predicted costs. The strength of these meihods to help arriving at a decision seems greater than their absolute predictive powers.

3.3.6 Bypassing of material at tidal inlets : As explained in Section 1 with reference to Fig 1.11, India has experienced severe erosion problems due to improvements of many inlets by jettics and/or dredged channels. This problem can only be solved by bypassing of material from the updrift side of the inlet to the downdrift side.

Improvement of the tidal inlets in India has some special features. In many cases, improvements have given morc adverse effects on the shorc stability than similar improvements clscwhere in the world. This is due to the skewness of the flow occurring during the rainy (monsoon) scason. The ebb flow becomes very predominant over the flood flow and the result is that materia! being transporicd as bed load as well as suspended load is jetted far out into the sea where it gets lost as it never returns to the shore. This effect is very obvious when during the monsoon the high flood discharges of a river breakthrough a barrier which largely remains closed during the non-monsoon period. It also ozcurs when the ebb flow during the monsoon produces a deep cut through or pushes out an existing offshore bar or a shoal further offshore. An example of the former is found at Ponnani and of the latter at Neendakara both in the Kerala State on the west coast. On the Bay of Bengal side, corresponding cases are found at numerous places in Andhra Pradesh, e.g., at Biminipatnam and in many monsoon estuaries of Orissa.

Jetty improved inlets are, therefore, even more dangerous for conditions prevailing in India than elsewhere. As many tidal inlets in India may need such improvements, the outlines of the mcthod and procedures 
are given in Table 3.11, and in the legend of Fig 3.21 which should be followed. The bypassing procedure which could prove to be most successful for Indian conditions is trap-dredging by which drift material is accumulated in dredged traps located at a convenient place from where it can be removed by hydraulic pipeline dredge at regular intervals. Figs. 3.2.2 and 3.23 show some practical locations of traps for improve-

OCEAN

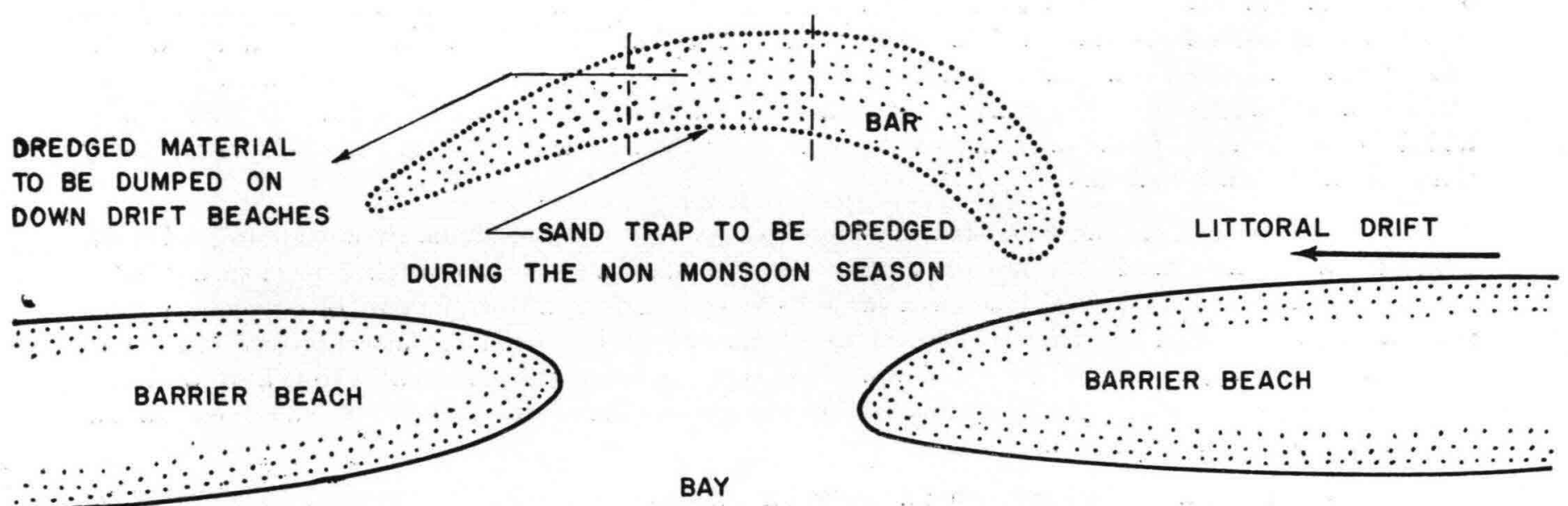

Fig. 3.22 Inlet maintenance to improve navigation by dredging.

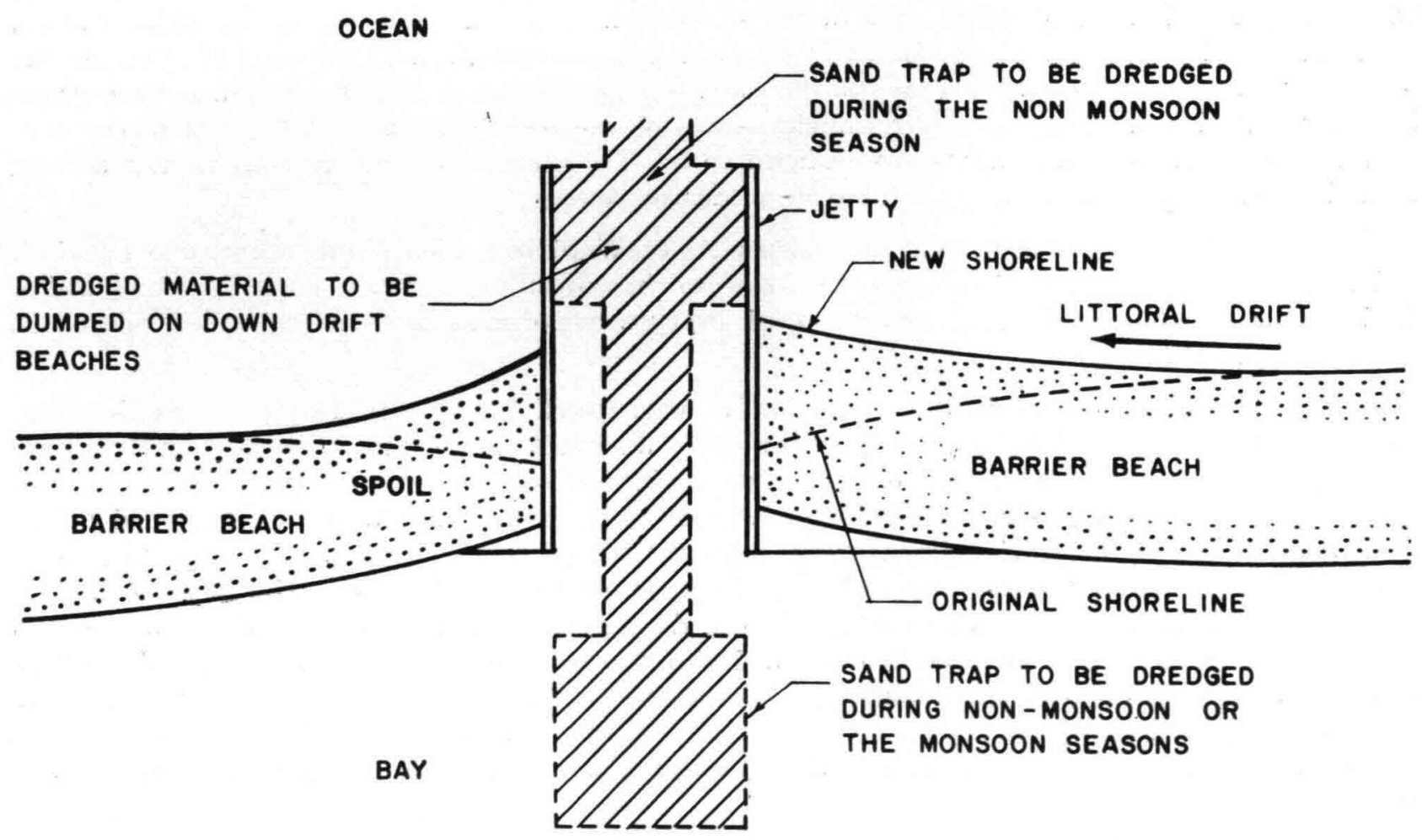

Fig. 3.23 Maintenance of inlet to improve navigation and to decrease loss of material to deeper water by ebb flows during the monsoon. 
ment of navigation as well as for the transfer of material to downdrift beaches by a hydraulic pipeline dredge where the discharge pipe is carried on pontoons or through a submerged pipcline in the case of excessive wave astion. Moderate wave action on the Indian shores makes it generally possible to operate hydraulic pipeline dredges in the open sea for at least during a major part of the non-monsoon season.

The situation in India as it stands today, is that suitable dredging equipment is not available for handling beach nourishment projects. But progress will definitely be achieved in this direction if continuous effort is made. At present, coastal structures such as groins, jetties and seawalls can still provide economical solution to coastal erosion problem in India. Efforts should, however, be made to develop coastal protective measures which interfere least with na:ure such as artificial nourishment by adopting suitable dredging and sand transfer systems. 


\section{Coastal Protection Management}

Some of the most important rules in planning of any coastal protective measure are:

(a) to look at the problem on a broader scale and to be farsighted.

(b) to plan coastal protection in full consideration with what is in the neighbourhood. In other words, coastal protection should always be handled by a large group of people, a public organization or a city council which would be able to take an overall view of the problem for the benefit of all concerned.

A well-coordinated programme with the participation of various intcrest-groups is required to consider multiple use of coastal resources. Although State governments are to administer coastal zone management programmes, both Losal and Central interests should be carefully considered along with State interests. Short-term and long-term interests have also to be considercd while planning any improvement programme in the coastal zone.

Administratively, one must distinguish between regulatory steps and steps towards improvements. Regulatorysteps are normally intended to control the construction or erection of all coastal structures to ensure that no structure will be placed or no action will be taken which will have harmful effects of an order of magnitude which will be against the interest of all concerned. Administration of such regulatory measures should necessarily be in public hands. Regulatory steps should include rules for the location of buildings on shores, particularly with respect to their minimum distance (set back) from an (eroding) dune, rules for the maintenance of dunes and coastal platforms and rules regarding the removal of beach material. Such removal should always be prohibited from all eroding shores.

The problem in India at present is connected with the enforcement of such rules, particularly in denesly populated shores wherc cvery metre of recession of the dune increases the congestion of houses, which are often saturated upto a maximum limit. In such cases, individuals or groups may become so desperate that they take actions which are not only inadequate for their own needs but dangerous to others who own property on the same beach. It is often very difficult to cope with such survival actions. The only practical way of handling such problems is by well-planned remedial measures based on both short-term and long-term considerations.

Steps on improvements include well planned coastal protective measures which are built to last long if maintained properly. As mentioned in Section 3.2.4, the situation in India favours the use of seawalls mainly of revetment type which stops the dune erosion, but it may not necessarily stop the beach erosion. Most often they do not, because erosion will continue to occur due to an imbalance in the material supply/loss system as explained in Section 3.1.1.

Administratively, action on coastal protection measures will have to come from one or more groups of people through a public agency-Central and/or State or local municipality, which should ultimately consider the action on planning and financing. Improvements, however, need not necessarily have to be directed only as counter attacks on the sea. It could well be the actions on the withdrawal of homes or 
other facilities for re-locating them further inland at public cost. The area affected by erosion may then be left as a recreational park for the public or for other usages by the public, protected and maintained at public cost.

Such steps, however, may easily infringe upon the rights of individuals and they may take a long time to resolve the dispute.

Coastal protection should not become a passive defence measure. India cannot afford to lose land to the sea in several of its populous states. It must win the battle by regaining the lost land by suitable measures and the ultimate answer to India's coastal protection problem undoubtedly lies in offshore dredging of sand for the nourishment of its starving beaches. 


\section{References}

1 Adriani, M.J. and Terwindt, J.H.J., 1974, "Sand Stabilization and Dune Building", Rijkswaterstaat Communications No.19, Directie Waterhuishounding on Waterbeweging, The Hague.

2 Bruun, P., 1962, "Sea Level Rise as a Cause of Shore Erosion," Proc. of the ASCE, Journal of Waterways and Harbours Division, No. WW1.

3. Bruun, P., 1972, "The History and Philosophy of Coastal Protection," Proc. of the 13th Coastal Engincering Conference, Vancouver, B.C., Canada.

4. Bruun, P., 1978, “The Stability of Tidal Inlets,” Elsevier Scientific Publishing Company, Amsterdam, The Netherlands.

5 Bruun, P., 1976, "Port Engineering," Chapter 6 on Littoral Drift. The Gulf Publishing Company, Houston, Texas.

6 Bruun, P. and Manohar, M., 1963, "Coastal Protection for Florida," Bulletin, Progress at the University of Florida, Vol. XVII, No. 8.

7. Bruun, P. and Purpura, J.A., 1963, "Emergency Measures to Combat Beach Erosion." Engineering Progress at the University of Florida, Vol. XVII, No. 6.

8 Bruun, P., 1964, "Withdrawn Dykes and Preservation Lines," Shore and Beach, Oct. 1964 and "Coastal Protection Procedures", Engineering Progress at the University of Florida, Vol. XVIII, No. 12.

9 Chiu, T.J., 1967, "Sand Transport by Wind," Tech. Rep. Dept. of Coastal Engineering, University of Florida.

Dean, R.J., 1974, "Compatibility of Borrow Materials for Beach Fills," Proc. of the 14th Coastal Engineering Conference, Copenhagen, Denmark.

11 Gopinathan, C.K. and Qasim, S.Z., 1974, "Mud Banks of Kerala-Their Formation and Characteristics," Indian Journal of Marine Sciences, Vol. 3, December 1974.

Hanscn, U.A., 1978, "Wave Set-up and Design Water Level," Proc. of the ASCE, Journal of Waterways Harbours and Coastal Engineering Division, No. WW2.

13 Hicks, S.D. and Shofons, Wm., 1965, "Yearly Sea Level Variations for the United States," Proc. of the ASCE, Journal of the Hydraulics Division, No. HY5.

14 Herbich, John B. and Ko, Stephen, C., 1968, "Scour of Sand Beaches in Front of SeaWall," Proc. of the 11th Coastal Engineering Conference, London, England.

15 Horikawa, K. and Shen, H. Wall, 1960, "Sand Movement by Wind Action on the Characteristics of Sand Traps", U.S. Army Corps of Engineers Beach Erosion Board, Tech. Memo., 119.

James, W.R., 1974, "Borrow Material Texture and Beach Fill Stability," Proc. of the 14th Coastal Engineering Conference, Copenhagen, Denmark.

17 James, S.R., 1975, "Techniques in Evaluating Suitability of Borrow Material for Beach Nourishment," TM-60, U.S. Army Corps of Engineers, Coastal Enginering Research Centre, Fort Belvoir, Virginia.

18 Krumbein, W.C., 1934, "Size Frequency Distribution of Sediments," Journal of Sedimentary Petrology, Vol. 4. 
19 Krumbein, W.C., 1938, "Size frequency distribution of Sediments and the normal phi curve" Journal of Sedimentary petrology, Vol. 28.

20 Krumbein, W.C., and Jamcs, S.R. 1965, "A Log Normal Size Distribution Model for Estimating Stability of Beach Fill Material”, TM-16, U.S. Army Corps of Engineers, Coastal Engineering Research Centre, Washington, D.C.

Kemp, P.H., 1960., "The Relation between Wave Action and Beach Profile Characteristics," Proc. of the 7th Coastal Engineering Conference, Hague, The Netherlands.

Kєmp, P.H. and Plinston, D.T., 1968, "Beaches Produced by Low Phase Difference", Proc. of the ASCE, Journal of Hydraulic Division, HY5.

Kramer, J., 1971, "Design Criteria for North Sea Dikes," Proc. of the ASCE, Journal of Waterways, Harbours and Coastal Engincering Division, No. WW4.

Landsberg, S. Y., 1956, "The Orientation of Dunes in Britain and Denmark in Relation to. Wind." Geol. J., Vol. 122.

Muriy, C.S., 1978, "Studies of the Physical Aspects of Shoreline Dynamics at Some Selected Places on the West Coast of India," Ph.D. Thesis, submitted to the University of Kerala.

Manohar, M. and Bruun, P., 1970, "Mechanics of Dune Growth by Sand Fences," The Dock and Harbour Authority, Vol. L 1, No. 600 .

Nordenstrom, N., 1971, "Methods for Predicting Longterm Distributions of Wave Loads and Probability Failure of Ships, Part I, Environmental Conditions and Short-term Response", Dnv-Report No. 71-2-5, Oslo.

Nayak, B.U., 1976, "On the Functional Design and Effectiveness of Groins in Coastal Protection," A Dissertation Submitted to the Graduate Division of the University of Hawaii in partial fulfillment of the requirements for the Degree of Doctor of Philosophy in Ocean Engineering.

Preinvesiment Survey of Fishing Harbours, Bangalore, 1975, "Report on Extended Investigations at Ramayapatnam," Govt. of India, Ministry of Agriculture.

Permanent International Association of Navigation Congresses, "Final Report of the International Commission for the Study of waves, 1976", Annex- to Bulletin No. 25 (Vol. III).

Phillips, C.J. and Willets, B.B., 1978, "A Review of Selected Literature on Sand Stabilization," Coasial Engincering Vol. 2, No. 2, published by the Elsevier Scientific Company, Amsterdam, The Netherlands.

Qasim, S. Z. and Gopinathan, C.K., 1971, "Silting in Navigational Channels of the Cochin Harbour Area," Journal of the Marine Biological Association of India, Vol. XIII, No. 1.

33 Rao, N.S.B. and Mazumdar, S., 1966, "A Technique for Forecasting Storm Waves," Indian Journal of Meteorology and Geophysics.

Reddy, M.P.M., Hariharan, U. and Kurian, N.P., 1977, "Coastal Erosion at Bengre, A Fishing Village near Mangalore', A Preliminary Study, Mahasagar-Bulletin of the National Institute of Oceanography, Vol. 10, Nos. 3 and 4.

Swamy, G.N., 1976, "Changes in Miramar-Caranzalem Beach, Goa, during the Pcriod of Shoaling in Aguada Bar," Mahasagar-Bulletin of the National Institute of Oceanography, Vol, 9 No. 1 \& 2.

Swamy, G.N. and Varadachari, V.V.R., 1978, "Erosion at Colva, Goa", Mahasagar-Bulletin of the National Institute of Oceanography, Vol. 11, Nos. 1 \& 2 . Pacific Ocean," Proc. of the 10th Coastal Enginecring Conference, Tokyo, Japan. 
38 Savage, R. P. and Woodhouse, W. W. Jr., 1968, "Creation and Stabilization of Coastal Barrier Dunes", Proc. of the 11th Coastal Engineering Conference, London, England.

39 Steers, J.A., 1947, “A Picture Book of the Whole Coast of England and Wales", Cambridge University Press, London.

40 The Central Water and Power Research Station at Poona has numerous reports on shore conditions in India. The reader may consult the CWPRS regarding information.

41 The Kerala Engineering Research Institute, Peechi has numerous reports on shore crosion in Kerala. The reader may consult the Institute regarding information.

42 U.S. Army Coastal Engineering Research Centre, 1966, "Shore Protection Planning and Design', Tech. Rep. No. 4.

43 U.S. Army Coastal Engineering Research Centre, 1973, "Shore Protection Manual”, Vol. I, II and III.

44 Wiegel, R.L. and Skjei, R. E., 1958, Breaking Wave Force Prediction," Proc. of the ASCE, Journal of Waterways and Harbour Division, No. WW2. 



\title{
Appendix $\AA$
}

\section{Wave Data Analysis}

\author{
N. M. Anand \\ National Institute of Oceanography, Dona Paula, Goa
}

\section{A.1 Wave statistics}

The instrumental wave data will be either in analog form or in digital form. The method suggested by Tucker (ref. 12) for the analysis of wave data which is in analog form is quitc simple, reliable and less time consuming. This method is based on the statistical theory devcloped by various authors (ref. 4) for the oscurrence of the maxima of a random function. Here the quantity $\mathrm{H}_{1}$ (the sum of highest crest and lowest trough) and $\mathrm{H}_{2}$ (the sum of second highest crest and the second lowest trough) are first determined (Fig. A.1). The statistical theory shows that these two quantities are a function of the root mean square deviation of the water surface $\sqrt{\mathrm{m}_{0}}$ and the number of waves $\mathrm{N}_{\mathrm{z}}$ (zero up-crossings) (sec Section A.3).

$$
\begin{aligned}
& \frac{\mathrm{H}_{1}}{\sqrt{m_{0}}}=2\left(2 \ln \mathrm{N}_{\mathrm{z}}\right)^{\frac{1}{2}}\left[1+0.289\left(\ln \mathrm{N}_{\mathrm{z}}\right)^{-1}-0.247\left(\ln \mathrm{N}_{\mathrm{z}}\right)^{-2}\right] \\
& \frac{\mathrm{H}_{2}}{\sqrt{m_{0}}}=2\left(2 \ln \mathrm{N}_{\mathrm{z}}\right)^{\frac{1}{2}}\left[1-0.211\left(\ln \mathrm{N}_{\mathrm{z}}\right)^{-1}-0.103\left(\ln \mathrm{N}_{\mathrm{z}}\right)^{-2}\right]
\end{aligned}
$$

Fig. A.2 shows these ratios plotted as a function of $\mathrm{N}_{\mathrm{z}}$ (ref. 12).

The significant wave height $\mathrm{H}_{\mathrm{s}}$ is computed as $\mathrm{H}_{\mathrm{s}}=4 \sqrt{ } \bar{m}_{0}$. The statistical crror involved in the estimation of $\mathrm{H}_{\mathrm{s}}$ is, however, little and the estimates are quite comparable to those of the mean of the highest one third of waves (significant wave height, $\mathrm{H}_{\mathrm{s}}$ ) in the record. Using $\mathbf{H}_{2}$, we can get quite reasonable estimates whereas from $\mathbf{H}_{\mathbf{l}}$ these would be on the conservative side. Further, the mean wave height $\mathrm{H}_{\mathrm{m}}$ can be computed from the work of Cartwright and Longuet-Higgins (ref. 4) as

$$
H_{m}=\sqrt{m_{0}}\left[\sqrt{2 \pi\left(1-\epsilon^{2}\right)}\right]
$$

where $\in$ is the spectral width parameter.

Also,

$$
\mathrm{H}_{\mathrm{m}}=\sqrt{m_{0}} \sqrt{2 \pi} \frac{\mathrm{N}_{\mathrm{z}}}{\mathrm{N}_{\mathrm{c}}}
$$$$
\text { .. } \quad \text {. }
$$

where $\mathrm{N}_{\mathrm{c}}$ is the number of crests in the given wave record.

The parameters thus evaluated from a single wave record are termed short-term wave statistics. One important assumption in short-term wave statistics is that the wave heights follow a Rayleigh's distribution (ref. 9) :

$$
\mathbf{R}(\mathrm{H})=1-\exp -\left[2\left(\mathrm{H} / \mathbf{H}_{\mathrm{s}}\right)^{2}\right]
$$$$
\cdots
$$

where $\mathrm{R}(\mathrm{H})$ is the probability of a wave height not exceeding $\mathrm{H} \cdot \mathrm{H}_{\mathrm{s}}$ is the parameter of the distribution. 


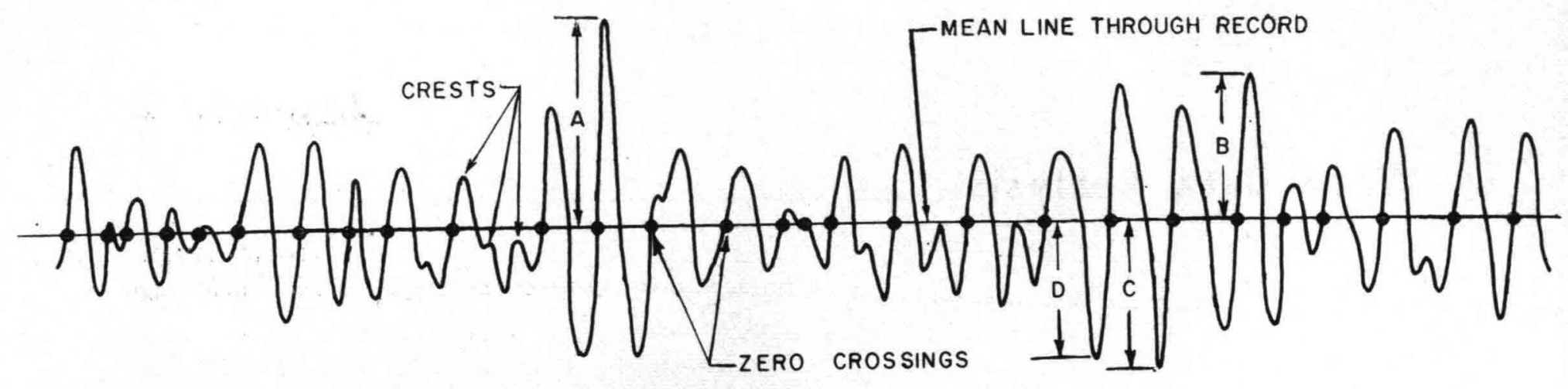

Fig. A.1 A definition sketch of a wave record.

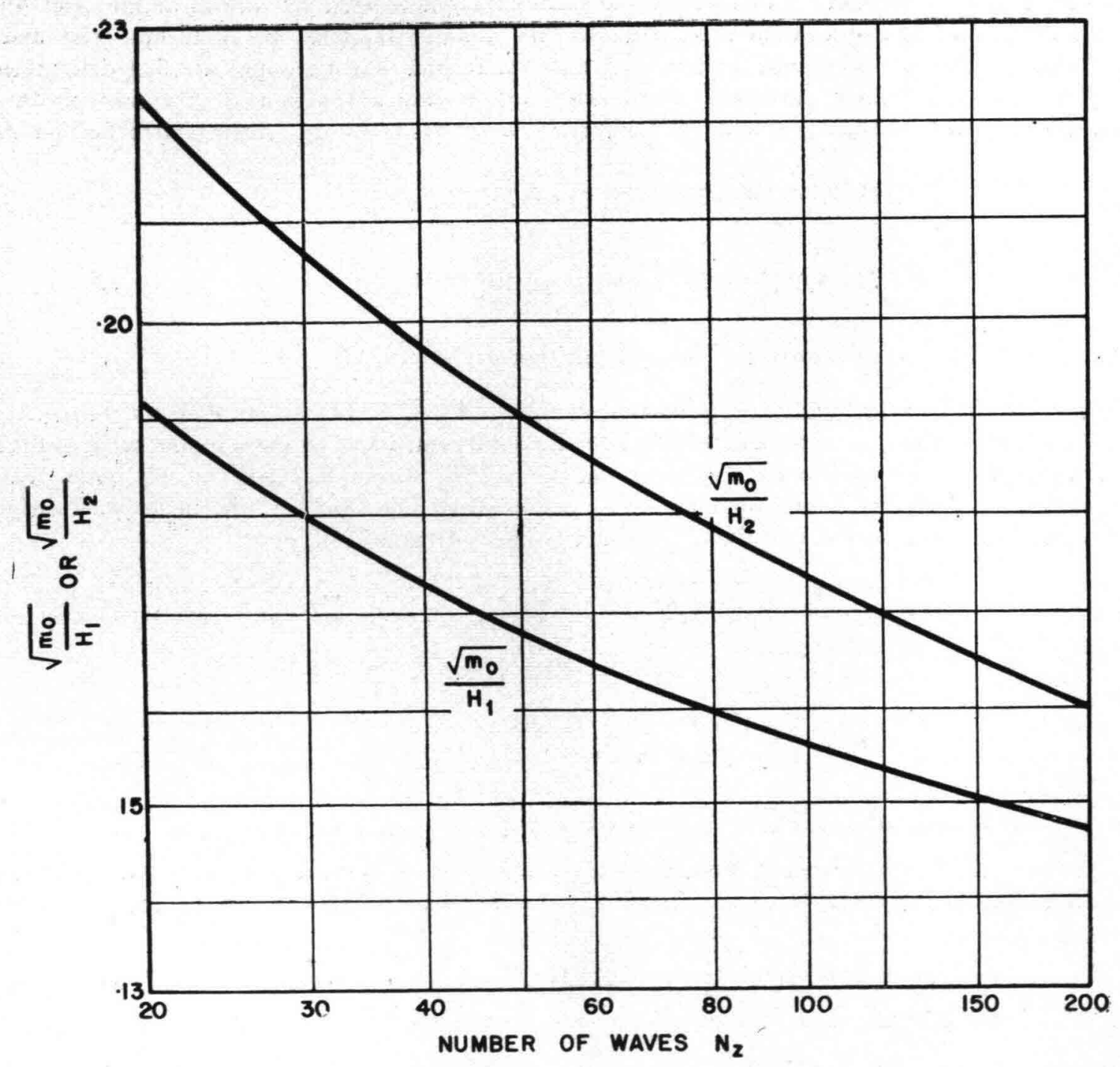

Fig. A.2 Relationship of $\sqrt{\mathrm{m}_{0}} / \mathrm{H}_{1}$ and $\sqrt{\mathrm{mo}_{\mathrm{o}}} / \mathrm{H}_{2}$ as a function of $\mathrm{N}_{\mathrm{z}}$ (ref. 12). 
An estimate of the most probable highest wave, $\mathrm{H}_{\max }$ among $\mathrm{N}$ waves is given by

$$
\mathrm{H}_{\max }=\mathrm{H}_{\mathrm{s}} \sqrt{\left(l_{\mathrm{n}} \mathrm{N}\right) / 2} \quad \ldots \quad \ldots
$$

The most probable highest among 1000 waves is then $\mathrm{H}_{\max }(1000)=1.86 \mathrm{H}_{\mathrm{s}}$. Knowing the average period of these waves, $\mathbf{N}$ can easily be converted into duration.

The extreme value distribution corresponding to the Rayleigh distribution $R_{N}\left(H_{N}\right)$ is given by

$$
\mathbf{R}_{\mathrm{N}}\left(\mathrm{H}_{\mathrm{N}}\right)=\exp \left[-\mathrm{N} \exp \left\{-2\left(\mathrm{H}_{\mathrm{N}} / \mathrm{H}_{\mathrm{S}}\right)^{2}\right\}\right] \quad \quad \cdots \quad \quad \ldots
$$

where $R_{N}\left(H_{N}\right)$ is the probability that the ultimate highest among $N$ waves shall be lower than $H_{N}$ and $H_{S}$ is a known parameter. Choosing $\mathrm{N}=1000, \mathrm{H}_{N}=15 \mathrm{~m}$ and $\mathrm{H}_{\mathrm{S}}=5 \mathrm{~m}$ gives $\mathrm{R}_{\mathrm{N}}\left(\mathrm{H}_{\mathrm{N}}\right)=0.999985$, which shows that there is a very low probability for the highest among 1000 waves to exceed $3 \mathrm{H}_{\mathrm{S}}$. If in the example, the above change of value of $H_{N}$ to $10 \mathrm{~m}$ results in $\mathrm{R}_{\mathrm{N}}\left(\mathrm{H}_{\mathrm{N}}\right)=0.715$, this would show that there is a fairly high probability (0.285) for the highest among 1000 waves to exceed $2 \mathrm{H}_{\mathrm{S}}$.

The statistics obtained from a collection of large number of wave records is called long-icrm statistics. Unlike the short-term statistics, the long-term statistics can not be deduced theorctically as the long term probability structure is a reflection of local and distant climatological features. Hence the data here are considered to be the result of random sampling from a population, the distribution of which is to be determined. Once a distribution which gives acceptably close fit to the data is found, extrapolation beyond the actual data base can be made.

In general, it is the experience of many investigators that the long-term distribution of $\mathbf{H}_{\mathrm{S}}$ follows a Weibull distribution. Weibull distribution gives a better fit especially at the upper tail which is most important in vicw of the extrapolations mentioned above. The thrce-parameter Weibull distribution is given by the equation:

$$
\mathbf{P}\left(\mathrm{H}_{\mathrm{S}}\right)=1-\exp \left[-\left\{\left(\mathrm{H}_{\mathrm{S}}-\mathrm{H}_{0}\right) /\left(\mathrm{H}_{\mathrm{C}}-\mathrm{H}_{0}\right)\right\}^{\gamma}\right]
$$

where $\mathbf{P}\left(\mathrm{H}_{\mathrm{S}}\right)$ is the probability that the wave height is less than or equal to $\mathrm{H}_{\mathrm{S}} \cdot \mathrm{H}_{0}, \mathrm{H}_{\mathrm{C}}-\mathrm{H}_{0}$ and $r$ are the location, scale and shape parameters of the distribution. Fig. A.3 gives a typical Wcibull plot of $\mathrm{H}_{\mathrm{S}}$ for the wave data collected at New Mangalorc Port.

Combining the equations A.5 and A.8, the long-term distribution of individual wave heights can be written as

$$
P(H)=\int_{0}^{\infty} R(H) p\left(H_{S}\right) d H_{S} \quad \ldots \quad \text {.. }
$$

because $\mathrm{H}_{C}$ is the parameter of $\mathrm{R}(\mathrm{H}) . \mathrm{P}(\mathrm{H})$ then gives the probability that $H$ shall not be excceded. Nordenstrom (ref. 10) showed that the equation A.9 can be approximated by a new Weibull distribution

$$
\mathbf{P}(\mathrm{H})=1-\exp \left[-\left(\mathrm{H} / \mathrm{C} \cdot \mathrm{H}_{\mathrm{C}}\right)^{\mathrm{D}}\right] \quad \ldots \quad \ldots .10
$$

$\mathrm{H}_{\mathrm{S}}$ and $r$ are known from the equation A.8. Knowing the value of $r$ the Table A.1 can be used to estimate the parameters $\mathrm{C}$ and $\mathrm{D}$ of the equation A.10.

The notion of "Return Period" is very much used in the engineering applications of probability distributions. The probability of a value equal to or exceeded by $x$ is given as $1-P(x)$. The reciprocal of this

$$
\mathrm{T}(x)=1 /[1-\mathrm{P}(x)]
$$$$
\text { .. } \quad \text {. }
$$

is called the Return Period. It is the number of observations such that, on the average, $x$ is exceeded.

If $T$ is the average time interval between the occurrences of the event being considered, the equation for the return period may be written as

$$
\mathrm{R}_{\mathrm{p}}=\frac{\mathrm{T}}{1-\mathrm{P}(x)}
$$$$
\begin{array}{ll}
\text {. } &
\end{array}
$$ 


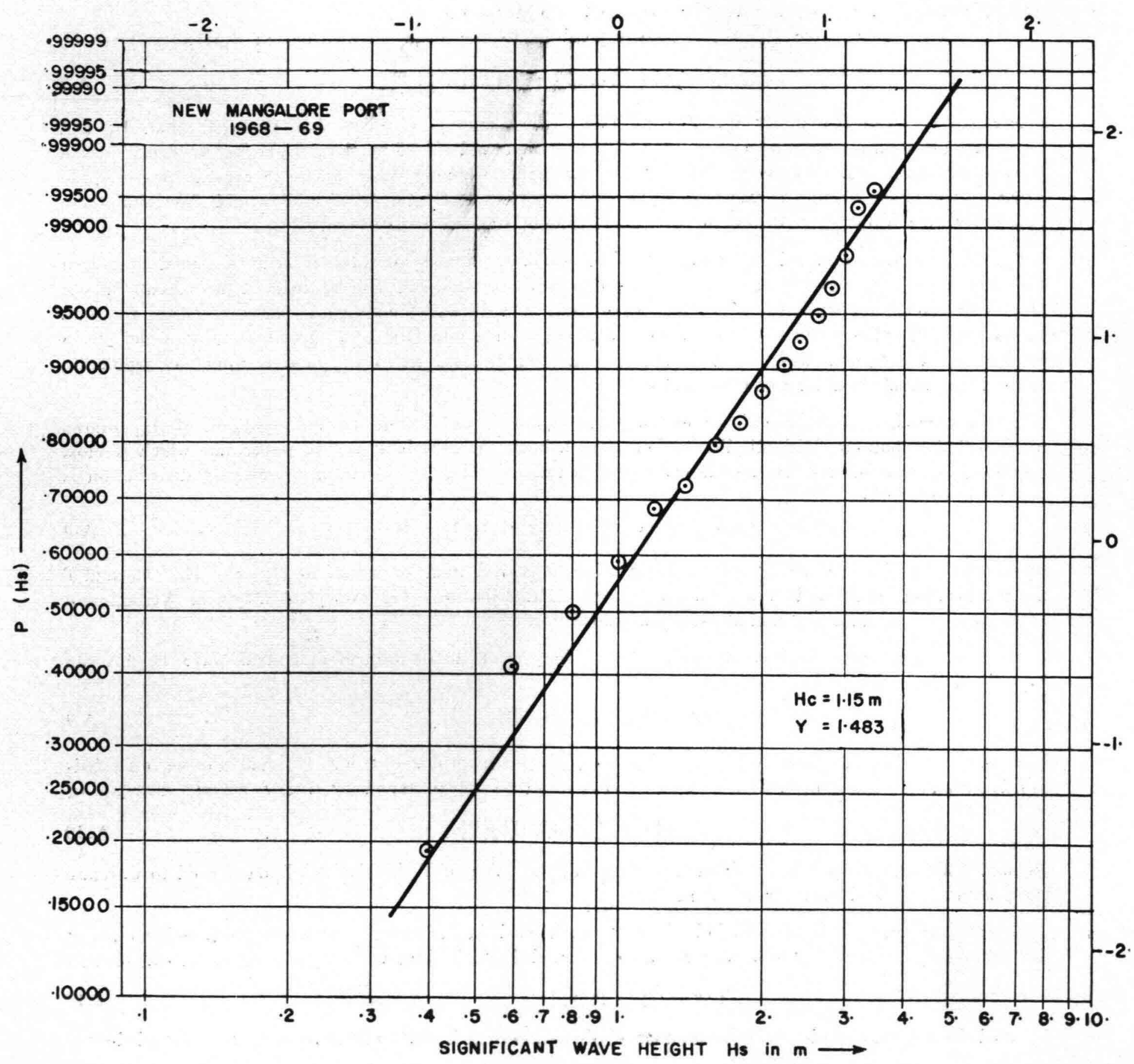

Fig. A.3 A typical Weibull plot for wave data at New Mangalore Harbour. 
Table A.1 Parameters of long-term distributions of individual wave heights (ref. 10).

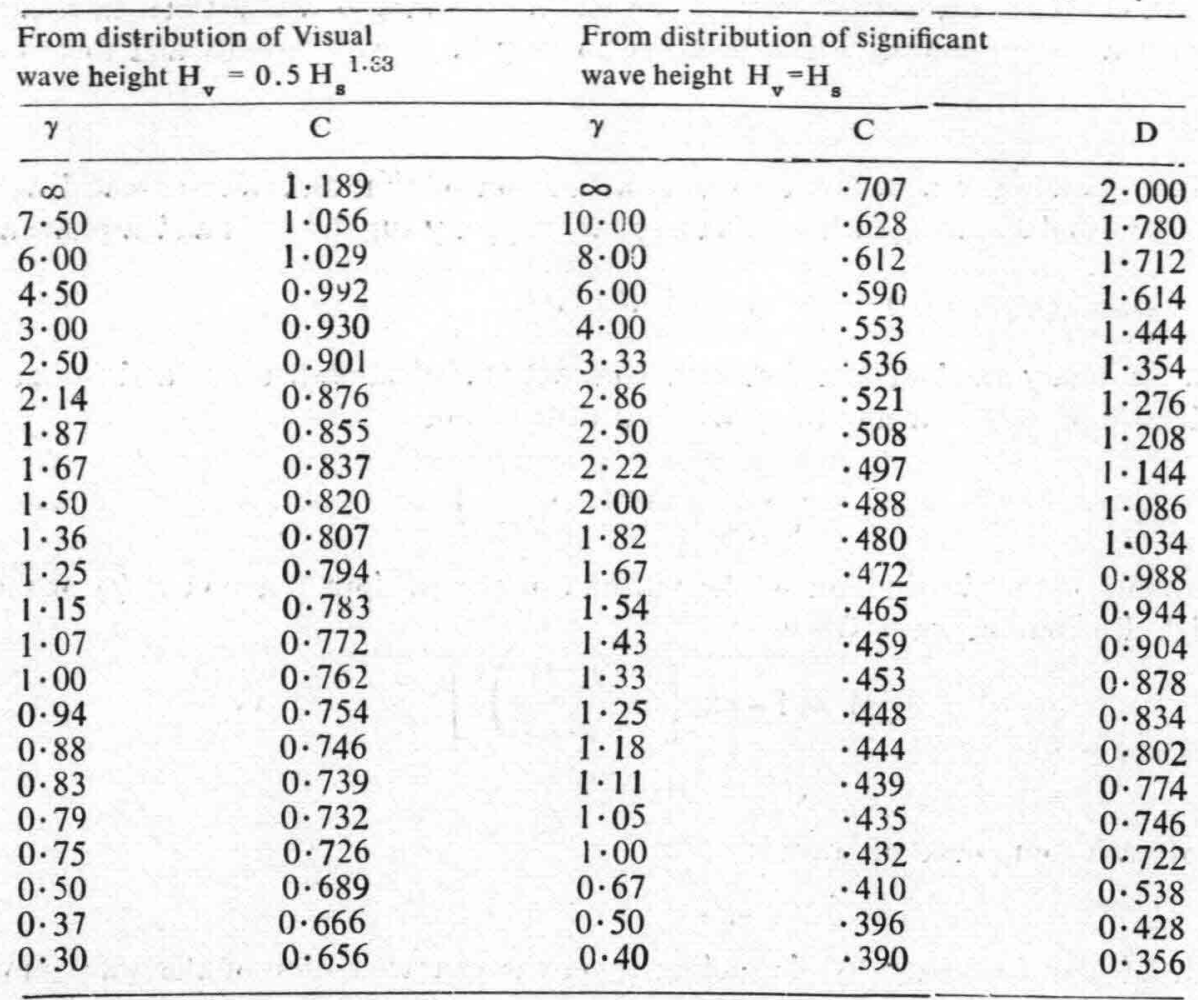

\section{A.2 Presentation of analysed data}

Presentation of the data should be of such a nature which is simple in format and yet it contains a large amount of information of value to the users. The most common methods of presentation of the wave data are discussed below.

It is found in practice that the wave height is best presented as percentage exceedance, rather than percentage occurrence for a unit wave-height interval. The exccedance graphs present the information in a form which allows the user to deduce at a glance the percentage of time in which the wave conditions would exceed any particular height.

Scatter diagrams give information about the joint distribution of the wave height and period which are of ten important. The inclusion of lines of consiant wave steepness helps to give an indication of severity of the conditions and contouring gives a quick indication of the frequency of occurrence of specific conditions. Information on the width of the spectrum is sometimes valuable and can best be presented as a percentage occurrence over the period. For constructional and operational purposes it is often important to know how long a given condition will last. The cumulative persistence diagram is very useful for this purpose. From this it is possible to decide at a glance how often and for how long wave conditions of certain specific heights and greater than these are likely to persist in one year (or season). This is of importance in planning the port-operation constructions and maintenance programmes. The persistence diagram is prepared by plotting a graph of the significant wave height throughout the year. For each height level, the duration of every occasion when conditions are at or above that level is listed, and the information is again presented as an exceedance.

Life time wave or the most severe wave condition, which might oscur during the life of a structure or over a long period of time say 25,50 or 100 years is often required. By experience it is found that at least 10 years data are required for this type of prediction by which one would have taken into account 
the annual and seasonal variations also. Extreme value analysis, taking annual extremes, will be probably a better method since the return period in this case has a relevance to actual time intervals between geophysical events such as severe storms which give rise to very large were heights and forces.

\section{A.3 Wave spectra}

Sea surface elevation $x$ at a given point is a function of time and can be treated as the sum of an infinite number of sinusoidal waves, each with an angular frequency $\omega_{i}=2 \pi / T_{i}$ and a phase angle $\phi_{i}, i \cdot e$,

$$
x(t)=\sum_{\mathrm{i}=1}^{\mathrm{N}} a_{\mathrm{i}} \cos \left(\omega_{\mathrm{i}} t+\phi_{\mathrm{i}}\right) \quad \ldots \quad \ldots
$$

$x(t)$ is a stationary random function with constant statistical parameters and it can be shown that the probability density of $x(t)$ is a normal (Gaussian) distribution

$$
p(x)=\frac{1}{\sqrt{2 m_{0}}} \exp \left(-\frac{x^{2}}{2 m_{0}}\right) \quad \ldots \quad \quad \ldots
$$

Consideration of the distribution of the maxima of the random function $x(t)$ or the wave heights leads to a Rayleigh distribution when $\epsilon=0$

$$
\mathrm{P}(\mathrm{H})=1-\exp \left[-\left(\frac{\mathrm{H}}{2 \sqrt{\mathrm{E}}}\right)^{2}\right] \quad \cdots \quad \quad \ldots
$$

where

$$
\sqrt{\mathrm{E}}=\mathrm{H}_{\mathrm{S}} / \sqrt{8}
$$

Energy of each component of wave is

$$
e_{\mathrm{i}}=\frac{1}{2} \mathrm{p} g a_{\mathrm{i}}{ }^{2},
$$

which varies with angular frequency ' $\omega$ ' depending upon the characteristics of the wave motion.

The energy density $S(\omega)$ of thes pectrum is the energy contained in the frequency band $\left(\omega, \omega+d_{\omega}\right)$.

$$
\mathrm{S}(\omega) \mathrm{d} \omega=\frac{1}{2} \sum_{\omega}^{\omega+\mathrm{d} \omega} a_{\mathrm{i}}^{2}
$$

The total energy contained in the whole spectrum is

$$
m_{0}=\int_{0}^{\infty} S(\omega) d \omega
$$

$m_{0}$ is the zero order moment of the wave spectrum or the area of the wave spectrum diagram and also the mean square deviation of the water surface $x(t)$.

The $n$th order spectral moment is defined as

$$
m_{\mathrm{n}}=\int_{0}^{\infty} \omega^{\mathrm{n}} \mathrm{S}(\omega) \mathrm{d} \omega
$$

From the statistical theory based on the works of Cartwright and Longuet-Higgins (ref. 4) the wave parameters can be determined from the wave spectra by the following equations

$$
\begin{array}{lll}
\mathrm{H}_{\mathrm{s}}=4 \sqrt{m_{0}} & \cdots & \cdots \\
\mathrm{T}_{\mathrm{z}}=2 \pi \sqrt{m_{\mathrm{O}} / m_{2}} & \cdots & . . \\
\mathrm{T}_{\mathrm{c}}=2 \pi \sqrt{m_{2} / m_{4}} & \cdots & . \\
\epsilon=\sqrt{1-\left(m_{2}^{2} / m_{0} m_{4}\right)} & \cdots & . \\
\mathrm{S}_{2}=\frac{2}{\pi g} \cdot \frac{m_{2}}{\sqrt{m_{0}}} & \cdots & .
\end{array}
$$

where $S_{2}$ is the wave steepness obtained from the wave parameters $H_{s}$ and $T_{z}$. 


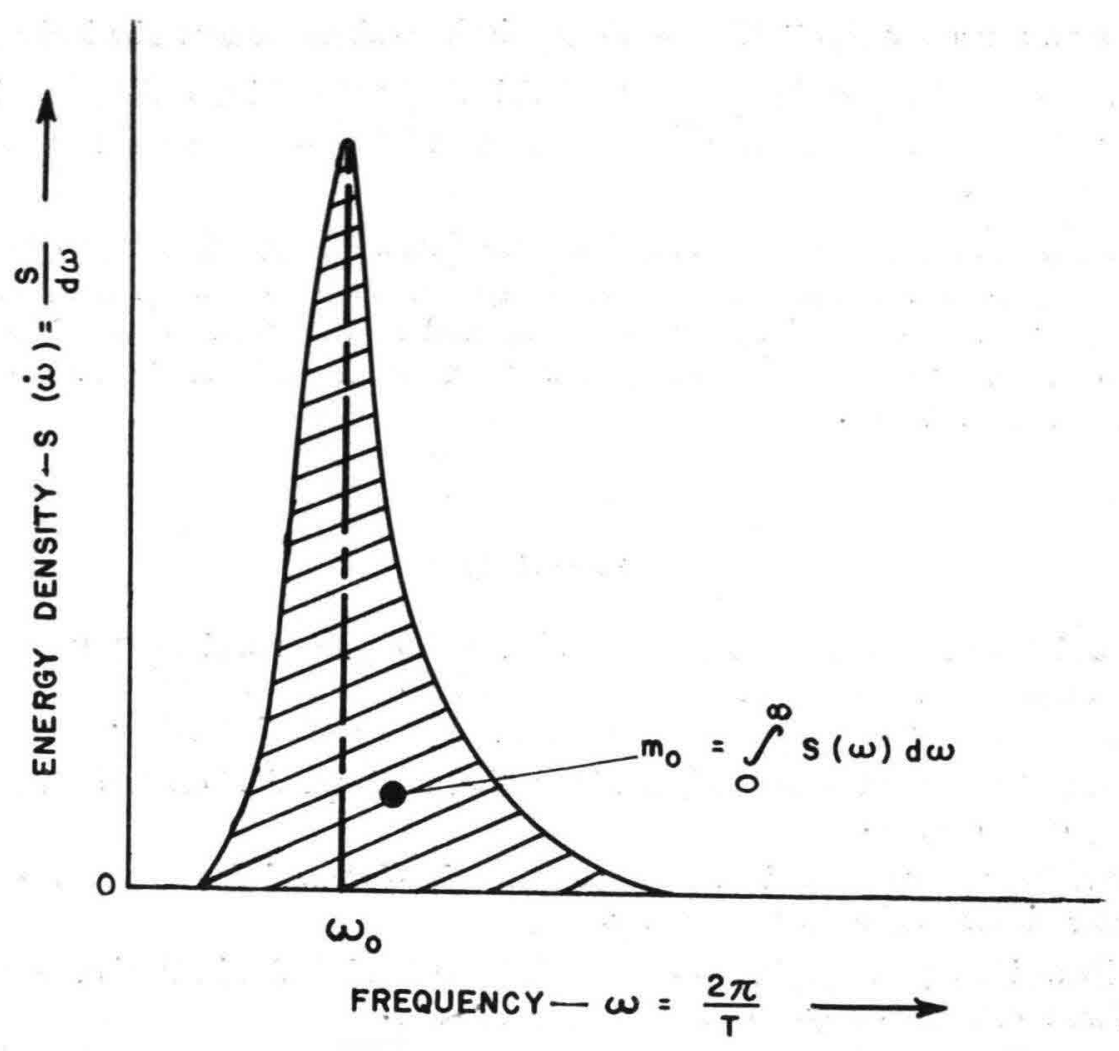

Fig. A.4 Wave energy density spectrum (ref. 6).

Fig. A.4 shows a typical diagram of the characteristics of the wave energy density spectrum.

The shape of the wave spectrum is an important part as estimates of many wave parameters can be derived directly from the moments of the spectrum as explained above.

Various shapes based on empirical data have been proposed, e.g., Pierson and Moskowitz (ref.11) and Hasselman et al. (ref.7). These spectral shapes were the results of fits between analytical expiession and empirical spectra assuming similarity theory by Kitaigorodskii (ref.8) to be valid.

Using $H_{S}$ and $T_{z}$ as parameters, the $P-M$ spectrum is given by

$$
S(\omega)=\frac{H_{s}^{2}}{4 \pi}\left(\frac{2 \pi}{T_{z}}\right)^{4} \omega^{-5} \exp \left[-\left(\frac{2 \pi}{T_{z}}\right)^{4} \frac{\omega^{-4}}{\pi}\right] \quad \cdots
$$

The period of the spectral peak, $T_{p}$ and $T_{z}$ are related in the following way

$$
\mathrm{T}_{\mathrm{P}}=(5 \pi / 4)^{\frac{1}{4}} \mathbf{T}_{\mathrm{z}}=1.408 \mathrm{~T}_{\mathrm{z}}
$$

The other spectrum mentioned above is the result of Joint North Sea Wave Projec $\imath$ (JONSWAP). The shape of this spectrum is given by

$$
\begin{aligned}
& \mathrm{S}(\mathrm{f})=\alpha g^{2}(2 \pi)^{-4} \exp \left\{-\frac{\delta}{4}\left(f \mid f_{\mathrm{p}}\right)^{-4}\right\}, \exp \frac{-\left(f-f_{\mathrm{p}}\right)^{2}}{2 \sigma^{2} f_{\mathrm{p}}^{2}} \\
& \sigma=\left\{\begin{array}{l}
\sigma \mathrm{a}=0.07 \text { for } f \leqslant J_{\mathrm{p}} \\
\sigma \mathrm{b}=0.09 \text { for } f>f_{\mathrm{p}}
\end{array}\right.
\end{aligned}
$$


with the help of five parameters $\alpha, f_{\mathrm{p}}, \gamma, \sigma_{\mathrm{a}}$ and $\sigma_{\mathrm{b}} . f_{\mathrm{p}}$ is the peak frequency and $\alpha$ is the Phillips constant. $\alpha, r, \sigma_{a}$ and $\sigma_{b}$ relate to the shape of the spectrum, $\sigma_{a}$ and $\sigma_{b}$ give the width of the left and right side of the spectrum respectively where as $r$ is the ratio of the maximum JONSWAP spectrum energy to that of the corresponding $\mathrm{P}-\mathrm{M}$ spectrum.

Methods for calculations of the spectra based on wave data are described in text books. There are two approaches to the problem. One is the Fourier Transform of the auto-correlation function of the digitized data and the other is by Fast Fourier Transform of the digitizcd data. The auto-correlation estimates in the latter case can be obtained by the inverse Fourier Transform of the spectral estimates. This procedure reduces the computer time and cost.

\section{REFERENCES}

1. Anand, N. M. and Houmb, O. G., 1978, "Estimation of Long-term and Extreme Value Distributions of Wave Parameters in Norwegian Waters", Report No. 11, Sept. 1978, Dept. of Port and Ocean Engineering, Universiíy of Trondheim, Norwegian Institute of Technology, Trondheim. Norway.

2. Battjes, J. A., 1970, "Long-term Wave Height Distribution at Seven Stations Around the British Isles", Internal Report No. A 44.

3. Bruun, P., Houmb O. G., Rye, H. and Saetre, H. J., "Wind, Wave and Current Data for Offshore Operations", Inter Ocean, düsseldorf, Germany.

4. Cartwright, D. E. and Longuet-Higgins, M. S., 1956, "The Statistical Distribution of the Maxima of a Random Function", Proc. Roy. Soc. London, A, Vol. 237.

5. Draper, L., 1966, "The Analysis and Presentation of Wave Data: A Plea for Uniformity", Proceedings of 10th Conf. on Coastal Engineering, Tokyo, Japan, Vol. 1.

6. Gourlay, M. R., 1973, "Wave Climate at Moffat Beach", Bulletin No. 16, Dept. of Civil Engineering, University of Queensland.

7. Hasselmann, K., et al., 1973, "Measurements of Wind-Wave Growth and Swell Decay during the Joint North Sca Wave project (JONSWAP)", Deutsche Hydrographische Zeitschrift, Reihe A ( $\left.8^{\circ}\right), \mathrm{Nr} \cdot 12$.

8. Kitaigorodskii, S. A., 1962, "Applications of the Theory of Similarity to the Analysis of Wind Generated Wave Motion as a Stochastic", Proc. Bull. Acad. Sci, USSR Geophys., Ser. No. 1, 73.

9. Longuet-Higgins, M. S., 1952, "On the Statistical Distribution of the Heights of Sea Waves", Jour- of Mar Res., Vol. XI, No. 3.

10. Nordenstrom, N., 1971, "Methods for Predicting Long-term Distributions of Wave Loads and Probability of Failure of Ships, Part I: Environmental Conditions and Short-term Response", DnV Rep. No. 71-2-5, Oslo.

11. Pierseon, W. J. and Moskowitz, L., 1964, "A Proposed Spectral from for Fully Developed Wind Seas Based on the Similarity Theory of S. A. Kitaigorodskii", Jour. Geophys. Res., Vol. 69, No 24 .

12. Tucker, M. J., 1963, “Analysis of Records of Sea Waves”, Proc. I. C. E, Vol. 26. 


\title{
Design of Sloping Rock Structures, Uprush Elevation and Rock Size
}

Appendix B

\author{
P. BRUUN \\ The Norwegian Institute of Technology, Trondheim, Norway
}

\section{B.1 Determination of uprush elevation}

The vertical height above the still water level to which water from an incident wave will rush up the face of the structure determines the required crest elevation of the structure, if wave overtopping can not be permitted.

The elevation of uprush on a shore structure depends upon the bottom and beach geometry, structural geometry and characteristics like slopes, friction and permeability and finally wave characteristics. A considerable literature on the subject exists. Specific information is found in refs. $1,2,3,7,8,12$ and 16 .

Uprun or uprush computation will determine the amount of wave overtopping over the crest of the structure. In this respect one usually distinguishes between overrun by 'green water' (solid-not split water) oversplash, that means separated water particles and spray which is water disintegrated to small particles down to dust size. The allowable amount of overtopping water depends upon the function of the structure. If it is a harbour breakwater, a considerable amount of overiopping may be accepted until it becomes so heavy that it generates considerable wave action inside the harbour and becomes a nuisance to navigation, berthing and mooring.

For coastal protective structures, design criteria are different. Depending upon the character of the land development behind the structure, particularly the clevation of the backland, one may expect some overtopping during major storms but not causing any serious flooding or damage to existing facilities and property. This will be the case with a major part of all coastal protective seawalls and revetments. The criteria may therefore, be set as 'non-excessive overtopping occurring only a few times a year' or 'heavier overtopping only accepted once in X years' where X could be any value between 2 and 10 years.

If the area behind the seawall (backland) is lower than the crest of the seawall, continued overwash over a few hours may cause severe flooding of the backland. In such a case, only little and very infrequent overtopping should be tolerated. This is the situation at many places on the Indian coasts where seawalls without backfills were erected at places where all dunes had been washed away.

Determination of the frequency and magnitude of overtopping requires detailed knowledge about the wave action which occurs at the site in question. A statistics of wave astion may be determined as mentioned in Section 2.3. The wave action which attacks the structure depends upon the location of the structure on the beach or bottom profile, that is, the depth at the toe of the structure during storm situations (ref.6). Next, wave uprush and the stability of the structure depends upon the wave and structural characteristics. Information on the results of tests on wave uprush may be found in numerous publications including refs. $2,3,11,12,13,14,15$ and 16 . parameters

Wave uprush $\mathrm{R}$ on a structure depend $\mathrm{s}$ upon the depth at the toe and the following dimensionless 


$$
\begin{aligned}
& \mathrm{H}_{0}{ }^{\prime} / g \mathrm{~T}^{2}=\frac{\text { Deep water wave height }}{\text { Acceleration due to gravity } \times \text { Wave period squared }} \\
& d / \mathrm{L}=\frac{\text { Depth at toe of structure }}{\text { Wave length }} \\
& d / \mathrm{H}^{\prime}=\frac{\text { Depth at toe of structure }}{\text { Deep water wave height }} \\
& \mathrm{H}_{0}{ }^{\prime} \text { is the unrefracted deep water wave height. }
\end{aligned}
$$

Figs. B.1 to B.8 (ref. 15) give the relative runup $\mathrm{R} / \mathrm{H}_{0}{ }^{\prime}$ as a function of structural slope, and deep water wavc steepness parameter $\mathrm{H}_{0}{ }^{\prime} / \mathrm{T}^{2}$. The results given in Figs. B.1 to B.8, based on small scale model tcsis, are required to be corrected for scale effects due to the inability to scale roughness effects in model tests. Runup values from Figs. B.1. to B.8 can be adjusted for scale effects by using

For a stepped 1 in 1.5 slope, Fig. B.11 gives value of relative runup for various ratios of $d_{\mathrm{s}} / \mathrm{H}_{0}{ }^{\prime}$ and $\mathrm{H}_{0}{ }^{\prime} / g \mathrm{~T}^{2}$ where $d_{\mathrm{s}}$ is depth at the toe of the structure. The structure, in all cases, is fronted by a 1 in 10 slope. The same is true for a rip-rap covered slope for which Fig. B.12 gives the data for slope 1 in 1.5 and for different $d_{\mathrm{s}} / \mathrm{H}_{0}{ }^{\prime}$ and $\mathrm{H}_{0}{ }^{\prime} / g \mathrm{~T}^{2}$ ratios.

A scientifically better justified approach is the use of the $\xi=\tan \alpha / \sqrt{\mathrm{H} / \mathrm{L}_{0}}$ factor which is thoroughly explaincd in 1efs. $3,7,8$ and 11 . Reference 11. gives the International standards for computation of wave runups and determination of stability of rubble mound structures. Figs. B.13 and B.14 are examples of how this may be done referring to a slope of 1 in 1.5 of smooth and rough quarry stone (e.g. laterite) breakwaters and $d / \mathrm{H}=\frac{\text { Depth at toe of structure }}{\text { Wave height at toe of structure }}$ ratios of 2.6 to 3.3 . Run-up $\left(R_{u}\right)$ and Rundown $\left(R_{d}\right)$ are given in dimensionless form. Data were derived from model test
results, and therefore, some scale effects are bound to oscur.

In nature, waves are not regular but occur in certain 'spectra'. The older the waves, the more regular they become gradually transforming to swells. The steepness of the waves is very important for uprush and stability (refs. 5, 8 and 9): As explained in ref. 16, one may then assume that the distribution of the runup of an irregular wave train can be calculated by assigning to ecah individual wave the runup value of a periodic wave train of corresponding height and period. Further a so-called Rayleigh distribution obtained assuming that the individua! wave runup elevations follow a so-called Rayleigh distribution. The runup distribution is given by

$$
\mathbf{R}_{\mathrm{p}} / \mathbf{R}_{\mathrm{s}}=0.707(\ln 1 / p)^{\frac{1}{2}}
$$

where $R_{s}$ is the runup for the significant wave height and $R_{p}$ is the runup assosiated with a particular probability of exceedance $p$. For example, let us assume that there is a need to know the one per cent runup, i.e., the elevation exceeded by one per cent of all the runups. One then has, lity of exceedance $p$.

This is for smooth slopes. If the structure is not smooth but consists of rock revetment, e.g., quarry stones as in most Indian revetments, a reduction factor to runup $r=\frac{\mathbf{R}_{\mathbf{s}} \text { rough }}{\mathbf{R}_{\mathbf{s}} \text { smooth }}$ may be applied as mentioned above (see Table B.1). It may be seen that $r=0.75$ to 0.80 for quarry stones, 0.60 to 0.65 for round stones and 0.50 to 0.60 for pell-mell rocks (just dumped at random and not as laterite and $r=0.6$ for pell-mell (rip-rap) India, it would be safe to assume $r=0.8$ for set stones 
Table B.1 Values of $r$ for various slope charasteristics (ref. 16).

\begin{tabular}{|c|c|c|c|c|}
\hline \multicolumn{2}{|l|}{ Slope characteristics } & \multicolumn{3}{|c|}{$r$} \\
\hline Smooth, less impermeable & $\cdots$ & $\cdots$ & 1.0 & \\
\hline Concrete blocks without offsets & $\cdots$ & $\cdots$ & 0.90 & \\
\hline Basalt blocks & $\cdots$ & $\cdots$ & 0.85 & to 0.90 \\
\hline Grass & $\cdots$ & $\cdots$ & 0.85 & to 0.90 \\
\hline One layer of rubble (impermeabl & ation ) & $\cdots$ & 0.80 & \\
\hline Set stones & $\cdots$ & $\cdots$ & 0.75 & to 0.80 \\
\hline Round stones & $\cdots$ & $\cdots$ & 0.60 & to 0.65 \\
\hline Rubble & $\cdots$ & $\cdots$ & 0.50 & to 0.60 \\
\hline Broken rubble & $\cdots$ & $\cdots$ & 0.50 & to 0.55 \\
\hline Two or more layers of rubble & $\cdots$ & $\ldots$ & 0.50 & \\
\hline Tetrapods & $\cdots$ & $\cdots$ & 0.50 & \\
\hline
\end{tabular}

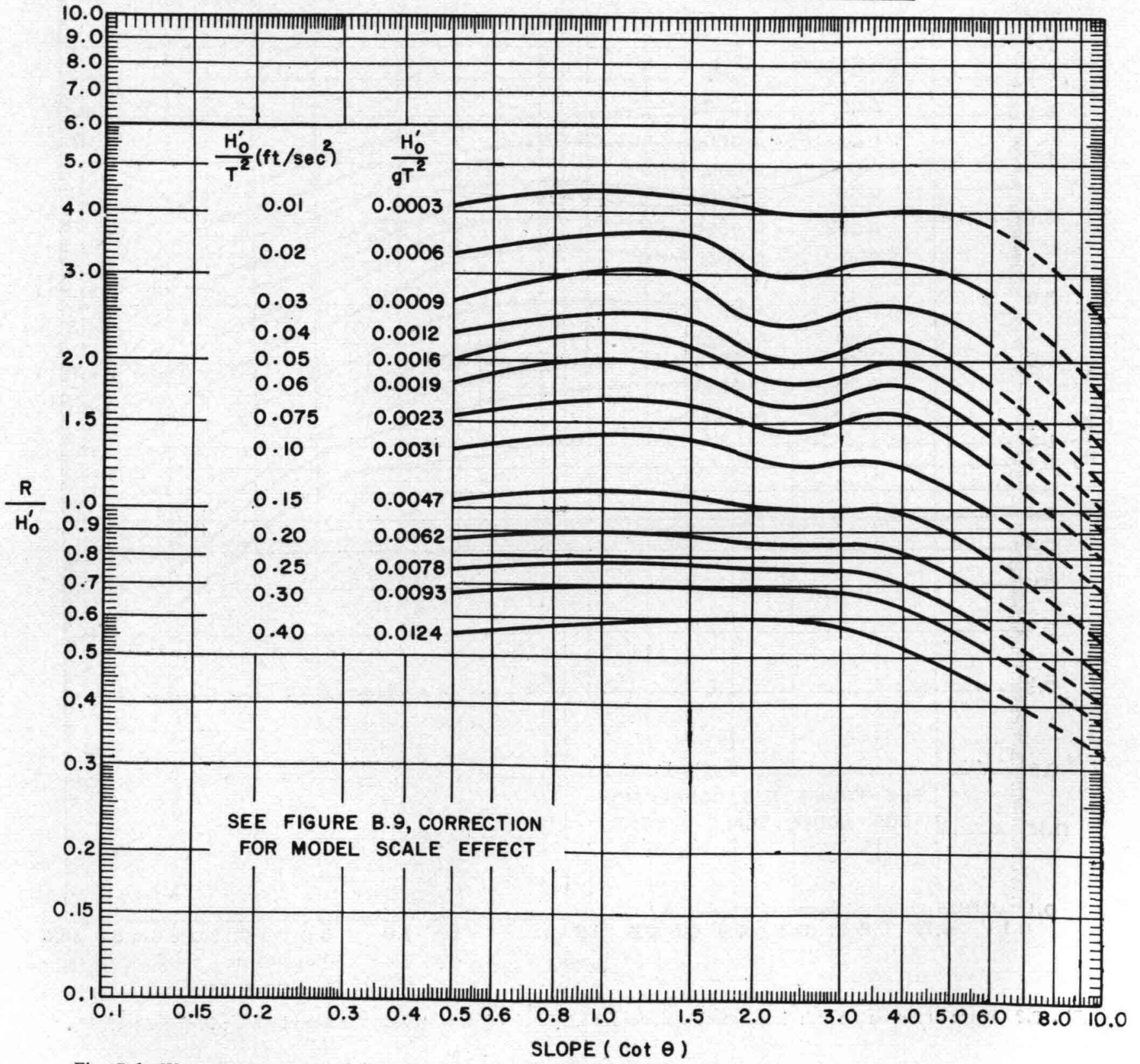

Fig. B.1 Wave runup on smooth impermeable slopes for $d_{\mathrm{s}} / \mathrm{H}_{0}{ }^{\prime}=0$ with structure fronted by a $1: 10$ slope (ref. 15). 
B.2 Determination of rock size for a coastal protection structure

Reference 4 gives a review on common reasons for damage or breakdown of rubble mound breakwaters. This section explains how armour rock size should be defermined to ensure stability. Due to the great confusion causcd by mutually contradictory empirical design formulae resulting in inadequate designs, sometimes unnecessarily overdesigned and sometimes underdesigned, the Permanent International Association of Navigation Congresses (PIANC) took the matter up by its "Waves Committee" and this resulted in a report on more rational design procedures (ref. 11). Briefly the report recommends that the design be based on $\xi=\tan \alpha / \sqrt{\mathrm{H} / \mathrm{L}_{0}}$ parameter.

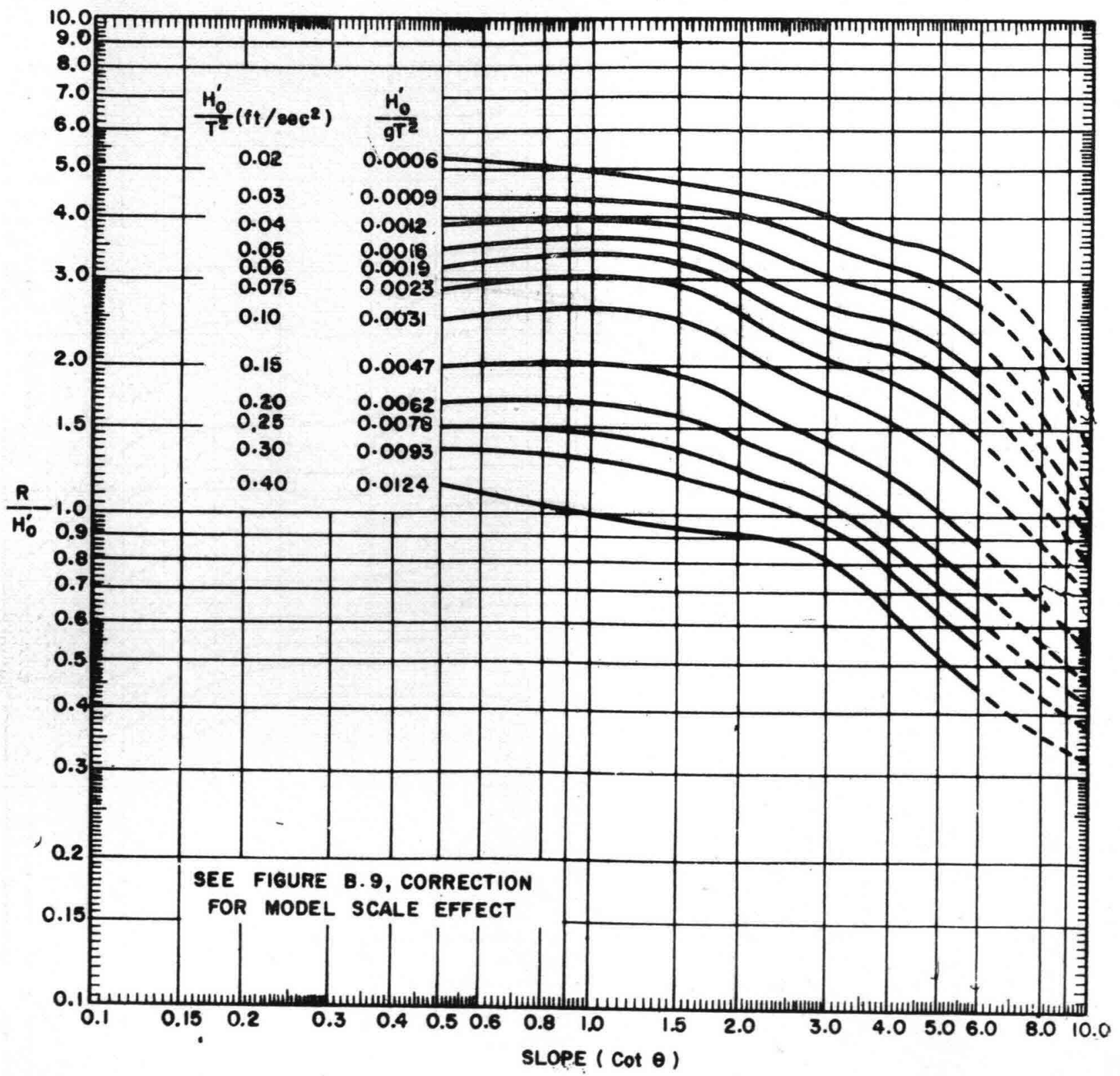

Fig. B.2 Wave runup on smooth impermeable slopes for $d / \mathrm{H}_{0^{\prime}}=0.45$ with structure fronted by a $1: 10$ slope (ref. 15). 


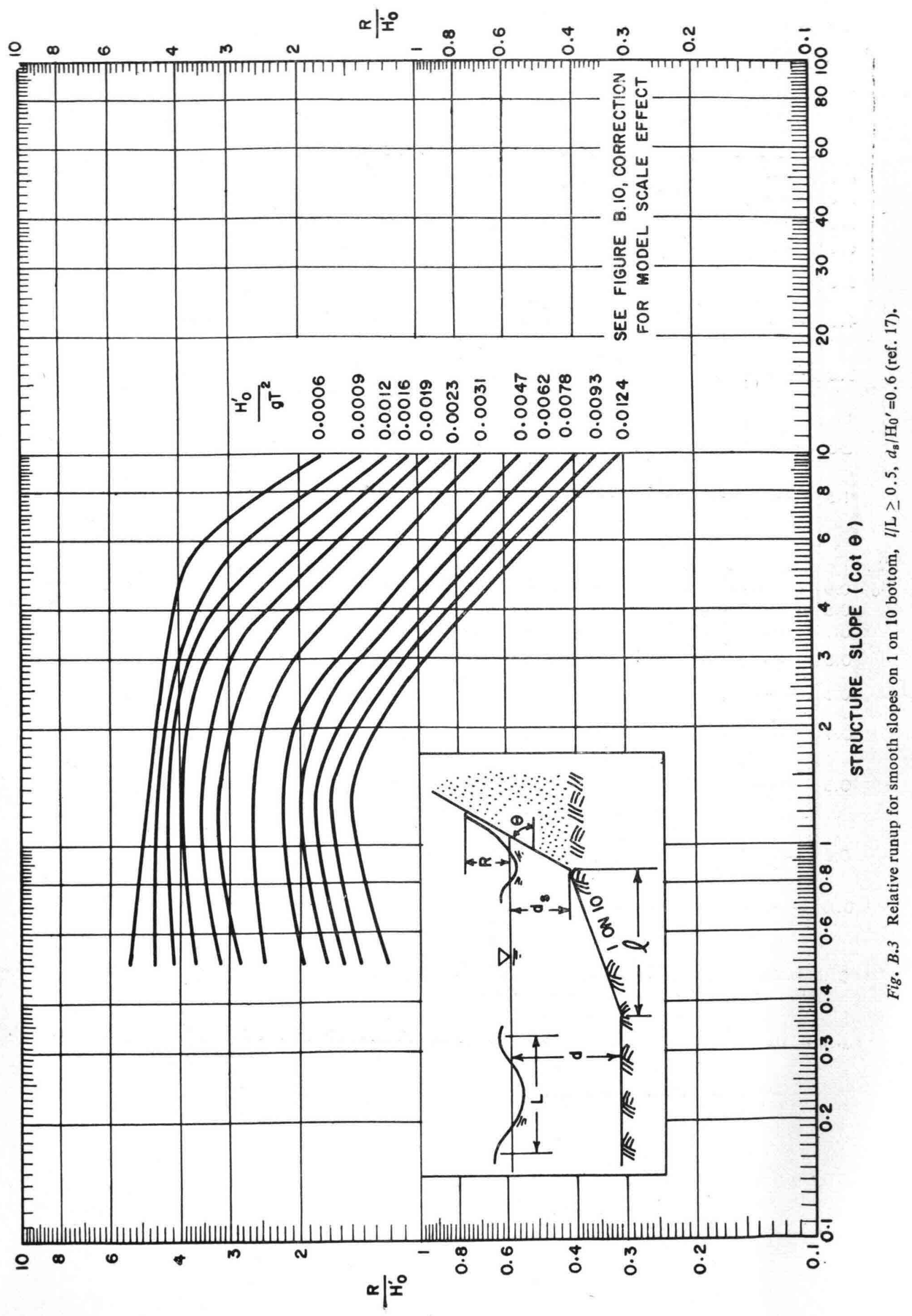




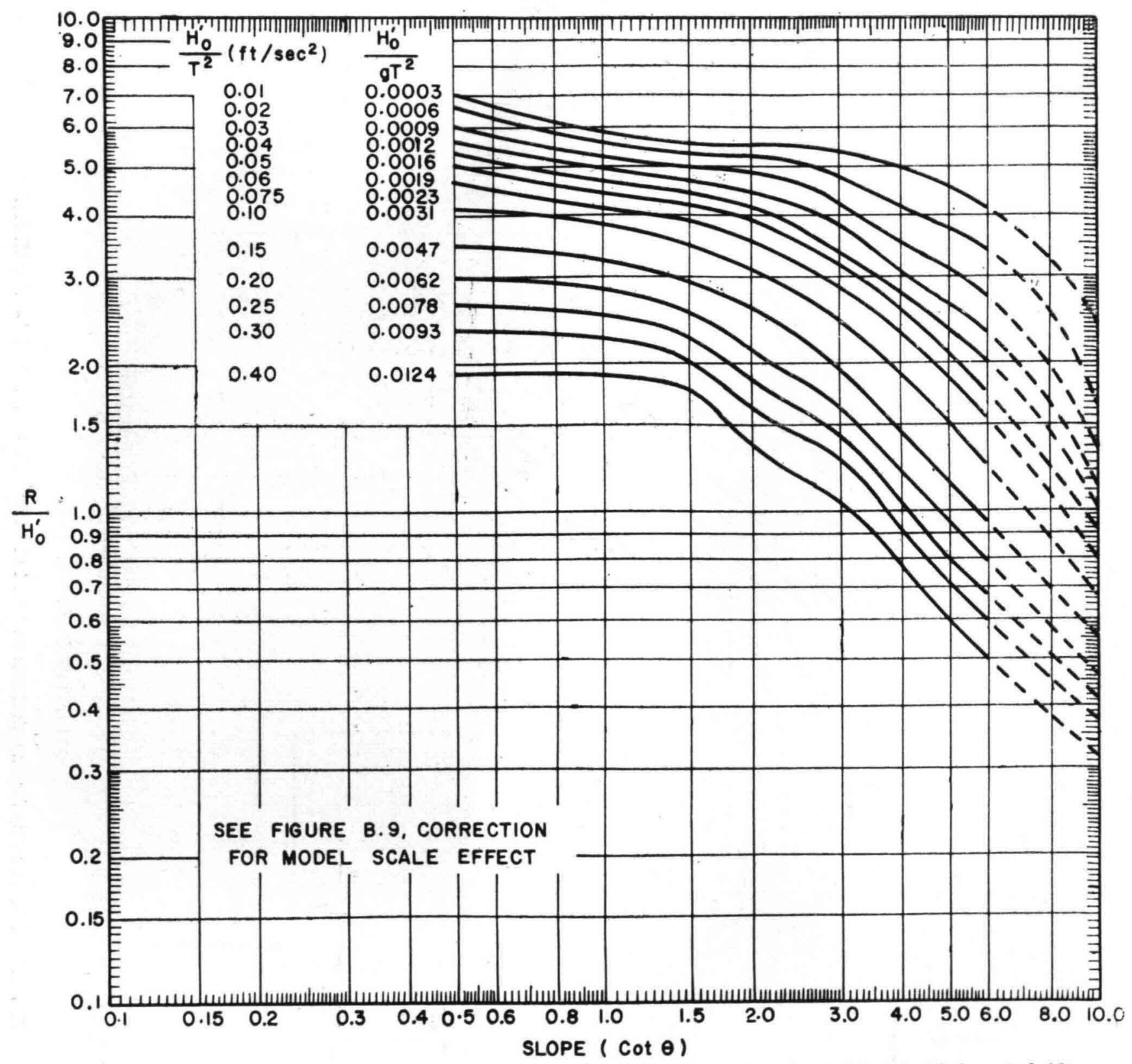

Fig. B.4 Wave runup on smooth impermeable slopes for $d_{\mathrm{B}} / \mathrm{H}_{0}^{\prime}=0.80$ with structure fronted by a $1: 10$ slope (ref. 15). 


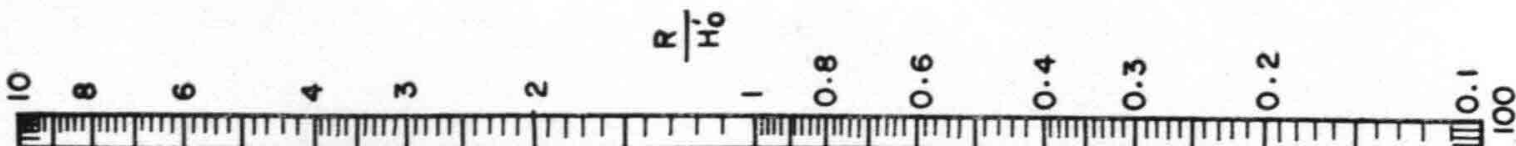

言

展

ํㅣㄴ

镸

E

E

E

E

E

- HHOHH

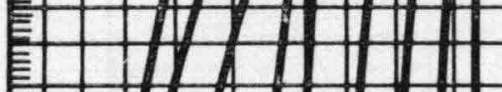

E

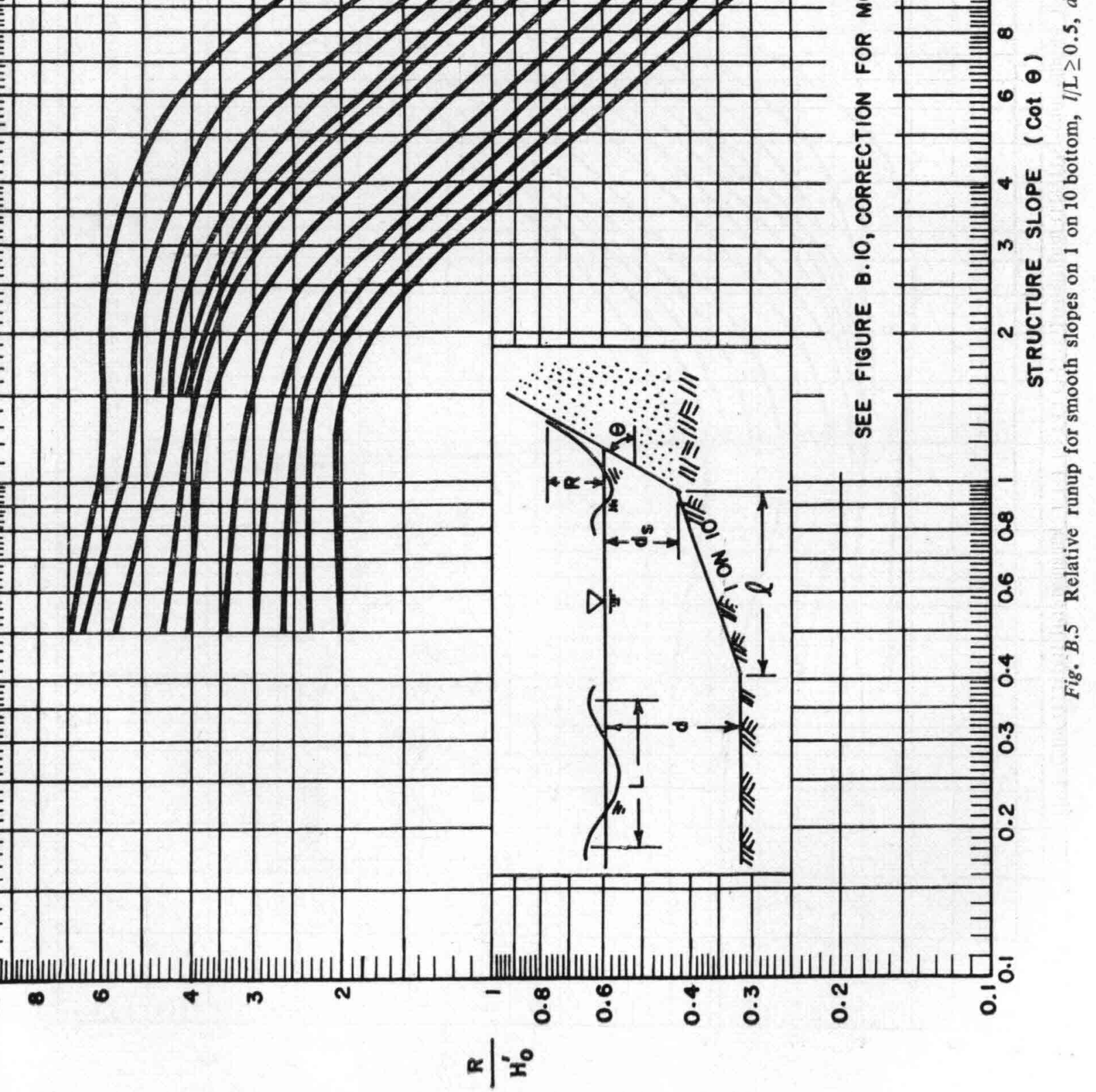




$$
\propto \mid \stackrel{\circ}{x}
$$

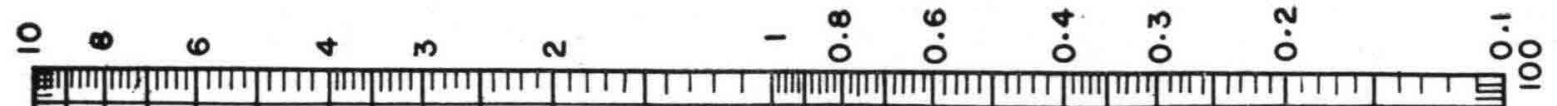

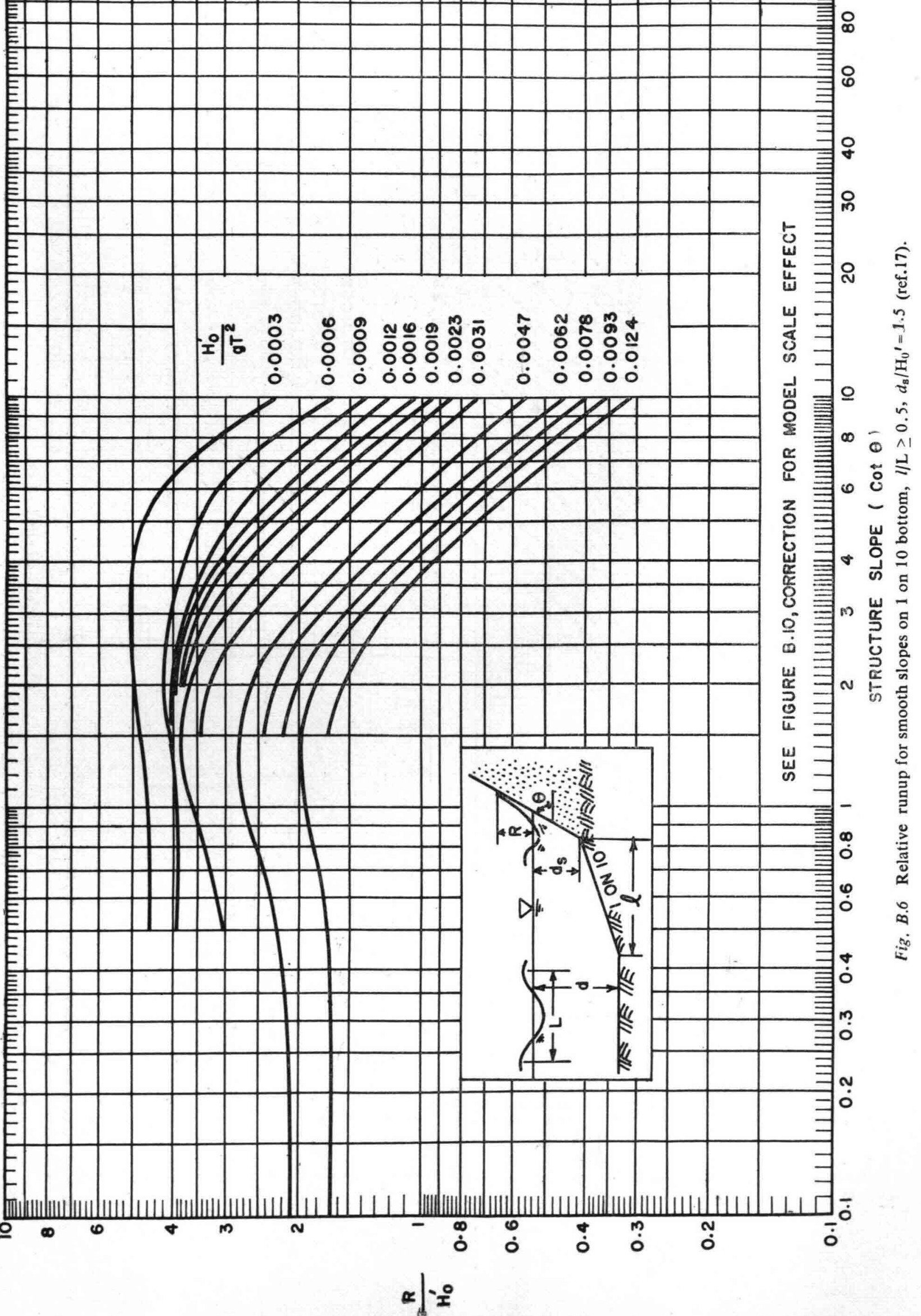




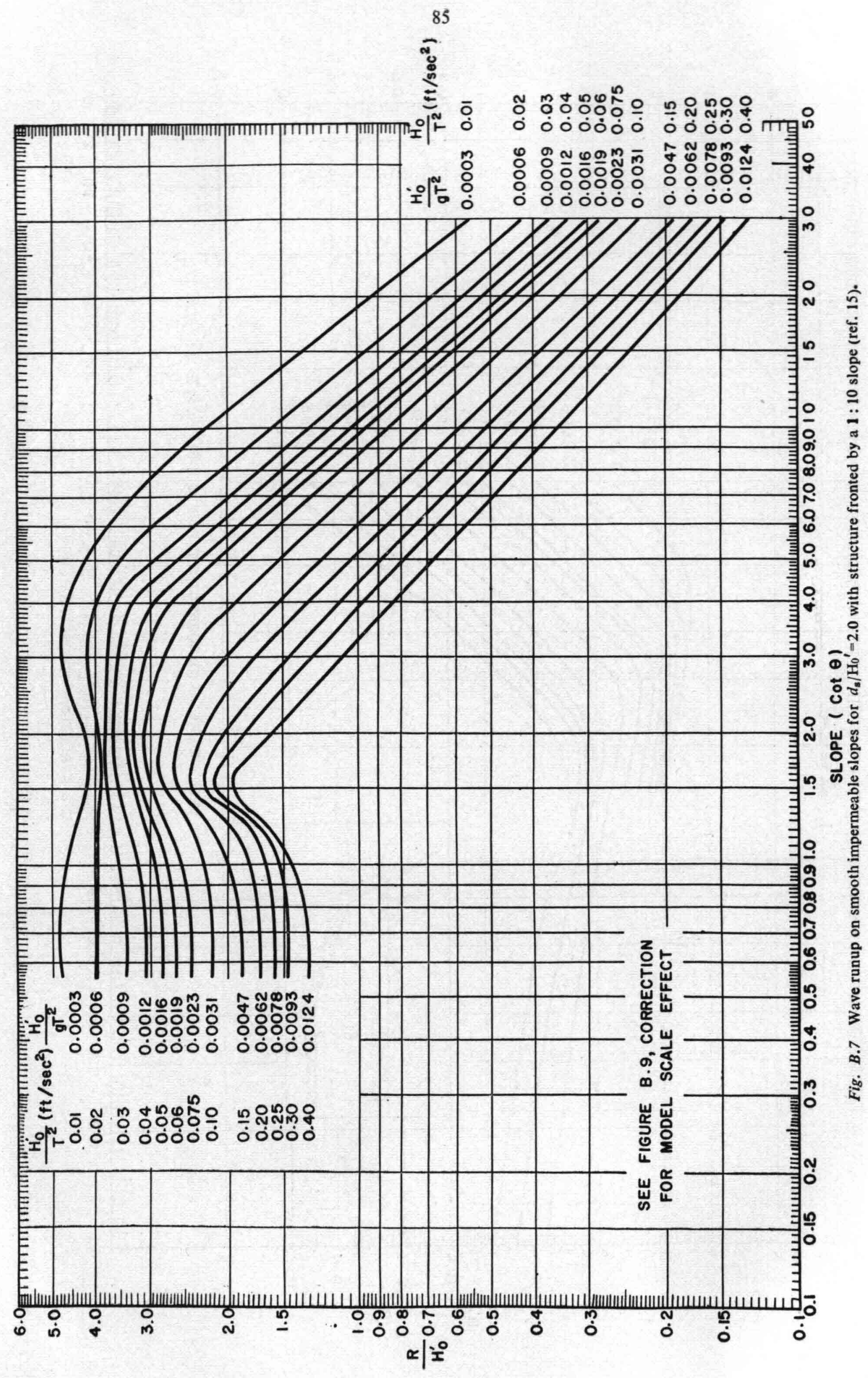




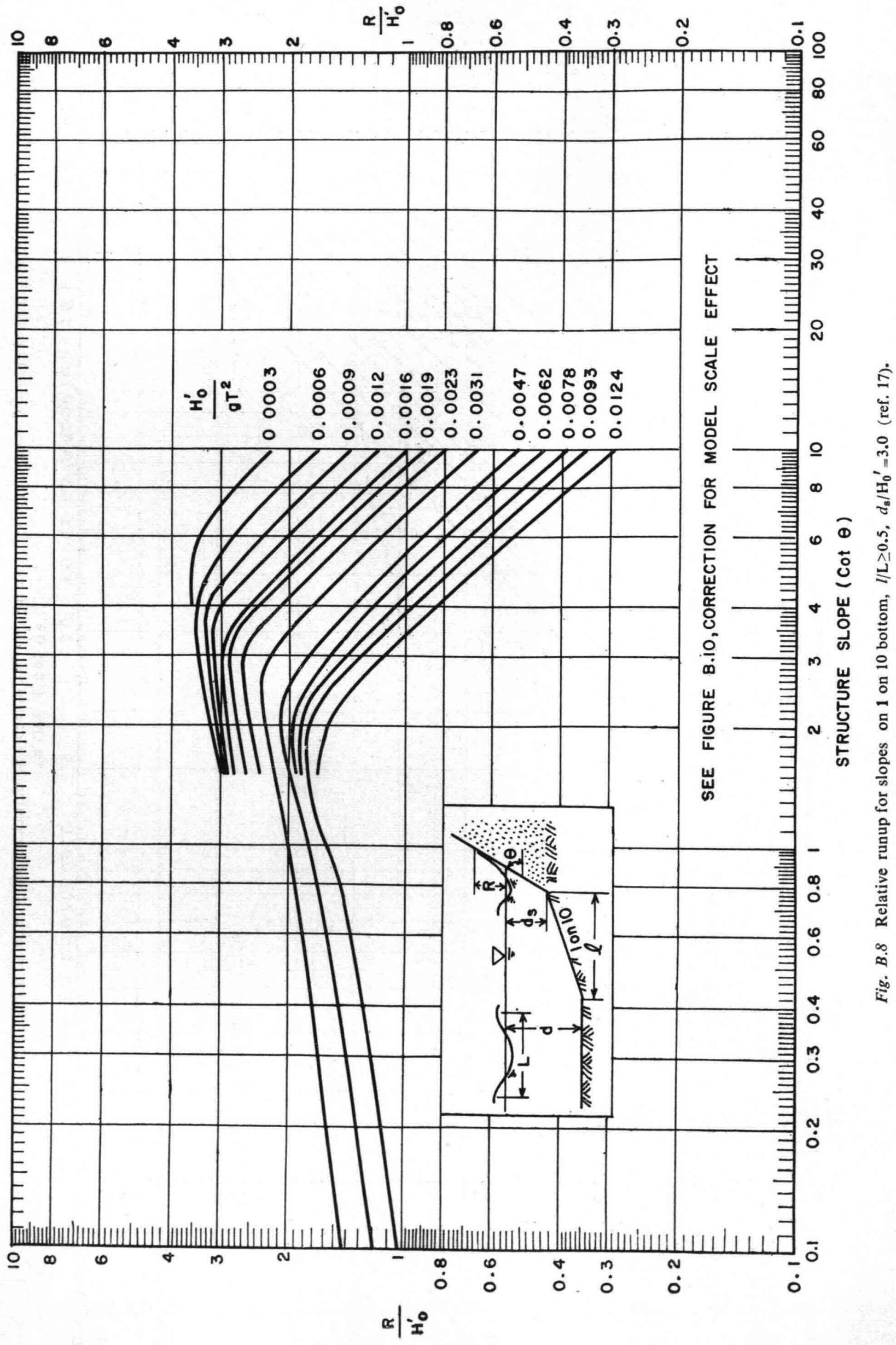




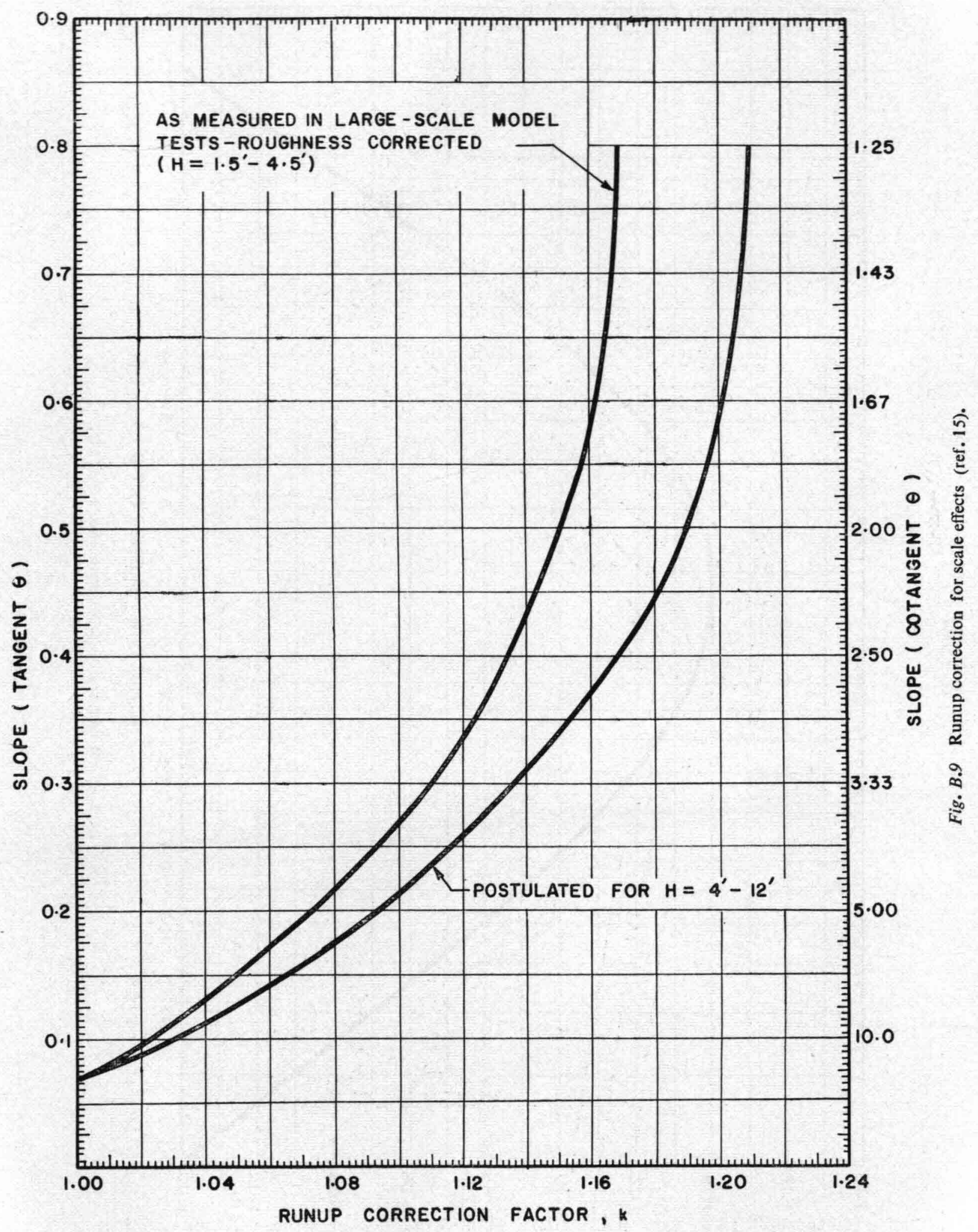




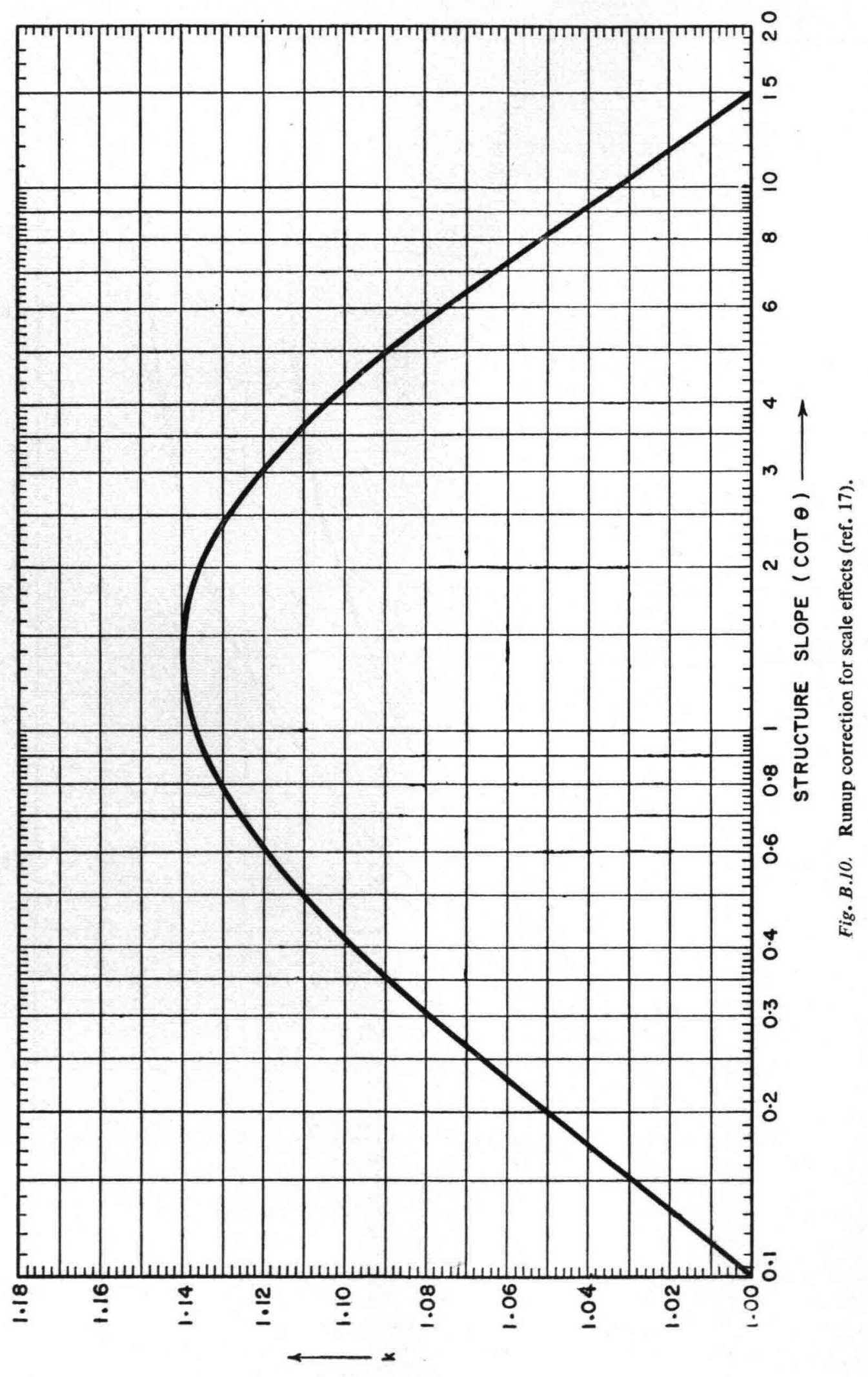




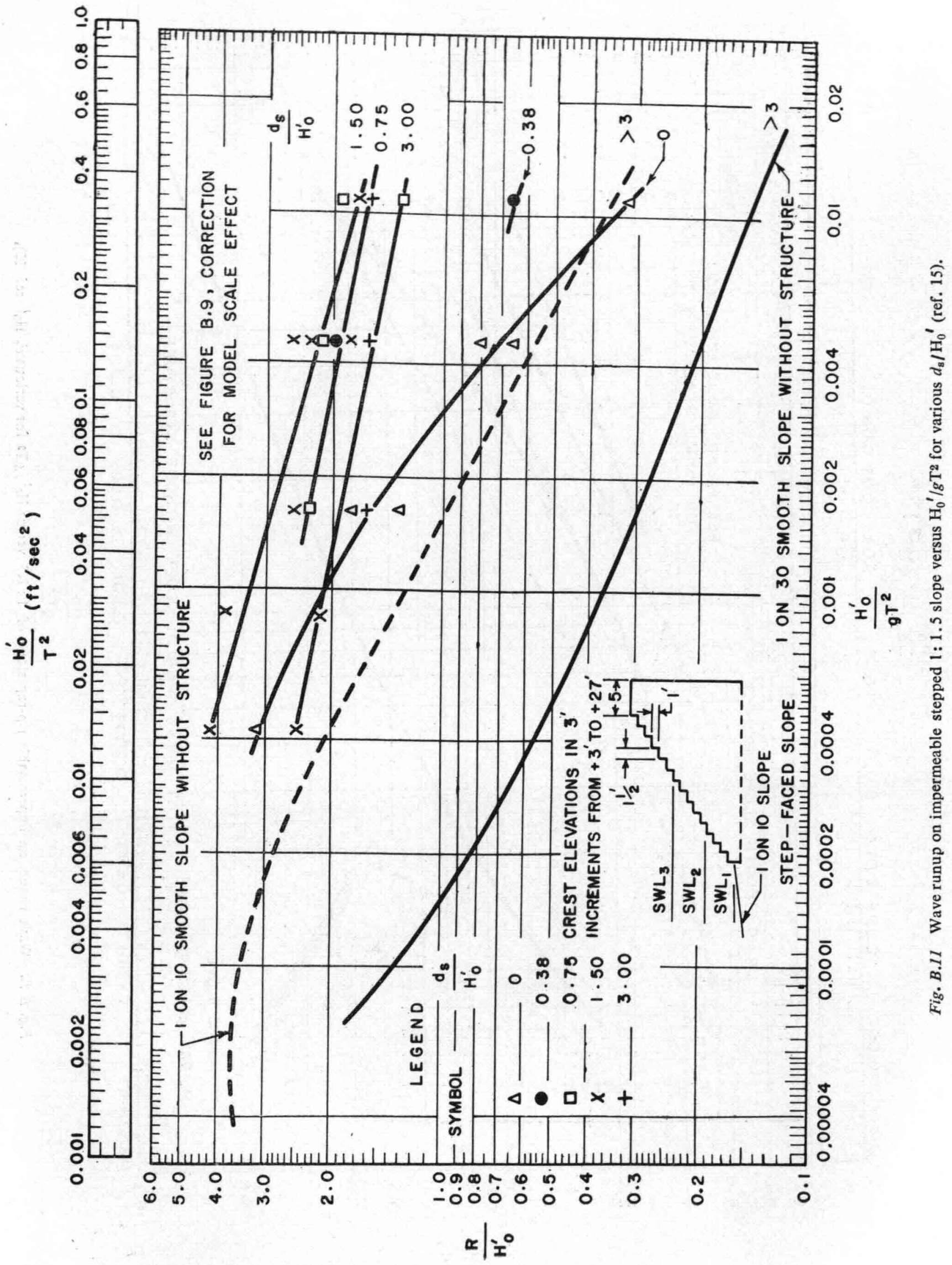




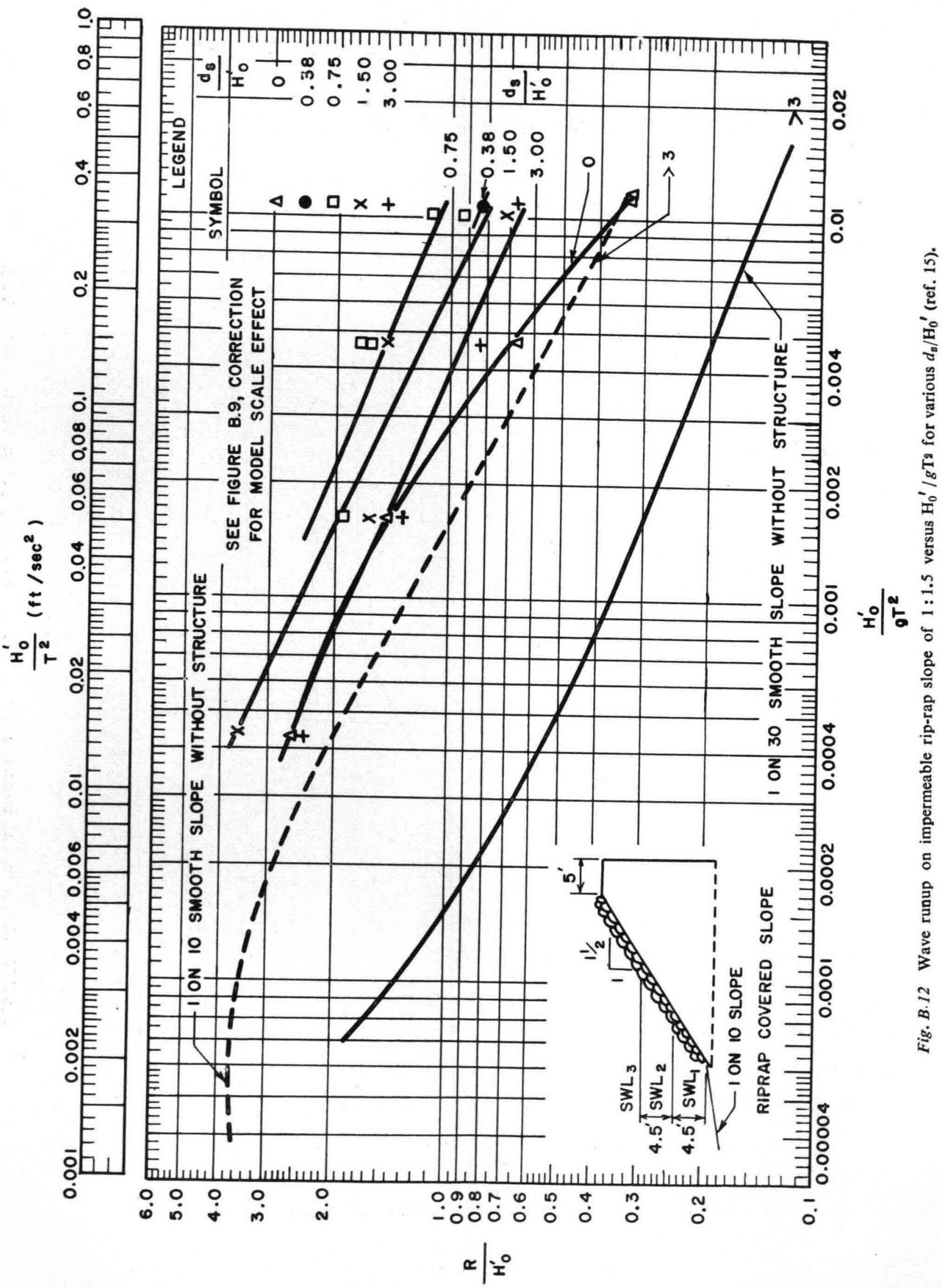




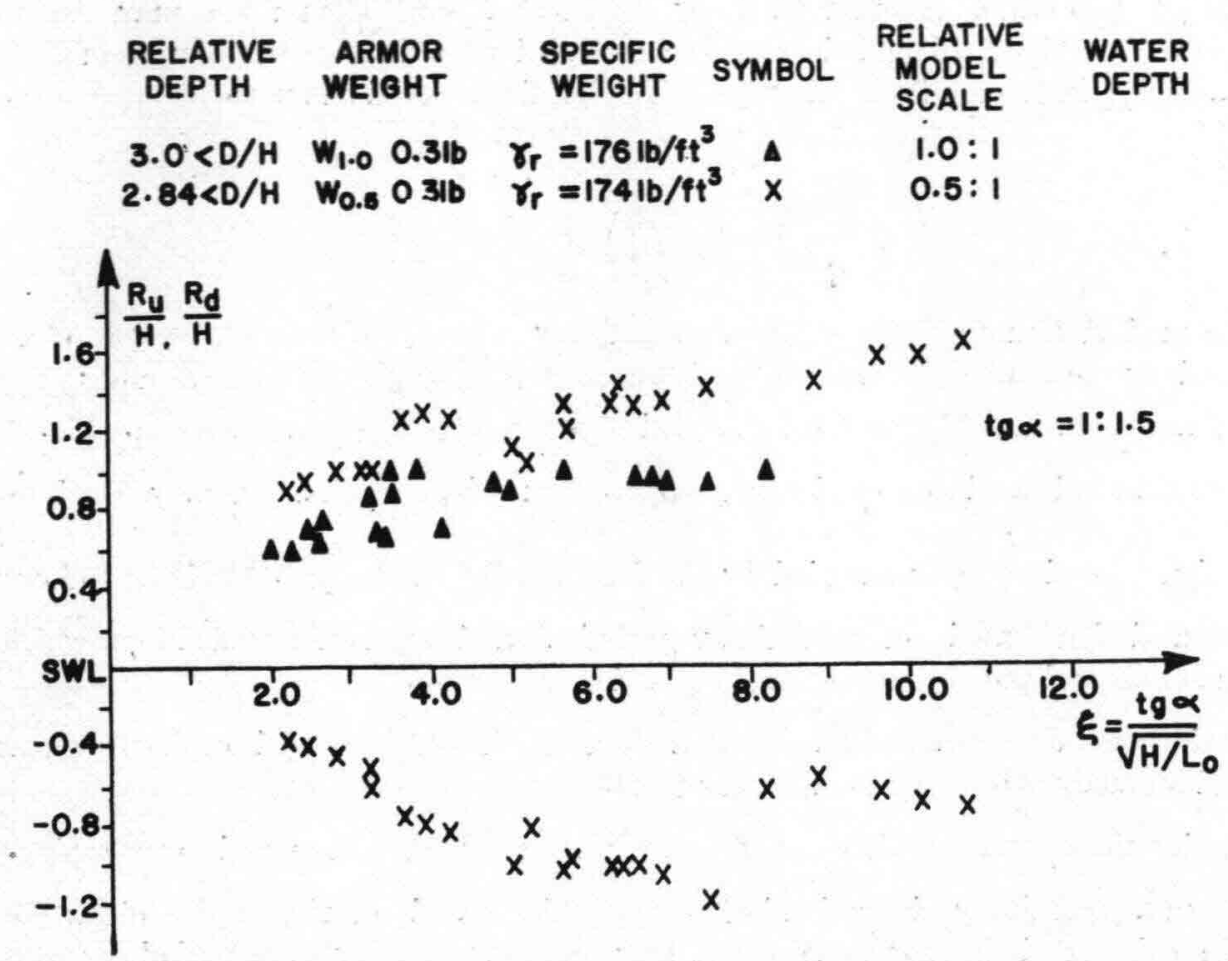

Fig. B.13 Wave runup/rundown on a smooth quarry stone slope (ref. 3).

Most of the existing design formulae are written as

$$
W=\frac{\gamma_{\mathrm{r}} \mathrm{H}^{3}}{K_{\mathrm{D}}\left(\frac{\boldsymbol{\gamma}_{\mathrm{r}}}{\gamma_{\mathrm{W}}}-1\right)^{3} \cot \alpha}
$$

$\mathrm{W}=$ weight of rock material to be used as armour

$\boldsymbol{\gamma}_{\mathrm{r}}=$ unit weight of rock material

$\boldsymbol{\gamma}_{\mathrm{w}}=$ unit weight of sea water

$\mathbf{H}=$ wave height in front of the structure

$\alpha=$ slope angle

$\mathbf{K}_{\mathbf{D}}=$ an empirical factor which, as proven by numerous experiments, does not only depend upon structural parameters but on wave and bottom geometry parameters as well.

Many publications give tables with $\mathrm{K}_{\mathrm{D}}$ values. As they are not reliable and not physically well argued, these values should be used with great care. As expressed by the above mentioned Committee of the PIANC in its report (ref. 11), the Commission considers the present stability formulae for rubble mound structures to have significant limitations. It is only for a preliminary assessment of the dimensions of quarry stone armour units that the formulae might be applied.

Some will, undoubtedly, claim that these principles may present an over-sophistication. Progress in engineering was however always achieved by sophistication which usually proved to be worthwhile replacing the rule of thumb by field experience and physical facts thereby obtaining better safety and economy. Handbook formulae often present a danger to good engineering practice. 
The design procedure recommended by the International Committee may be understood as follows with reference to Fig. B.16 and defining the so called zero-damage stability number $\mathrm{N}_{\mathrm{ZD}}$ referring to the highest wave $\mathrm{H}_{\mathrm{ZD}}$ in front of the structure which produces no damage to the structure.

$$
\mathrm{N}_{\mathrm{ZD}}=\frac{\mathrm{H}_{\mathrm{ZD}}}{\left(\frac{\mathrm{W}_{50}}{\gamma r}\right)^{\frac{1}{3}}(\mathrm{~S} \gamma-1)}
$$

where $\mathrm{W}_{50}$ is the median armour rock weight at which fifty per cent of the total weight of armour gradation is contributed by rock of lesser weight. $S_{\gamma}$ is the specific weight of the armour: Fig. B.16 is a typical design feature having $\mathrm{N}_{\mathrm{ZD}}$ as ordinate and $\xi=\tan \alpha / \sqrt{\mathrm{H} / \mathrm{L}_{\circ}}$ as abscissa. Fig. B.16 refers to $\frac{d}{\mathrm{H}_{\mathrm{ZD}}} \geqslant 3.0$. Results are indicated for four different slopes. It may be seen that generally $\mathrm{N}_{\mathrm{ZD}}$ is lowest for $\xi \leqslant 3$.

The design procedure recommended by the PIANC Committee (ref. 11) is as follows:

1. Select a design based on preliminary technical and economic evaluations which include the availability of materials and possibilities of handling and construction.

2. Examine a number of actual wave spectra from the chosen site (based on short term as well as long term statistics and on analysis of exceptional phenomena).

3. Consider the effects of the offshore wave parameter on runup and avertopping.

4. Perform a preliminary determination of block size based on the results of the former analysis using one of the existing design formulae (preferably one that includes wave period or length) and the considerations regarding wave steepness and actual values.

5. Conduct a hydraulic model experiment to check and finalize the design.

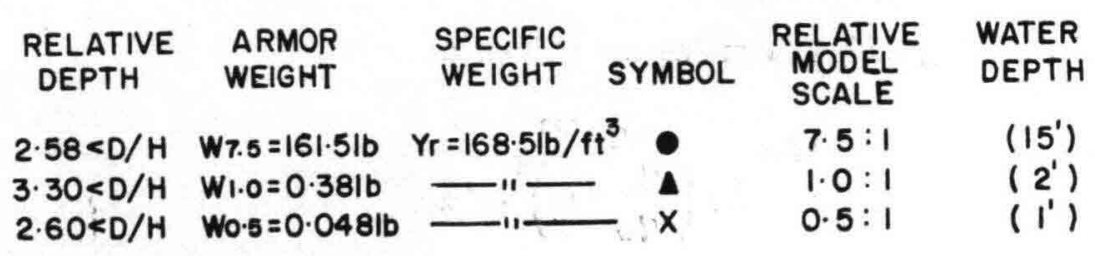

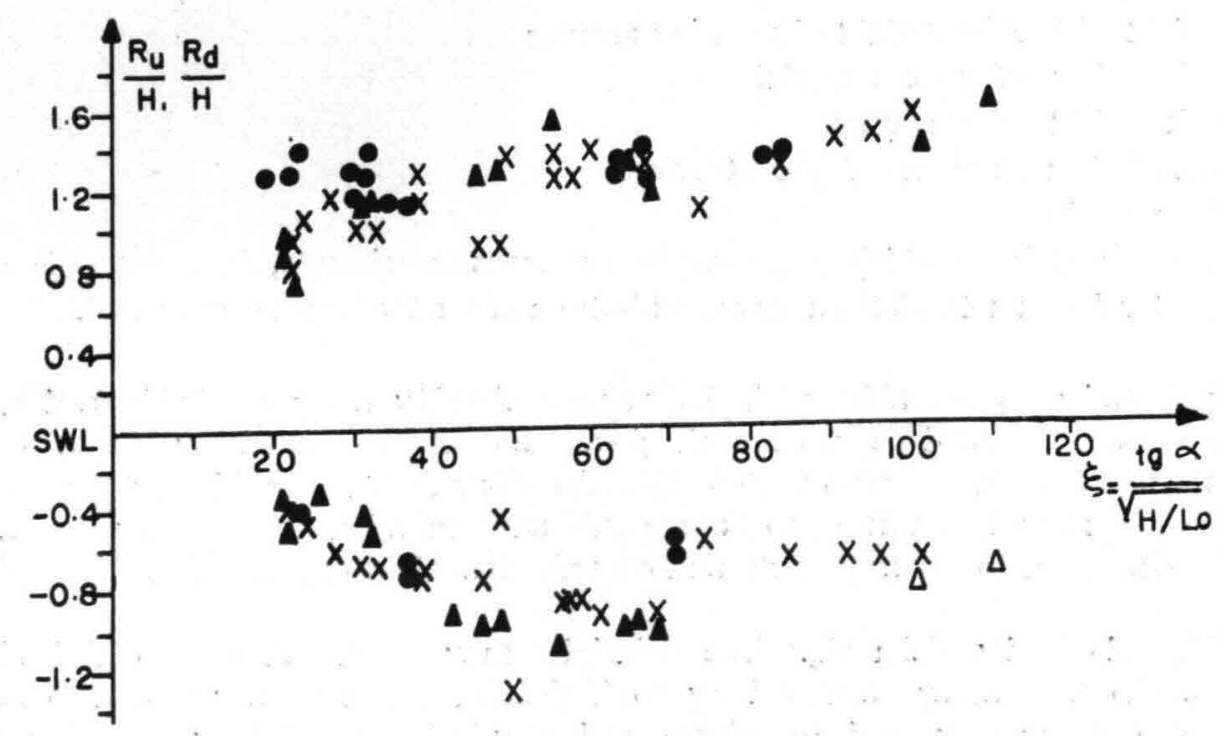

Fig. B.14 Wave runup/run-down on rough quarry stone slope (ref. 3). 
The experiments should preferably be carried out with irregular waves. However, they may be done with regular waves considering the combinations of $\mathrm{T}, \mathrm{H}$ and $\alpha$, which are particularly dangerous to stability (including stability of the pier-head and stability of the parts of the breakwater where the direction or the cross-section of the structure changes). These experiments should also cxaminc, in detail, the economic distribution of armour blocks of various weights along the slopes. Unless the wave pattern is truly two-dimensional, the Committee recommends that three-dimensional stability tests must be done at a suitable modei scale using design waves for the various wave directions and should be weighted in accordance with the frequency of occurrence to obtain the average effect of all directions. Final design should be based on probability of oscurrence and the duration of the storms which include particularly dangerous values, but causing damages within the permissible limits.

6. Although the Committee realizes that soil mechanics may play an important role in the whole design procedure, the recommendations given have been limited to hydraulic conditions only.

As regards the thickness of material layers for the elements placed at random, this must be determined by model experiments but it may be assumed that each layer thickness must be composed

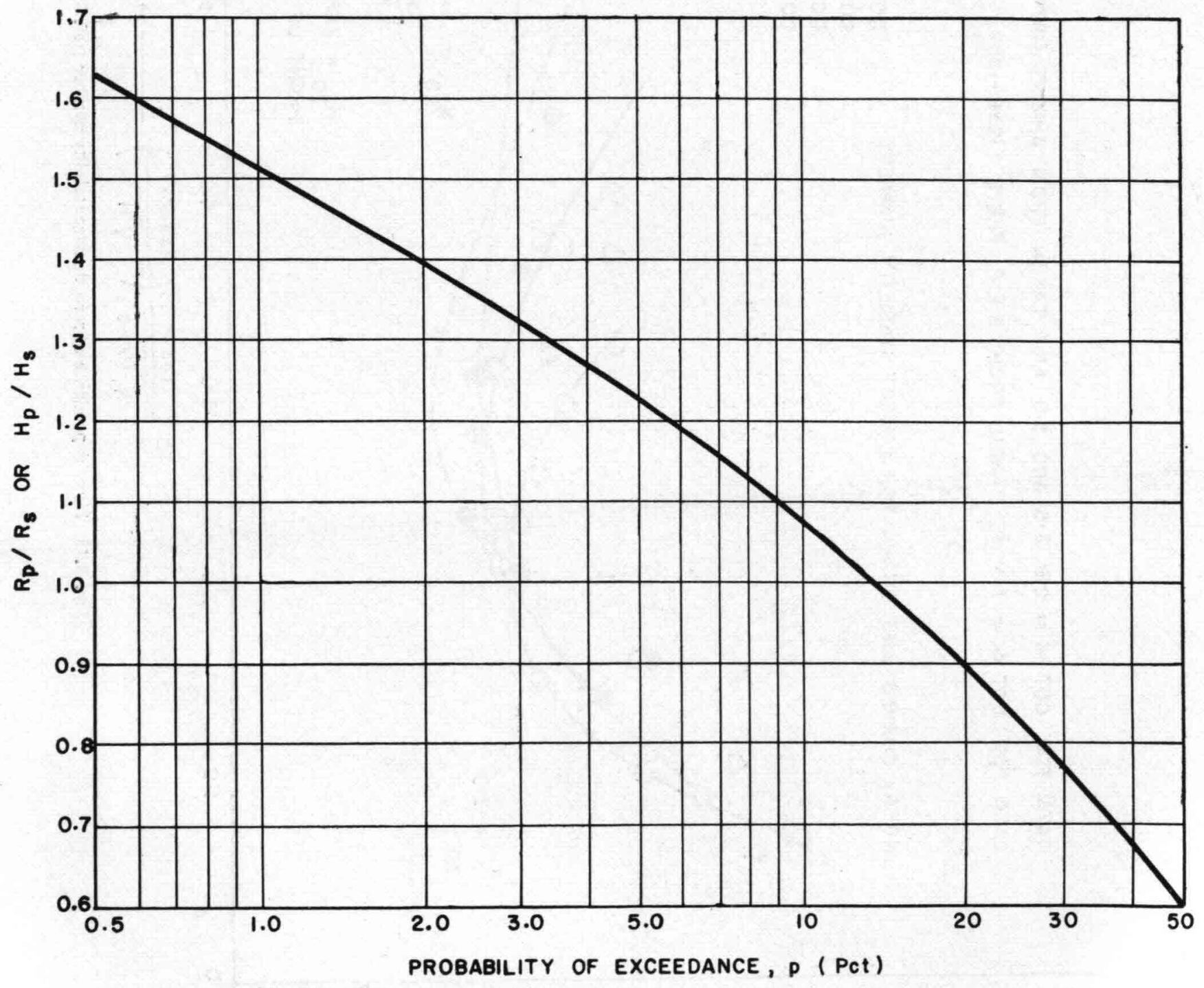

Fig. B.15 Relative runup $R_{p} / R_{s}$ or relative wave height $H_{p} / H_{s}$ as a function, of the probability of exceedance $P$. 
- 药

号 敢

in 2

in

iा

II

点

운

芯占

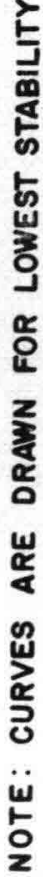

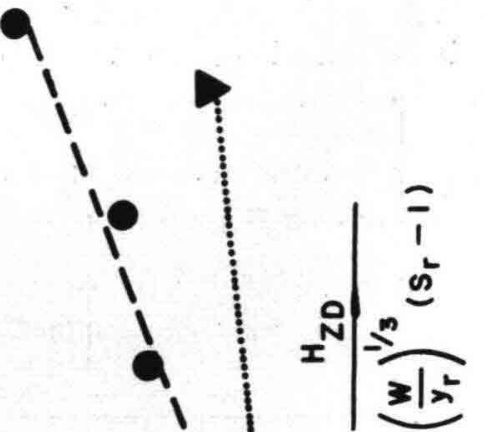

喜

岂 㟧 
of a minimum of 2 pieces of artificial or natural heavy blocks of rockfill and a minimum of 3 or 4 pieces for smaller size blocks.

Recent model tests have shown that the stability of armour blocks is dependent on the packing density, the number of blocks per unit area and the armour layer thickness, as increase in packing density or armour layer thickness was found to increase the armour stability (stability factor) significantly.

The runup height $\mathrm{R}$ along the armour layer is an important factor in fixing the upper level of the structure. ! As stated earlier, the $\xi$ value is also the main parameter establishing the runup height $R$. Sometimes overtopping may be allowed, in that case the dimensions of the harbour side armour units can only be assessed by small scale experiments, in which the simulation of irregular waves is essential. The run-down, which also depends on the $\xi$ value, influcnces the extent to which the heavy armour layer should be placed on the seaside slope below the still water level.

Structural aspects of the stability of concrete blocks should of course be looked into carefully to avoid disasters by breakage of blocks in the mound (ref. 11).

Appendix $\mathrm{E}$ gives information on the rocks available along the coasts of India. While designing coastal protective structures, it is necessary to find out the maximum size of rocks that are available at a given site and where they can be placed in structure depending upon the losation of the structure, design wave, beach geometry and other environmental parameters.

As the situation in practically all cases in India is that the coastal protective scawalls will be placed right on the beach or in very shallow water, it is usually safe to use a maximum wave height equal to the depth at the toe of the structure with reference to storm tide elevation as the design wave height for the structure. As the wave period is known, it will then be possible to calculate

$$
\xi=\tan \alpha / \sqrt{\mathrm{H} / \mathrm{L}_{\mathrm{o}}}=\frac{(\tan \alpha) 1.25 \mathrm{~T}}{\mathrm{H}} .
$$

Considering a breakwater and assuming $\tan \alpha=1: 2, \mathrm{H}=2 \mathrm{~m}, d=$ depth $=6 \mathrm{~m}, \mathrm{~T}=10 \mathrm{sec}$, one arrives at $\xi_{0}=\frac{0.5 \times 1.25 \times 10}{1.4}=4.5$ and the corresponding $\mathrm{N}_{\mathrm{ZD}}$ value from Fig. B.16 is about 2 . Rock size will then be about 500 kilograms assuming a specific gravity of 2.65 .

It may be observed that $\mathrm{N}_{\mathrm{ZD}}$ can be reduced to $<2$ by lowering the wave period. The consequence of this could be an increase in the rock size to be determined from the formulae B.1 or B.2.

Table B.2 gives typical data for slopes of $1: 2,1: 3$ and $1: 4$ with wave heights of $1,1.5,2$ and 2.5 metres and wave periods from 6 to $10 \mathrm{sec}$. The specific gravity of rock is taken as 2.65 . This corresponds

TableB. 2 Approximate rock sizes in kilograms for various wave heights, slopes and wave periods $T=6$ to 10 seconds (specific gravity $2 \cdot 65$ ).

For $1<d / \mathrm{H}<2$

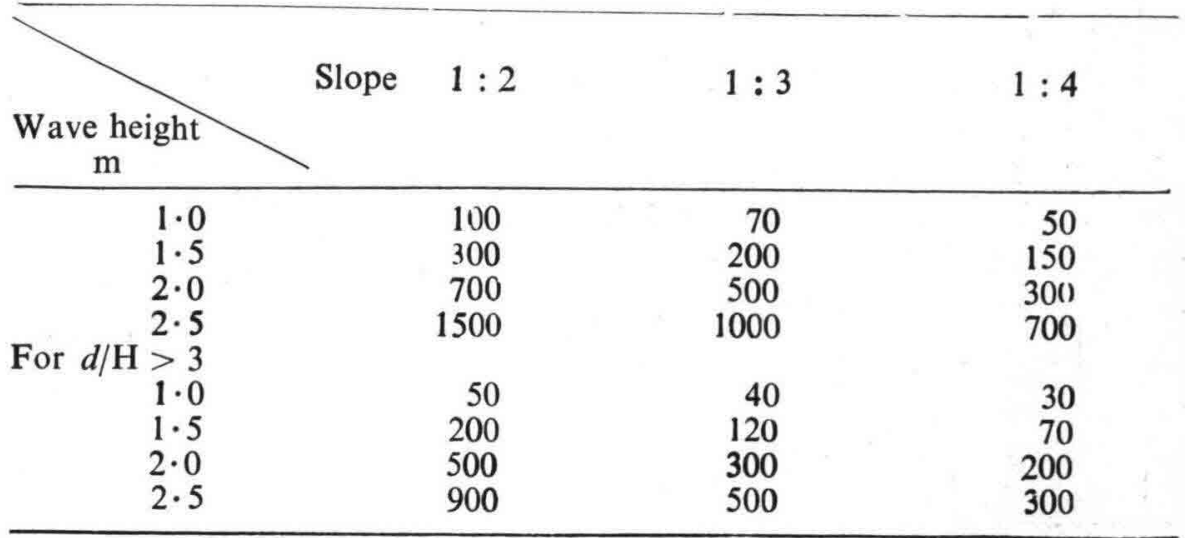

Note : For $\mathbf{2}<d / \mathrm{H}<3$, suitable values can be obtained by careful interpolation. 
to granite and laterite which are the most common material available for the construction of seawalls and revetments in India. If material of a different specific gravity is used correction must be applied using a factor of $\left(\frac{2 \cdot 65-1}{\mathrm{~S}_{\text {actua } 1}{ }^{-1}}\right)^{3}$ for increasing (or decreasing) $\mathrm{W}$.

For the design of structures in deeper waters, more sophistication in calculation procedure should be used. Design is then based on risk analysis as explained in great detail in ref. 3 .

\section{References}

1 Bruun, P. and Johannesson, P., 1976, "Parameters Affecting the Stability of Rubble Mounds", Proc. ASCE, J. Waterways, Harbours and Coastal Engg. Div., WW2.

2 Bruun, P., 1976, "Port Engineering", The Gulf Publishing Company, Houston, Texas.

3 Bruun, P. and Gunbak, A.R., 1977, "Stabiliiy of Structures in Relation to $\xi=\tan \alpha / \sqrt{\mathrm{H} / \mathrm{L}_{\mathrm{o}}}$. Risk Criteria in Design", Coastal Engineering, 1, Published by Elsevier Scientific Company, Amsterdam, The Netherlands.

4 Bruun, P., 1979, “Common Reasons for Damage or Breakdown of Mound Breakwaters", Coastal Engineering, Vol. 2, No. 3, Published by Elsevier Scientific Company, Amsterdam, The Netherlands.

5 Chakrabarti, S. H. and Cooley, R.P., 1977, "A Statistical Relationship Between Individual Heights and Periods of Storm Waves", J. Geophys. Res., Vol. 82, No. 3.

6 Galvin, C.J., 1968, "Breaker Type Classification on Three Laboratory Beaches", J. Geophys. Res., Vol. 73, No. 12 .

7 Gunbak, A.R., 1977(a), "Stability Tests on a 1 in 2.5 Slope Breakwater using Two Wave Spectra", Div. of Port and Ocean Engg., Tech. Univ. Norway, Rep. No. 10-1977.

8 Gunbak, A.R. 1977(b), "Rubble Mound Breakwaters", Div. Port Ozean Engg., Tech. Univ. Norway, Rep. No. 11-1977.

9 Longuet-Higgins, M.S., 1975, "On the Joint Distribution of the Periods and Amplitudes of Sea Waves", Proc. J. Geophys. Res., Vol. 80, No. 18.

10 Overvik, T. and Houmb, O.G., 1977, "A Note on the Distribution of Wave Steepness", Div. of Port and Occan Engineering, The Norwegian Institute of Technology, Rep. No. 11.

11 Permanent International Association of Navigation Congresses, "Final Report of the International Commission for the Study of Waves, 1976", Annex to Bulletin No. 25 (Vol. III).

Plough, J., 1978-79, "Paper on the Importance of Wave Groups", Presented at the Coastal Engineering Conference in Hamburg, Aug. 1978, In Press by the ASCE.

13 Saville, T., Jr., 1962, “An Approximation of the Wave Runup Frequency Distribution”, Proceedings of the Eighth Conference on Coastal Engineering, pp. 48-59.

14 Technical Advisory Committee (1974) on "Wave Runup and Overtopping" and on "Protection Against Inundation", Rijkswaterstaat, Hague, The Netherlands.

15 U.S. Army Coastal Engineering Research Centre, 1973, "Shore Protection Manual", Vol. I, II, and III.

16 U.S. Aımy Coastal Engineering Research Centre, 1977, "Prediction of Irregular Wave Overtopping", CETA Report Nos. 77-2 and 77-7.

17 U.S. Army Coastal Engineering Research Centre, 1978, "Revised Wave Runup Curves for Smooth Slopes", CETA Report No. 78-2. 


\title{
Sampling Procedures and Sediment Analysis
}

Appendix C

\author{
A. K. JAIN \\ National Institute of Oceanography, Dona Paula, Goa
}

\section{C.1 Beach sampling}

Generally grain size distribution of the beach sediment varies from point to point. Thus sufficient number of teach samples should te collected in such a way that composite grain size distribution is obtained which reflects the representation of each variation in grain size distribution. Though fixed rules for beach sampling can never be made, a general guideline can, however, be established.

Beach samples should be collected (a) along the profile at regular elevation difference below and above the plunger zone (Fig. C.1), (b) along the shoreline at regular distance intervals at each elevation (Fig. C.2) and (c) during the pre-monsoon and post-monsoon periods. Although, in general, core samples are not presently being collected from the beach, such samples would be more representative if they are collected upto a certain depth instead of surface samples (ref. 1).

In order to satisfy the above general guidelines, the number of samples to be collected should, often, be very high. Depending on the topographic regularity of the beach, the degree of accuracy desired for estimating the renourishment factor, the time available for sampling etc., the number of samples to be collected can be decreased or increased.

\section{C.2 Borrow site sampling}

Generally sediments for beach nourishment are obtained from land, lagoon or from estuarine sources. For the unknown geometry of the deposits of these areas, random or regular core sampling on a grid would be very appropriate. Here, the point to be kept in mind is that the composite characteristics of the borrow site material should be as representative as the beach composite. Also, a potential region of borrow site should be known in terms of depth upto which material can be excavated or dredged economically and the amount of sediment available from a site.

To determine the composite properties of a representative set of beach or borrow site samples, a simple and effective method would be to total the percentage of sediment in each size interval for all the samples and then divide by the number of samples. This method would be appropriate for the samples collected according to some regular pattern and hence the time required for the analysis would be slightly greater.

An alternative method would be to mix parts of the actual samples and then do a single size analysis of the mixture. Mathematically, this method and the methoddescribed in the earlier paragraph should give an identical result. But in actual practice it is not so. The major benefit of mixing samples is the reduction of laboratory time and cost of analysis. However, care should be taken in the laboratory to obtain random splits of appropriate size from the samples. These splits must be mixed completely to eliminate bias in obtaining the final sample of the mixture. Where samples are collected to represent equal parts of the beach or borrow site, sample splits of equal weights are mixed. Splits of unequal size would be appropriate when sampling plan requires a weight factor. It is probably best to combine samples or 


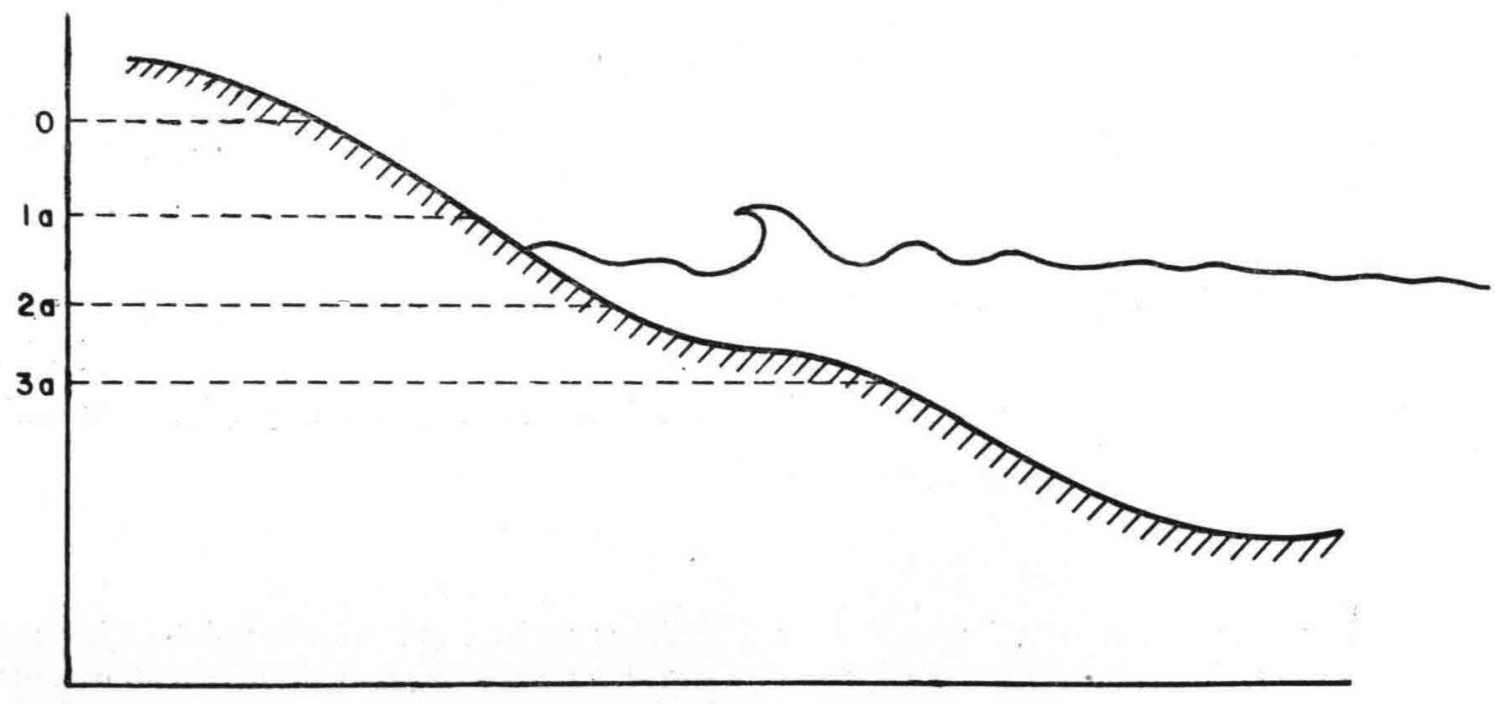

Fig. C.1 Sampling scheme along a beach profile.

to analyse them by elevation groups in order to have the data in a form useful to evaluate a beach or to design a beach fill project.

\section{C.3 Sediment analysis}

To obtain the size ranges and weight percentages, grain size analysis is carried out either by settling technique or by sieve analysis. In setîling techniques, a small amount of sample is allowed to fall through a water column of known length and the change in weight with respect to time at a particular depth is noted. This change in weight and time is then converted into weight per cent and grain size data, using fall velocity equations.

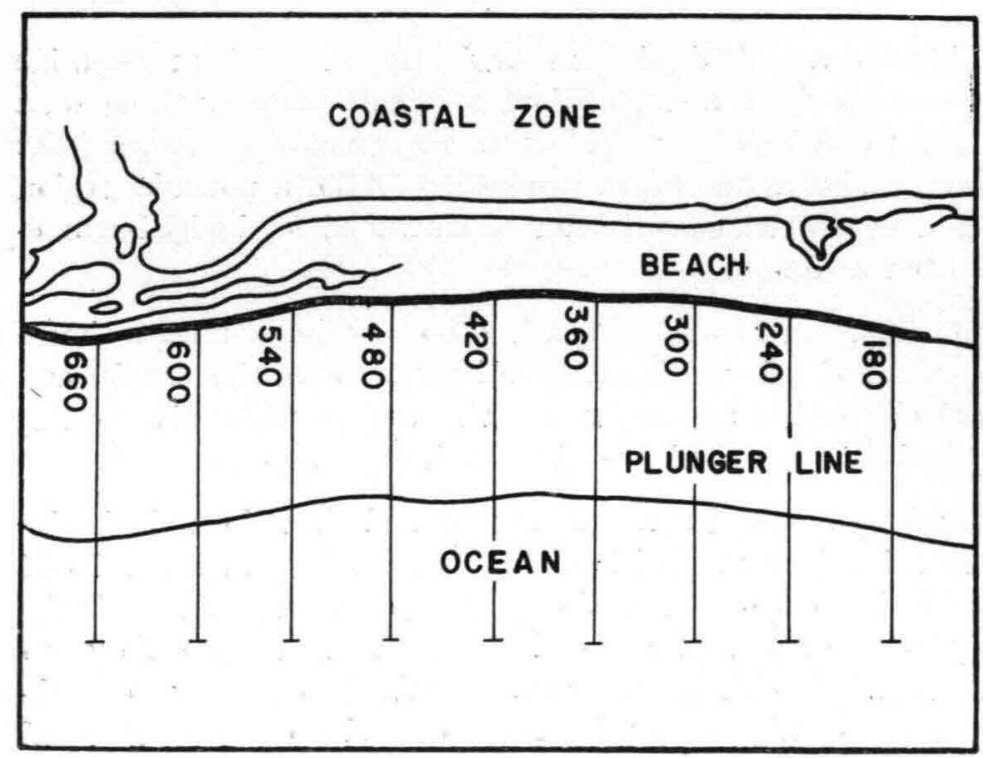

Fig. C.2 Sampling scheme along a shoreline.

While the settling technique is good for silty and clayey sediments it has some inherent deficiencies for beach sediments. The fall velocity equation does not take into account the effects of varied particle shapes, densities and interaction between the particles themselves and the bourdary of the cylinder. Though the settling technique is more analogous to real environmental conditions, sieve analysis is generally preferred owing to its simplicity and reliability.

For sieve analysis, a dried sample of known weight is mechanically shaken through a set of sieves placed one over the other (from finer to coarser). The weight of the sample retained on each sieve is determined which is then converted into percentage weight. For sieve analysis, sieves are generally graded in equal phi numbers with a preferred interval of $\frac{1}{2} \phi$ (Table C.1). The shaking time for the sieves is of the order of 20 minutes. 
Table C.1 Grain size scales and soil classification systems.

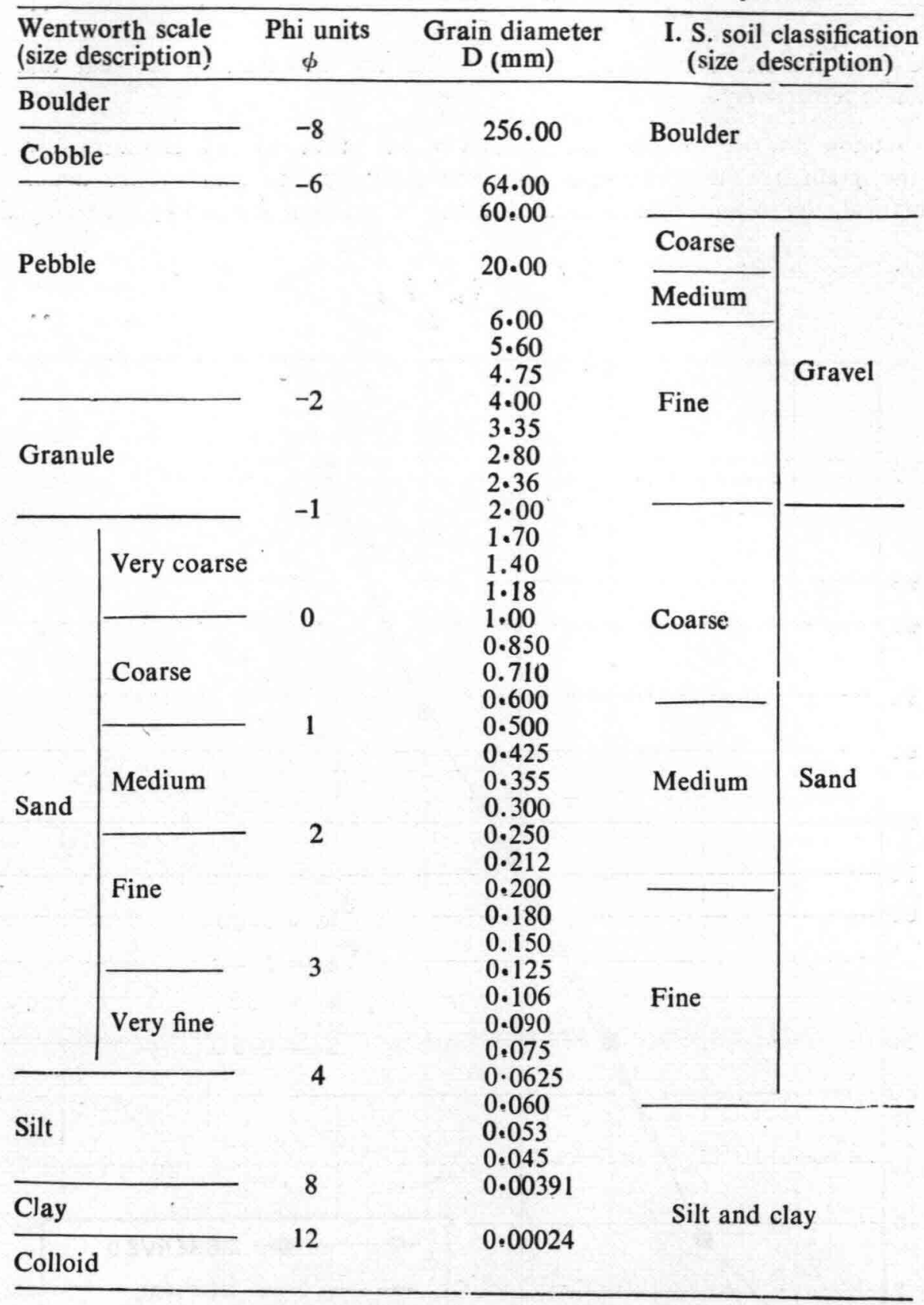

After getting the size and weight per cent data, the weight percentage for each size $\phi$ in values is plotted. This grain size distribution is symmetrical and bell shaped with a maximum frequency ozcurring at $\phi=\mu$ and the inflexion points at $\mu \pm \sigma$ where $\mu$ is phi mean and $\sigma$ is phi sorting equivalent to standard deviation (ref. 1). Each combination of $\mu$ and $\sigma$ values defines one normal curve from a large family of possible normal curves. The curves in this family are similar because all are symmetrical and the areas under each are the same for specific distances measured in $\sigma$ units from the mean. Thus $\sigma$ can be used to measure both the spread of phi sizes under the distribution curve and the areas under the distribution curve. For example, 68 per cent of the area under a normal curve would lie between $\pm \sigma$ from the mean or between 84 per cent and 16 per cent of the cumulative plot (ref. 1 and 2). The estimate of phi sorting, $\mathrm{S}$ then would be 


$$
S=\frac{\phi_{84}-\phi_{16}}{2}
$$$$
\cdots
$$$$
\text { .. }
$$

where $\phi_{\mathbf{8 4}}$ and $\phi_{16}$ are the sediment sizes in phi units that are finer than 84 per cent and 16 per cent by weight of the sample respectively.

It is a common practice to select an estimate of the mean, $M$ that is statistically more efficient specially where the grain size distribution is not completely symmetrical. If an actual distribution is completely symmetrical, the mean would be located at the 50 per cent $\phi$ size $\left(\phi_{50}\right)$ or be equal to the median size.

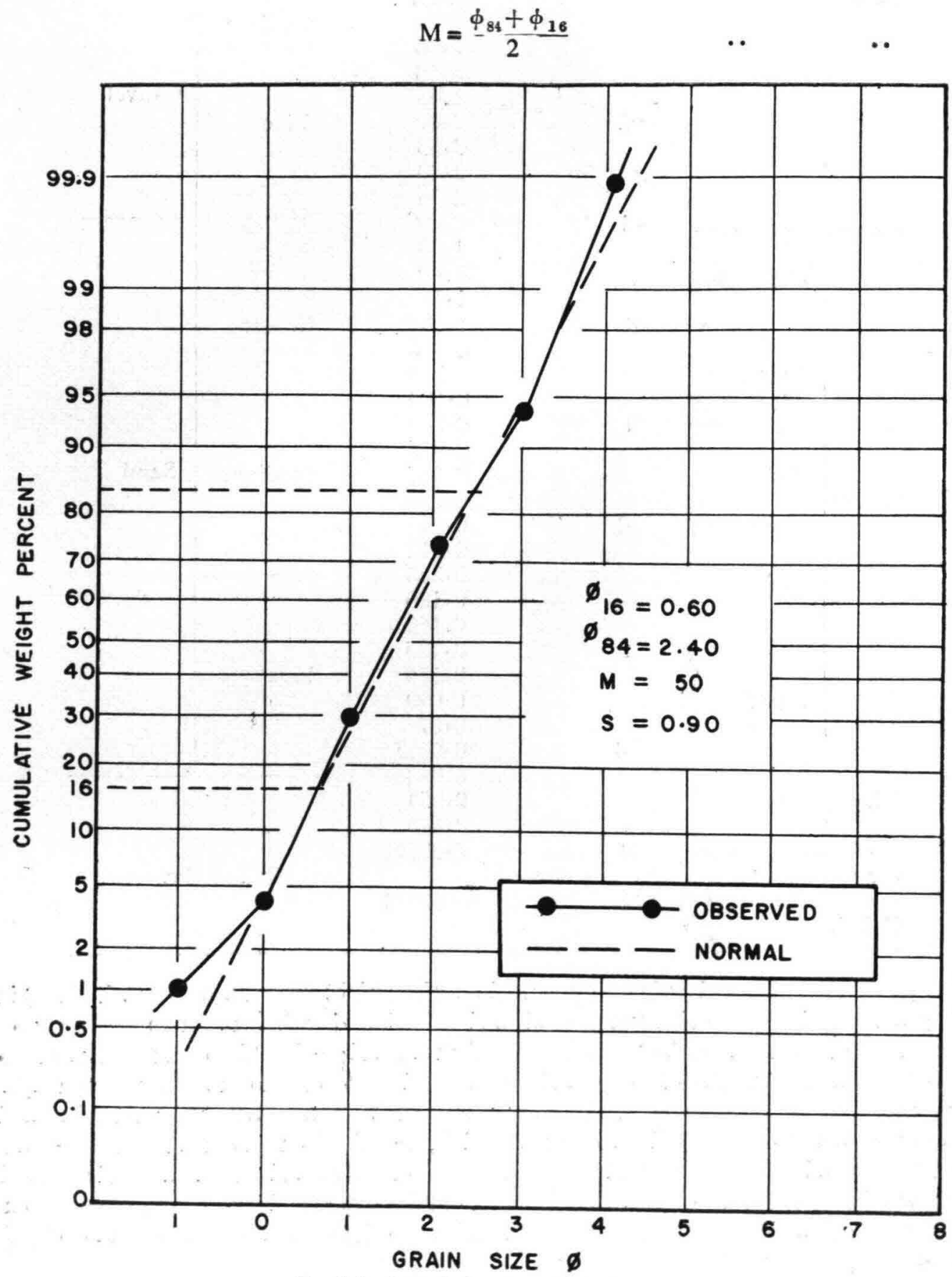

Fig. C.3 Cumulative size plot (ref, 1). 
For a symmetrical distribution, equation C.2 will give the median size but for an asymmetrical distribution, $\mathbf{M}$ will be the most reliable estima e of the $\phi$ mean. Thus $\mathbf{S}$ and $\mathbf{M}$ are perhaps the best estimates of the standard deviation, $\sigma$ and $\phi$ mean, $\mu$ for describing a unimodal sediment grain size distribution. A common method to calculate $\mathbf{S}$ and $\mathbf{M}$ is shown in Fig. C.3. In this figure, size data have been plotted as cumulative distribution on $\log$ probability paper in such a way that $\phi$ and percentage coordinates of a point on the curve indicate the percentage of coarser than a given $\phi$ size. The sizes associated with 84 per cent and 16 per cent finer by weight are interpreted directly to calculate $S$ and $M$ (ref. 1 and 2 ).

\section{References}

1 Hobson, R.D., 1977, "Review of Design Elements for Beach-Fill Evaluation", U.S. Army Corps of Engineers, Coastal Engineering Research Centre, Fort Belvoir, Va. Technical Paper No. 77-6.

2 James, W. R., 1975, "Techniques in Evaluating Suitability of Borrow Material for Beach Nourishment", TM-60, U.S. Army Corps of Engineers, Coastal Engineering Research Centre, Fort Belvoir, Virginia. 



\title{
Stability of Earth Slopes and Retaining Structures
}

\section{Appendix D}

\author{
A. K. J $\mathrm{AIN}$ \\ National Institute of Oceanography, Dona Paula, Goa.
}

\section{D.1 Stability of earth slopes}

The failure of a mass of soil in a downward and outward movement of a slope is called a slide or slope failure. Slides may occur gradually or suddenly. They are usually caused by excavation, by undercutting the foot of an existing slope, by a gradual disintegration of the structure of the soil, by an increase of the pore water pressure in a few exceptionally permeable layers, or by a shock that liquifies the soil. Several factors which affect the stability of slopes include failure plane geometry, non-homogeneity of soil layers, tension cracks, dynamic loading and seepage flow.

\section{D.2 Failure mechanism}

D.2.1 Failure of earth slopes : The slopes of the earth structures fail generally by sliding of a portion of structure from the rest of the structure as shown in Figs. D.1, D.2 and D.3 (see also Figs. 3.7, 3.8 and 3.9). At failure, the shear resistance and intergranular frictional resistance along the sliding surface are not sufficient to retain the sliding portion.

Successive multiple slip failures or creep movements can also take place in earth slopes of cohesive as well as cohesionless soils (ref. 8). During creep, the shear strength of the soil decreases progressively. This creep on the slopes may be continuous or seasonal. Seasonal creep is generally due to changes in the temperature and water content of the soil. While the seasonal creep occurs gradually in clayey and silty soils, continuous creep which is caused by gravitational forces occurs below the surface zone. It generally occurs in shales, argillaceous schists etc.

D.2.2 Failure of retaining structures : In retaining structures, the wall may fail by either overturning or by sliding. The retaining wall with its foundation may slide (Fig. D.4) along the base due to inadequate shear resistance available (ref. 4). For sliding, many other potential slip surfaces are also possible (Figs. D.5 and D.6). If the surrounding soil consists of medium to soft clay, a circular slip surface may develop as shown in Fig. D.5. The most dangerous slip circle is usually the one that penetrates deepest into the soft material. If the soil consists of over consolidated stiff clay, failure may occur along a surface that is nearly horizontal or approximately parallel to the ground surface as in Fig. D.6.

D.2.3 Failure of anchored sheet piles: Fig. D.7 shows various possible failure mechanisms of an anchored sheet pile. The sheet pile may fail due to breaking of the tie or the anchorage system or failure may take place due to outward movement of the toe of the pile because of inadequate passive resistance at the toe. It may also be possible that the sheet pile may fail in buckling or due to sliding on the larger slip surface as formed in natural slopes. Excessive settlement of the filling, behind the sheet pile, may also cause the failure. 


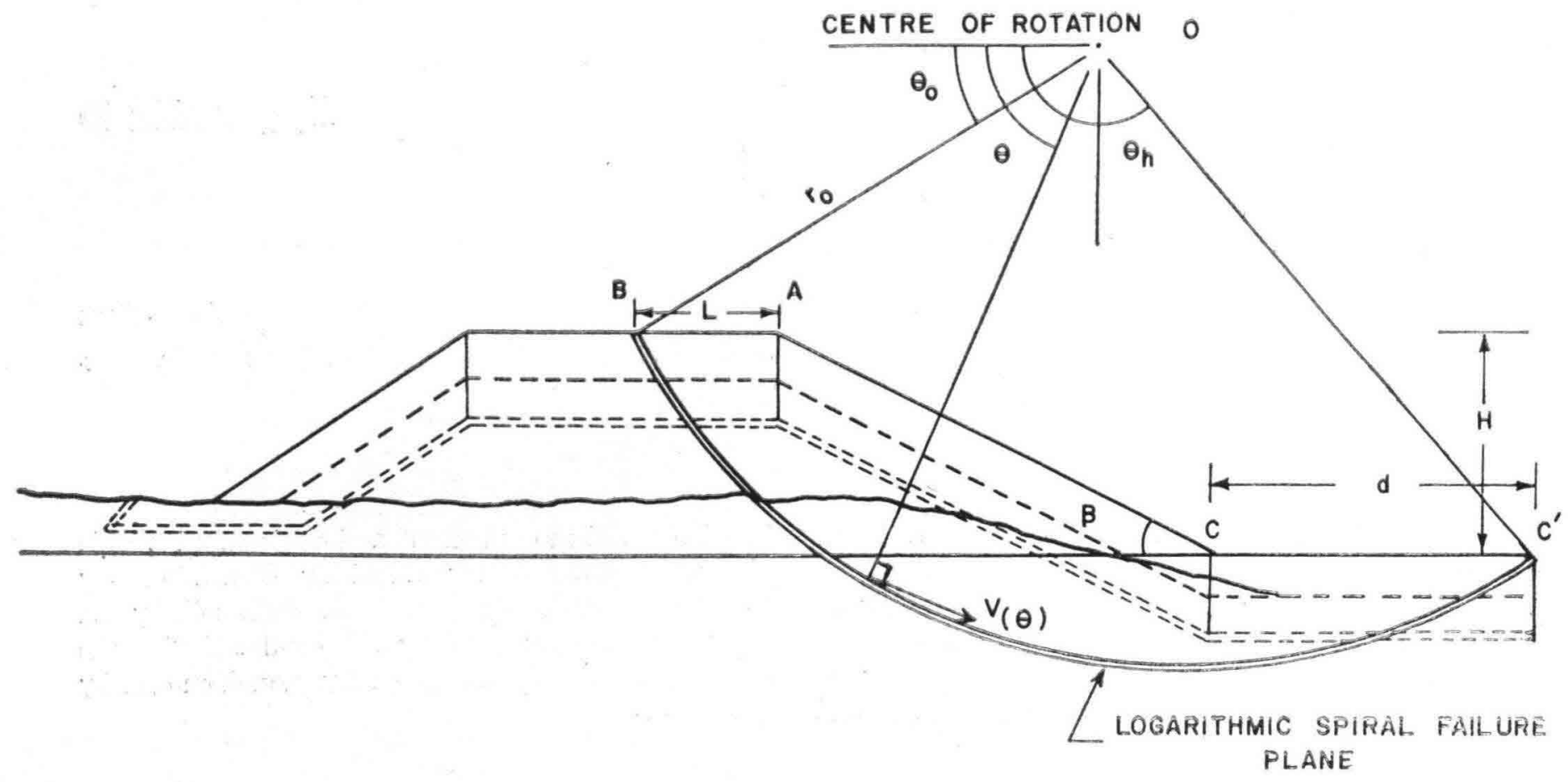

Fig. D.1 Failure mechanism for an embankment slope.

\section{D.3 Method for slope stability analysis}

There are quite a few methods currently available for performing slope stability analysis. The use of circular are and logarithmic spiral failure planes for the stability analysis (ref. 2 and 6) can generally be made for coastal soils. Though the circular arc analysis is more critical than the logarithmic spiral, it is generally observed that the shape of the failure plane is not very sensitive in the analysis of the stability

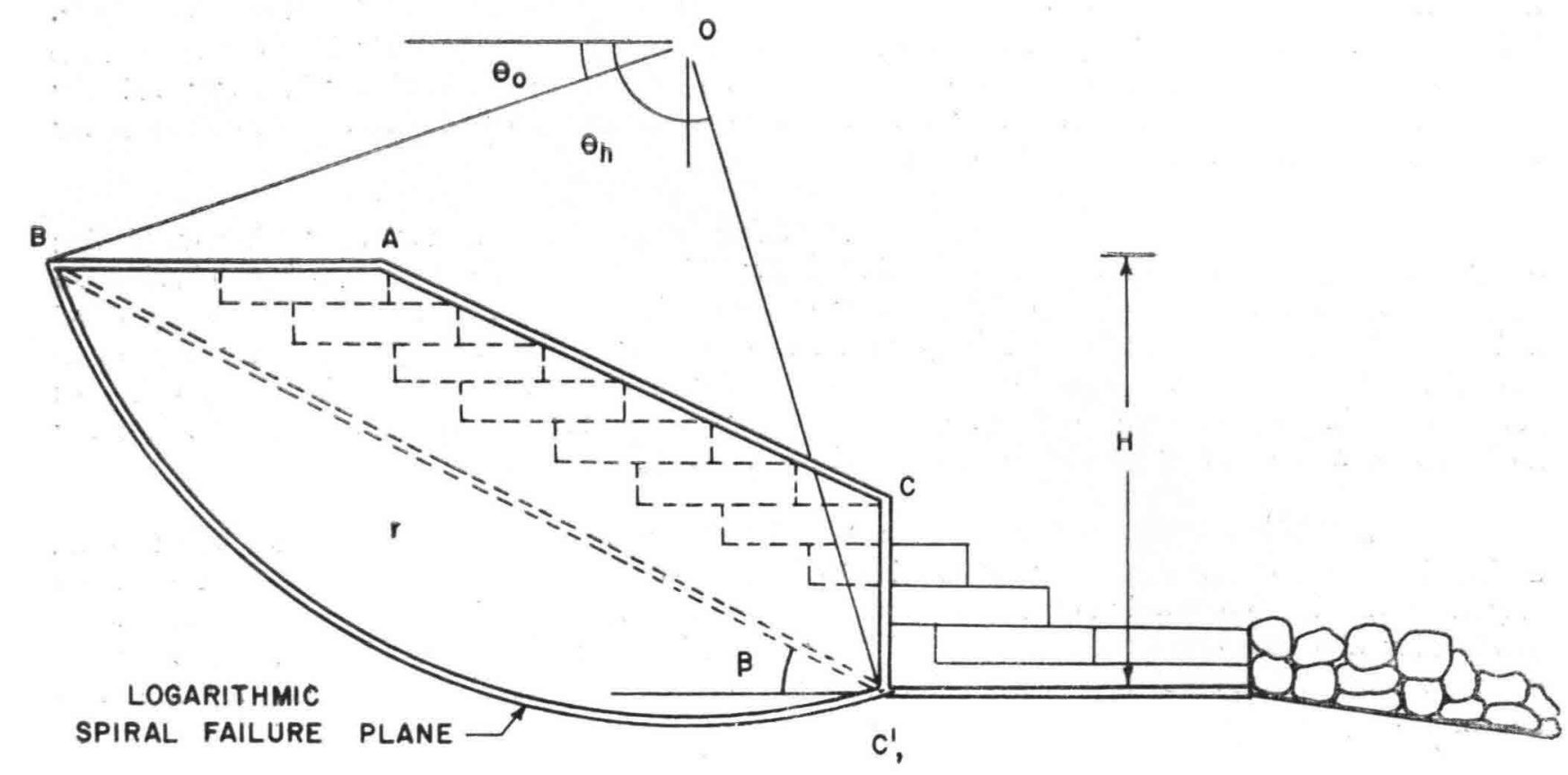

Fig. D.2 Failure mechanism for a stepped seawall slope. 


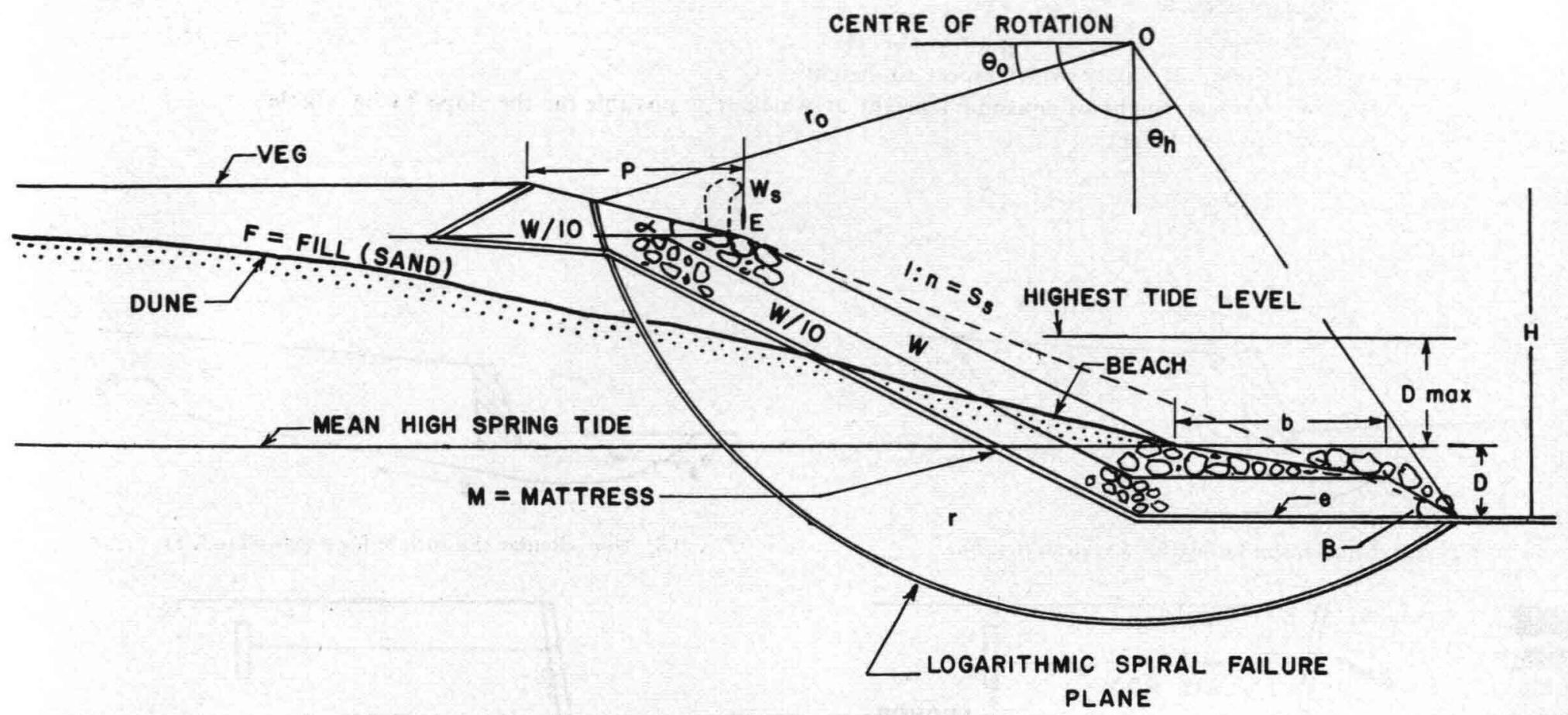

Fig. D.3 Failure mechanism for revetment slope.

problems. The advantage of assuming the logarithmic spiral angle equal to the value of friction angle of the soil is, all intergranular forces acting on the spiral slip surface are directed towards the centre of the spiral.

D.3.1 Factor of safety : The use of a factor 'of safety by engineers is to indicate whether or not a foundation soil or earthwork will fail under the worst service conditions for which it was designed. For determining the factor of safety for a slope Taylor (ref. 7) suggested the critical height as a parameter.

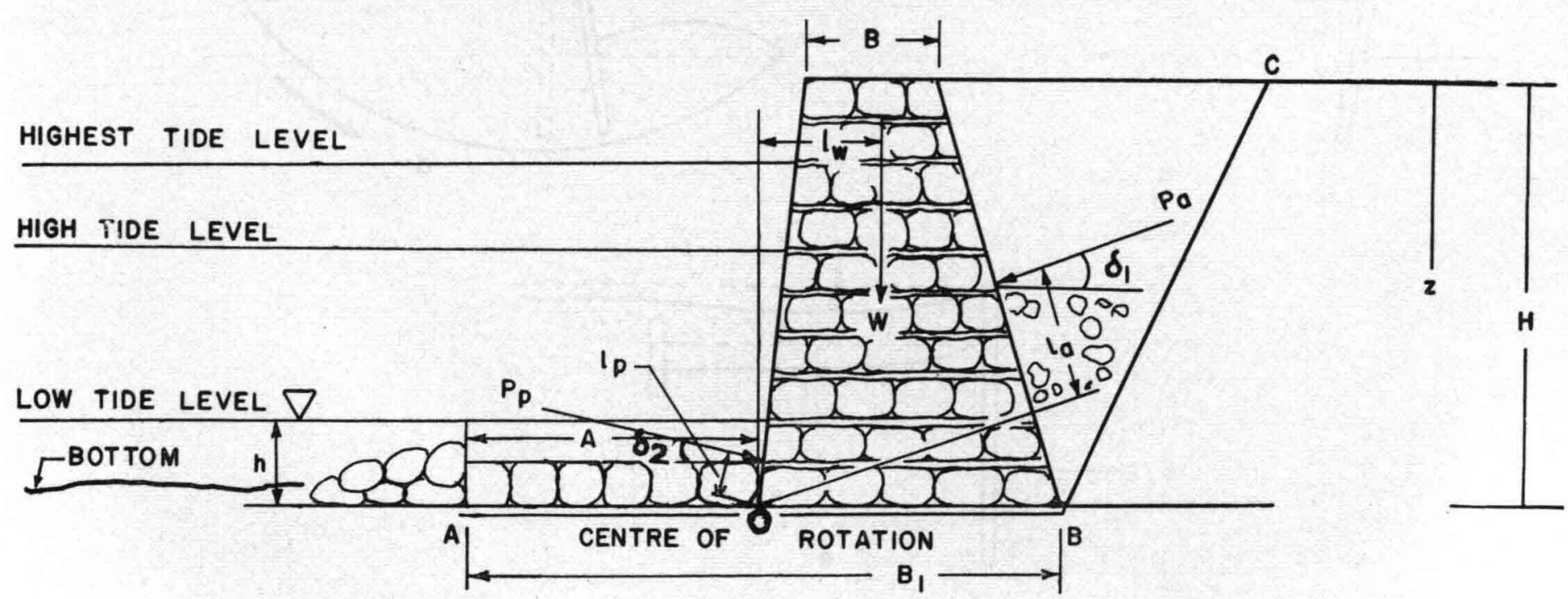

Fig. D.4 Force acting on a gravity seawall. 
This may be expressed as

$$
\mathrm{F}_{\mathrm{H}}=\mathrm{H}_{\mathrm{C}} / \mathrm{H}
$$

D.1

where $F_{H}=$ factor of safety with respect to height

$\mathrm{H}_{\mathrm{C}}=$ critical height or maximum height at which it is possible for the slope to be stable

$\mathrm{H}=$ actual height

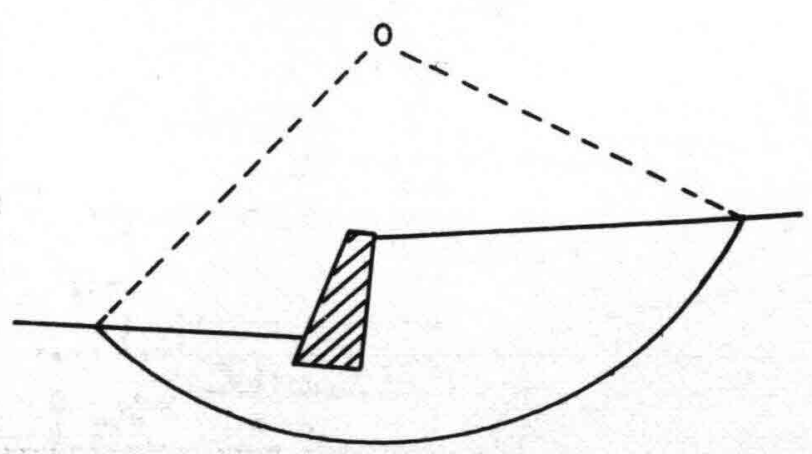

Fig. D.5 Circular slip surface for a seawall (ref. 8).
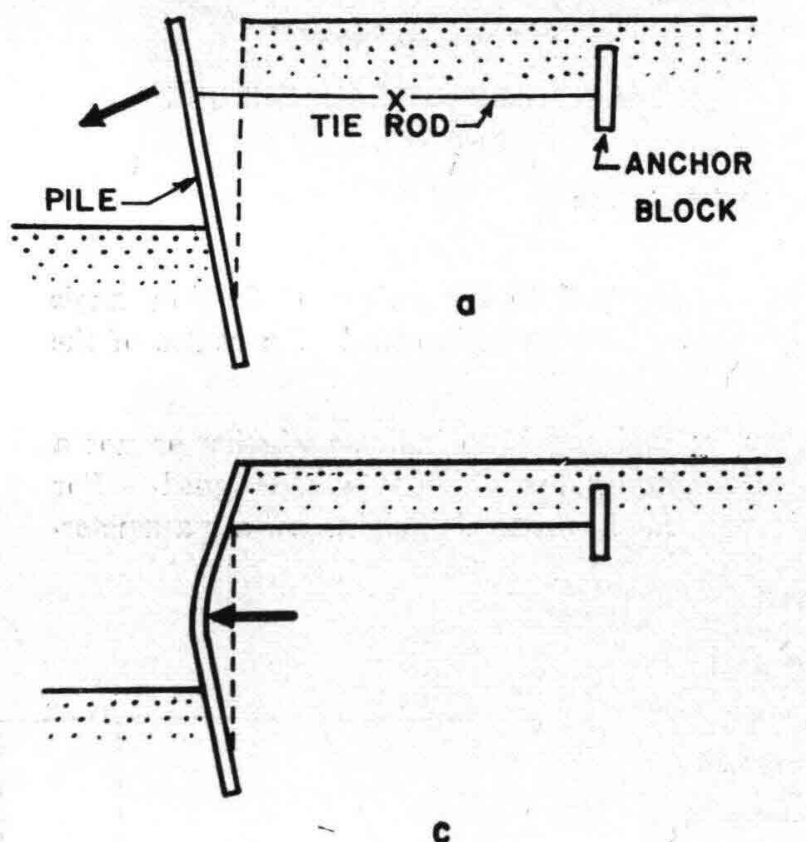

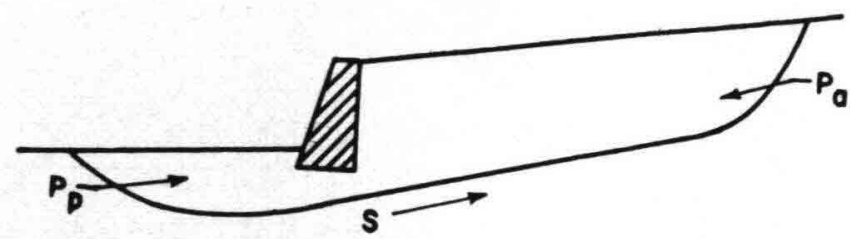

Fig. D.6 Non-circular slip surface for a seawall (ref. 8)
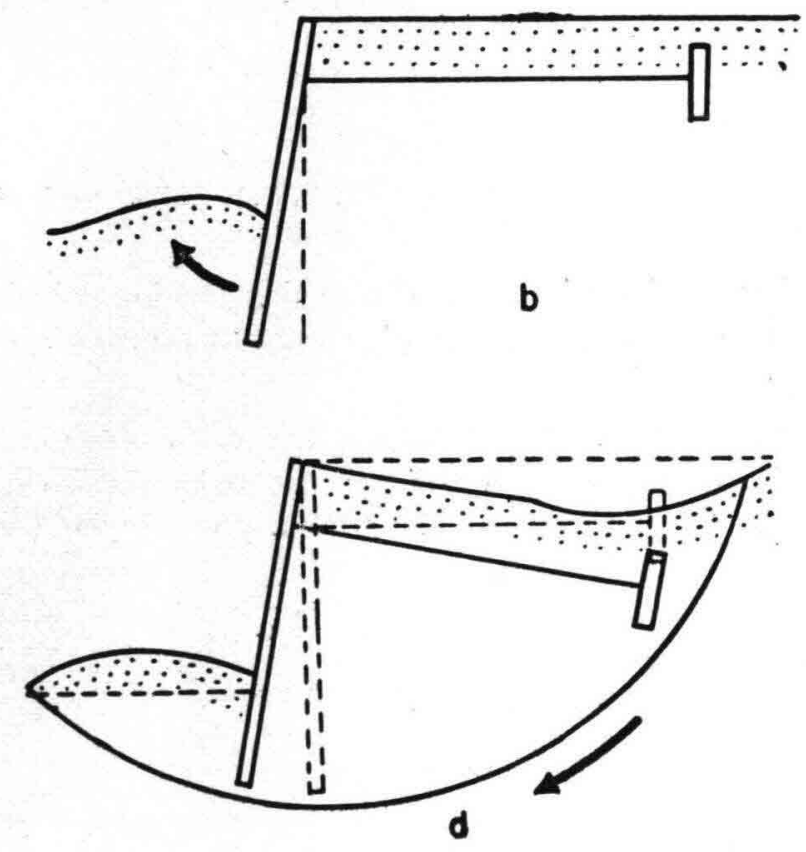

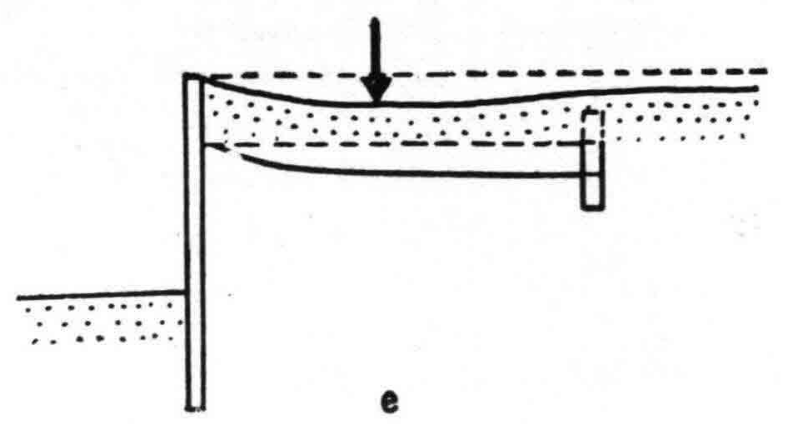

Fig. D.7 Some failure mechanisms for piled retaining walls (ref. 8). 
D.3.2 Logarithmic spiral method: This method uses the concept of yield critcrion and its associated flow rule which is governed by the stress strain relationship (ref. 1). The underlying principle of the method is that the soil mass will collapse if there is any compatible pattern of plastic deformation for which the rate of work due to external loads exceeds the rate of internal energy dissipation.

The assumed failure mechanism is shown in Fig. D.1. The region $A B C^{\prime} C A$ rotates as a rigid body about the centre of rotation $O$ with the materials below the logarithmic spiral surface $\mathrm{BC}^{\prime}$ remaining at rest. Thus the surface $C^{\prime} B$ is surface of velocity discontinuity. The mechanism can be specified by three variables $\theta_{\mathrm{o}}, \theta_{\mathrm{h}}$ and $\mathrm{H}$ where $\theta_{\mathrm{o}}$ and $\theta_{\mathrm{h}}$ are the angles between the horizontal and the chords $\mathrm{OB}$ and $\mathrm{OC}^{\prime}$ respectively and $\mathrm{H}$ is the height of the embankment. From the geometrical relationship it may be shown that the ratios $\mathrm{H} / r_{\mathrm{o}}$ and $\mathrm{L} / r_{\mathrm{o}}$ can be expressed in terms of the angles $\theta_{\mathrm{o}}$ and $\theta_{\mathrm{h}}$. The rate of internal and external work done by the region can be computed from these values.

The internal dissipation of energy occurs along the surface of discontinuity $\mathbf{B C}^{\prime}$. The differential rate of dissipation of energy along this surface can be obtained by multiplying the differential area $r d \theta / \cos \phi$ of this surface by the cohesion $c$ and the tangential discontinuity in velocity $\mathrm{V} \cos \phi$ across the surface. The total iniernal dissipation of energy is found by integration over the whole surface. Further manipulations in mathematical derivatives will result in expression for critical height, $\mathrm{H}_{c}$ as

$$
\begin{aligned}
& \begin{array}{llll}
\mathrm{H}_{\mathrm{c}} \leqslant c . \mathrm{N}_{\mathrm{s}} / \gamma & \ldots & \ldots & \text { D.2 }
\end{array} \\
& \begin{array}{lllll}
\text { or } & \mathrm{N}_{\mathrm{s}}=\gamma \cdot \mathrm{H}_{\mathrm{c}} / c & \ldots & \ldots & \text { D.3 }
\end{array}
\end{aligned}
$$

where $\gamma_{H_{c}} / c$ is dimensionless term called the stability factor $N_{s}$. Fig. D.8 shows variation of $N_{s}$ with the slope angle $\beta$ and the angle of internal friction $\phi$ with $\alpha$ varying from 0 to $\phi$ (ref. 8 ), where $\alpha$ is the slope of the surcharge soil.

The values of $c$ and $\phi$ can be known from laboratory tests conducted for the soil. The boulders lying on the slope and at the toe are presumed to offer no frictional resistance. The angle $\beta$ can be calculated from the slope of the bank. Then the corresponding value of $\mathrm{N}_{\mathrm{s}}$ can be obtained from Fig. D.8. From this $\mathrm{N}_{\mathrm{s}}$ value, critical height of the slope can be determined by using the formula $\mathrm{H}_{c}=c \mathrm{~N}_{\mathrm{s}} / \gamma$. For saturated soils, $\gamma$ should be the saturated unit weight of the fill soil. For situations

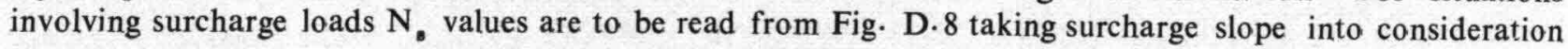

Fig. D.2 shows another shape of the embankment. In this model, due to preferred line of failure (mattress on the beach sand) there is a high probability that logarithmic spiral (failure line) may pass through the toe. Fig. D.9 presents a comparison of stability factor values for failure planes passing through and below the surface of the structure. A small difference can be noticed when slope angle $\beta$ and friction angle $\phi$ are small for the above two cases.

\section{D.4 Retaining structures}

Most retaining structures - gravity wall, cantilever wall, counterfort wall etc. are free at the top to move. If the walls have foundation footings resting on soil, the walls usually tilt as the top moves away from the backfill. Movements of a wall designed with conventional safety factors are usually adequate to satisfy the deformation condition for an active pressure. Saturation of soil has significant effect on the wall. Adequate drainage installations should, therefore, be provided for the type of wall shown in Fig. D.4, passive earth pressure acts on the front of the wall and active earth pressure on the backside. For the stability analysis, the earth pressure may be computed by Rankine's theory (ref. 1). In general, the backfill is cohesionless soil, thus, the active and passive earth pressure can be written as

$$
\begin{aligned}
& \mathbf{P}_{\mathrm{a}}=\gamma_{z}(1-\sin \phi) /(1+\sin \phi) \\
& \mathbf{P}_{\mathrm{p}}=\gamma_{z}(1+\sin \phi) /(1-\sin \phi)
\end{aligned}
$$$$
\begin{array}{ll}
\cdots & \cdots \\
\cdots & \cdots
\end{array}
$$ 


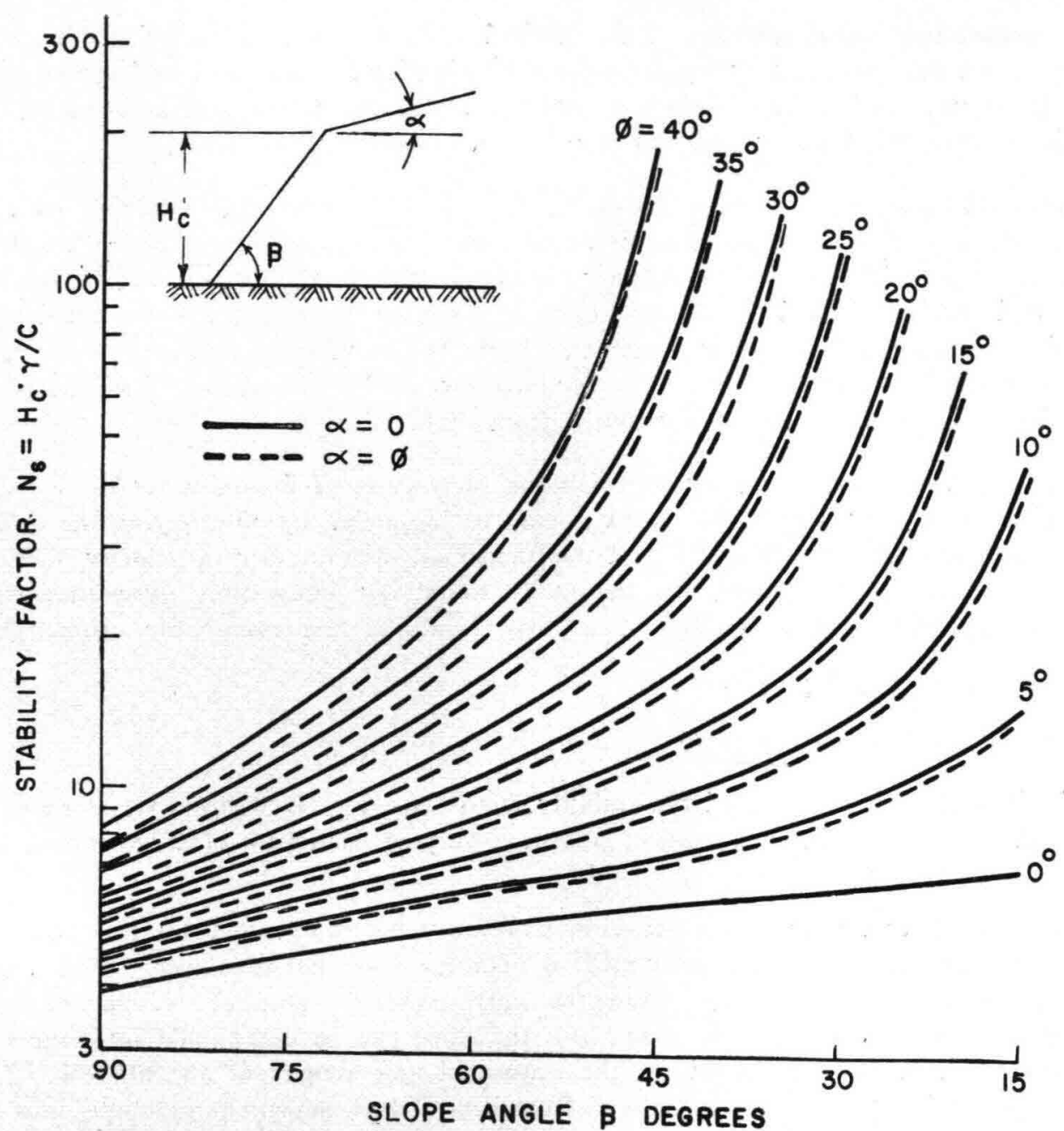

Fig. D.8 Effect of slope angle and friction angle on stability factor (ref. 8).

where

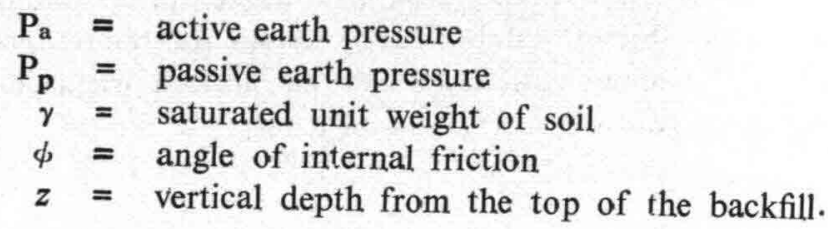

D.4.1 Stability of retaining structures: Due to earth pressure, the retaining structure may be unstable from two points of view. ( $i$ ) the structure may be subjected to a large unbalanced moment and fail by overturning or ( $i i)$ the shear failure along the slip surface may occur in the soil mass that
surrounds the wall and may result in sliding.

In Fig. D. 4 for overturning case, the failure may occur with retaining structure rotating about the point $\mathrm{O}$. Summation of moments about $\mathrm{O}$ will give

$$
\mathrm{P}_{\mathrm{a}} \cdot l_{\mathrm{a}}=\mathrm{P}_{\mathrm{p}} \cdot l_{\mathrm{p}}+\mathrm{W} \cdot l_{\mathrm{w}}
$$

A safety factor $F_{s}$ should be provided so that

where $F_{s}$ is taken as 1.5 .

$$
\mathrm{P}_{\mathrm{a}} \cdot l_{\mathrm{a}}=\left(\mathrm{P}_{\mathrm{p}} \cdot l_{\mathrm{p}}+\mathrm{W} \cdot l_{\mathrm{w}}\right) / \mathrm{F}_{\mathrm{s}}
$$$$
\text { - }
$$$$
\text { . D.7 }
$$ 


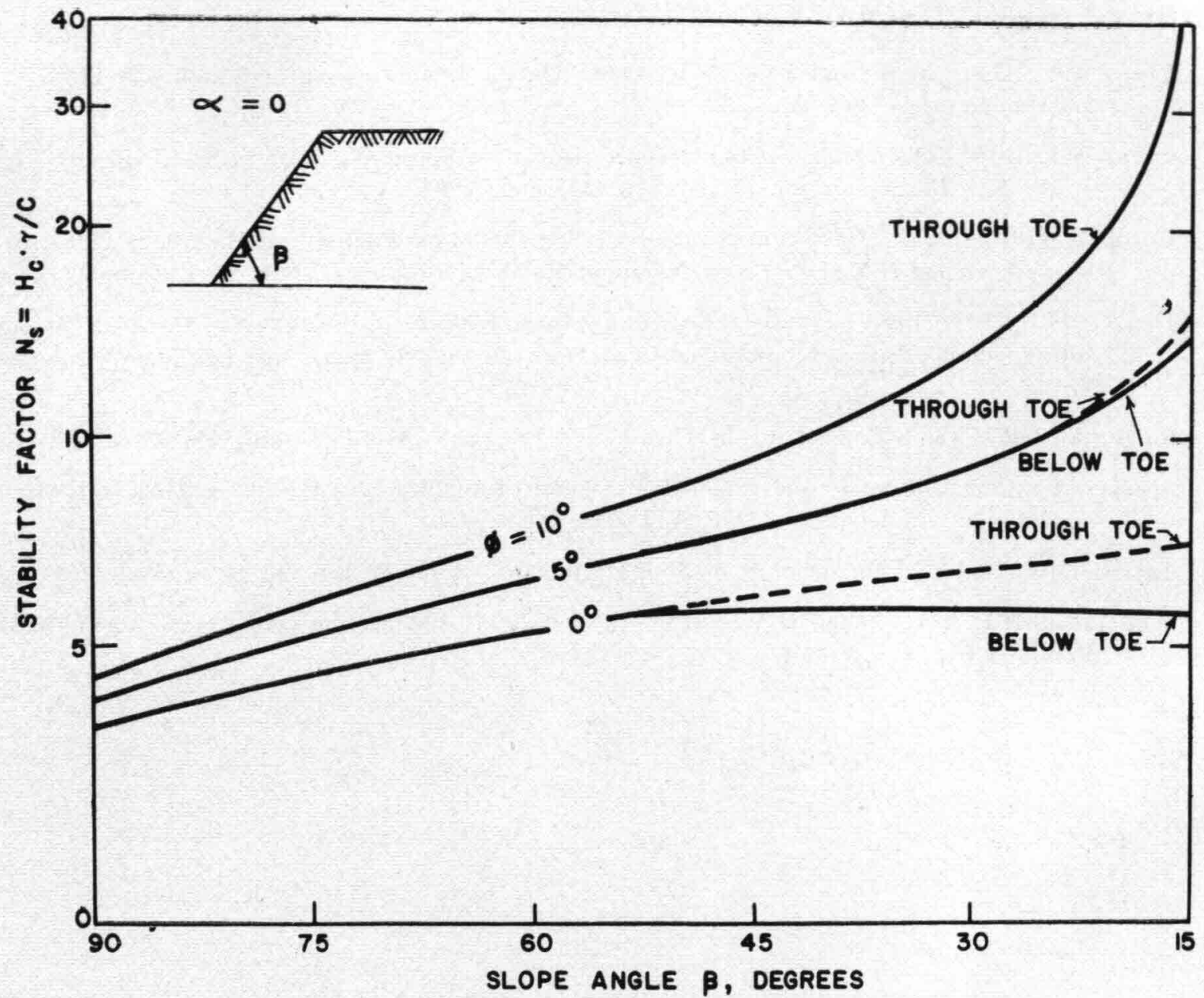

Fig. D.9 Stability factors for failure plane passing through and below the toe a structure (ref. 8 ).

$P_{\mathrm{a}}=$ total active earth pressure

$P_{\mathrm{p}}=$ total passive earth pressure

$\mathrm{W}=$ weight of the retaining wall

$l_{\mathrm{a}}, l_{\mathrm{p}}, l_{\mathrm{w}}=$ normal distances of $\mathrm{P}_{\mathrm{a}}, \mathrm{P}_{\mathrm{p}}$ and $\mathrm{W}$ respectively from the axis of rotation $\mathrm{O}$.

The sliding occurs when the shear stress along the line passing through the mattress becomes equal to the shear strength. One possible slip surface may be AOBC as in Fig. D.4. The safety with respect to this slip surface may be calculated by summation of forces in the horizontal direction. Considering the wall as a free body, it can be shown that

$$
\mathrm{P}_{\mathrm{p}} \cdot \cos \delta_{2}+\mathrm{S}=\mathrm{P}_{\mathrm{a}} \cdot \cos \delta_{1}
$$$$
\text { . }
$$

where $S$ is shearing resistance between the soil and the base of the wall and $\delta_{1}$ and $\delta_{2}$ are the angles of active and passive earth pressures. To provide safety factor $F_{s}$, it can be written as

$$
\begin{array}{llllr} 
& P_{\mathrm{p}} \cdot \cos \delta_{2}+S=F_{s}\left(P_{a} \cdot \cos \delta_{1}\right) & . & . . & D \cdot 9 \\
\text { or } & P_{s}=\left(P_{p} \cdot \cos \delta_{2}+S\right) /\left(P_{a} \cos \delta_{1}\right) & \ldots & . . & D \cdot 10
\end{array}
$$

For cohesionless soils the above equation generally indicates the critical condition and therefore, can be applied to coastal structures. For more detailed information Chapters 10, 11, 12 and 13 of Foundation Engineering Handbook (1975) edited by H. F. Winterkorn and H. Y. Fang and published by Van Nostrand Reinhold Company, New York (ref. 8). may be referred to. 


\section{References}

1 Chen, W.F., Giger M.W. and Fang, H.Y., 1969, “On the Limit Analysis of Stability of Slopes”, Soils and Foundations, Vol. 9, No. 4.

2 Chen, W.F., 1970, "Discussion of Circular and Logarithmic Spiral Slip Surfazes by E. Spencer", Journal of the Soil Mcchanics and Foundation Division, ASCE, Vol. 96, SM.1.

3 Cornfield, G.M., 1975, "Shcct Pile Siructurcs" in Foundation Engineering Handbosk edited by H.P. Winterkorn and H.Y. Fang, Van-Nostrand Reinhold Company, Ncw York.

4 Henkcl, D.J., 1957, "Investigations of Two Long Term Failures in London Clay Slopes at Woodgreen and Northolt", Proc. 4 International Conference on Soil Mechanics and Foundation Engineering, Vol. 2 .

5 Singh, A·, 1967, "Soil Engincering in Theory and Practice", Asia Publishing House, Bombay.

6 Spencer, E., 1969, "Circular and Logarithmic Spiral Slip Surfaccs", Journal of the Soil Mechanics and Founda ion Division ASCE, Vol. 95, No. S. M. 1.

7 Tayler, D.W., 1948, "Fundamcntals of Soil Mechanics", John Willey and Sons, New York.

8 Winterkorn H.F. and Fang H.Y., 1975, "Foundatiom Engineering Handbook", Van-Nostrand Reinhold Co, New York. 


\title{
Appendix E
}

\section{Rocks for Coastal Protection}

\author{
B. G. WAGLE AND K. H. VORA \\ National Institute of Oceanography, Dona Paula, Goa
}

\section{E.1 Introduction}

Protection to shoreline may be requircd for beach stabilization, for backshore protection from waves and storm surgcs, for inlet stabilization and for piotection of the harbour. Depending upon a particular requirement, a suitable structure is constructed from locally available material wherever possible. It is not always possible to mect all the specifications required for the construction material while designing a coastal structure. The building material losally available plays a significant role in bringing down the to:al cost of a structure. The qualitative requirements of rocks for coastal protection are only a few but they are rcquired in large quantities. Therefore, it is essential that they are naturally occurring/outcropping in the vicinity of the structure proposed to be constructed.

\section{E.2 Essential properties of rocks for coastal protection}

The strength properties of rocks vary significantly within the same rosk-iype and even within the same formation and therefore, it is only in a general way that the properties can be discussed. Durability, hardness, compactness, porosity are critical in determining the suitability of a rock for construction at sea (ref. 13).

The requirements for coastal protection demand that the rosk must have sufficient strength to withstand hostile forces of the sea. The rock should also have a high resistance against chemical corrosion as the sea water corrodes almost everything with which it is in constant interaction. Some important properties of rocks with examples of common rozk types along the Indian coasts are discussed below.

E.2.1 Durability : Rocks are aggregates of minerals and therefore, the nature of constituents and manner in which they are held together determine the capacity of particular rock to withstand disintegration and decomposition due to heat, pressure, etc. Of spcsial importanse is the chemical action of sea water and that too on sedimentary rocks.

Granites and basalts are generally preferred because of their fine grains and absence of joints. Sedimentary rocks, i.e., sandstone, shale or limestone are products of secondary dynamic conditions, and therefore, they yield easily to powerful forces. Phyllites and schists may be durable, however, their cleavages may sometimes make them unfavourable.

E.2.2 Hardness : Hardness of rock is dependent on many factors such as constituent minerals, mode of origin and nature of cementing material in sedimentary rocks. Igneous rocks are comparatively harder than the sedimentary rocks while granites, dolerites and basalts are harder among the igneous rocks and quartzite is harder due to dominance of quartz. In the case of metamorphic rocks, hardness depends on the plane. A plane parallel to the cleavage naturally will have less hardness than the one perpendicular to the cleavage. Phyllites and slates are good examples of this. 
E.2.3 Strength : The strength of rock is defined as its ability to resist crushing under direct pressure or sometimes its resistance to fracture when it is subjected to transverse forces. Strength of material is more important as some rocks have less strength in a wet condition than when they are dry.

E.2.4 Size : Since rocks are to be used in specific sizes according to particular design for the coastal protection, the availability of rocks in a particular size becomes very important.

E.2.5 Weight : Heavier stones have grcater density, lower porosity and greater compactness. Thus fine grained, heavy dense rocks are highly desirable in coastal protection works.

E.2.6 Porosity and absorption : Porosiiy of the rock plays a significant role in the selection of the material which would be under constant attack of waves. Highly porous rocks are generally not favoured. Sea water will have negligible effects on granites and basalts whereas limestone is bound to react and will get dissolved in sea water. Laterite, though highly porous has been reported to have a high resistance to chemical decomposition and can be used for coastal protection as an alternative to other rock types of better quality. Due to abundance of laterite along the coasts of India, its use may be explored. comparison.

Table E.1 gives the range of values of important properties for some common rock types for

Table E.1 Important engineering properties of common rock types (ref. 15).

\begin{tabular}{|c|c|c|c|c|c|}
\hline Rock & $\begin{array}{l}\text { Young's } \\
\text { Modulus at } \\
\text { zero load } \\
105 \mathrm{~kg} / \mathrm{cm}^{2}\end{array}$ & $\begin{array}{l}\text { Bulk density } \\
\mathrm{g} / \mathrm{cm}^{3}\end{array}$ & $\begin{array}{l}\text { Porosity } \\
\text { per cent }\end{array}$ & $\begin{array}{l}\text { Compressive } \\
\text { strength } \\
\mathrm{kg} / \mathrm{cm}^{2}\end{array}$ & $\begin{array}{r}\text { Tensile } \\
\text { strength } \\
\mathrm{kg} / \mathrm{cm}^{2}\end{array}$ \\
\hline Granite & $2-6$ & $2 \cdot 6-2 \cdot 7$ & $0.5-1.5$ & $1000-2500$ & $70-250$ \\
\hline Dolerite & $7-10$ & $3 \cdot 0-3 \cdot 05$ & $0.1-0.5$ & $2000-3500$ & $150-300$ \\
\hline Basalt & $6-11$ & $2 \cdot 8-2 \cdot 9$ & $0 \cdot 1-1 \cdot 0$ & $1500-3000$ & $100-300$ \\
\hline Sandstone & $0 \cdot 5-8$ & $2.0-2 \cdot 6$ & $5-25$ & $200-1700$ & $40-250$ \\
\hline Shale & $1-3 \cdot 5$ & $2 \cdot 0-2 \cdot 4$ & $10-30$ & $100-1000$ & $20-100$ \\
\hline Limestone & $1-8$ & $2 \cdot 2-2 \cdot 6$ & $5-20$ & $300-3500$ & $50-250$ \\
\hline Quartz & - & $2 \cdot 65$ & $0.1-0.5$ & $1500-3000$ & $100-300$ \\
\hline Gneiss & - & $2 \cdot 9-3$ & $0: 5-1 \cdot 5$ & $500-2000$ & $50-200$ \\
\hline Slate & - & $2 \cdot 6-2 \cdot 7$ & $0.1-0.5$ & $1000-2000$ & $70-200$ \\
\hline Laterite* & - & $1 \cdot 8-2 \cdot 2$ & - & $7-25$ & - \\
\hline
\end{tabular}

Another factor which needs consideration in the use of locally available rocks apart from the cost of quarrying and transportation, labour, altitude, and is the design life of the structure and the cost involved in the replacement of material within that period versus the cost of transporting better material from sources at greater distances.

\section{E.3 General geology of peninsular India}

The Indian peninsula is divided into three well defined regions, $i \cdot e$, the peninsular, the Indogangetic alluvial plains and the extra peninsula. The southern Indian shield known as the peninsula is a triangular tract extending about $1500 \mathrm{~km}$ from north to south. It has a width of about $800 \mathrm{~km}$. The larger part of the shield is underlain by a vast complex of ancient gneissic and granitic rocks for which the name 'peninsular gneiss' has been given. These are typically migmatitic gneiss with alternate bands of amphibolite and tonalite with inclusions of older rocks (ref. 12). Islands and lenses of various sizes with a granitic and granodioritic composition are common within the gneissic complex. Over these ancient rocks lie Pre-Cambrian and later sediments and extensive sheets of horizontal Deccan Traps. Some Mesozoic and Tertiary sediments are found mainly along the coastal regions. The Western and the Eastern Ghats are the main mountains along the Indian coasts.

The western ghats is a long unbroken escarpment extending for about $1280 \mathrm{~km}$ parallel to the west coast and mark an important physiographic feature of the Indian peninsula. The ghats 
commence south of the Tapti estuary in Gujarat and extend south up to Cape Comorin as a wall with only one major break at Palghat. The ghats comprise many geological formations of differing physical and structural characteristics. The northern half of the ghats from the Tapti valley down to Goa is formed of horizontal beds of massive Deccan Traps. South of Goa, the horizontal bedded traps give place to steeply dipping gneisses and schists and further south in Kerala, the ghats recede inland leaving a fertile coastal plain (ref. 11).

The Eastern Ghats include a series of rather detached hill ranges of heterogenous composition. These do not belong to a single geological formation, but vary with the country-side through which the hills pass. The ghats stretch intermittently from the northern border of Orissa, through the coastal regions of Andhra Pradesh to join the Nilgiris in the western part of Madras. They are uniform in their charaster in Orissa and in the northern part of Andhra down to the valley of the Krishna river. They are composed of garnetiferrous sillimanite gneisses and large masses of charnockite (ref. 8).

The close of the Mesozoic era was marked by the outpouring of enormous lava flows which spread over vast areas of western, central and southern India. The lavas spread out far and wide as nearly horizontal sheets. The area now occupied by the Deccan Traps is about 500,000 sq km covering Gujarat, Maha-. rashtra, Madhya Pradesh and extending up to parts of Andhra Pradesh and Karnataka. The Deccan Traps are thus the most extensive geological formation of peninsula at present, with the exception of the metamorphic and igneous complex of Archaean age. Dykes are numerous in the traps but thcy are not evenly distributed, some areas being devoid of them and others closely crowded with them. In many localities they form excellent building stones, provided that proper varieties are carefully chosen.

\section{E.4 Geology of the coastal zone}

Eastern and western coasts of India show some significant differenccs. The eastern coast is markedly low-lying with a number of large river deltas. The western coast is largely devoid of deltas and a large stretch especially in the central part is marked by cliffs and promontorics (Maharashtra-Konkan coast) and lakes, lag oons or backwaters in the south (Malabar coast). At some places, especially along the tidal estuaries, deltaic fronts or salt marshes, mangrove swamps line the coasts. The coastline in front of the deltas, for example, the Ganges is liable to significant changes owing to the constant struggle between the seaward growth of the delta, the erosion by the waves and the formation of sand bars.

E.4.1 Kutch coast : A 5 to $16 \mathrm{~km}$ wide strip along the coast of Kutch is largely covered by alluvium consisting of wind blown loam and sand underlain by clay (Fig. E-1). Between the alluvial belt and the traps there are two belts of Tertiaries roughly parallel to the shore. The older beds consist of clays and limestones of Eocene Age. The younger beds are sandstones and clays ranging in age from lower Miozene to Pliocene (ref. 1). Occurrence of miliolite rocks is also reporied from Kutch but no outcrops are seen along the coast (ref. 2).

E.4.2 Kathiawar coast : Deccan traps occur very close to the shore in norihern part while in other areas the traps recede to the interior. Along the south-west coast from Porbandar to Veraval miliolites are extensively exposed along the coast and extend 30 to $40 \mathrm{~km}$ inland. The formation over the Pliocene and Miocene rocks directly overlies the Deccan traps towards the north and easi. On the coast, its thickness increase appreciably and these form a thick wedge against the older traps (Fig. E.1). Along the southern part of the coast, the thickness of the miliolite formation has been estimated to be $60 \mathrm{~m}$ or more (ref. 2). The formation is marked by thin banding oblique lamination and a gentle seaward dip of $5^{\circ}-15^{\circ}$. The miliolite is coarser near the shore but becomes progressively finer grained with increasing distanze from thz shores (ref. 9). Though the basalt occurs more than $25 \mathrm{~km}$ from the shore, becausc of its durability it will be advantageous to use the basalt instead of miliolite limestone for coastal protection works.

E.4.3 South Gujarat coast: The rivers Mahi, Tapti and Narmada form broad and fertile alluvial plain at their confluence with the sea (Fig. E.1). The plain resembles to a considerable extent the alluvial plains of the cast coast. The plain covers a greater part of the Surat, Broach and Ahmedabad districts. It 


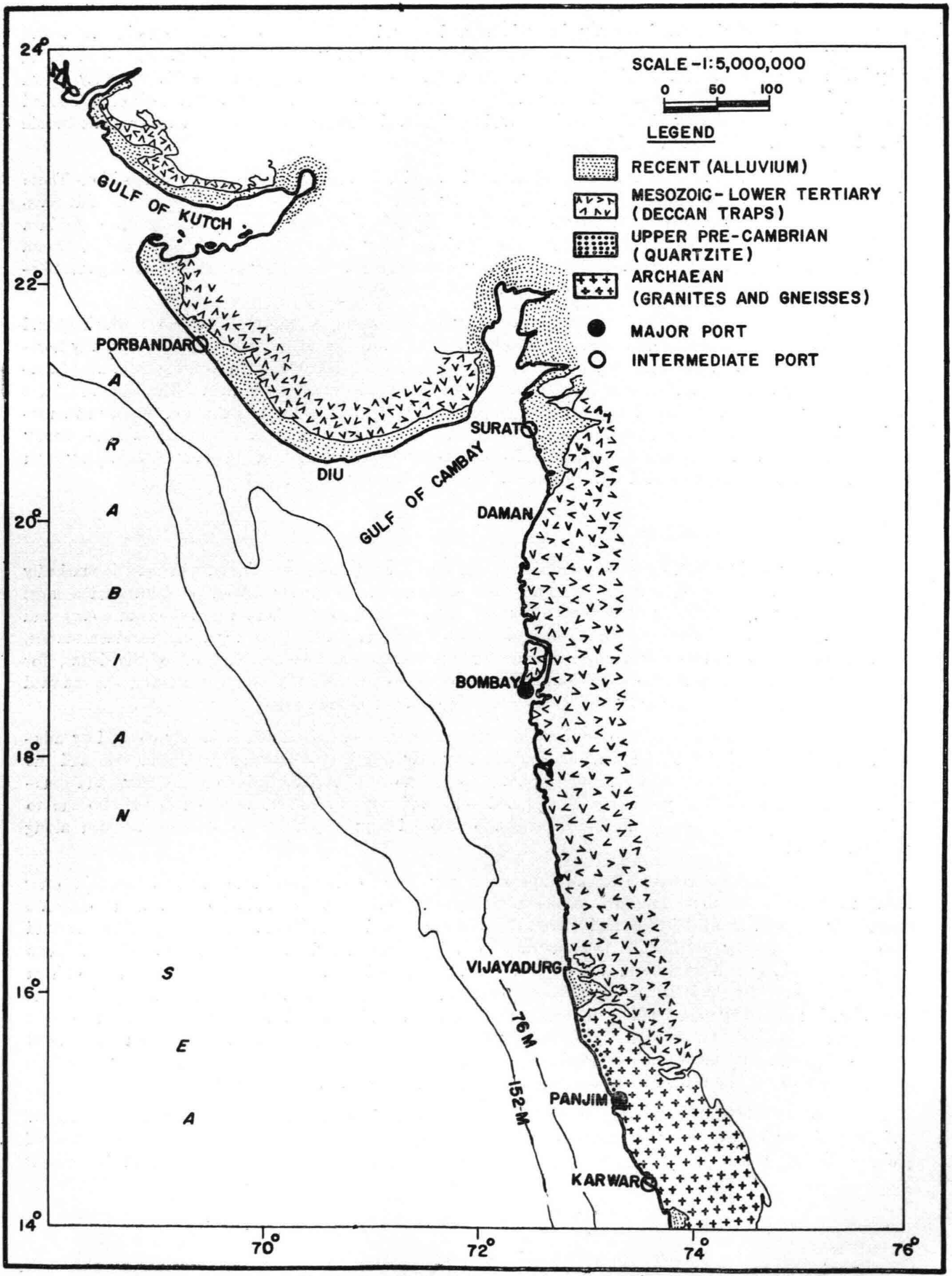

Fig. E 1 Geological map of north-west coast of India, 
extends from the Rann of Kutch to just south of Daman. In the north, it joins the recent deposits of the Indus Valley (ref. 10).

Cambay trough runs nearly north-south and it is bounded by faults on its eastern and western sides. The Deccan traps which are exposed at the surface on both the sides of the trough, in Kathiawar and Baroda areas, have been faulted down to a depth of over $1800 \mathrm{~m}$ in the trough. The traps are covered by a full succession of Tertiaries. The Tertiaries between Broach and Surat are capped with laterite. A number of small detached outcrops of Bagh beds (Cretaceous) occur along the east-west trending Narmada Valley from Bagh to beyond Baroda. The formations are cherts, impure shelly limestones, quartzitic sandstones and shales. The sandstones underlying the Bagh beds, particularly near Baroda provide large quantities of excellent building stones of very handsome appearance and durability (ref. 14).

E.4.4 Konkan coast: From Daman to Vijaydurg in Ratnagiri District, the Deccan trap is the dominant geological formation and extends upto the coast and possibly continue to the shelf also (Fig. E.1). The lava flows at some places are separated by thin beds of lacustrine or fluviatile sediments (ref. 14). The traps usually consist of basalt or dolertie. The most common being a dark green or nearly black normal augite basalt without olivine and often with significant assembly of basic glass. The rocks do not vary in its composition over wide areas. The average specific gravity is 2.9 but there is a wide difference in texture. Most of the varieties are homogenous, hard and compact (ref-10) but some are vesicular and scoriaceous. The amygdaloidal cavities are filled up by numerous secondary minerals like calcite, quartz and zeolites. The quartzites are megascopically uniform micaceous (usually biotite) which gives rise to a feeble schistosity. The quartzites are dark grey to whitish grey and buffish white fine to coarse grained and massive to well stratified. Massive milky white quartz veins are seen cutting across the quartzites at many places. The quartzites have been intruded by quartz veins and basic dykes.

A laterite of variable thickness caps the geological formations along the coast. The laterite covers almost the entire coastal track except very steep slopes, rivers, valleys and the alluvial areas.

Granite and gneisses with intercalations of metabasalt form the dominant rocks of the coastal area from Betul to Karwar. The gneisses composed of fine grained quartz and feldspar are well bounded. The banding is generally parallel to the foliation but some streaks of quartz and feldspars cut across the foliation. The gneisses gradually merge with the massive coarse grained and unfoliated granite. The metabasalts represent very low grade metamorphosed Dharwarian basalt with feeble schistosity.

E.4.5 Malabar coast : The narrow coastal belt from Karwar to north of Quilon (except Calicut to Cannanore) is covered by alluvium which adjoins the gneisses and granites to the east (Fig. E.2). The gneisses are typically migmatitic with alternate bands of amphibolite and tonalite. Inclusions, lenses and islands of older rocks of granites, granodiorites and charnokites are common in the gneisses. From Calicut to Quilon laterite capped tertiary beds cover the gneisses in the coastal area. From Calicut to Cannanore, the alluvial belt is very narrow and the gneisses almost abut the coasts.

Along the south-west coast of India, various types of rocks constituting the ancient formations, i.e., gneisses, garnetiferous sillimanite bearing granulitic, gneisses of high grade metamorphism, leptynites charnockites, crystalline limestones and graphitic schists are exposed at some distance from the coast (ref. 7).

Near Cape Comorin crystalline gneisses of Cardamon hills abut the shore. The coastal alluvium occupy the forms of an extremely narrow zone and landward is underlain by coastal tertiaries followed by gneisses and granites. The coastal area from Cape Comorin to Rameshwaram is largelycovered by Tertiary and Recent sediments.

E.4.6 Coromandal coast : Between Manamadurai and Pondicherry, extending from the coast to about $80 \mathrm{~km}$ inland the area is covered by tertiary to cretaceous sedimentary rocks (Fig. E.2). Theese sedimentary rocks overlie the gneisses and charnockites of the basement (ref. 3, 4 and 5).

Between Cauveri delta to Visakhapatnam, there are isolated outcrops of the upper Gondwanas along a narrow strip of the country between the coast and gneisses to the east. The upper Gondwanas for the most part are composed of littoral sandstones, gravel and conglomerate rock with ozcasional shale intercalations (ref. 14). 


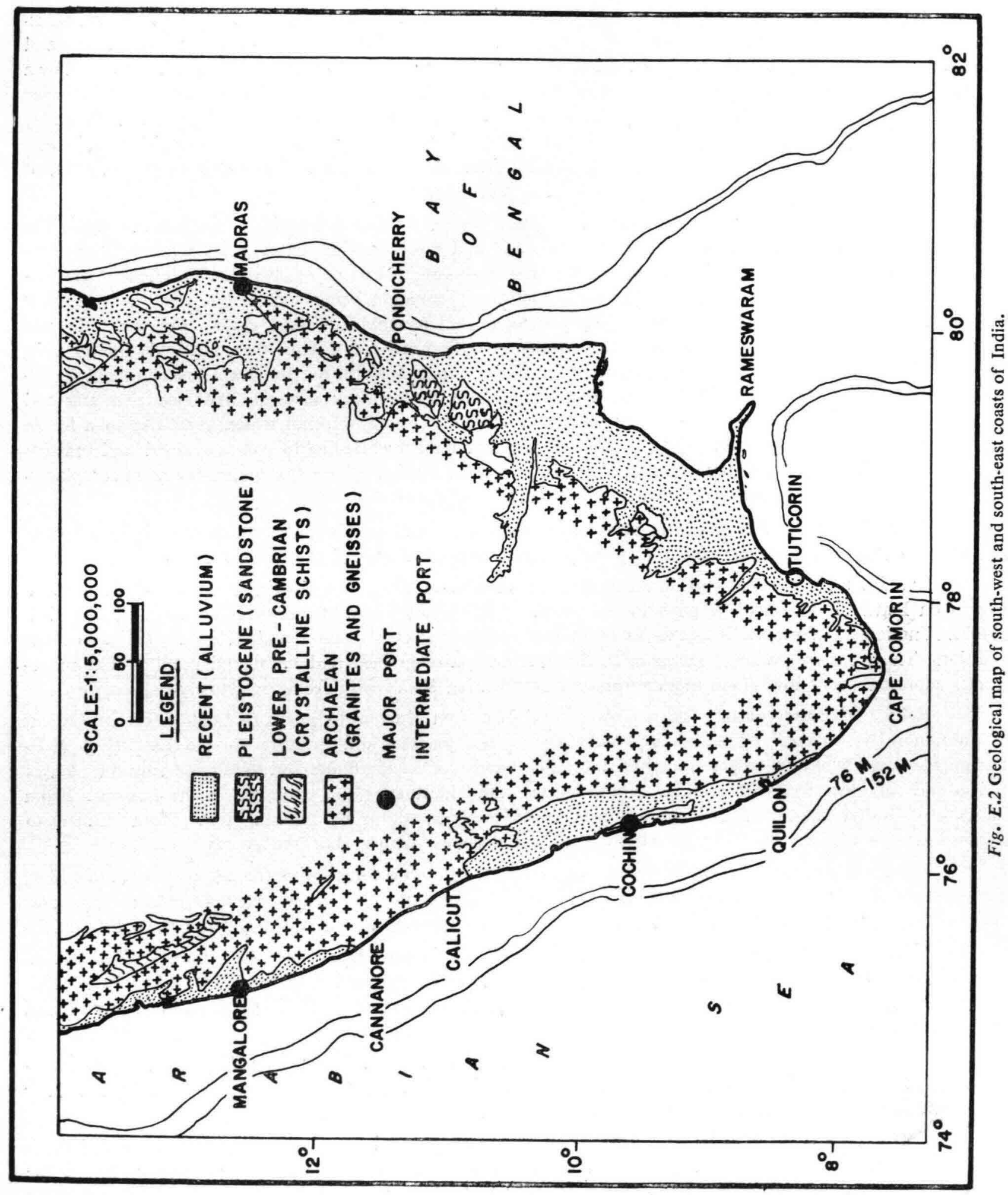




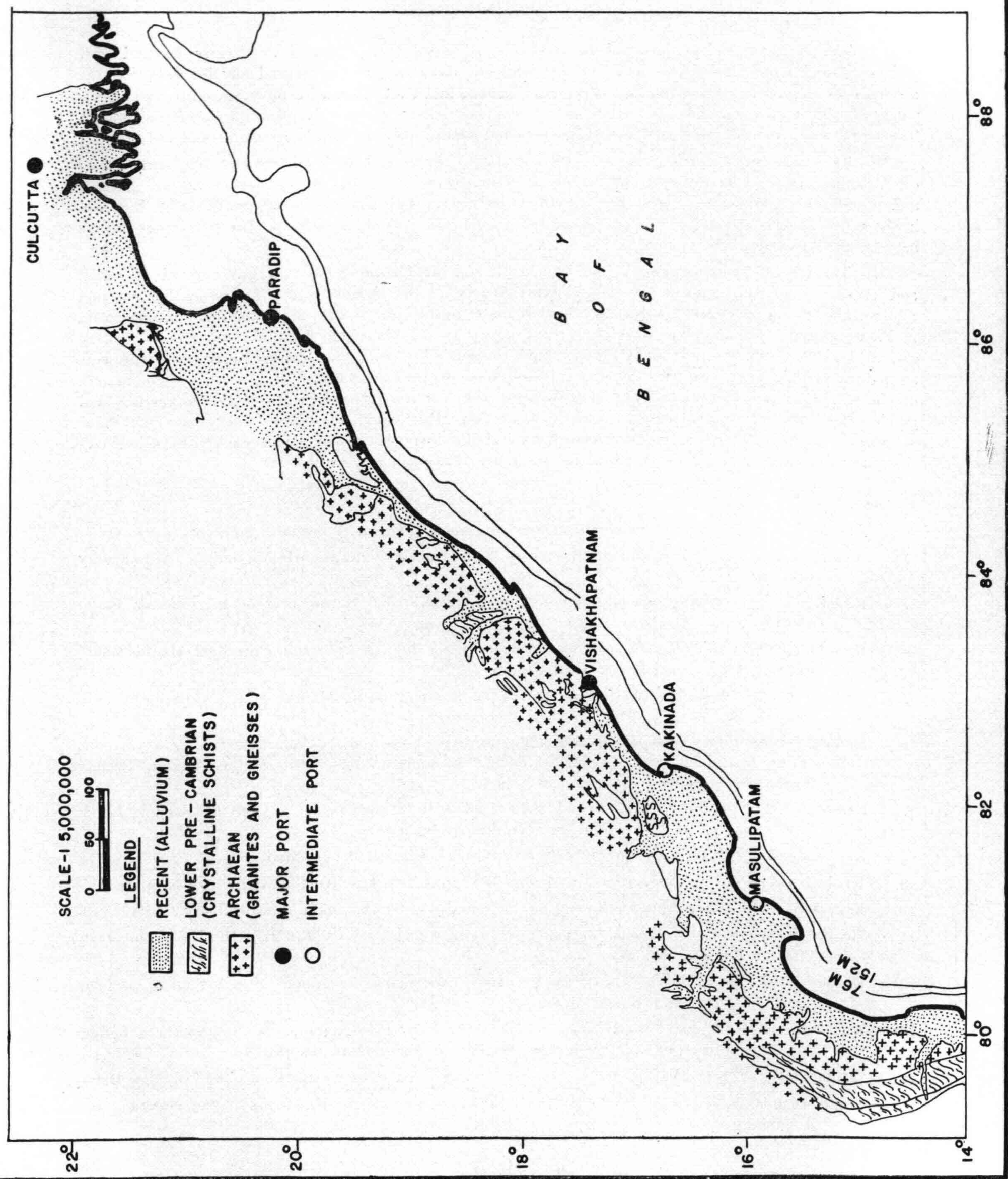

Fig. E.3 Geological map of north-east coast of India. 
The Krishna and Godavari deltas and the adjoining coastal tracks are largely covered with pleistocene and recent deposits of the rivers. The thickness of the recent alluvium gradually decreases from the shore to the delia heads where the ancient granite, gneisses and basic rocks are exposcd. A narrow triangular patch of the Upper Gondwanas occurs in the Godavari valley south near the town of Rajahmundry. The Upper Gondwanas consist of limestones, clays and sandstones with boulder conglomerates (ref. 14).

The northern Circars coast from Kakinada to Puri is mainly covcred by alluvium except off Visakhapatnam where the rosk cliffs abut the shore (Fig. E.3). In the intorior the ancient gneisses and granites with khondalitos and charnockitos are exposed. The khondalites are particularly dominant in the north-eastern and souih-wesicrn cxircmities of the region. A small outcrop of charnockites occurs between the Vasamdhara river and the Chilka lake.

The coastal region betwcen the Mahanadi and the Ganges deltas is largely covered by recent and sub-recent deltaic deposits of these rivers. Shoreward the coastal zone of Ganga delta region adjoins the mangrove tidal forests of Sunderbans. Towards the west the monotony of the plain in Balasore and Midnapore is broken by sand dunes. In the Mahanadi delta the topography of the coastal region is marked by mangrove swamps towards the shore but further inland it represents an alluvial deliaic plain traversed by wide distributaries of river Mahanadi. The north-western margin of the deltaic plains is marked by lateritic hills near Cuttack. The ancient crystallines, gneisses and granites are exposed to the west at some distance from the shore, the nearest they reach the shore is Balasore (about $30 \mathrm{~km}$ ). In the Mahanadi delta and the north patches of older fossiliferous sedimentaries (Baripada banks and Upper Gondwanas) occur near Baripada and Puri.

\section{References}

1 Ahmed, E., 1972, "Coastal Geomorphology of India", Orient Longman, Bombay.

2 Biswas, S. K., 1971, “The Miliolite Rocks of Kutch and Kathiawar (Western India)”, Sedimentary Geology, 5 pp.

3 Kailasam, L. N., 1961, "Seismic Exploration in the Karaikal-Nagore area of the Cauvery Basin, Madras State", Current Science, 30.

Kailasam ,L. N., 1964, "On the Siructure of the Sedimentary Basin of the Coastal Area of the Madras State" Bullctin of the Indian Gcophysical Union, 1.

5 Kailasam, L. N·, 1966, "Gcophysical Studies of the Ramnad Basin, Madras State", Current Science, Vol. 35, No. 8 .

6 Kailasam, L·N., 1968, "Some Results of Geophysical Exploration over the Cretaceous Tertiary Formations of the Mrdras Coast", Gcological Society of India, Memoir No. 2 of Crctaccous Tertiary Formations of South India, Scminar Volume.

7 Krishnan, M. S., 1966, "Tectonics of India", Bulletin of the Indian Geophysical Union, Na. 3, Proceedings of the Symposium on Tectonics.

8 Krishnan, M.S., 1968, "Geology of India and Burma", Higginbothams, Madras.

9 Krishna Swamy, S. K., 1972, "India’s Mineral Resourccs", Oxford IBH Publishing Co, New Delhi.

10 Lele, V.S., 1973, "The Miliolite Limestone of Saurastra, Wcsícrn India”, Sedimentary Gcology, 10.

11 Pascoc, E.H., 1964, "A Manual of Gcology of India and Burma", Vol. III, Third Edition, Guvt. of India Press, Calcuitta.

12 Radhakrishna, B. P., 1967, "The Western Ghats of the Indian Peninsula", Proceedings of Seminar on Gcomorphological Studies in India.

13 Radhakrishna, B. P. and Vasudev, V. N., 1977, "The Early Pre-Cambrian of the Southern Indian Shicld", Journal of the Guological Society of India, Vol. 18, No. 10.

14 Wadia, D. N., 1975, "Gcology of India", Fourih Edition, Tała McGraw Hill Publishing Co·, New Delhi.

15 Winterkorn, H.F. and Fong, H. Y., 1975, "Foundation Engineering Handbook", Van-Nostrand and Reinhold Co., New York. 


\title{
Appendix F
}

\section{Dune Vegetation Along the Indian Coast}

\author{
A. G. UNTAWALE \\ National Institute of Oceanography, Dona Paula, Goa.
}

\section{F.1 Introduction}

The coastal vcgctation is of a specialiscd na ure which grows under different conditions. It consists mainly of 4 difforcnt groups: (1) marinc algae or scaweeds, (2) sea grasses, (3) mangroves and (4) sand dunc vegciation or sirand flora. Marine algac and sea grasses are purély aquatic communities whilc the mangroves arc partially aquatic planis which prefer interitidal areas having tidal influence. The sand dune vcgciation or sirand flora on the other hand, is a to:ally different plant community which grows on a sandy shore beyond the highest high tide level.

The ability of dunc vegciation for binding the sand is well known. Cleghorn and Iyer have describcd the sand binding plants of the south-east coast of India (refs. 5 and 10). The rapid increase in the dcsert aica of the world, has promptcd intensive efforts to determine new and effective measures to stop or at least control the movement of the sand dunes. Flora of the littoral states of India written by Hocker, Gamble, Haines, Blotter and Cooke include the classical works in which different specics of the dune vegetation have been described (refs. 2, 6, 7, 8 and 9).

Phyiogeographical distribution of dune vegetation along the Indian coastline has received much attention from the beginning of this century. Champion and Seth have classified the littoral and tidal swamp forests of India (ref. 3). This was subsequcntiy followed by the important work of Rao and Sastiy on the classification of coastal vegetation (ref. 14).

Dune formation along the coast takes place as a result of movement of sand particles from the intcridal to the tackshore rcgion with the help of wind (sce Section 3.3.2). These sandy beaches or duncs consiantly change thcir profile or structure because of their dynamic nature. Sometimes, the moving sand dunes pose much danger to the shoreline (Plate F.6: a). Here, the dune vegetation plays a major role in minimising the wind speed and also the movcment of sand from the dunes.

Along the east and west coasts of India, vast areas have been covered by sandy beaches or dunes (Table F.1). Conservation or management of these areas requires immediate attention.

\section{F.2 Climatological factors}

Climate of different maritime states shows a distinct variation. Four typical examples on the west coast (Jamnagar and Mormugao) and on the east coast (Pamban and Vishakhapatnam) will give a fair idea of the fluctuations in climatological conditions (Fig. F.1).

\section{F.3 Classification of a sandy shore}

Krumbein and Slack have suggested 4 zones of sandy shores, namely (1) nearshore bottom, (2) foreshore, (3) backshore and (4) dunes (ref. 11). Champion and Seth have classified the dunes under 

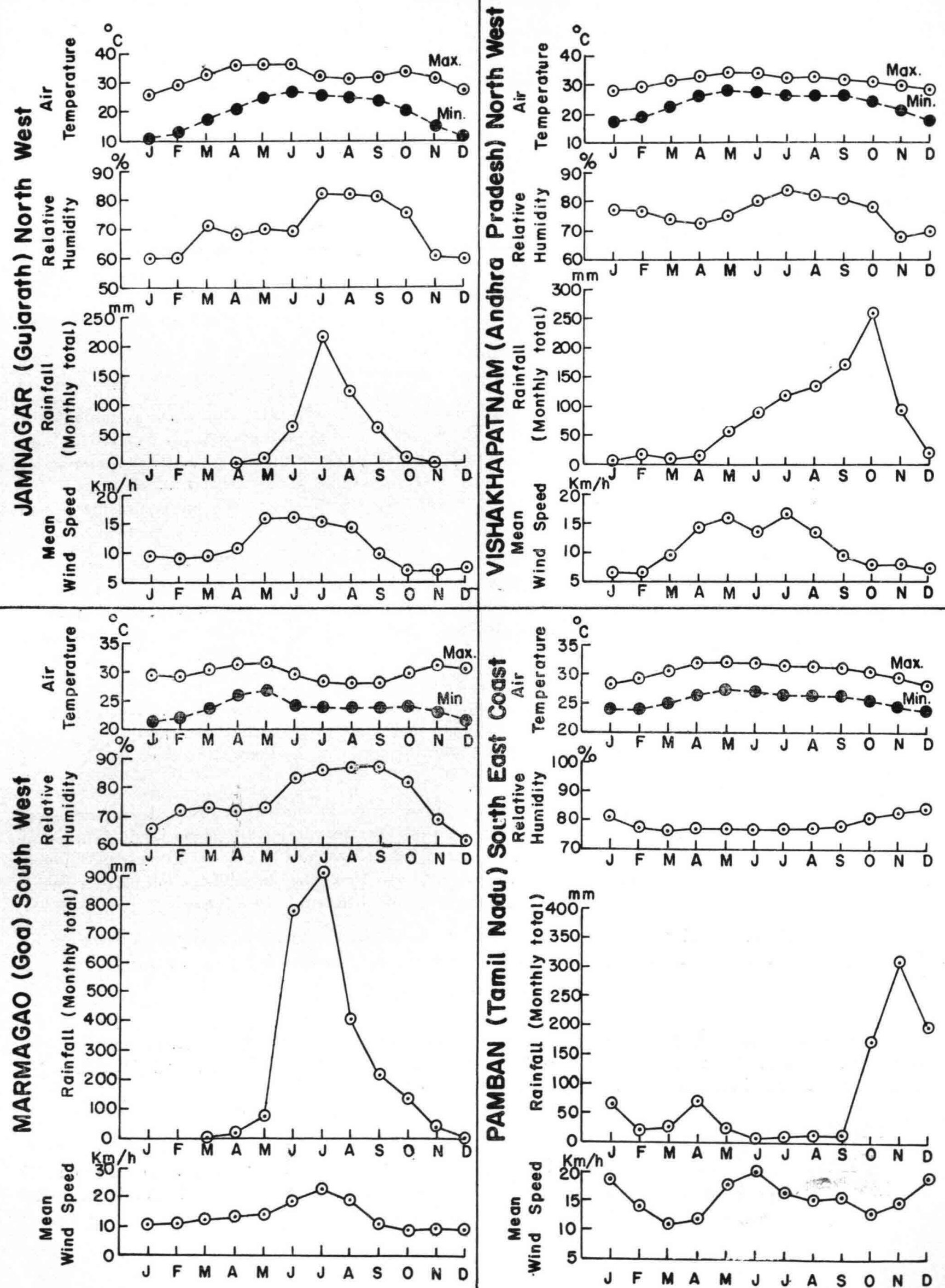

\& $20 \mathrm{~m} / \mathrm{h}$

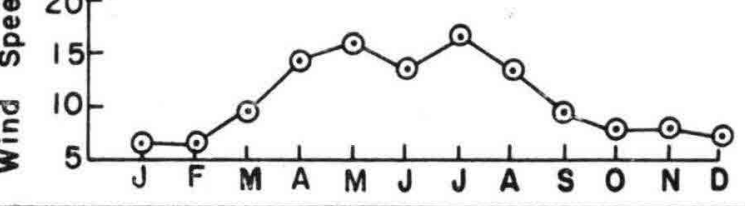

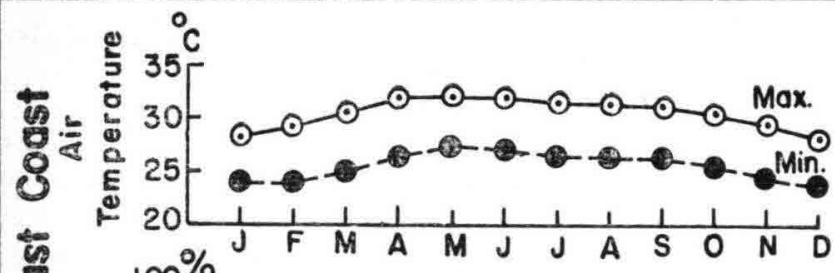

$100 \%$

wi 90

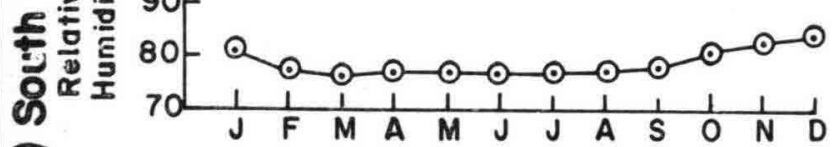
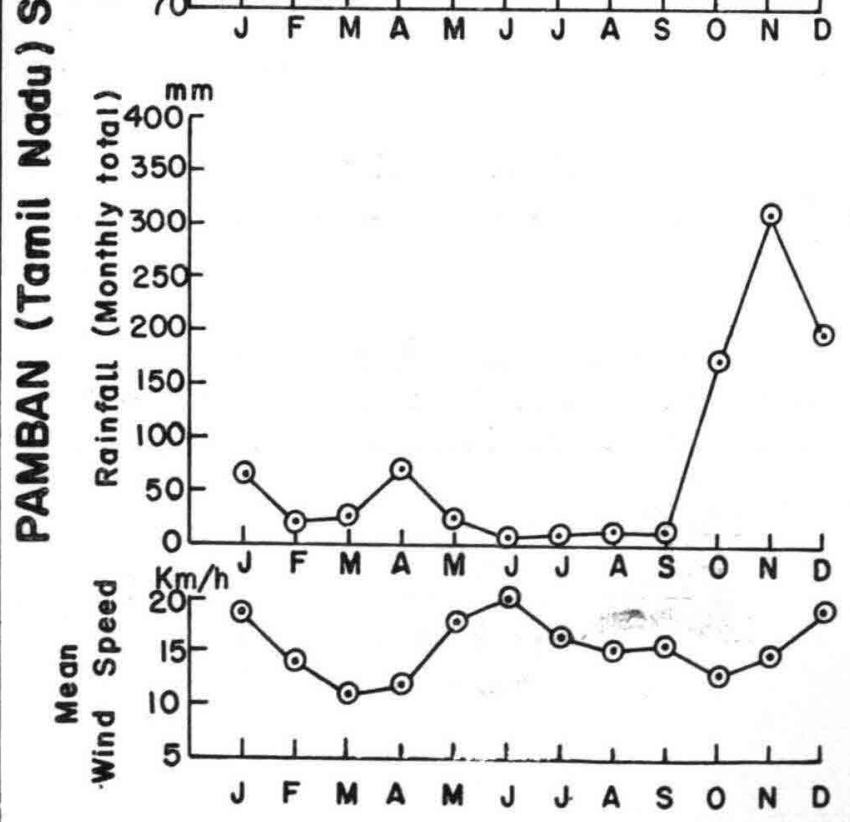
Table F.1 Distribution of sandy beaches along the Indian coastline.

\begin{tabular}{|c|c|c|}
\hline 1. & $\begin{array}{l}\text { Gujarat (Kutch, Saurashtra } \\
\text { and S. Gujarat) }\end{array}$ & $\begin{array}{l}\text { Limited sandy beaches, in between } \\
\text { muddy or rocky shores }\end{array}$ \\
\hline 2. & Maharastra & $\begin{array}{l}\text { Local sand strips along the coast inter- } \\
\text { cepted by rocky cliffs }\end{array}$ \\
\hline 3. & Karnataka & : Extensive sandy beaches of limited width \\
\hline 4. & Kerala & $\begin{array}{l}\text { Extensive sandy beaches of limited width } \\
\text { often interspersed with coastal lagoons } \\
\text { and lateritic or rock bound beaches }\end{array}$ \\
\hline 5. & Tamilnadu & $\begin{array}{l}\text { Sand strips along the deltaic shores and } \\
\text { rock bound beaches at the southern end }\end{array}$ \\
\hline 6. & Andhra Pradesh & $\begin{array}{l}\text { Sand strips of limited width often inter- } \\
\text { cepted by the Godavari and Krishna } \\
\text { rivers and their tributaries }\end{array}$ \\
\hline 7. & Orissa & $\begin{array}{l}\text { Extensive sand strips in the Konarak- } \\
\text { Puri buldge }\end{array}$ \\
\hline 8. & West Bengal & $\begin{array}{l}\text { Sand strips of limited width in Midna- } \\
\text { pore district and Sunderbans sea face }\end{array}$ \\
\hline 9. & Andaman Islands & $\begin{array}{l}\text { Sand strips intercepted by bluffs, rocks } \\
\text { or shingle along the coastilne. }\end{array}$ \\
\hline
\end{tabular}

'littoral forests' (type 4A/L1) (ref.3). Rao and Sastiy have classified the strand vegetation into (1) Strand sand (Type 4A/SS1). (2) Strand ro:k (Type 4A/SR2). (3) Strand co:al (Type 4A/SC3). The 'strand sand' has further been subdivided into (i) open pioneer zone or outer zone, (ii) closed herbareous zone, (iii) middle mixed or bushy zone and (iv) inner woodland zone (ref. 14)

Generally the pioncer zone of the sand dune arca is covered by coarse sand as the finer sand particles are blown by the wind towards woodland zone. The soil in pioneer zone has low water holding capacity and it is slightly alkaline to acidic.

Different aspects of the sand dune like grannulometry, $\mathrm{pH}$, percentage of organic matter etc. varies in open pioneer zone, closed herbasious zone, middle mixed zone and woodland zone. Accordingly soil changes from fine sand to coarse sand with clay or silt. $\mathrm{pH}$ varies from 6.5 to ncutraliiy. Percentage of calcium carbonate decreases, while organic matter increases from pioneer zone towa-ds woodland zone. Increase in organic matter enhances the water holding capacity of the soil.

Chapman has divided the dunes into (i) embryo dune, (ii) yellow dune and (iii) grey dune azcording to the growth of the dune with its vegetation (ref. 4).

F.3.1 Species distribution: There are several types of dune vcgetation distributed along the cast and west coasts of India. The composition of the vegetation changes with the climatological and edaphic factors. As mentioned earlier, the climate along the east and wcst coast shows considerable variation. As a result of this the species also show different patierns in distribution, zonation etc.

Rao has further subdivided the west and east coasts into Kutch, Saurashtra, souih Gujarat, Maharashtra, Mysore, Kerala, Tamilnadu, Andhra Pradesh, Orissa and Wesí Bcngal. So far, about 148 species, representing 115 genera of 49 different families which can be considercd as dunc vegetation have been reported from the Indian coast. The zonal distribution of the strand flora along the Indian coastline is presented in Table F.2 (ref. 13). 
Table F.2 Distribution of dune species along the Indian coast.

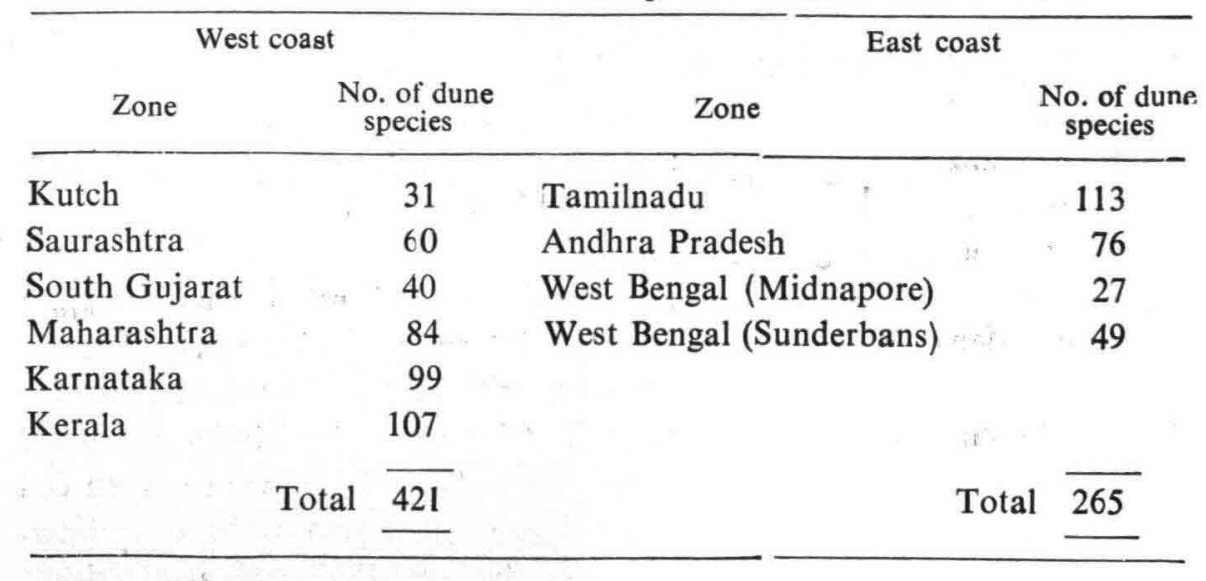

It is observed that the dune species on the west coast of India are almost double than those of the east coast. The maximum dune species have been recorded from Tamilnadu followed by Kerala, Karnataka, Maharashtra, Andhra Pradesh and Saurashtra.

Rao has grouped the dune vegetation according to its specialised characters (ref. 13):

(1) Mat forming stranded creepers

(2) Diffusely branching, prostrate or erect strand herbs and hedges

(3) Strand climbers

(4) Strand plants with perrenating organs

(5) Strand shrubs and trees

(6) Strand stunted trees.

On the basis of these observations, he is of the opinion that the dune vegetation of India is a mixture of Polynesian and Malaysian, Persio-Arabian/Western and a few indigenous species.

F.3.2 Dominant dune vegetaion: The major components of the dune vegetation from Saurashtra coast are Hydrophylax maritima, Ipomea pes-caprae, Asparagus dumosus, Halopyrum mucronatum, Cypreus conglomeratus, C. aristatus and Sporobolus trimulus (ref. 15).

The sand dune flora of the Goa coast is represented by Ipomea pes-caprae, Spinifix littoreus and Cypreus arenarius (ref. 17) and (Fig. F.2).

Rao et al. have described the dune flora of coastal Tamilnadu (ref. 16). The principal floral elements are Ipomea pes-caprae, Cyperus arenarius, Spinifix. littoreus and these are found in the open pioneer zone.

Large scale plantations of coconut, cashew-nut, Casurina equisettifiolia on the sand dunes can be included as the recently introduced species (Plate F.6:b). However, there are some interesting species like Hyphnae indica along the Saurashtra and Goa coasts, which have come from other countries. It has generally been accepted that the dune flora includes a large element derived from the weed flora of the adjoining agricultural fields.

\section{F.4 Environmental factors}

Climatological factors such as rainfall, air temperature, humidity and wind speed as well as the edaphic factors like sand texture, $\mathrm{pH}$, humus content, soil temperature and the ground moisture play an jmportant role in the distribution and growth of dune vegetation. Because of the extreme conditions the dune plants have developed certain characteristic features in their internal and external morphology.

Atmospheric temperature in the dune regions directly affects the dune temperature. The barren dune temperature is usually more than that in the vegetation area. The humus content and moisture minimise the temperature in the vegetation zone. 


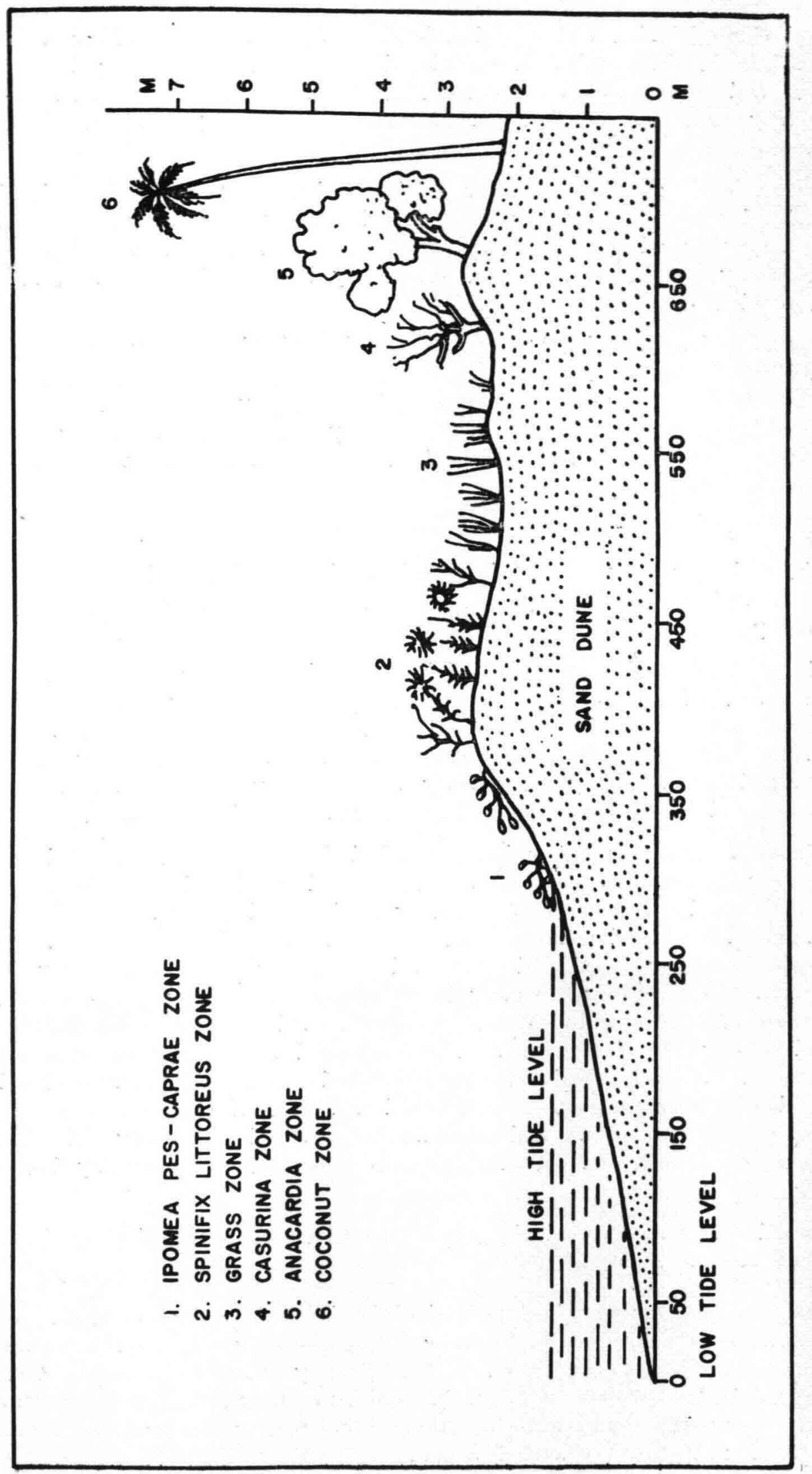

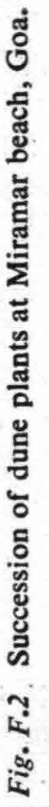


The rate of precipitation and the duration of rainfall are important factors for the dune community. These help in the germination of seeds, decomposition of organic matter, rapid growth of the dune plants and create favourable condition in the dune region. The rainfall by itself binds the sand temporarily. Generally, the dune plants complete their life cycles during the monsoon and posimonsoon seasons.

Wind is one of the most important factors in the dune ecosystem. It helps in the formation, movement and also destruction of the dunes. It also decreases the surface moisture and the surface temperature. Increase in the wind speed enhances the transpiration rate in dune plants. Cyclonic or stormy conditions usually result in the destruction of dunes by dispersing dune vegetation and by changing the configuration of dunes.

Dune vegetations have a tendency to develop extensive rhizoidal root system which also helps in binding the sand. The shoot portion of the plants prevent or minimises the movement of sand while the fibrous or rhizoidal roots of these plants perform important physiological and mechanical functions. To face extreme conditions of high temperature, wind velocity and low water availabiliiy, these plants have developed thick cuticle, sunken stomata, specialised inflorescence and sceds, as well as fleshy leaves.

\section{F.5 Formation, growth pattern and propagation of dunes}

The main species generally start their growth at the strandline and backshore region. This is a very sensitive area where there is every chance of dune erosion, either by the incoming waves during the highest tide or by strong winds.

The seeds, propugules and fragments of the dune vegetation start their germination from the strandline in favourable season (monsoon). At the strandline, the dune generally has litter or debris, which after undergoing decomposition, adds to the humus content. Once the sced germinates and the plant establishes the rate of their further growth, if conditions are favourable, bccomes very fast. They try to develop horizontal and vertical root systems as early as possible. By the time favourable season is over, the plants are well rooted. This is the first stage in the formation of dune vegetation.

Second phase starts after the monsoon is over, that is, during the post-monsoon period. Surface moisture reduces during these months because of increase in the wind speed and air temperature. This results in the loosening of the sand grains which are blown by wind. The dune flora obstructs the flow of sand and ultimately a mound is formed near the plant. If the rate of sand movement or ascretion is more, the dune plants get completely buried under the sand. If the layer of sand is veiy thick and the dune plants are not able to grow, they ultimately die off. Otherwise, gencrally offshoots from the lacral sides or axils of the plants grow rapidly to come out of the sand dune for further growth. Occasionally due to high wind velocity, the dune vegetation gets uprooted and breaks into fragments, while the dune itself migrates. In favourable conditions, these scattered fragments get esíablished and form their own small or big dunes. Once the plant is well settled and forms a dune, the offshoots of the same plants creep above or below the surface and forms another smaller dune (primary and secondary dunes). The secondary dunes, eventhough small in size, give some protection to the primary dune by regulating the wind speed.

Untawale and Nair have reported the growth pattern in some pioncer dune species from the Goa coast (ref. 17). These are as follows:

1. Ipomea pcs-caprae (I. biloba): This species belonging to the family Convolvulaceae has very long branches. It creeps all over the dune surface. The average length of the tap root varics from 5 to $8 \mathrm{~m}$. The length of the creeping branches is from 5 to $7 \mathrm{~m}$. The shoot system spreads covering a large area. At regular intervals, two rootlets develop in the nodal region to give mechanical strength to the creepcr and also help in binding the dune sand. The average internode was found to be $10.3 \mathrm{~cm}$, while the rootlets were $35.95 \mathrm{~cm}$ in length (Plate F. 3: a and b). 
2. Spinifix littoreus (S. squarossus): This plant belongs to the family Poaceae (grass family). It is a vcry siurdy plant and shows all the characters of a typical dune vegetation. This plant also has similar tendency of growth like I. Pes-caprae. The average length of the main rhizoidal root is about $15-20 \mathrm{~cm}$, while the length of the rootlets at nodes is about $28.5 \mathrm{~cm}$. Its shoot attains the average height of $72.1 \mathrm{~cm}$. The length of the internode is about $6.7 \mathrm{~cm}$ (Plates F.1, 2: a and b).

3. Launea pinnatifida: This species belongs to the family Asteraceae (Compositae). Its tap root gocs up to a depth of $50 \mathrm{~cm}$ depending upon the moisture content of the dune. The shoot portion develops into many offshoots which creep over the dune surface. At every node, there is a rhizoidal growth. The average lengih of these rootlets is about $8.25 \mathrm{~cm}$, while the shoot is very dwarf, approximately $1.90 \mathrm{~cm}$ in height. The average length of the internode is $9.5 \mathrm{~cm}$.

4. Cyperus arenarius: This is a Cyperaceous plant, which forms a dense mat on the dune surface, particularly in areas which are moist. Its rhizome is of a shallow type. The stolons of this plant creep below the surface about $3.5 \mathrm{~cm}$ deep. The shoot, however, attains an average height of $32.1 \mathrm{~cm}$. The distance between the nodes is $4.55 \mathrm{~cm}$ (Plate F.4: $\mathrm{a}$ and b).

The success of the dune plants lies in their ability to perennate and to develop extensive horizontal and vertical root and shoot systems in unfavourable conditions.

Propagation in dune plants is both by vegetative means and by seeds. Sprouting from the disintegrated shoots is common and important. The fruits and seeds of dune plants can remain viable in the high temperature sand as well when oscasionally exposed to sea water. The entire inflorescence or the arrangement of fruits in Spinifix littoreus has been specially developed to favour their dispersal in a wide area.

During the dry season most of the herbaceous species on the dunes, excepting a few sturdy plants, die off and remain dormant for a long time. However, again during the monsoon, they sprout and start their normal growth.

\section{F.6 Management of dune vegetation}

From the time immemorial the coastal regions along with sandy dunes, have been used by man for different activities. As a result of population pressure, the coastal dunes have been utilized without understanding the dangerous effects, their disappearance can cause to the surrounding environment. Indiscriminate cutting of coastal vegetation and over-exploitation of beach sand for developmental works have resulted in erosion of vast coastal areas. Sand dunes are very important systems which need careful planning and management.

In India sandy shores and nearby areas are being extensively used for agriculture, housing, highways, recreation and tourist resorts. Therefore, it is necessary to have effective management policies for the conservation and protection of sand dunes. Chapman and Ranwell have some important suggestions on the development of sand dunes with the help of plants (ref. 4 and 12). The most important factor in the dune management is the vegetation cover of the dunes. A few suggestions given below in developing or increasing the vegetation cover may be useful.

Movement of the sand or dune can be checked by growing appropriate plant species which should be planted in the backshore from where the sand movement begins. Thus a good carpet vegetation will effectively minimise the sand movement.

Suggested species of plants for the dunes are:

(a) Ipomea pes-caprae

(b) Spinifix littoreus

(c) Cyperus arenarius

(d) Periploca sp. (Plate F.5: a and b)

(e) Urochondria $\mathrm{sp}$.

At the landward end of the backshore region, cover can be given by growing trees as wind breaker. The species suggested for this zone is Casurina equisettifolia which grows extremely well in Indian 
conditions. The litter fall of this species forms a dense mat on the surface, which not only checks the sand movement but also creates a favourable conditions for the ground flora. The same trees after a few years can be effectively used for the fabrication of dune fence systems and mattresses to prevent the dune movement further.

Afforestation of dune areas can be done either by directly using suckers, stolons, fragments or by broadcasting of the seeds of dune plants. In the monsoon months, transplanting the seedlings from nursaries to dune areas will also be very helpful. These nursaries can be planned in coastal sandy areas. Seedlings can be grown in small polythene bags which could be transferred as such to the desired areas.

\section{F.7 Harvesting and processing}

The plants should be dug out with care that most roots remain attached to the plants. The clumps should be seperated into suckers with the desired number of stems. Plants should be cleaned of dead vegetation and should be trimmed to a length of 45 to $50 \mathrm{~cm}$ to facilitate mechanical transplanting.

Transplanting techniques for most species of beach grass are well known. Transplantation is highly recommended for the areas adjacent to the beach berm and for vulnerable areas which are subjected to erosion. Most critical areas require densely spaced transplants to ensure successful stabilisation. Transplanted seedlings of dune species can be protected by checker board methods using dead branches of any tree (Fig. F.3). The size of these checkers can be decided according to wind velocity and sand movement.

Seeding is practical only when protection from erosion and from dry winds has already been provided by mulching or frequent irrigation and is therefore not applicable to most beach areas. Beach grass seeds are not available from commercial sources and must be harvested from wild plants. The exploitation or cutting of dune vegetation by man or by cattle grazing should be strictly prohibited. Similarly, disturbing the seedlings of dune vegetation should also be avoided.

Sand dune areas could possibly be used for the cultivation of suitable crop plants which can tolerate maximum salinity. Such species can even be grown under irrigation using brackish water or sea water. Efforts are being made by the Central Salt and Marine Chemicals Research Institute, Bhavnagar (Gujarat) to grow certain species of wheat, bajra, barley, cotton, jawar, kodo millet, onion, etc. on the coastal dunes of the Orissa. Also, large scale plantation of jojoba (oil plant) and guyale (rubber plant) in arid regions may prove to be economical.

Movement of the dune sand in the barren area could be controlled by using dune fences (see Section 3.3.2). These fences could be fabricated by using dry wood or dead branches of the most abundant trees of various coastal states, like Casurina, coconut, cashew and various mangrove trees. However, utmost care is essential to avoid large scale cutting of well grown trees which may cause secondary problems.

\section{F.8 Fertilizers and manures for dune vegetation}

In India, not much work has been done on the effects of fertilizers and manures for the sand dune vegetation. According to Adriani and Terwindt, the use of nitrogen has a better effect than phosphate, for the growth of dune vegetation (ref. 1). They have also investigated the possibility of using sand binders such as COLAS, Shell Sandfix and UNISOL. These sand binders are useful in the coastal areas with a moderate wind speed and thus lead to less sand movement. However, the regions which are frequently experiencing stormy weathers, the sand binders may not be of much importance.

Marine algae along the Indian coast get accumulated on the shores every year in a large quantities. Mixed seaweed meal or liquid extract from the seaweeds can be used either as a manure or liquid fertilizer particularly in the nursaries established for dune vegetations. These algae have agar, alginate, caragennan, mucilage as well as several growth promoting hormones. Some of the algal extracts also can be used as sand binders. However, some of these aspects require further studies. 


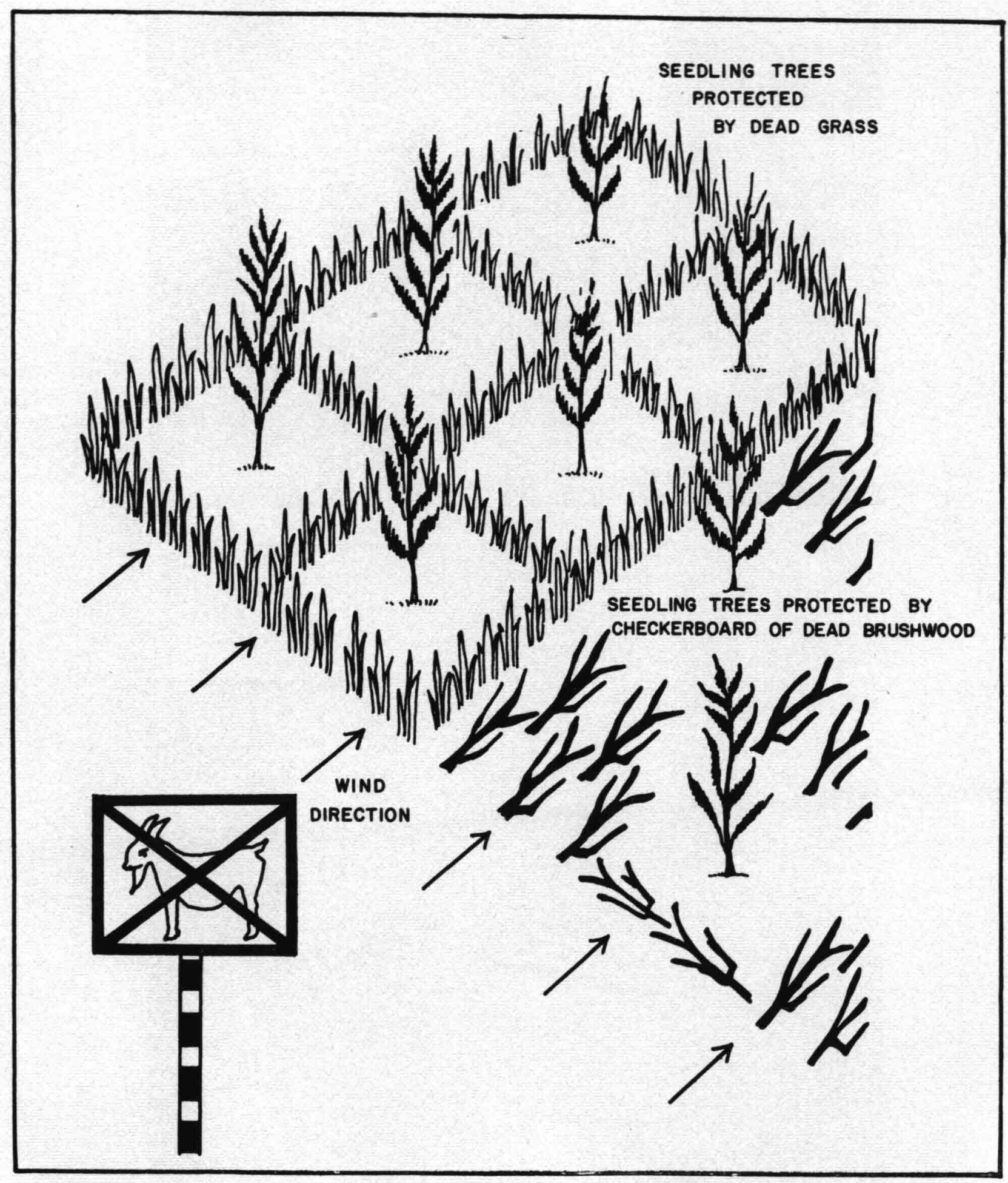

Fig. F.3 Protection of transplanted seedlings by 'Checker board' method, 


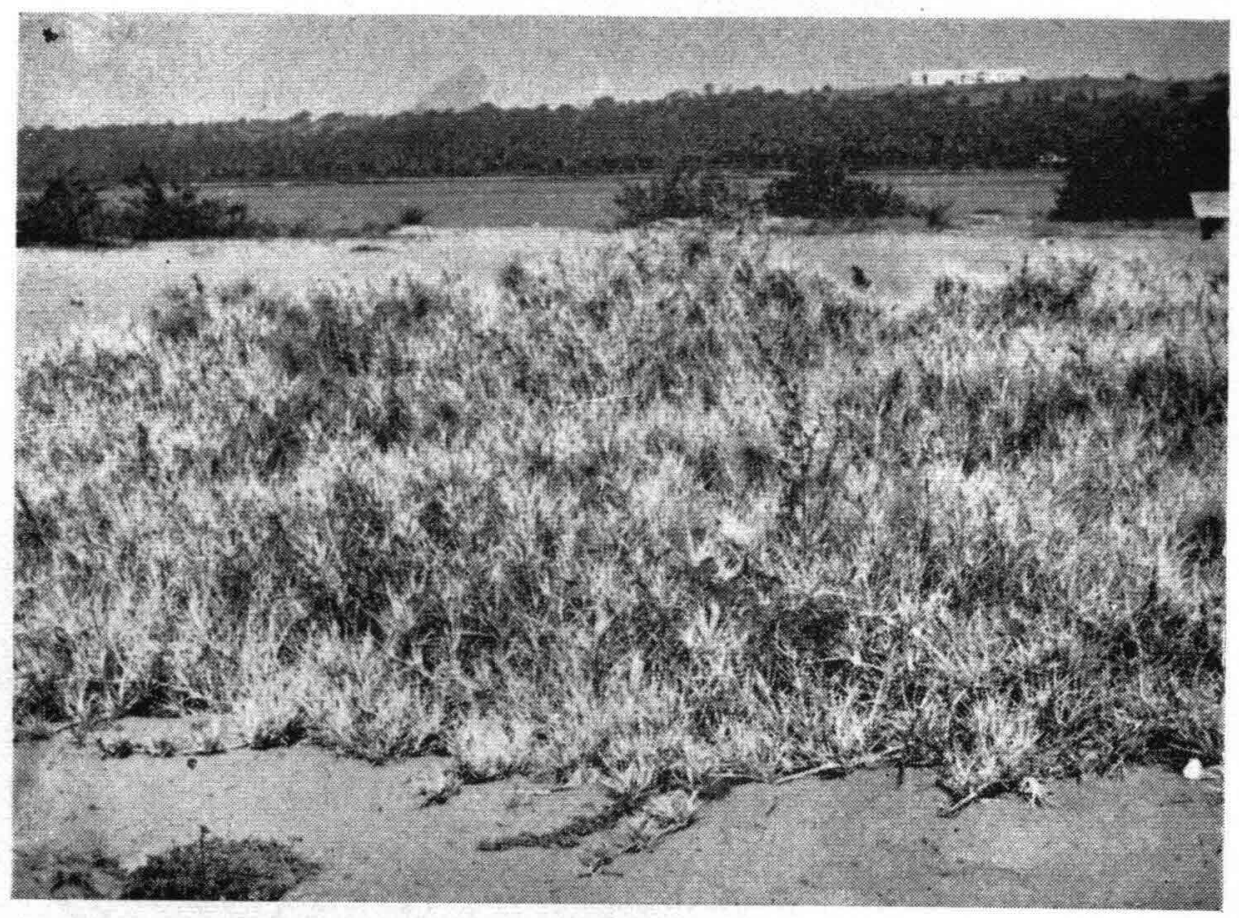

Plate F.I (a) Dune formation by Spinifix littoreus at Miramar, Goa.

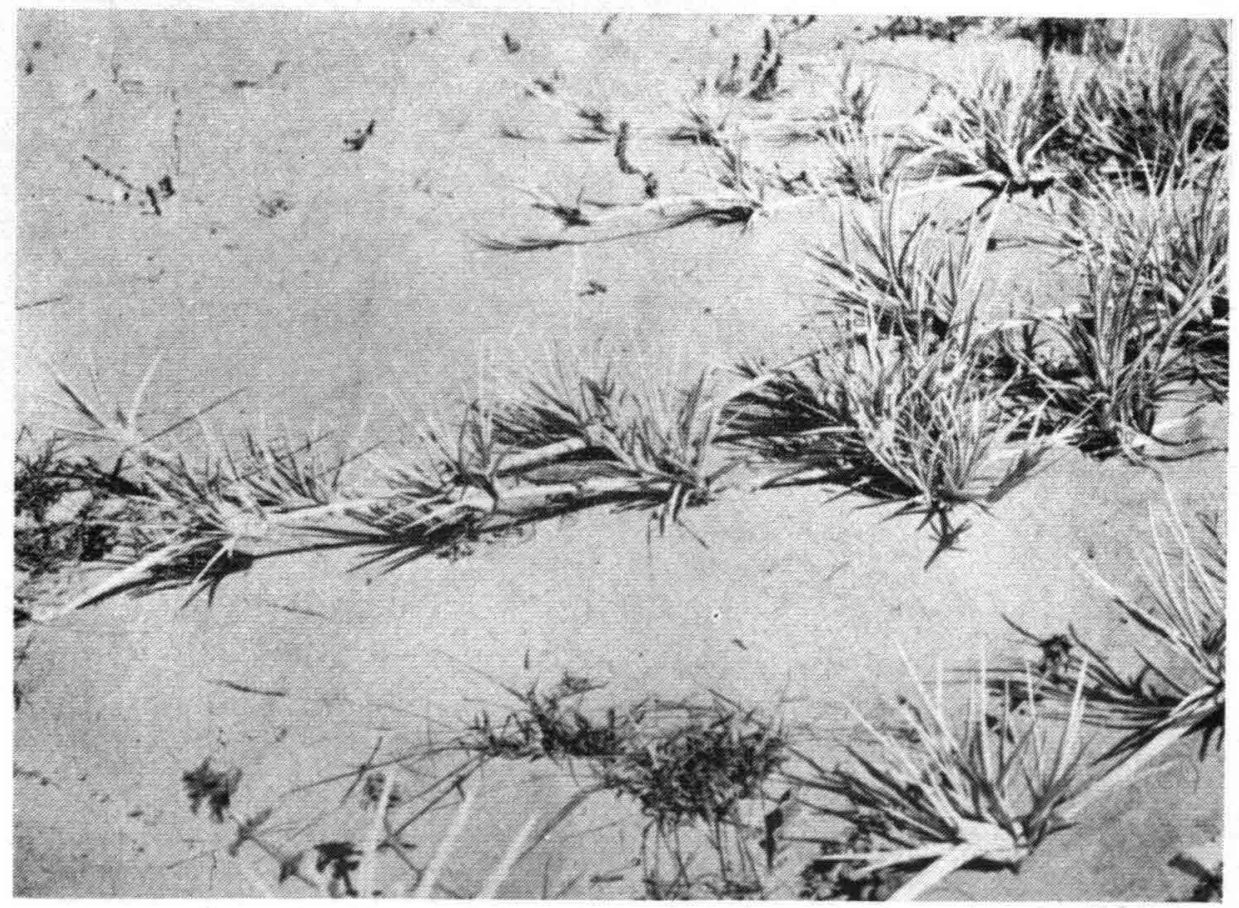

Plate F.I (b) Growth of S. littoreus. 

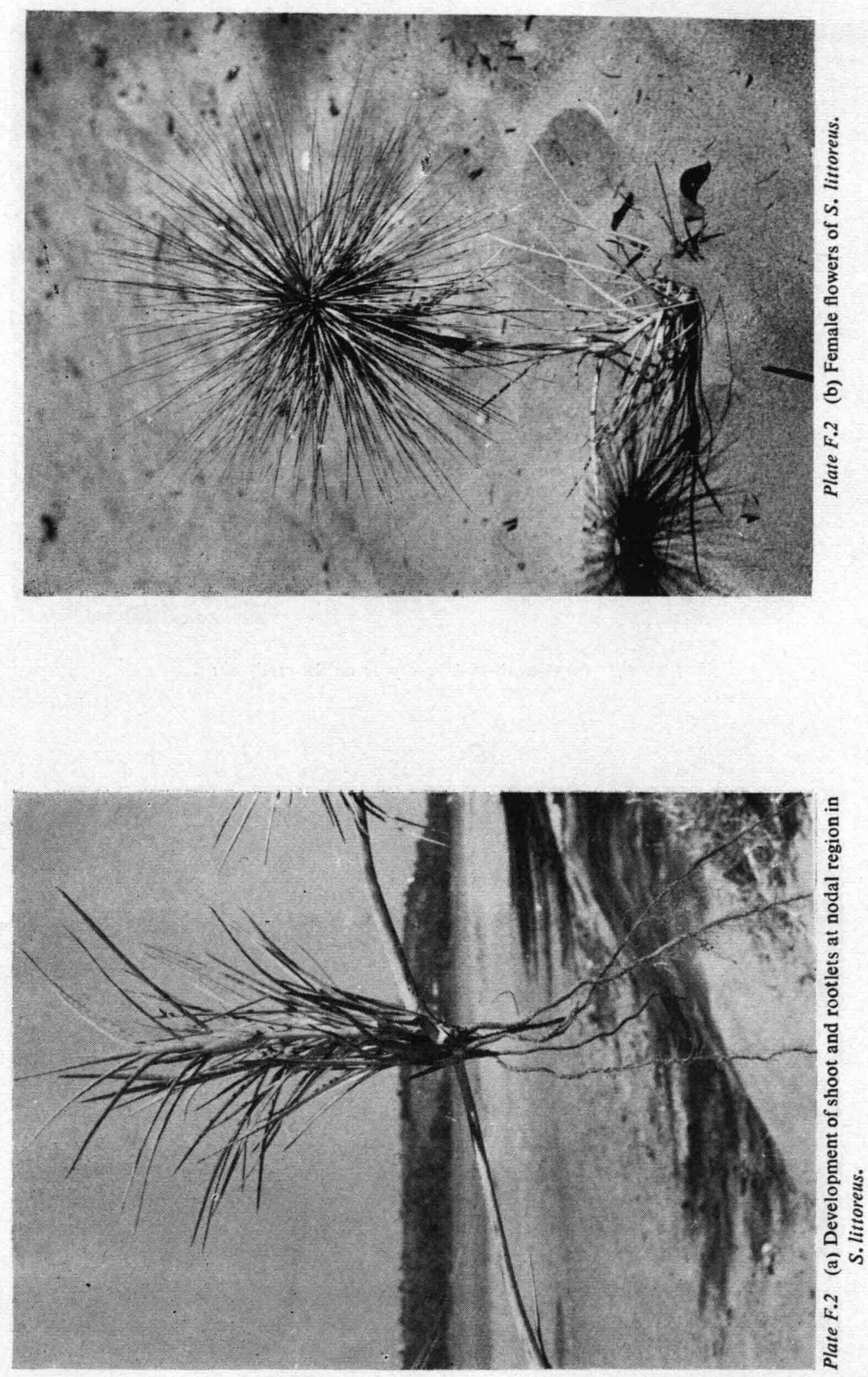


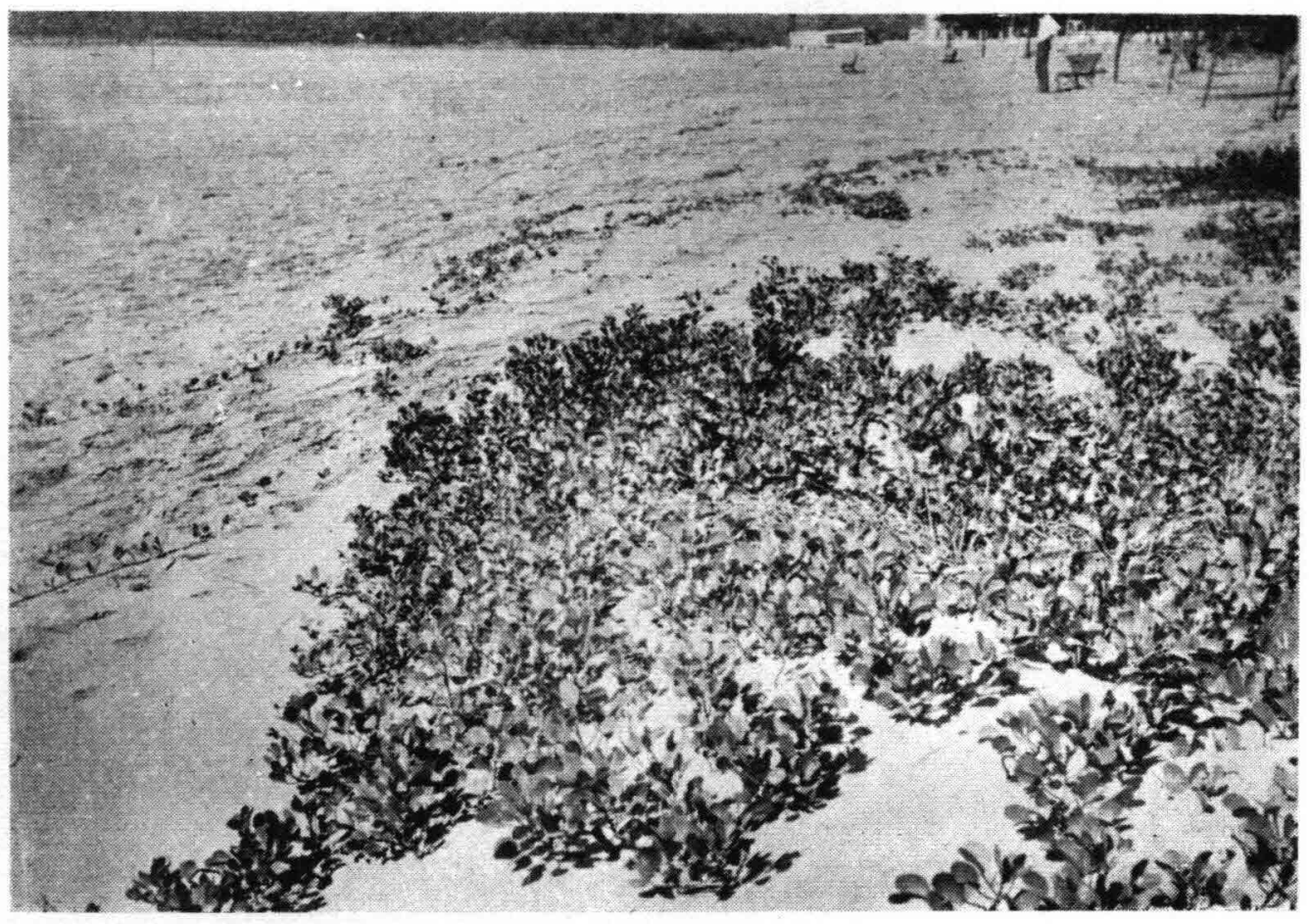

Plate F.3 (a) Growth of I. pescaprae on the sandy dune.

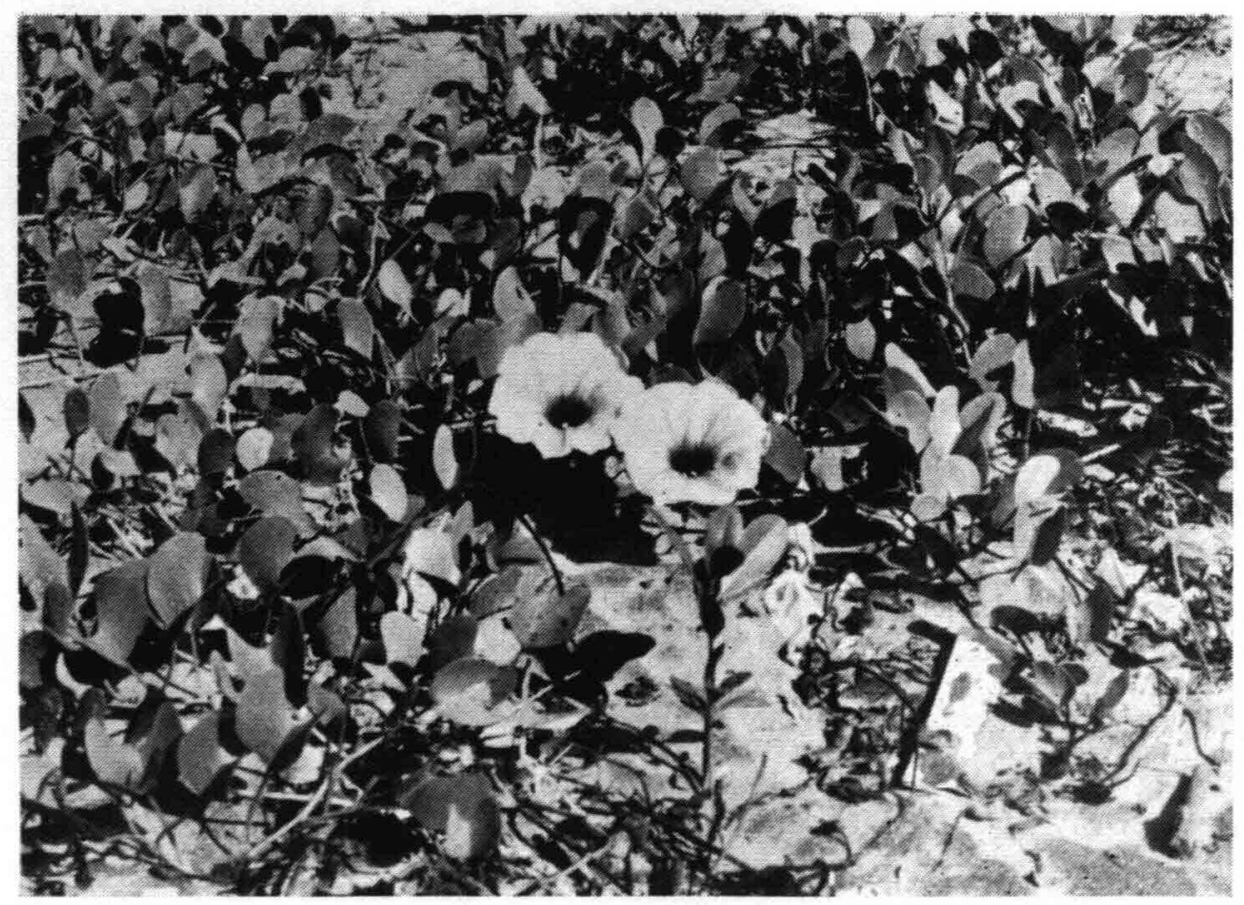

Plate F.3 (b) Typical bilobed and fleshy leaves of I. pescaprae, 


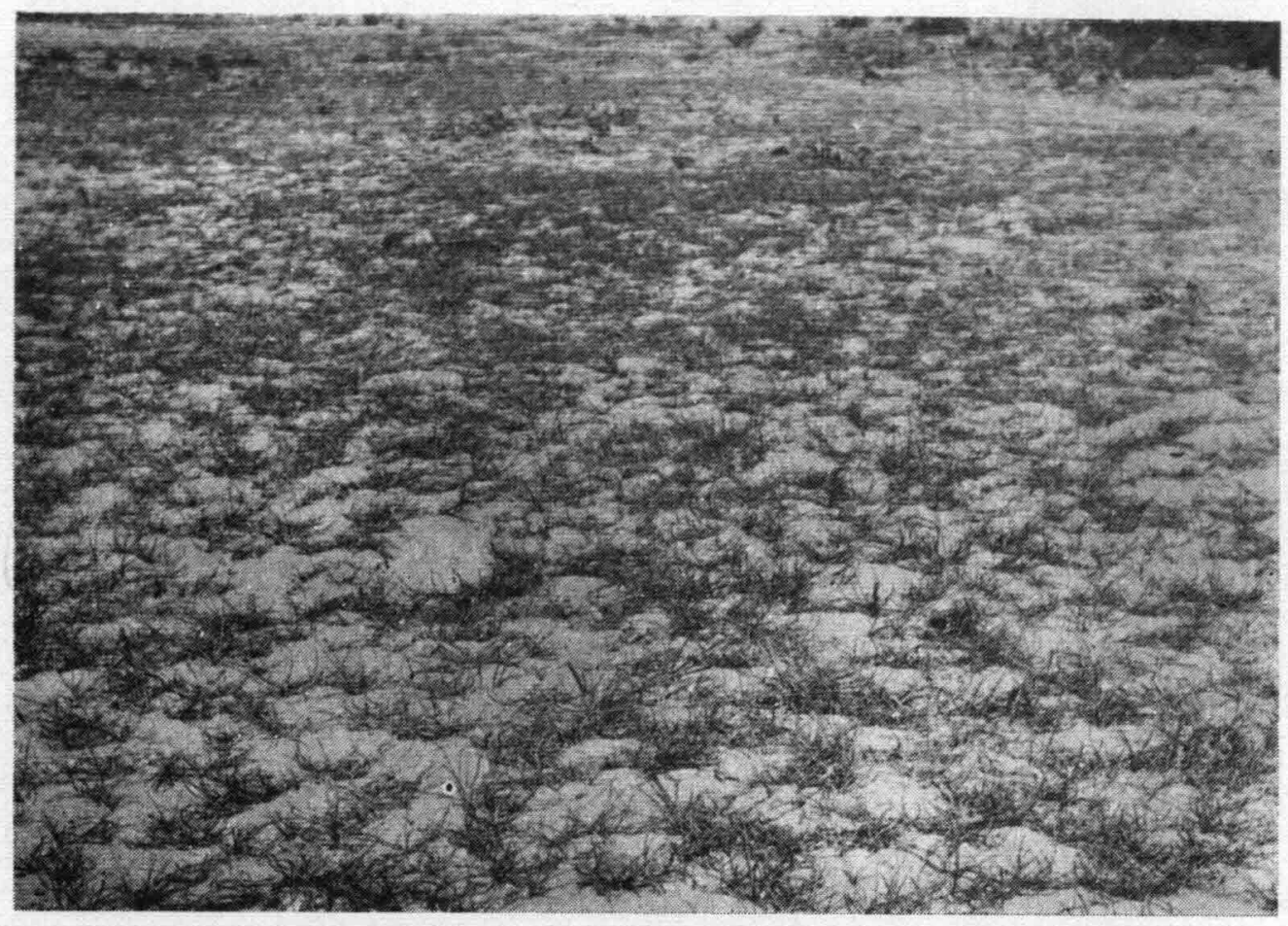

Plate F.4 (a) Carpet flora of Cyperus arenarius on sand dune at Miramar, Goa.

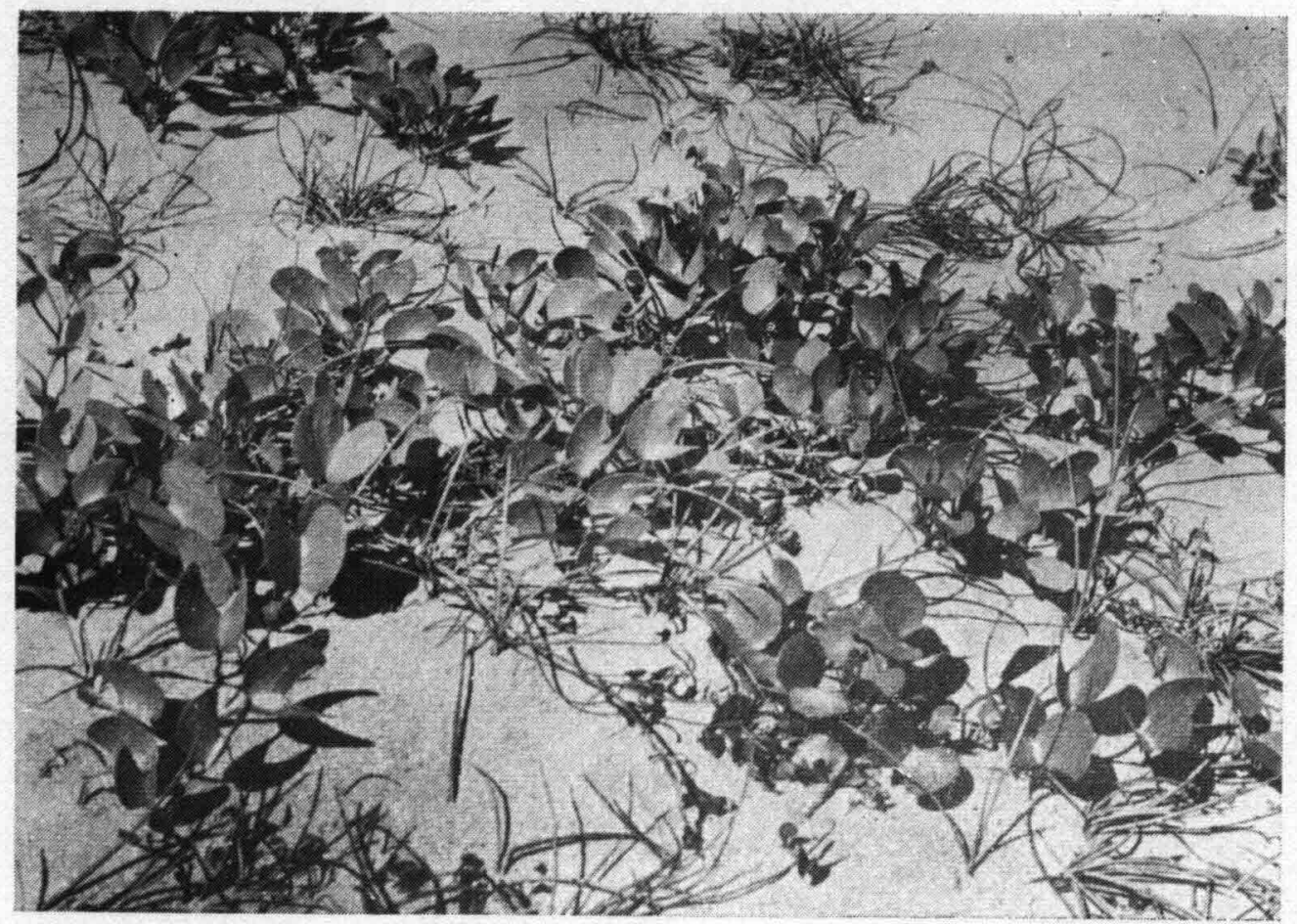

Plate F.4 (b) Mixed vegetation of C. arenarius and I. pescaprae. 


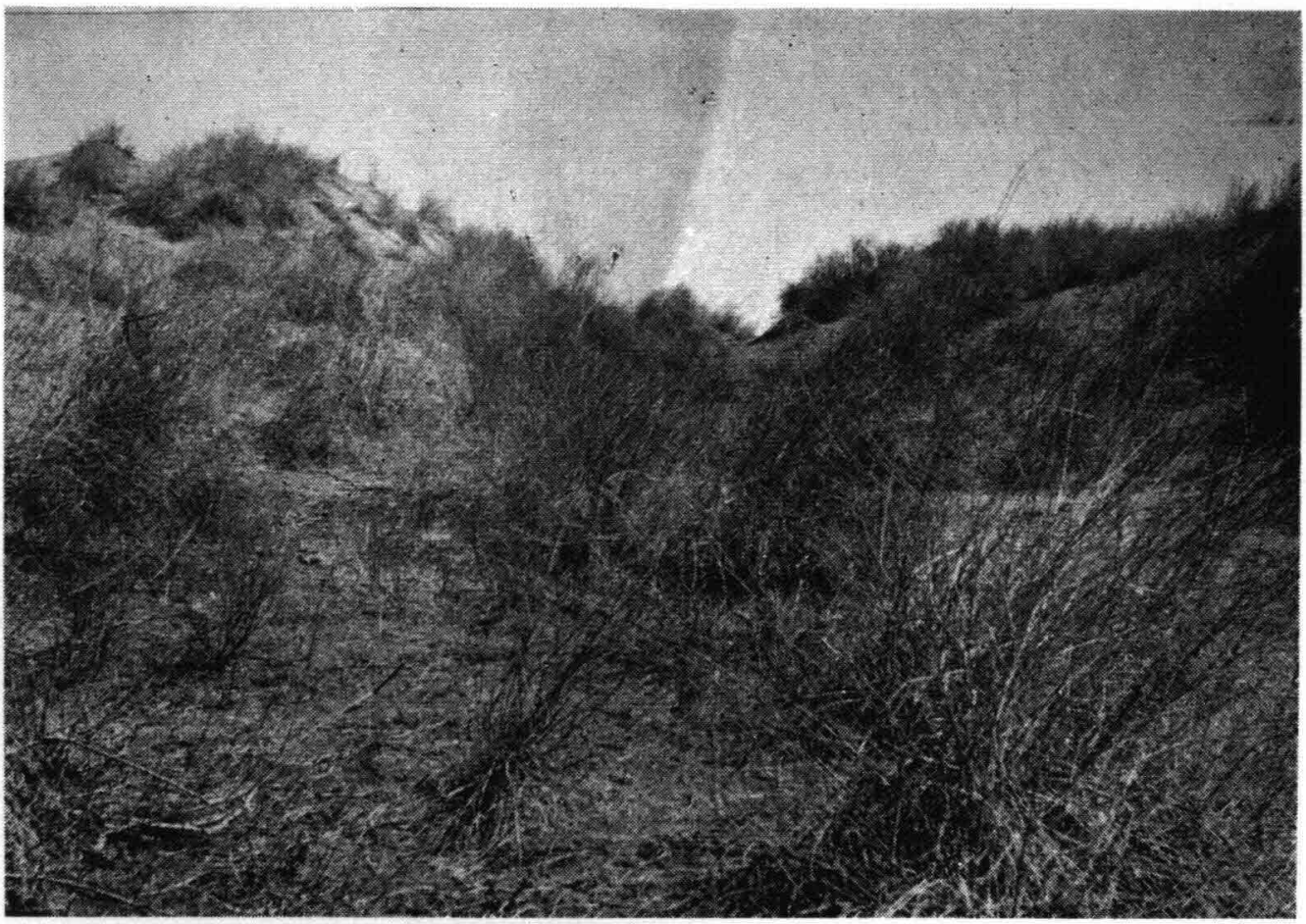

Plate F.5 (a) Growth of Periploca sp. on sand dunes of Saurashtra.

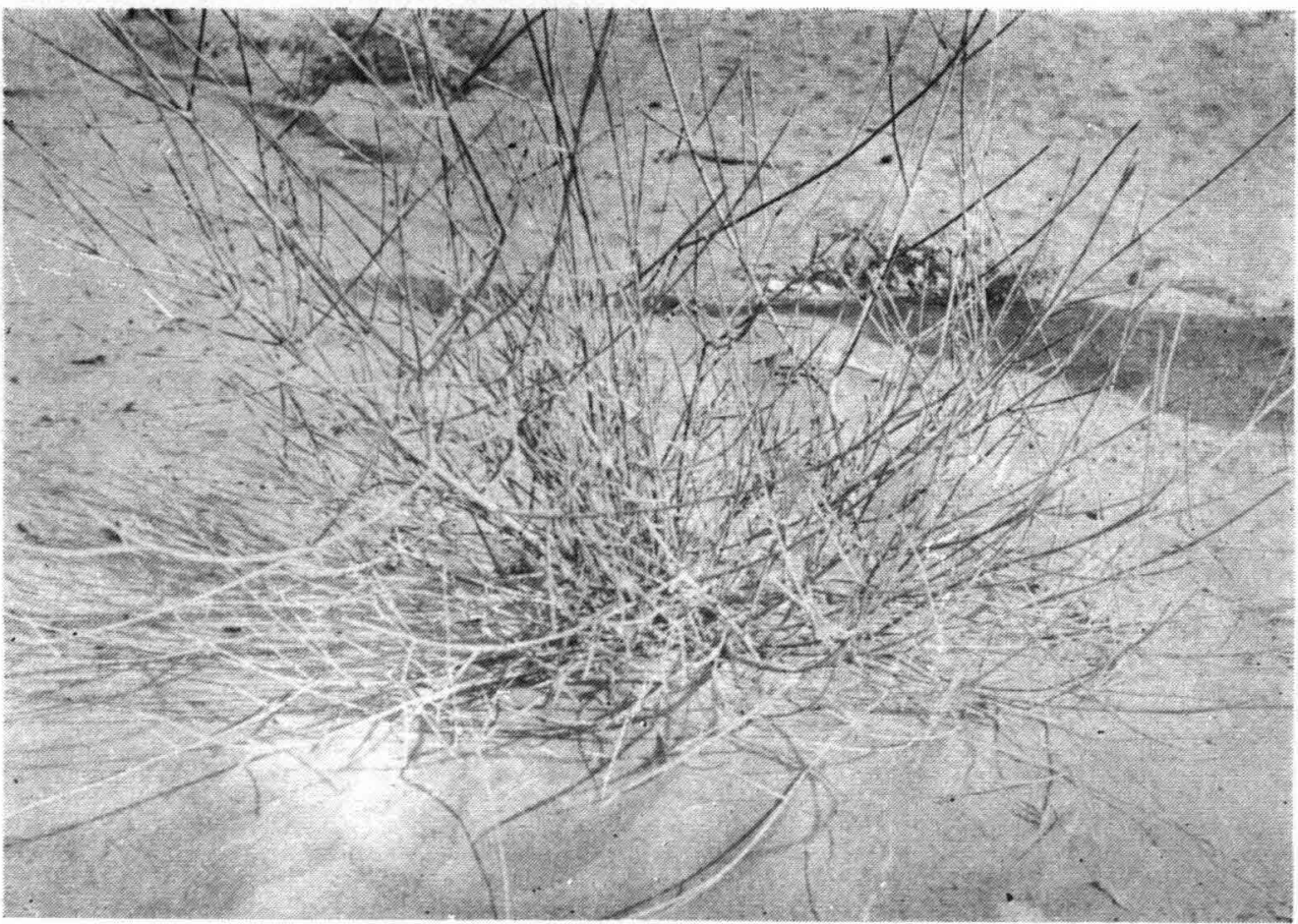

Plate F.5 (b) Periploca sphylla growing in sand in an arid region. 


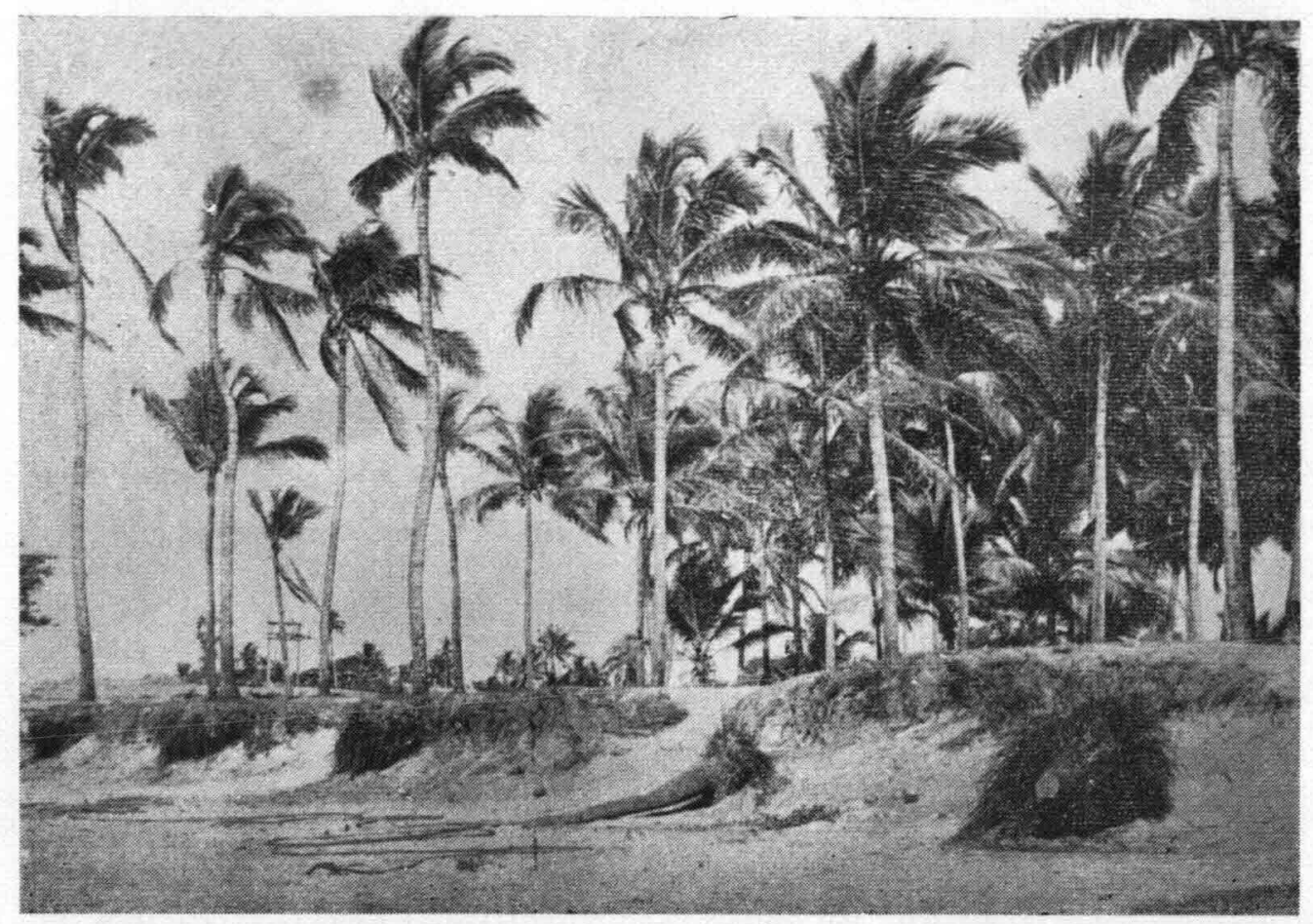

Plate F.6 (a) Coastal erosion of sandy beach at Miramar, Goa.

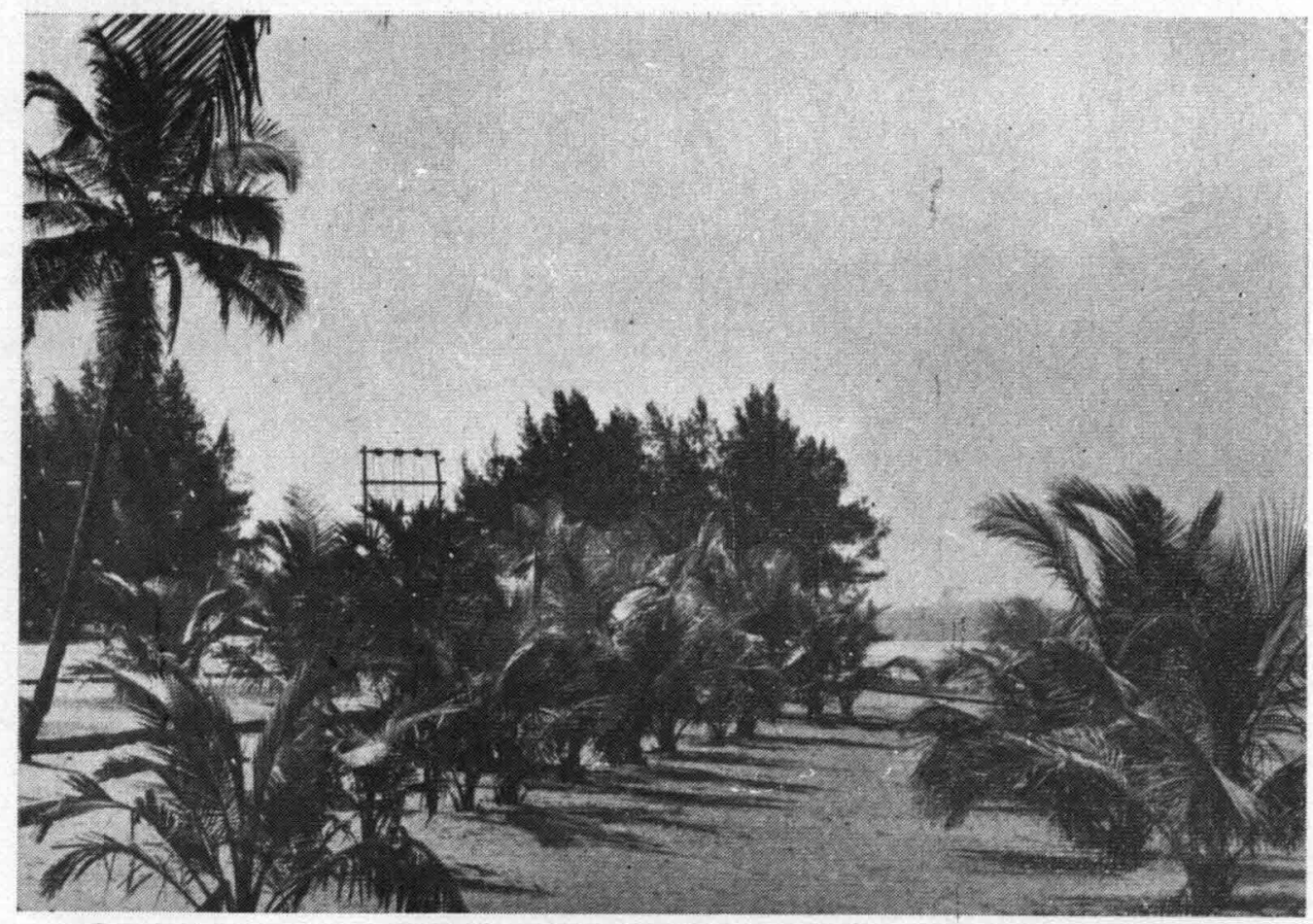

Plate F.6 (b) Coconut plantation on sandy beaches, 


\section{References}

1 Adriani, M. J. and Terwindt, J. H. J, 1974, Sand Stabilisation and Dune Building, Rijkswaterstaat Communications, No.19, Rijkswaterstaat Deltadienst, The Hague.

2 Blatter, E., 1908, On the Flora of Kuich, Part I \& II, J. Bombay nat. Hist. Soc., 18 and 19.

3 Champion, H. G. and Seth, S. K., 1968, A Revised Survey of the Forest Types of India, Manager of Publications, Delhi.

4 Chapman, V. J., 1976, Coastal Vegetation, Pergamon Press, New York.

5 Cleghorn, H., 1856, On the Sand Binding Plants of Madras Beach, Madras, J. Litt. Sci., NS 1.

6 Cooke, T., 1908, The Flora of the Presidency of Bombay, Bot. Survcy of India, Calcutta.

7 Gamble, J. S., 1900, The Flora of the Presidency of Madras, Bot. Survey of India, Calcutta.

8 Haines, H. H., 1961, The Botany of Bihar and Orissa, Bot. Survey of India, Calcutta (Reprinted Edition).

9 Hooker, D. D., 1875, The Flora of British India, Vols. 1-7, London.

10 Iyer, Subramania, V., 1909, Sand Binding Plants, Indian For., 35.

11 Krumbein, W. C. and Slack H. A., 1956, The Relative Efficiency of Beach Sampling Methods, Tech. Memo. Beach Eros. Bd., U. S., 90.

12 Ranwell, D. S., 1972, Ecology of Salt Marshes and Sand Dunes, Chapman and Hall, London.

13 Rao, T. A., 1971, Distributional Resume of the Maritime Strand Flora of India, Bull Bot. Survey of India, 13.

14 Rao, T. A. and Sastiy, A. R. K., 1972, An Ecological Approach Towards Classification of Coastal Vcgctation of India, 1. Strand Vegctation, Indian For-, Oct.

Rao, T. A. and Aggrawal, R. K., 1971, Ecological Siudies of Saurashtra Coast and Neighbouring Islands. III. Okhamandal Point to Diu, Coastal areas, Proc. Symp. Problems of Indian Arid Zone, Jodhapur,

Rao, T. A., Sastry, A. R. K., Basu P. and Mandal N. R., 1975, A Contribution to the Coastal Flora and Vegetation of Tamil Nadu (India), Indian For., 101 (8).

Untawale, A. G. and Nair S. A., 1974, Ecology of Sand Dune Vegetation in Relation to Beach Stability at Miramar, Gua, Mahasagar - Bull natn. Inst. Oceanogr., 7. 
Pif 